Portland State University

PDXScholar

$1-1-2011$

\title{
Discovery of Novel Amidotransferase Activity Involved In Archaeosine Biosynthesis and Structural and Kinetic Investigation of QueF, an Enzyme Involved in Queuosine Biosynthesis
}

Vimbai Masiyanise Chikwana

Portland State University

Follow this and additional works at: https://pdxscholar.library.pdx.edu/open_access_etds Let us know how access to this document benefits you.

\section{Recommended Citation}

Chikwana, Vimbai Masiyanise, "Discovery of Novel Amidotransferase Activity Involved In Archaeosine Biosynthesis and Structural and Kinetic Investigation of QueF, an Enzyme Involved in Queuosine Biosynthesis" (2011). Dissertations and Theses. Paper 140.

https://doi.org/10.15760/etd.140

This Dissertation is brought to you for free and open access. It has been accepted for inclusion in Dissertations and Theses by an authorized administrator of PDXScholar. Please contact us if we can make this document more accessible: pdxscholar@pdx.edu. 
Discovery of Novel Amidotransferase Activity Involved In Archaeosine Biosynthesis and Structural and Kinetic Investigation of QueF, an Enzyme Involved in Queuosine Biosynthesis

by

Vimbai Masiyanise Chikwana

A dissertation submitted in partial fulfillment of the requirements for the degree of

\author{
Doctor of Philosophy \\ in \\ Chemistry
}

Dissertation Committee: Dirk Iwata-Reuyl, Chair

Michael Bartlett

Niles Lehman

Kevin Reynolds

Reuben Simoyi

Portland State University

(C) 2011 


\begin{abstract}
The 7-deazaguanosine nucleosides queuosine $(\mathrm{Q})$ and archaeosine $\left(\mathrm{G}^{+}\right)$are two of the most structurally complex modified nucleosides found in tRNA. Q is found exclusively in the wobble position of $\mathrm{tRNA}_{\mathrm{GUN}}$ coding for the amino acids asparagine, aspartate, histidine and tyrosine in eukarya and bacteria, while $\mathrm{G}^{+}$occurs in nearly all archaeal tRNA at position 15 .

In archaea preQ $_{0}$ is inserted into tRNA by the enzyme tRNA-guanine transglycosylase (TGT), which catalyzes the exchange of guanine with preQ $\mathrm{Q}_{0}$ to produce preQ $_{0}$-tRNA. The first objective of this study was to identify and characterize the enzyme(s) catalyzing the conversion of $\mathrm{preQ}_{0}$-tRNA to $\mathrm{G}^{+}$-tRNA. Comparative genomics identified a protein family possibly involved in the final steps of archaeosine biosynthesis, which was annotated as TgtA2. Structure based alignments comparing TGT and TgtA2 revealed that TgtA2 lacked key TGT catalytic residues and contained an additional module. The gene corresponding to tgtA2 from Methanocaldococcus jannaschii (mj1022) was cloned, expressed and the purified recombinant enzyme characterized. Recombinant $M j$ TgtA2 was shown to convert preQ $0_{0}$-tRNA to $\mathrm{G}^{+}$-tRNA using glutamine, asparagine or $\mathrm{NH}_{4}{ }^{+}$as nitrogen donors in an ATP-independent reaction. This is the only example of the conversion of a nitrile to a formamidine known in biology.
\end{abstract}

QueF catalyzes the reduction of $\mathrm{preQ}_{0}$ to 7-aminomethyl-7-deazaguanine ( $\mathrm{preQ}_{1}$ ) in the queuosine biosynthetic pathway. The second aim of this study was the transient state kinetic analysis of substrate binding and catalysis by the enzyme QueF, 
as well as investigation of the effects of ligands on its quaternary structure. Gel filtration and sedimentation equilibrium analyses indicated that QueF exists as a hybrid population in a rapid equilibrium between decamer and pentamer states. Addition of preQ $_{0}$ to $\mathrm{QueF}$ resulted in shifting the equilibrium towards the decamer state, as did the addition of divalent metals. Potassium chloride at high concentrations was found to disrupt the quaternary structure of QueF. Intrinsic tryptophan and NADPH fluorescence was used to determine the substrate binding to QueF by stopped-flow kinetic studies. Studies on the binding of $\mathrm{preQ}_{0}$ to $\mathrm{QueF}$ in conjuction with binding NADPH to the QueF mutant E78A-thioimide intermediate suggested a two-step mechanism consisting of a fast bimolecular process and a subsequent slower unimolecular process, while the binding of $\mathrm{preQ}_{0}$ to the $\mathrm{C} 55 \mathrm{~A}$ mutant was monophasic, consisting of only the fast bimolecular process. Thioimide formation was monitored by UV-Vis; under single turnover conditions the data fit well to single exponential rise. However, at high $\mathrm{preQ}_{0}$ concentrations two phases could be observed. The reduction of the thioimide was determined under single turnover conditions by both UV-Vis and fluorescence, and comparable rates were obtained from both techniques. These results indicate that the binding of $\mathrm{preQ}_{0}$ and NADPH to QueF, as well as thioimide formation, are very rapid; and that reduction of the thioimide is most likely the rate limiting step. Analysis of component rates suggests structural changes occur between these steps, further limiting the overall rate. 


\section{DEDICATION}

I humbly offer my heartfelt thanks to my siblings; Maggie, Bev, Fafi and Tinashe; they have been a constant source of love, concern, support and strength all these years. I also want to thank my husband, Edward Chikwana, without his encouragement and understanding it would have been impossible for me to finish this work. Lastly, I wish to thank my parents, Susan and Lucas Masiyanise, for always believing in me. Their unconditional love and encouragement has been more than I could ever ask for. To them I dedicate this thesis. 


\section{ACKNOWLEDGEMENTS}

I would like to express my deepest and sincere gratitude to my advisor, Prof. Dirk Iwata-Reuyl for the continuous support of my Ph.D study and research, for his patience, motivation and enthusiasm. I was fortunate to have an advisor who gave me the freedom to explore on my own, and at the same time was always accessible to listen and give advice. I thank my fellow labmates in the Iwata-Reuyl Group who made the lab a convivial place to work and for the stimulating discussions. I am deeply grateful to Ben Turner for the insightful discussions and helping me sort out the technical details of my transient kinetic work.

Dr. Michael Bartlett, Dr. Niles Lehman, Dr. Kevin Reynolds and Dr. Reuben Simoyi, deserve a special thanks as my thesis committee members. I appreciated the insightful comments and constructive criticisms at various stages in my graduate studies. I owe my sincere gratitude to Dr. Simoyi and his group for giving me unlimited access to their stopped-flow instruments. I am thankful to our collaborators Dr. Manal A. Swairjo for the X-ray crystallography and analytical ultracentrifugation of QueF and Dr. Valérie de Crécy-Lagard for the Bioinformatics and in vivo analysis of archaeosine formation.

Many friends helped me stay sane throughout the difficult years in graduate school with their support and care. I greatly value their friendship and I deeply appreciate their belief in me. 


\section{TABLE OF CONTENTS}

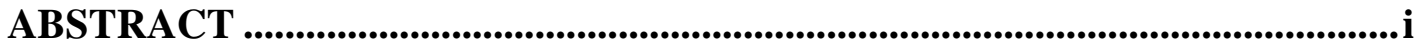

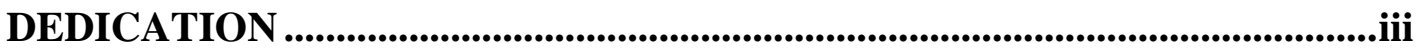

ACKNOWLEDGEMENTS ...............................................................................

LIST OF TABLES.........................................................................................viii

LIST OF FIGURES..................................................................................................

1. INTRODUCTION ................................................................................................ 1

1.1 Transfer ribonucleic acids .......................................................................................... 1

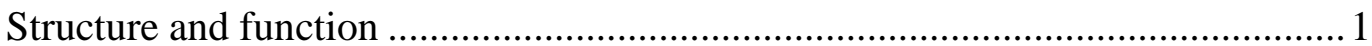

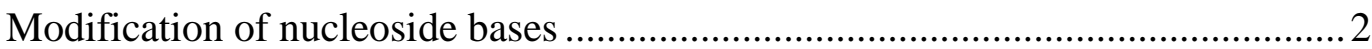

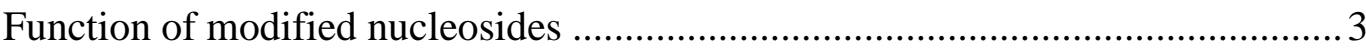

1.2 Deazaguanosine derivatives: archaeosine and queuosine...................................5

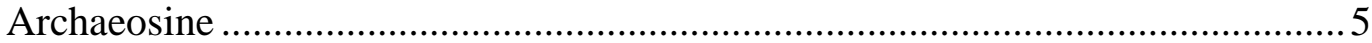

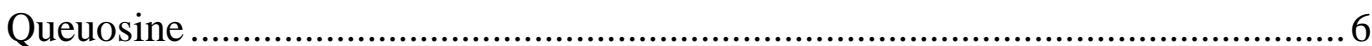

1.3 Queuosine and archaeosine biosynthesis..........................................................7

1.4 NADPH 7-cyano-7-deazaguanine oxidoreductase (QueF)................................9

1.5 S-Adenosylribosylmethionine:tRNA ribosyl transferase isomerase (QueA)

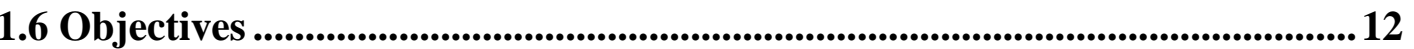

2. MATERIAL AND METHODS ...............................................................14

2.1 General methods and materials ....................................................................14

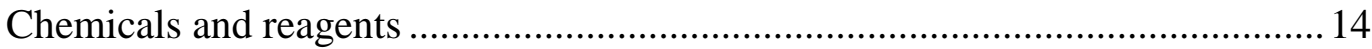

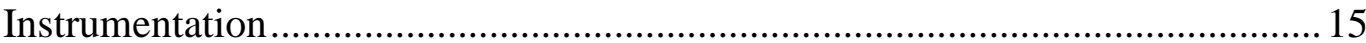

Strains, media and growth conditions ................................................................ 16

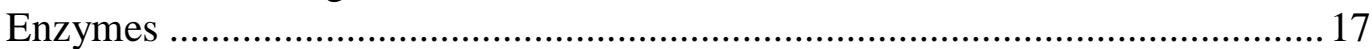

T7 polymerase expression and purification......................................................... 18

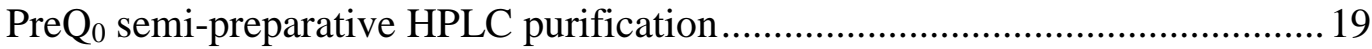

2.2 Methanocaldococcus jannaschii TgtA2 (MjTgtA2) .............................................20

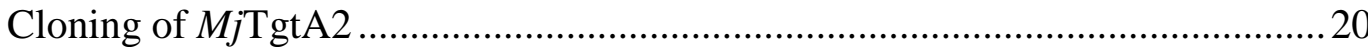

Overexpression and purification of recombinant MjTgtA2 ..............................21

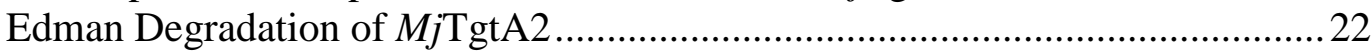

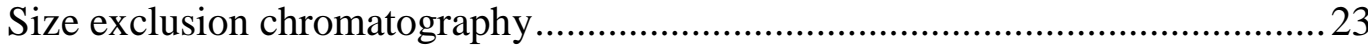

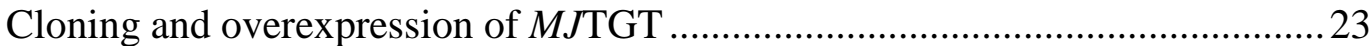

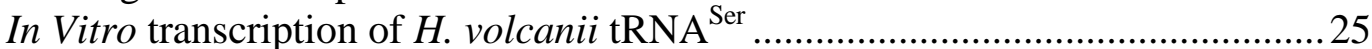

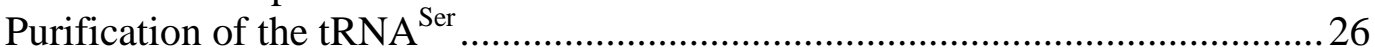

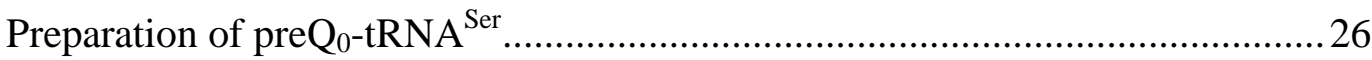




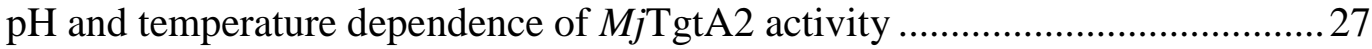

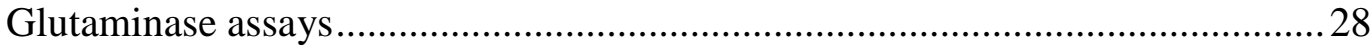

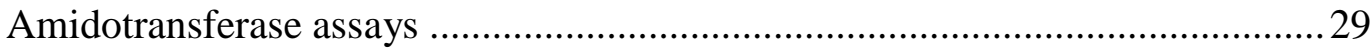

2.3 NADPH 7-cyano-7-deazaguanine oxidoreductase ..........................................31

Expression and purification of wild type $\mathrm{His}_{6}-\mathrm{QueF}, \mathrm{His}_{6}-\mathrm{C} 55 \mathrm{~A}$ and $\mathrm{His}_{6}-\mathrm{E} 78 \mathrm{~A}$

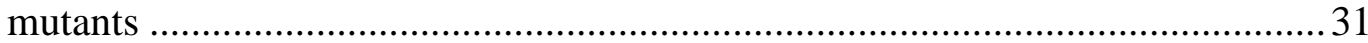

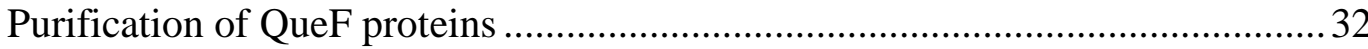

Preparation of glassware for metal analysis and apoprotein preparation ............. 33

Determination of the effect of metals on QueF activity ................................... 33

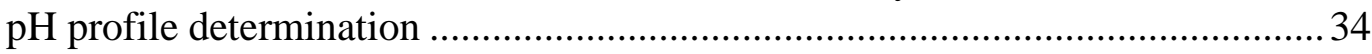

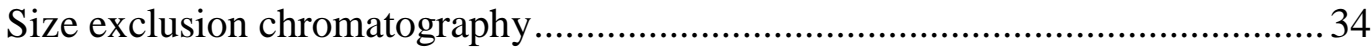

Development of fluorescence assays for use in stopped flow kinetics ................ 35

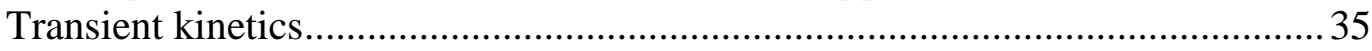

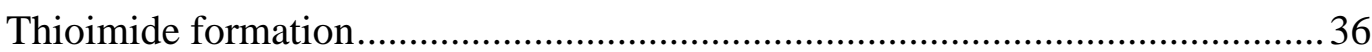

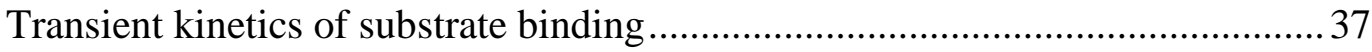

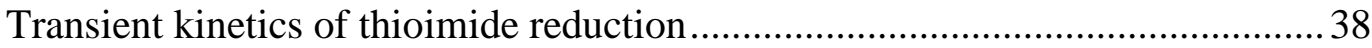

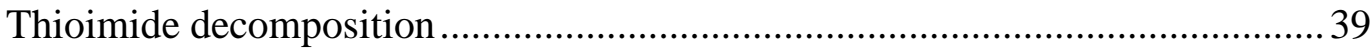

2.4 S-Adenosylribosylmethionine:tRNA ribosyl transferase isomerase............41

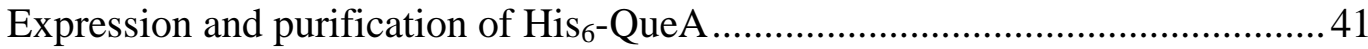

Expression and purification of $E$. coli tRNA-Guanine Transglycosylase (TGT) 43

Adenine phosphoribosyltransferase (APRTase) expression and purification ...... 44

5-phosphoribosyl-1-pyrophosphate (PRPP) synthetase expression and

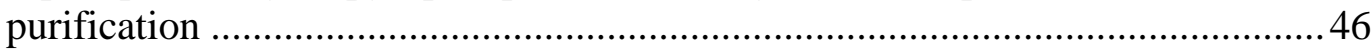

S-adenosylmethionine synthetase (MetK) expression and purification .............. 47

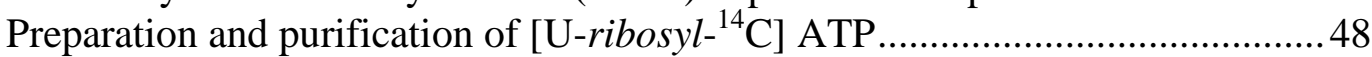

Synthesis and purification of unlabelled and [U-ribosyl- $\left.{ }^{14} \mathrm{C}\right]$-AdoMet ...............50

In vivo expression and purification of $\mathrm{tRNA}^{\mathrm{Tyr}}$..............................................5 50

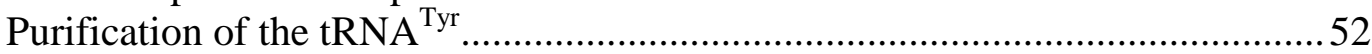

In vitro transcription and purification of minihelix $17-\mathrm{mer}$...............................53

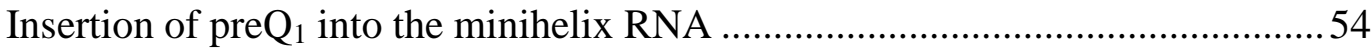

Determination of stereospecific abstraction of hydrogen by QueA ....................55

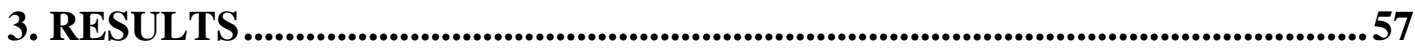

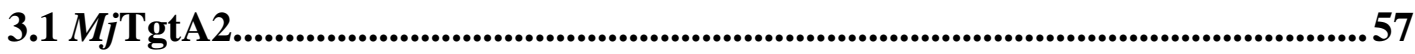

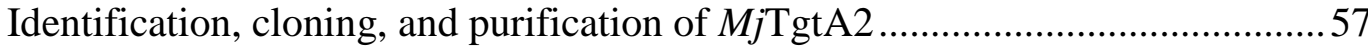

Determination of self-cleavage sites in $\mathrm{N}$ - and C-terminal fusions of MjTgtA2 .59

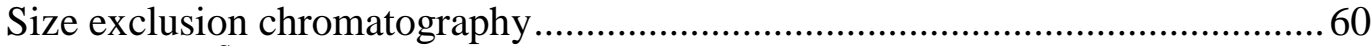

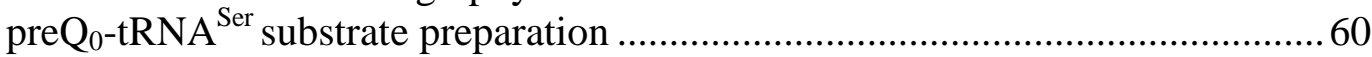

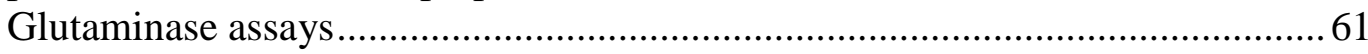

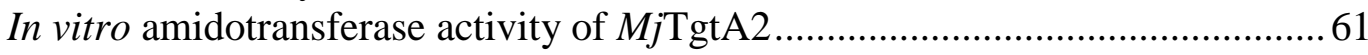

3.2 NADPH 7-cyano-7-deazaguanine oxidoreductase..........................................6 63

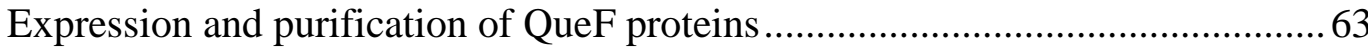




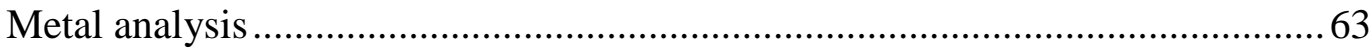

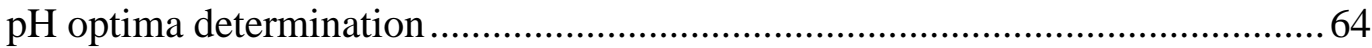

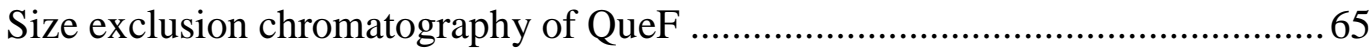

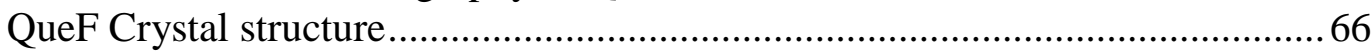

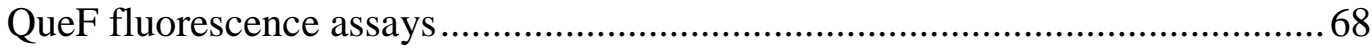

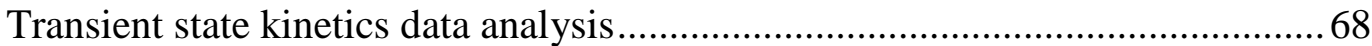

Fluorescence measurements of preQ $_{0}$ binding to QueF C55A...........................69

Fluorescence measurements of preQ $_{0}$ binding to wild type QueF ...................... 70

Absorbance measurements of thioimide formation in QueF under pre-steady state

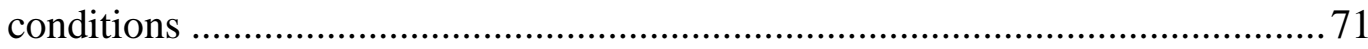

Fluorescence measurements of NADPH binding to the E78A mutant QueF-

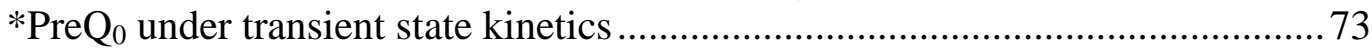

Fluorescence measurements of NADPH binding and thioimide reduction under

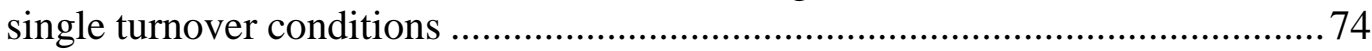

Absorbance measurements of thioimide reduction monitored at $390 \mathrm{~nm}$........... 75

Absorbance measurements of thioimide decomposition .................................. 76

3.3 S-Adenosylribosylmethionine:tRNA ribosyl transferase isomerase .............77

Stereospecific abstraction of the C5' proton by QueA ...................................... 77

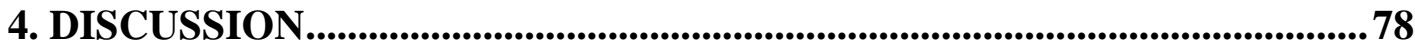

4.1 Archaeosine synthase .......................................................................................... 78

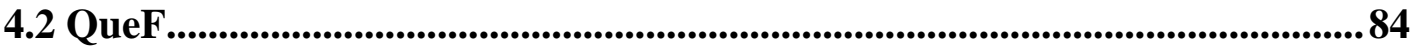

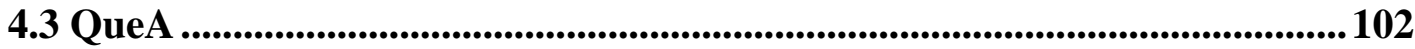

Tables and Figures .....................................................................................104

Reference List ....................................................................................................... 146 


\section{LIST OF TABLES}

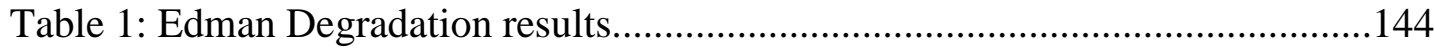

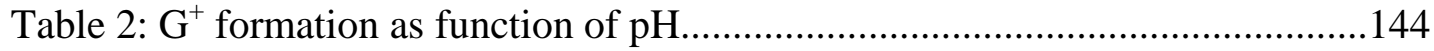

Table 3: Calculated rate constants for E78A-PreQ $Q_{0}$ binding NADPH at $20{ }^{\circ} \mathrm{C} \ldots \ldots . . .144$

Table 4: Calculated rate constants for wild type QueF for NADPH binding and catalysis at $20^{\circ} \mathrm{C}$ (NADPH fluorescence)................................................144

Table 5: Calculated rate constants for wild type $\mathrm{QueF}_{\text {for }} \mathrm{preQ}_{0}$ binding and catalysis $20^{\circ} \mathrm{C}$ (tryptophan fluorescence)................................................145

Table 6: Calculated rate constants for $\mathrm{C} 55 \mathrm{~A}$ QueF for $\mathrm{preQ}_{0}$ binding $20^{\circ} \mathrm{C}$ (tryptophan fluorescence).

Table 7: Other rates determined by UV absorbance determined at $30{ }^{\circ} \mathrm{C}$..................145 


\section{LIST OF FIGURES}

Figure 1: The structures of the 7-deazaguanosine hypermodified nucleosides of

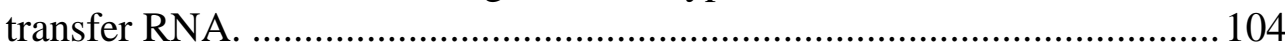

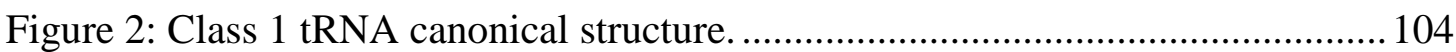

Figure 3: Electron density difference in the base plane between $\left[\mathrm{Mg}\left(\mathrm{H}_{2} \mathrm{O}\right)_{5} \mathrm{G}\right]^{2+}$ and

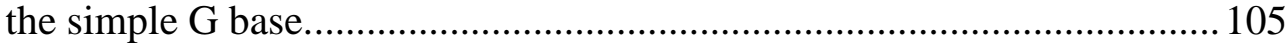

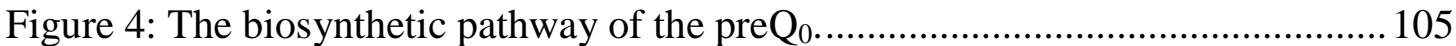

Figure 5: The biosynthetic pathways of archaeosine and queuosine in archaea and

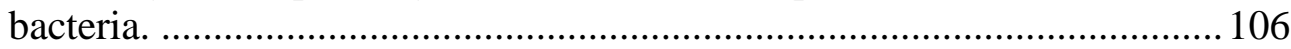

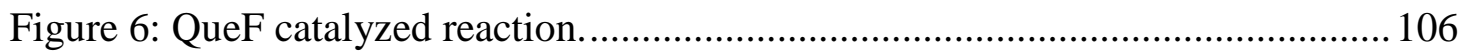

Figure 7: Multimeric barrels by the T-folds for functionally different enzyme.......... 107

Figure 8: Different pathways of nitrile metabolism. ................................................... 107

Figure 9: Proposed kinetic scheme of QueF based on the Bi-Uni-Uni Ter-Ter Ping

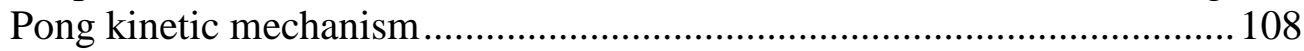

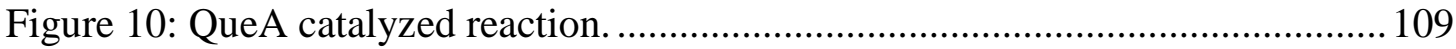

Figure 11: QueA follows an ordered $\mathrm{Bi}$ - Ter mechanism........................................ 109

Figure 12: Possible Mechanisms of the QueA Reaction Consistent with C-N bond

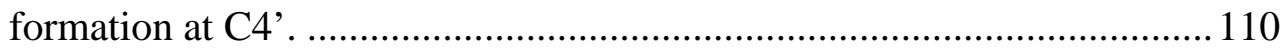

Figure 13: Conformations about the C4'-C5' bond of AdoMet.................................. 110

Figure 14: $\operatorname{PreQ}_{0}$ semi-preparative HPLC purification. ............................................ 111

Figure 15: Schematic of a stopped flow instrument...............................................111

Figure 16: Analysis of the TgtA and TgtA2 families................................................ 112

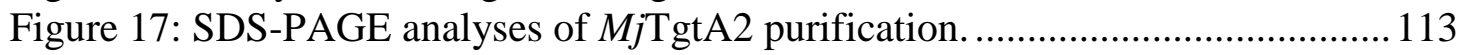

Figure 18: Edman degradation of $M j$ TgtA2 bands.................................................. 114

Figure 19: HPLC gel filtration analysis of Thioredoxin-His ${ }_{6} M j \mathrm{TgtA} 2$ and cleaved MjTgtA2.

Figure 20: Purification of tRNA ${ }^{\mathrm{Ser}}$ from prep cell...............................................115

Figure 21: Glutaminase activity of $M j \mathrm{TgtA} 2$ coupled with glutamate dehydrogenase activity.

Figure 22: Glutaminase activity as a function of increasing concentration of MjTgtA2.

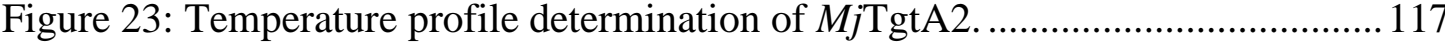

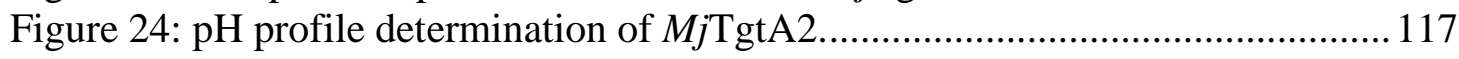

Figure 25: Activity of MjTgtA2 in different buffers................................................ 118

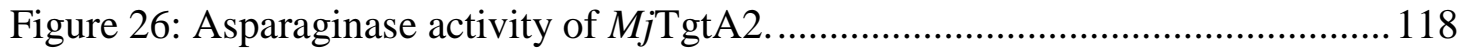

Figure 27: HPLC analysis of tRNA nucleosides from MjTgtA2 activity. ..................119

Figure 28: ESI mass spectrum of nucleosides archaeosine and $\mathrm{preQ}_{0}$ nucleoside..... 120

Figure 29: SDS/PAGE analyses of QueF purification by $\mathrm{Ni}^{2+}$-NTA agarose

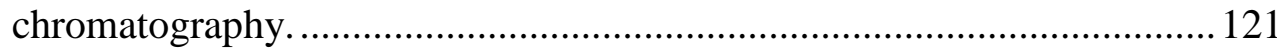

Figure 30: SDS/PAGE analyses of cleaved QueF proteins........................................ 121

Figure 31: Effect of Divalent metals on native QueF activity.................................... 122

Figure 32: Effect of Divalent metals on demetallated QueF activity.......................... 123

Figure 33: Effect of $\mathrm{KCl}$ concentration on QueF activity......................................... 124 
Figure 34: pH profile determination of QueF................................................... 125

Figure 35: HPLC analytical gel filtration analysis of QueF................................. 126

Figure 36: HPLC analytical gel filtration analysis of QueF-PreQ ${ }_{0}$ complex. ............ 127

Figure 37: B. subtilis QueF Homodecamer. ........................................................ 128

Figure 38: Crystal structure of QueF pentamer.................................................. 128

Figure 39: Thioimide formed in the active site of QueF........................................ 129

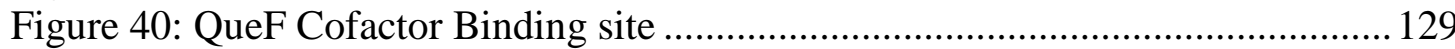

Figure 41: QueF and NADPH Fluorescence. .................................................. 130

Figure 42: Transient state analysis of tryptophan quenching upon $\mathrm{preQ}_{0}$ binding to

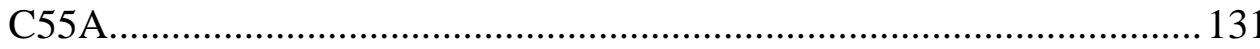

Figure 43: Transient state analysis of tryptophan quenching upon $\mathrm{pre}_{0}$ binding to wild type QueF. ................................................................................. 132

Figure 44: Absorbance measurements of thioimide formation in QueF under transient

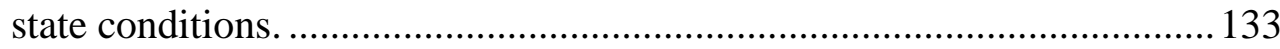

Figure 45: Transient state analysis of NADPH binding to E78A ............................ 134

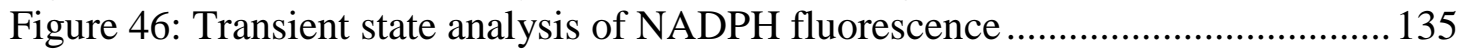

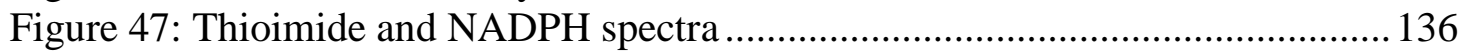

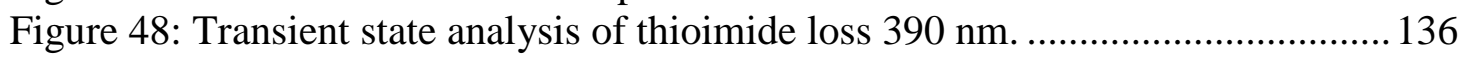

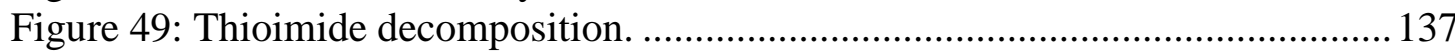

Figure 50: SDS/PAGE analyses of QueA purification........................................ 137

Figure 51: LC analysis of tRNA ${ }^{\text {tyr }}$ hydrolysates before and after QueA catalysis ..... 138

Figure 52: Mass spectrometry analysis of the oQ generated from QueA reactions ... 138

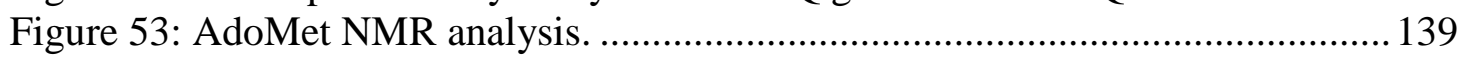

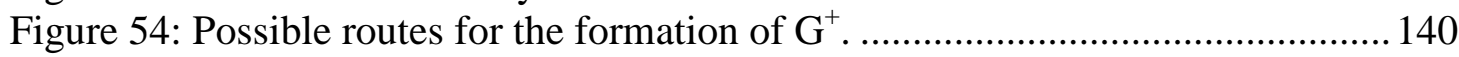

Figure 55: Alignment of unimodular FolE (GTP cyclohydrolase I) and YkvM (QueF)

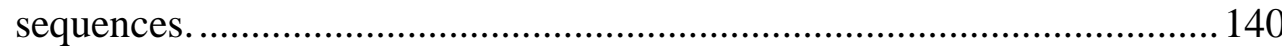

Figure 56: Three-dimensional model B. subtilis QueF. ........................................ 141

Figure 57: Proposed chemical mechanism for the QueF catalyzed reaction.............. 141

Figure 58: Partial structure of QueF with bound $\mathrm{preQ}_{0}$ showing the electrostatics around the tryptophan residue in the presence and absence of preQ $_{0} \ldots \ldots .142$

Figure 59: NADPH quenching in a reaction with QueF-*PreQ $\mathrm{Q}_{0}$ under mutiple turnover conditions. 


\section{INTRODUCTION}

\subsection{Transfer ribonucleic acids}

\section{Structure and function}

Transfer ribonucleic acid (tRNA) is the information adapter molecule interfacing the amino-acid sequence of a protein and the genetic information in deoxyribonucleic acid (DNA). The function of tRNA is essential to the process of translation, engaging in highly specific interactions with both nucleic acids and proteins. Most tRNAs from all organisms have a similar cloverleaf-fold secondary structure. Typically, there are four

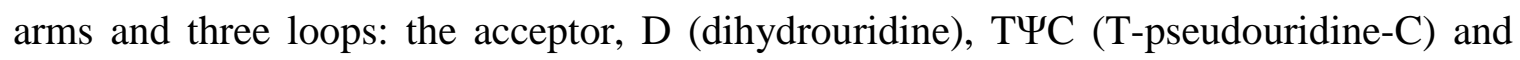
anticodon arms, D, TYC and anticodon loops (some tRNA molecules feature a fourth or variable loop). The tertiary L-shape of tRNA is the result of the stacking of the acceptor

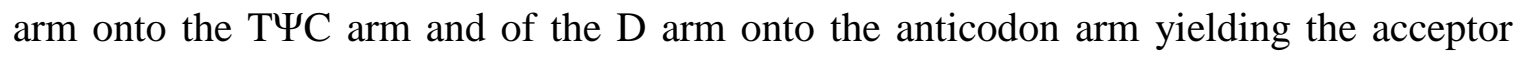
stem and anticodon stem respectively (1). Most tRNAs have between 75-95 nucleotides.

In addition to the role of tRNA in protein synthesis, tRNA is also involved in a variety of other functions, including the activation of amino acids, initiation and regulation of protein synthesis, RNA metabolism, nuclease degradation, reverse transcriptase primer, cell wall biosynthesis, membrane components and protein modification (2). 


\section{Modification of nucleoside bases}

A characteristic structural feature of RNA is the presence of post-transcriptional modifications, with naturally occurring RNAs containing numerous chemically altered nucleosides. They are formed by enzymatic modification of the primary transcripts during the complex RNA maturation process. To date, over 100 structurally distinguishable modified nucleosides originating from different types of RNAs have been reported and collected in the RNA Modification Database $(3,4)$. The extent of total nucleoside modification in tRNA molecules from plant and mammals is high (up to $25 \%$ ), whereas that in homologous tRNAs from bacteria is lower (2-15\%) and the organelles have the lowest level of modification (1-6\%) (5).

The modifications of the four canonical nucleosides adenosine, guanosine, uridine and cytosine vary from simple structural changes of the base or ribosyl moieties to hypermodifications (1). Simple modifications typically require a single enzyme and involve a small structural change such as methylation, isomerization or reduction of a base (1), whereas hyper-modification of nucleosides typically involves multiple enzymatic steps and results in substantial structural changes (1). Very few enzymes are needed for the transcription of tRNA, whereas a vast number participate in its post-transcriptional modification. An estimated $1 \%$ of bacterial genomes are dedicated to encoding genes necessary for tRNA nucleoside modifications (6), indicating the importance of such modifications to cell function. 


\section{Function of modified nucleosides}

The structural complexities of many modified nucleosides, their locations in specific sites in the tRNA molecule and their ubiquitous presence in a wide variety of organisms imply a critical role in tRNA function. By the end of 2008, 107 structurally distinct modified nucleosides had been identified from different RNAs from various Eukarya, Bacteria, or Archaea. Some modifications are found in all the three domains while others are only found in either one or two domains (5).

Modifications in the tRNA anticodon region are particularly prevalent and directly affect tRNA function by modulating codon-anticodon interactions; $30-40 \%$ of all codon recognition is accomplished through tRNA wobble recognition of more than one codon (7). Many post-transcriptional modifications have been found to occur at the tRNA's wobble position 34 as well as position 37 ( $3^{\prime}$-adjacent to the anticodon); these are the two most modified positions in tRNA with the greatest variety of modification chemistries found among all tRNAs (7). Many modifications located outside of the anticodon region function in general to stabilize the L-shaped tertiary structure of tRNA (8).

Some base modifications found at the wobble position appear to have evolved to counter wobble base pairing while others evolved to facilitate it. Modifications in the anticodon stem loop also aid in reading frame maintenance, promote translocation and cognate codon binding, as well as changing the codon read (9) as in lysidine $\left(\mathrm{k}^{2} \mathrm{C}\right)(7)$. Lysidine is a lysine (Lys)-containing cytidine derivative that occurs at the wobble position of 
tRNA $^{\text {Ile }}$ that bear the CAU anticodon in their tRNA sequence and are specific for the AUA codon (7). The CAU anticodon also occurs in tRNA ${ }^{\text {Met }}$ responsible for AUG decoding. The lysidine modification converts the codon specificity of tRNA with the CAU anticodon from AUG to AUA and the amino acid specificity from methionine (Met) to isoleucine (Ile), thus preventing the misreading of AUA as Met (10).

Position 37 of the tRNA usually contains a modified purine nucleoside. Transfer RNAs recognizing codons beginning with A usually have $\mathrm{N}^{6}$-threonylcarbamoyl-adenosine $\left(\mathrm{t}^{6} \mathrm{~A}\right)$ at this position (1). These modifications play a critical role in the stabilization of codon-anticodon pairing through base-stacking interactions and function to maintain the reading frame (1). Another modification that occurs at this position is N1-methylguanosine $\left(\mathrm{m}^{1} \mathrm{G}\right)$, which is conserved among the three domains of life (11). It has been found to play various roles in different tRNAs. In bacterial tRNA ${ }^{\text {Pro }}$, the methyl group at the $N 1$ position of G37 prevents incorrect base pairing with messenger RNA (12), it also contributes to efficient and accurate aminoacylation. In archaeal tRNA ${ }_{\mathrm{GCA}}^{\mathrm{Cy}} \mathrm{m}^{1} \mathrm{G} 37$ enhances the aminoacylation rates of phosphoseryl-tRNA synthetase $(13,14)$ and cysteinyl-tRNA synthetase (13). Other functions of specific tRNA modifications include HIV replication $\left(\mathrm{m}^{1} \mathrm{~A}_{58}\right)$ (15), cell cycle control $\left(\mathrm{ms}^{2} \mathrm{i}^{6} \mathrm{~A}_{37}\right)$ (16), and vitamin $\mathrm{B} 6$ metabolism $\left(\Psi_{38-40}\right)(17)$. 


\subsection{Deazaguanosine derivatives: archaeosine and queuosine}

Archaeosine and queuosine are two of the most structurally complex hypermodified nucleosides identified in tRNA (Figure 1). Both modified nucleosides share the unusual 7-deazaguanosine core in which the N-7 atom of the base is replaced by a carbon. Queuosine is characterized by a cyclopentenediol ring appended to 7-aminomethyl-7deazaguanosine $(18,19)$, whereas in archaeosine there is a formamidino side chain at position 7 (20).

\section{Archaeosine}

Archaeosine $\left(\mathrm{G}^{+}\right)$occurs specifically at position 15 in the dihydrouridine loop of archael tRNA, a site not modified in known bacterial and eukaryotic tRNA sequences. Archaeosine was first discovered during the sequencing of tRNA ${ }^{\mathrm{Met}}$ from Thermoplasma acidophilium (21). Its structure was shown to be neither purine nor pyrimidine but 7formamidino-7-deazaguanosine (20).

Tertiary base pairs are important to the structure of canonical tRNAs. Pairing of base 15 to 48 is crucial as it brings together the $\mathrm{D}$ and $\mathrm{V}$ loops, and is referred to as the Levitt base pair (Figure 2). Nucleotides at positions 15 and 48 do not form the canonical Watson-Crick base pairing, but form a reverse Watson-Crick (RWC) pairing (22). Proper

folding interactions in tRNA ${ }^{\text {Phe }}$ from yeast has been shown to require G15-C48 base pair for the correct interaction of the $\mathrm{T}$ and $\mathrm{D}$ arms (23). Magnesium binding and archaeosine 
modification have been suggested to stabilize the Levitt base pair in tRNAs by inducing electron redistribution, which results in stabilization of the RWC geometry (24) (Figure 3). The positively charged formamidine group of archaeosine at the interface of the Dloop/T-stem in the tertiary structure of the tRNA has also been suggested to be important in structural stabilization of the tRNA through electrostatic interactions with the anionic phosphates (20).

\section{Queuosine}

Queuosine (Q) and its derivatives are found at position 34 in tRNA with the GUN anticodon (tRNA ${ }^{\text {Asp,Asn,His,Tyr }}$ ) (25-28) exclusively in bacteria and eukaryotes, with the exception of Saccharomyces cerevisiae, Thermus thermophilus, mycobacterium and mycoplasma. Queuosine can be further modified by the addition of a mannosyl group to Q-tRNA $^{\text {Asp }}$ or galactosyl group to Q-tRNA ${ }^{\text {Tyr }}$ in mammalian tRNA (29), or glutamate to tRNA $^{\text {Asp }}$ in bacteria (30). Queuosine has been implicated in a number of physiological phenomena including eukaryotic cell proliferation and differentiation (31), tyrosine biosynthesis in mammals (32), translational frameshifts essential to retroviral protein biosynthesis $(33,34)$ and bacterial virulence $(35)$. In eukaryotes queuosine has been further shown to be important in neoplasm staging (36). Most of the evidence to date support the hypothesis that queuosine plays a role in modulating translational fidelity (37). From experimental data (38) and computational modeling based on the crystal 
structure of tRNA ${ }^{\mathrm{Asp}}$ it appears that queuosine is structurally restrictive for anticodon loop flexibility (36), which could function in eliminating codon bias.

\subsection{Queuosine and archaeosine biosynthesis}

The first step of $\mathrm{Q}$ and $\mathrm{G}^{+}$biosynthesis in bacteria and archaea, respectively, follows the pathway of pteridines and folic acid biosynthesis (39) as well as that of the 7-deazaadenine antitumor antibiotics such as toyocamycin (40), with GTP cyclohydrolase I (GCYH-I) $(41,42)$ which catalyzes the conversion of GTP to 7,8-dihydroneopterin triphosphate $\left(\mathrm{H}_{2} \mathrm{NTP}\right)$.

Comparative genomics resulted in identification of four genes (queC, queD, queE, and $q u e F)$, which are involved in the queuosine biosynthetic pathway of Bacillus subtilis (B. subtilis) in a previously undefined operon (43). E. coli QueD was recently shown to catalyze the conversion of 7,8-dihydroneopterin triphosphate to 6-carboxy-5,6,7,8-tetrahydropterin $\left(\mathrm{CPH}_{4}\right)(44)$, which is then converted to the novel intermediate 7-carboxy-7deazaguanine (CDG) (45) by QueE, a member of the radical SAM enzyme superfamily. Radical SAM proteins catalyze diverse reactions, including unusual methylations, isomerization, sulfur insertion, ring formation, anaerobic oxidation and protein radical formation (46). The carboxylate moiety on CDG is converted subsequently to a nitrile to yield preQ $_{0}$ by QueC an ATP-dependent reaction, in which ammonia serves as the nitrogen source (45). The $\mathrm{preQ}_{0}$ biosynthetic pathway is shown in Figure 4. 
The pathways for $\mathrm{Q}$ and $\mathrm{G}^{+}$diverge after the formation of preQ $_{0}$. In bacteria NADPH dependent 7-cyano-7-deazaguanine oxidoreductase (QueF) catalyzes the NADPHdependent conversion of the nitrile moiety of preQ $_{0}$ to the primary amine group in 7aminomethyl-7-deazaguanine ( $\left.\mathrm{preQ}_{1}\right)(47)$. The bacterial tRNA-guanine transglycosylase (TGT) then introduces preQ ${ }_{1}$ into an appropriate tRNA with the concomitant release of the genetically encoded guanine at position 34 (48). TGT catalyzes the base-exchange reaction by cleaving the $\mathrm{N}$-glycosidic bond, without breaking the phosphodiester backbone (49). The penultimate step is catalyzed by QueA which results in the introduction of an epoxyclopentanediol ring to the primary amine of $\mathrm{preQ}_{1}$ forming the intermediate epoxy-queuine (oQ) (50). The final conversion to form the cyclopentenediol of queuosine is catalyzed by an uncharacterized enzyme that may be $\mathrm{B}_{12}$-dependent (51). Eubacteria are unique in their ability to synthesize queuosine de novo, whereas eukaryotes utilize a salvage system or acquire queuine from their diet and from intestinal flora $(28,52,53)$, and insert this directly into tRNA by the eukaryotic TGT (54).

In archaea, preQ $_{0}$ is directly incorporated into the tRNA by an archaeal TGT, which exchanges preQ $_{0}$ for the guanine in position 15 of tRNA resulting in the formation of preQ $_{0}$-tRNA. In vitro guanine was found to be a substrate to archaeal TGT, but not $\operatorname{pre}_{1}$, archaeosine, and queuine (55). The biosynthetic pathways of archaeosine and queuosine are shown in Figure 5. The enzyme responsible for the conversion of preQ $\mathrm{Q}_{0^{-}}$ tRNA to $\mathrm{G}^{+}$-tRNA was unknown until the work reported in this thesis. 


\subsection{NADPH 7-cyano-7-deazaguanine oxidoreductase (QueF)}

QueF is an oxidoreductase that utilizes two equivalents of NADPH in a four electron reduction of the nitrile group of $\mathrm{pre}_{0}$ to the primary amine of $\mathrm{preQ}_{1}(47)$. The reaction catalyzed by QueF is shown in Figure 6. The amino acid sequence homology between QueF and GTP cyclohydrolase I resulted in an initial mis-annotation of QueF as a GTP cyclohydrolase (FolE) in the sequence databases. The QueF family possess a characteristic motif, named the QueF motif, $\mathrm{E}(\mathrm{S} / \mathrm{L}) \mathrm{K}(\mathrm{S} / \mathrm{A}) \mathrm{hK}(\mathrm{L} / \mathrm{Y})(\mathrm{Y} / \mathrm{F} / \mathrm{W})$ where $\mathrm{h}$ is a hydrophobic amino acid bracketed on the $\mathrm{N}$ - and $\mathrm{C}$ - terminal sides by at invariant Cys and Glu, respectively. The QueF motif is absent from the FolE family, while key zinc binding His and Cys residues found in the FolE family are absent from the QueF family; these differences are the best identifiers of QueF sequences in genome databases (47).

Based on a homology model QueF was suggested to belong to the tunnel fold (T-fold) family of proteins (56). The T-fold proteins bind substrates belonging to the purine and pterin families. The T-fold family is comprised of two structural subfamilies, the unimodular and bimodular proteins. The unimodular proteins possess a single T-fold domain and are comprised of approximately 160 amino acid residues. The bimodular proteins however possess tandem T-fold domains and are comprised of approximately 280 amino acid residues (57). Functional assembly consists of 2 barrels face-to-face; some structures of the T-fold proteins are shown in Figure 7. 
Substrate binding occurs at the interface of subunits and is anchored by a conserved Glu /Gln; the presence of Glu/Gln in the active site is characteristic of T-fold proteins (57). In dihydroneopterin aldolase (Glu74), 6- pyruvoyl tetrahydropterin synthase (Glu 107), and urate oxidase (Gln 228), the conserved Glu/Gln is positioned such as to serve as an acceptor for the pyrimidine ring of the substrate (57). In all of these examples, the conserved Glu/Gln forms two hydrogen bonds to the substrate (57).

The discovery of QueF activity added a novel class of chemistry to nitrile metabolism (Figure 8). The other pathways currently known in nitrile metabolism involve hydrolysis by nitrile hydratase and nitrilase, and oxidation by oxygenase to give cyanohydrins (58).

\subsection{S-Adenosylribosylmethionine:tRNA ribosyl transferase isomerase (QueA)}

QueA catalyzes the penultimate step in the biosynthesis of queuosine, an unprecedented transfer and isomerization of the ribosyl moiety from S-adenosylmethionine (AdoMet) to preQ $_{1}$-tRNA to give epoxyqueuosine modified tRNA, oQ-tRNA (Figure 10). The reaction is accompanied by the rearrangement of the ribosyl moiety and the elimination of methionine and adenine $(50,59)$.

Kinetic analysis revealed that QueA follows an ordered sequential bi-ter mechanism in which preQ ${ }_{1}$-tRNA binds to the enzyme followed by AdoMet to form a ternary complex, followed by the transfer of the ribosyl group to $\mathrm{preQ}_{1}$ and release of products in the order 
adenine, methionine and oQ-tRNA (Figure 11) (60). The regiochemistry of the C-N bond formation between $\mathrm{preQ}_{1}$-tRNA and AdoMet has been elucidated through the utilization of $\left[1^{\prime}-{ }^{13} \mathrm{C}\right]$ AdoMet in the QueA reaction followed by the identification of the isotopically enriched carbon in the oQ nucleoside (61). NMR data supports C-3 as the site of enrichment, implicating $\mathrm{C}^{-4^{\prime}}$ of AdoMet as the site of C-N bond formation.

Two possible mechanisms are implicated, consistent with $\mathrm{C}-\mathrm{N}$ bond formation at $\mathrm{C}^{\prime}$. In the mechanism (A) proposed for the reaction catalyzed by QueA (Figure 12) the first step of the mechanism involves the deprotonation of AdoMet at $\mathrm{C}-5^{\prime}$ to give the sulfonium ylide I. The subsequent opening of the ribose ring followed by elimination of adenine generates the vinyl sulfonium II. Nucleophilic attack of the $\mathrm{preQ}_{1}$ methylamine at the C4' position generates the sulfonium ylide III which subsequently attacks the C-1' aldehyde to give the alkoxy-cabocycle IV. Intramolecular $\mathrm{S}_{\mathrm{N}} 2$ attack of the alkoxy oxygen on the adjacent carbon results in the formation of oQ-tRNA and the elimination of methionine (60). In mechanism (B) nucleophilic attack by the amine in an $\mathrm{S}_{\mathrm{N}} 2$ reaction forms the $\mathrm{C}-\mathrm{N}$ bond in the first step before the $\mathrm{C}^{\prime}$ proton is removed (Figure 12). The elimination/addition mechanism (mechanism A) is compatible with loss of either proton since stereochemistry at $\mathrm{C}^{-} 5^{\prime}$ destroyed in the formation of the vinyl sulfonium II. But, elimination/addition mechanism requires either syn or anti relationship between the proton removed and the $\mathrm{C}^{\prime}-\mathrm{O}$ bond that is cleaved, the conformations are shown in Figure 13. The conformation about the $\mathrm{C}^{\prime}-\mathrm{C} 5^{\prime}$ of bond AdoMet, indicates that the reaction would most likely favor the trans conformation, 
resulting in the loss of the proS hydrogen, as this conformation is less sterically demanding than the syn conformation. In contrast, an $\mathrm{S}_{\mathrm{N}} 2$ mechanism (mechanism B) requires loss of C-5'-proR proton of AdoMet due to known streochemistry of oQ and the stereochemical integrity of sulfonium ions. Thus, elucidating the stereochemistry of the

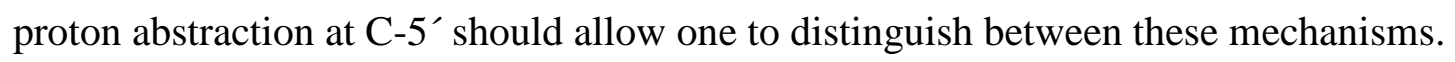

\subsection{Objectives}

The overall objectives of the work described in this thesis were to investigate several enzymatic steps in the biosynthetic pathway leading to queuosine and archaeosine. The work focused specifically on the following:

\section{Methanocaldococcus jannaschii TgtA2}

The objectives of this work were to test the hypothesis that $\operatorname{tgtA2}$ encodes the enzyme responsible for the final step of archaeosine biosynthesis, and to biochemically characterize the enzyme.

\section{NADPH 7-cyano-7-deazaguanine oxidoreductase (QueF)}

The objectives of this work were to determine the elementary rate constants in the kinetic mechanism of the reaction catalyzed by QueF (Figure 9), as well as identifying the rate limiting step(s) in this reaction. In particular, to apply transient kinetic analyses to 
elucidate the kinetics of substrate and cofactor binding, and the rates of thioimide formation reduction. As well as the investigation of the effects of ligands on its quaternary structure.

\section{S-Adenosylribosylmethionine:tRNA ribosyl transferase isomerase (QueA)}

The objective of this work was to test two putative mechanisms for the QueA catalyzed reaction by elucidating the stereochemistry of deprotonation at $\mathrm{C} 5^{\prime}$ of AdoMet. 


\section{MATERIAL AND METHODS}

\subsection{General methods and materials}

\section{Chemicals and reagents}

Buffers, salts and reagents of the highest quality grade available were purchased from Sigma (St. Louis, MO) unless otherwise noted. DEPC (diethylpyrocarbonate) treated water was used in the preparation of all solutions for RNA related assays. Dithiothreitol (DTT), isopropyl- $\beta$-D-thiogalacto-pyranoside (IPTG), kanamycin sulfate, $\beta$-NADPH ( $\beta$ Nicotinamide adenine dinucleotide phosphate), $\beta$-NADP ${ }^{+}, \mathrm{DEPC}$ and ampicillin were purchased from RPI Corporation (Chicago, IL). The radiochemicals $\left[\mathrm{U}_{-}{ }^{14} \mathrm{C}\right]$-glucose, $[8-$ $\left.{ }^{14} \mathrm{C}\right]$-guanine, $\left[8-{ }^{14} \mathrm{C}\right]$-adenine, $\left[\mathrm{U}-{ }^{14} \mathrm{C}\right]$-L-glutamine and $\left[{ }^{3} \mathrm{H}\right]$-L-asparagine were purchased from Moravek (Brea, CA). Adenine, adenosine, guanosine, ATP, GTP, UTP, CTP, methionine, ribose-5-phosphate, phospho(enol)pyruvate trisodium salt, and the resins BND-cellulose, DEAE-cellulose, sephadex G25 and PEI cellulose TLC plates were all purchased from Sigma. Nickel-nitrilotriacetic acid agarose $\left(\mathrm{Ni}^{2+}-\mathrm{NTA}\right.$ agarose $)$ was purchased from Qiagen (Valencia, CA). Silica TLC plates, Whatman GF-B and Whatman P81 filter disks were purchased from Fisher Scientific (Pittsburgh, PA). Centricon YM-10 and Amicon Ultra YM-10 centrifugal devices, Amicon Ultra-MC spin filters and HA filters were from Millipore (Billerica, MA). Dialysis cassettes were obtained from Pierce (Rockford, IL). Plasmid Mini-Kits were from Fermentas (Glen Burnie, MD) and Qiagen. AntiRNase was purchased from Ambion, Inc (Austin, TX). 
Oligonucleotides were obtained from Integrated DNA Technologies (San Diego, CA). The Bradford dye binding reagent from BioRad (Hercules, CA) was used for protein determination. All reagents for sodium dodecyl sulfate polyacrylamide gel electrophoresis (SDS-PAGE) and 10\% acrylamide/Tris-HCl precast gels were purchased from BioRad. SDS-PAGE analysis was carried out using $12 \%$ gels and visualized with Coomassie Brilliant Blue. Invitrolon membranes (PDVF membranes) were from Invitrogen. Gel filtration molecular weight standards were purchased from Sigma. The mj1022 gene was custom synthesized by GenScript. DNA sequencing was carried out at the DNA sequencing core facility at Oregon Health and Sciences University (OHSU), Portland, OR. Edman degradation was carried out by the Molecular Structure Facility at University of California, Davis. The LIC cloning kits containing either pET30Xa or pET32Xa plasmids were from Novagen. M. jannaschii genomic DNA was kindly provided by Dr. Anna-Louise Reysenbach (Portland State University, Portland, OR).

\section{Instrumentation}

PCR was carried out on a GeneAmp PCR system 2400 from PerkinElmer Life Sciences. UV-Vis spectroscopy was performed with a Varian Cary 100 spectrophotometer equipped with a thermostated cell holder. Fluorescence spectroscopy was carried out on a QM3 spectrofluorimeter from Photon Technology International and a Gemini XPS microplate spectrofluorimeter from Molecular dynamics. HPLC was carried out using a Hitachi L-7100 pump system with an L-4500A photodiode array detector, and controlled 
via the Hitachi ConcertChrome software. Centrifugation was carried out on an Avanti J20 centrifuge, an LE-80K Ultra centrifuge using a Ti-60 rotor, and a Model TJ 6 swinging bucket centrifuge, all from Beckman Coulter, Inc. SDS-PAGE was carried out on a mini Protean III from BioRad. Small molecule mass spectrometry was performed on a LCQ Advantage ion-trap mass spectrometer (Thermo Electron, San Jose, CA) equipped with an electrospray ionization (ESI) source at the BioAnalytical Shared Resource/Pharmacokinetics Core Facility in the Department of Physiology and Pharmacology at OHSU, Portland, Oregon, or on a MicroTOF-Q tandem mass spectrometry instrument (Bruker, Billerica, MA) utilizing ESI in the Department of Chemistry at Portland State University. Radioactivity was quantified with a Beckman LS 6500 liquid scintillation counter. The pump used for column chromatography of RNA was a Model EP-1 Econo pump and Econo-column from BioRad. An Amersham Biosciences Typhoon 9200 variable mode imager with ImageQuant 5.2 software was used for phosphorimaging. Stopped flow experiments were carried out on both a HiTech Scientific SF 61-DX2 double mixing stopped flow spectrophotometer and Hi-Tech Scientific SF-61 AF single mixing stopped flow spectrophotometer. The same $75 \mathrm{~W}$ Xenon Arc lamp was used for both spectrophotometry and spectrofluorimetery.

\section{Strains, media and growth conditions}

DH5 $\alpha\left(\mathrm{F}^{-}\right.$ 80 lacZAM15 $\Delta($ lacZYA-argF)U169 recA1 endA1 hsdR17(rk-, mk+) phoA supE4 thi-1 gyrA96 relA1 tonA) (Invitrogen), NovaBlue (endA1 hsdR17 $\left(\mathrm{r}_{\mathrm{K} 12}{ }^{-} \mathrm{m}_{\mathrm{K} 12}{ }^{+}\right)$ 
supE44 thi-1 recA1 gyrA96 relA1 lac $\mathrm{F}^{\prime}\left[\operatorname{proA}^{+} B^{+}\right.$lacl ${ }^{q} Z \Delta M 15:: \operatorname{Tn} 10\left(\right.$ Tet $\left.\left.^{\mathrm{R}}\right)\right]$ (Novagen), BL21 (DE3) $\mathrm{F}^{-}$ompT gal dcm lon $h s d S_{\mathrm{B}}\left(\mathrm{r}_{\mathrm{B}}{ }^{-} \mathrm{m}_{\mathrm{B}}{ }^{-}\right) \lambda(\mathrm{DE} 3$ [lacI lacUV5-T7 gene1 indl sam7 nin5]) (Novagen) were used for cloning or protein over-production, and were routinely grown in $\mathrm{LB}$ medium (BD Diagnostic System) at $37^{\circ} \mathrm{C}$. Growth media were solidified with $15 \mathrm{~g} / \mathrm{L}$ agar for the preparation of plates. Transformation of E. coli was performed following standard procedures. Ampicillin (amp, $100 \mu \mathrm{g} / \mathrm{mL}$ ) and Kanamycin (kan, $50 \mu \mathrm{g} / \mathrm{mL}$ ), were used as needed.

\section{Enzymes}

Crude aminoacyl-tRNA synthetase from E. coli, L-glutamic dehydrogenase type I from bovine liver, pyruvate kinase type II from rabbit muscle and bacterial alkaline phosphatase were purchased from Sigma as ammonium sulfate suspensions. Phosphoriboisomerase from torula yeast, hexokinase type F-300 from baker's yeast, nuclease $\mathrm{P}_{1}$ from Penicillium citrinum, venom phophodiesterase I, lysozyme, and DNase were purchased as lyophilized powders from Sigma and stored in 50\% glycerol with the appropriate buffer at the recommended temperature. PfuUltra ${ }^{\mathrm{TM}}$ DNA polymerase was purchased from Stratagene. T4 DNA ligase and restriction enzymes were purchased from Fermentas and New England Biolabs. Recombinant Saccharomyces cerevisiae adenine phosphoribosyl-transferase (APT1) was expressed from pQEAPT1 in E. coli BL25 (a generous gift from Dr. Milton Taylor, Indiana University). Recombinant 5phosphoribosyl-1-pyrophosphate (PRPP) synthetase from Salmonella typhimurium was expressed from pBSR11R in E. coli JM831 (a gift from Dr. Vern L. Schramm, Albert 
Einstein University). Recombinant T7 polymerase was expressed from pT7-911Q in $E$. coli DH5a. Recombinant S-adenosyl-methionine synthetase (MetK) was expressed in $E$. coli DH5 $\alpha$ from pK8 (pK8 was a gift from Dr. G. Markham, Fox Chase Cancer Center, PA).

\section{T7 polymerase expression and purification}

Recombinant T7 polymerase was expressed in pT7-911Q/DH5 $\alpha$ E. coli cells at $37{ }^{\circ} \mathrm{C}$ in LB/amp. Cells from a glycerol stock were used to inoculate $3 \mathrm{~mL}$ of $\mathrm{LB} / \mathrm{amp}$ medium. After 12 hours a $1 \mathrm{~mL}$ aliquot was removed and used to inoculate $100 \mathrm{~mL}$ of LB/amp medium in $500 \mathrm{~mL}$ flasks. The cultures were incubated at $37{ }^{\circ} \mathrm{C}$ and $250 \mathrm{rpm}$ for 12 hours with shaking, after which $5 \mathrm{~mL}$ aliquots were taken and used to inoculate $500 \mathrm{~mL}$ of LB/amp medium in $2.5 \mathrm{~L}$ flasks. After 3 hours of incubation at $37^{\circ} \mathrm{C}$ and shaking at $250 \mathrm{rpm}$ an optical density at $600 \mathrm{~nm}\left(\mathrm{OD}_{600}\right)$ of about 0.9 was reached and IPTG was added to a final concentration of $0.5 \mathrm{mM}$ and the cells were grown for an additional 4 hours. The cells were collected by centrifugation at 7,500 $\mathrm{x}$ for 15 minutes at $4{ }^{\circ} \mathrm{C}$ and frozen with liquid nitrogen. The cells were stored at $-80{ }^{\circ} \mathrm{C}$ until further use.

The cells were resuspended to $250 \mathrm{mg} / \mathrm{mL}$ in $50 \mathrm{mM}$ Tris- $\mathrm{HCl}$ (pH 8.0), $100 \mathrm{mM} \mathrm{KCl,} 2$ $\mathrm{mM} \beta \mathrm{ME}, 1 \mathrm{mM}$ imidazole, and $1 \mathrm{mM}$ PMSF. Lysozyme was added to a final concentration of $250 \mu \mathrm{g} / \mathrm{mL}$ and the cells incubated at $37{ }^{\circ} \mathrm{C}$ for 30 minutes, followed by 3 intervals of freeze-thaw cycles. DNase was added to a final concentration of $10 \mu \mathrm{g} / \mathrm{mL}$ 
and the cells were left at $37{ }^{\circ} \mathrm{C}$ for an additional 30 minutes. The cell lysate was centrifuged at 26,000 $\mathrm{x} g$ for 30 minutes after which it was filtered through a low protein binding $0.45 \mu \mathrm{m}$ MCE filter. The CFE was loaded onto a $10 \mathrm{~mL}$ column containing $\mathrm{Ni}^{2+}$-NTA agarose equilibrated in lysis buffer. The column was washed with lysis buffer containing $10 \mathrm{mM}$ imidazole. The recombinant T7 polymerase was eluted with $100 \mathrm{mM}$ imidazole in lysis buffer without PMSF. The collected eluate was concentrated to about $2 \mathrm{~mL}$ using the Amicon Ultra YM-10 and dialyzed overnight against 4 L of lysis buffer without PMSF, then stored at $-80{ }^{\circ} \mathrm{C}$ as a $50 \%$ glycerol stock in aliquots of $100 \mu \mathrm{l}$.

\section{PreQ $Q_{0}$ semi-preparative HPLC purification}

$\mathrm{PreQ}_{0}$ was synthesized as previously described by Migawa (62). $\mathrm{PreQ}_{0}$ was purified on a semi-preparative Luna C18 column $(250$ x $10 \mathrm{~mm}, 5 \mu \mathrm{m})$ from Phenomenex. The preQ 0 eluted in a 20 minute run, eluting at 12.5 minutes under gradient conditions; $96 \% 25 \mathrm{mM}$ $\mathrm{NH}_{4} \mathrm{OAc}(\mathrm{pH}$ 6.0)/4\% methanol for 10 minutes followed by a gradient of $96 \% 25 \mathrm{mM}$ $\mathrm{NH}_{4} \mathrm{OAc} / 4 \%$ methanol up to $85 \% 25 \mathrm{mM} \mathrm{NH}_{4} \mathrm{OAc} / 15 \%$ methanol over 10 minutes at a flow rate of $4 \mathrm{~mL} / \mathrm{min}$. 


\subsection{Methanocaldococcus jannaschii TgtA2 (MjTgtA2)}

\section{Cloning of $M j$ TgtA2}

The Methanocaldococcus jannaschii mj1022 gene corresponding to tgtA2 was amplified from both genomic DNA and a custom synthesized gene (GenScript) via PCR and cloned with either $\mathrm{N}$ - or $\mathrm{C}$-terminal $\mathrm{His}_{6}$-fusions using the following primers:

Gen1022F 5'-GGTATTGAGGGTCGCATGCTCGAACCAATTG-3'

Gen1022R 5'-AGAGGAGAGTTAGAGCCTCAGCTTTTAACATTTC-3'

Syn1022F 5'-GGTATTGAGGGTCGCCATATGCTGGAACCG-3'

Syn1022R 5'-AGAGGAGAGTTAGAGCCGGATCCTTACG-3'

CterF 5'-GAAAACCATATGCTGGAACCGATTGCGTACG-3'

CterR 5'-GTGGTGCTCGAGCGATTTAACATTGCGAATATTC-3'.

Primers for amplification of mj1022 from genomic DNA (Gen1022) and the synthetic gene (Syn1022) were designed for subsequent LIC cloning in pET32Xa with an Nterminal thioredoxin-His ${ }_{6}$-fusion (Trx-His 6 -fusion). The primers for amplification of the synthetic gene with a C-terminal $\mathrm{His}_{6}$-fusion (Cter) contained the restriction sites (underlined) for $N d e \mathrm{I}$ and $\mathrm{XhoI}$ to allow directional cloning into a pET30 vector. The genes were amplified from genomic DNA (20 ng) or synthetic template (10 ng) with PfuUltra ${ }^{\mathrm{TM}}$ DNA polymerase using the following program: $95{ }^{\circ} \mathrm{C}$ (5 minutes), 30 cycles

of $95{ }^{\circ} \mathrm{C}$ (30s), $60{ }^{\circ} \mathrm{C}$ (genomic DNA), $55^{\circ} \mathrm{C}$ (synthetic gene, N-terminal fusion), or $57^{\circ} \mathrm{C}$ (synthetic gene, C-terminal fusion) (30s), and $72{ }^{\circ} \mathrm{C}$ ( 2 minutes), followed by a final extension at $72{ }^{\circ} \mathrm{C}$ for 10 minutes and hold at $4{ }^{\circ} \mathrm{C}$. Amplification of the genes for the 
construction of N-terminal fusions were followed by insertion of the PCR products into pET32Xa following the manufacturer's instructions to give pVCII-120 (native gene) and pVCIII-28 (synthetic gene). Amplification of the gene for construction of the C-terminal fusion was followed by restriction digestion of the PCR product with $N d e \mathrm{I} / \mathrm{XhoI}$, gel purification (1\% agarose), and ligation into $N d e \mathrm{I} / \mathrm{XhoI}$ digested pET30 using T4 DNA ligase to give pVCIV-42. Plasmid DNA was isolated from all three constructs and the primary structure of the genes confirmed by sequencing.

\section{Overexpression and purification of recombinant $M j \operatorname{TgtA} 2$}

The plasmids containing mjTgtA2 were transformed into E. coli BL21(DE3) for expression of the variously tagged recombinant proteins. Cultures of transformed cells were grown at $37{ }^{\circ} \mathrm{C}$ in either $\mathrm{LB} / \mathrm{kan}$ or $\mathrm{LB} / \mathrm{amp}$ with shaking $(250 \mathrm{rpm})$ until an $\mathrm{OD}_{600}$ of 0.9 was obtained, IPTG was added to a final concentration of $0.25 \mathrm{mM}$, and the cells were grown for an additional $4 \frac{1}{2}$ hours. The cells were collected by centrifugation at $7,500 \times \mathrm{g}$ for 15 minutes at $4{ }^{\circ} \mathrm{C}$ and frozen with liquid nitrogen. The cells were stored at $-80^{\circ} \mathrm{C}$ until needed.

Frozen cell paste was suspended to $250 \mathrm{mg} / \mathrm{mL}$ in $50 \mathrm{mM}$ HEPES (pH 7.0), $0.75 \mathrm{M}$ $\mathrm{NaCl}, 2 \mathrm{mM} \beta \mathrm{ME}$, and $1 \mathrm{mM}$ PMSF. Lysozyme was added to a final concentration of $250 \mu \mathrm{g} / \mathrm{mL}$ and the cells incubated at $37{ }^{\circ} \mathrm{C}$ for 30 minutes, followed by 3 intervals of freeze thaw cycles. DNase was added to a final concentration of $10 \mu \mathrm{g} / \mathrm{mL}$ and the cells 
were left at $37^{\circ} \mathrm{C}$ for an additional 30 minutes. The cell lysate was centrifuged at 26,000 x $g$ for 30 minutes at $4{ }^{\circ} \mathrm{C}$, and the cell-free extract recovered and filtered $(0.45 \mu \mathrm{m}$ $\mathrm{MCE})$. The $\mathrm{CFE}$ was heated at $60{ }^{\circ} \mathrm{C}$ for 15 minutes followed by centrifugation for 20 minutes at 20,000 $\mathrm{x}$; this cycle was repeated at $75^{\circ} \mathrm{C}$. The heat-treated CFE was loaded onto a column containing $\mathrm{Ni}^{2+}$-NTA agarose equilibrated in lysis buffer, and washed with 10 volumes of lysis buffer containing $25 \mathrm{mM}$ imidazole but without PMSF. The TrxHis $_{6}$ fusion protein was eluted with $250 \mathrm{mM}$ imidazole in lysis buffer without PMSF. The eluant was concentrated to $2 \mathrm{~mL}$ using the Amicon Ultra YM-10 and dialyzed overnight against $4 \mathrm{~L}$ of lysis buffer without imidazole or PMSF. To remove the Trx$\mathrm{His}_{6}$ affinity tag the fusion protein $(20 \mathrm{mg})$ was incubated with Factor $\mathrm{Xa}(20 \mu \mathrm{g})$ at room temperature in $100 \mathrm{mM}$ Tris- $\mathrm{HCl}(\mathrm{pH} 8.0), 0.5 \mathrm{M} \mathrm{NaCl}, 1 \mathrm{mM} \mathrm{CaCl}_{2}$, and $1 \mathrm{mM}$ DTT for $\sim 20$ hours. The cleaved recombinant protein was then recovered after passing over a $\mathrm{Ni}^{2+}$-NTA agarose column.

\section{Edman Degradation of $M j$ TgtA2}

To allow the $\mathrm{N}$ - and C-terminal recombinant fusion proteins to self-cleave the Trx-His $6^{-}$ $M j$ TgtA2 and MjTgtA2-His ${ }_{6}$ fusion constructs $(\sim 100 \mu \mathrm{g}$ each $)$ were incubated in $100 \mathrm{mM}$ HEPES (pH 7.0), 0.5 M NaCl, and $2 \mathrm{mM} \mathrm{BME}$ at $4{ }^{\circ} \mathrm{C}$ for up to 4 weeks. The proteins were then electrophoresed on a precast $10 \%$ acrylamide/Tris- $\mathrm{HCl}$ gel. Electroblotting onto an Invitrolon membrane was carried out for 1 hour at $22 \mathrm{~V}$ according to the manufacturer's instructions using NuPAGE transfer buffer. The membrane was then 
stained with Coomassie blue followed by washing with $50 \%$ methanol, air-drying, and specific bands analyzed by Edman sequencing.

\section{Size exclusion chromatography}

Size exclusion chromatography was used to determine the native molecular weight of MjTgtA2 using a BioSep-Sec-4000 column (Phenomenex) with a mobile phase of $50 \mathrm{mM}$ phosphate (pH 7.2), $100 \mathrm{mM} \mathrm{KCl}$ and a flow rate of $1 \mathrm{~mL} / \mathrm{min}$. The void volume $\left(\mathrm{V}_{0}\right)$ and total bead volume $\left(\mathrm{V}_{\mathrm{T}}\right)$ were measured with blue dextran $(2000 \mathrm{KDa})$ and potassium ferricyanide $\left(\mathrm{K}_{3}\left[\mathrm{Fe}(\mathrm{CN})_{6}\right] 329 \mathrm{Da}\right)$. The column was calibrated with MWGF1000 standards. The partition coefficient $\left(\mathrm{K}_{\mathrm{D}}\right)$ values were calculated according to the equation $\left(\mathrm{Ve}-\mathrm{V}_{0}\right) /\left(\mathrm{V}_{\mathrm{T}}-\mathrm{V}_{0}\right)$ where $\mathrm{Ve}$ is the elution volume of the protein of interest, then plotted vs. log MW to generate a standard curve.

\section{Cloning and overexpression of $M J T G T$}

The mj0436 gene corresponding to mjtgt was amplified from genomic M. jannaschii via PCR with PfuUltra ${ }^{\mathrm{TM}}$ DNA polymerase using the following primers:

pET30-MJTGT-sense 5'-GGTATTGAGGGTCGCATGACTTTTGAGAT-3' pET30-MJTGT-antisense 5'-AGAGGAGAGTTAGAGCCTCACTTATTTAT-3'. The primers were designed for subsequent LIC cloning into pET30Xa. The genes were amplified from $10 \mathrm{ng}$ genomic DNA using the following program: $95{ }^{\circ} \mathrm{C}$ (5 minutes), 30 cycles of $95{ }^{\circ} \mathrm{C}(30 \mathrm{~s}), 45^{\circ} \mathrm{C}(30 \mathrm{~s})$, and $72{ }^{\circ} \mathrm{C}$ (2 minutes), followed by an extension at 72 
${ }^{\circ} \mathrm{C}$ for 10 minutes and hold at $4{ }^{\circ} \mathrm{C}$. Amplification of the gene was followed by insertion of the PCR product into pET30Xa following the manufacturer's instructions to give pVCV-39. Plasmid DNA was isolated and the primary structure of the genes confirmed by sequencing.

Recombinant His $_{6}-M J T G T$ protein was expressed in pVCV-39/E. coli BL21(DE3) cells at $37^{\circ} \mathrm{C}$ in $\mathrm{LB} / \mathrm{kan}$ medium. $\mathrm{LB} / \mathrm{kan}$ medium $(3 \mathrm{~mL})$ was inoculated from a single colony of the cells, after 12 hours of incubation at $37^{\circ} \mathrm{C}$; a $1 \mathrm{~mL}$ aliquot was used to inoculate $100 \mathrm{~mL}$ of LB/kan medium. The cultures were incubated at $37^{\circ} \mathrm{C}$ and $250 \mathrm{rpm}$ for 12 hours and a $5 \mathrm{~mL}$ aliquot was taken and used to inoculate $500 \mathrm{~mL}$ of $\mathrm{LB} / \mathrm{kan}$ medium. After about 3 hours an $\mathrm{OD}_{600}$ of 0.9 was reached and protein over-expression was induced by the addition of IPTG to a final concentration of $0.25 \mathrm{mM}$. The cell cultures were grown for an additional 4-5 hours when the cells were collected by centrifugation at $7,500 \mathrm{x} g$ for 15 minutes and frozen with liquid nitrogen. The cells were stored at $-80{ }^{\circ} \mathrm{C}$ until further use.

The cells were resuspended to a density of $250 \mathrm{mg} / \mathrm{mL}$ in $50 \mathrm{mM}$ Tris- $\mathrm{HCl}(\mathrm{pH} 8.0), 300$ $\mathrm{mM} \mathrm{KCl,} 2 \mathrm{mM} \beta \mathrm{ME}$, and $1 \mathrm{mM}$ PMSF. Lysozyme was added to a final concentration of $250 \mu \mathrm{g} / \mathrm{mL}$ and the cells incubated at $37^{\circ} \mathrm{C}$ for 30 minutes, followed by 3 intervals of freeze-thaw cycles. DNase was added to a final concentration of $10 \mu \mathrm{g} / \mathrm{mL}$ and the cells were left at $37^{\circ} \mathrm{C}$ for an additional 30 minutes. The cell lysate was centrifuged at 26,000 $\mathrm{x} g$ for 30 minutes. The CFE was filtered using a low protein-binding $0.45 \mu \mathrm{m}$ MCE 
syringe filter, then loaded onto $10 \mathrm{~mL}$ of $\mathrm{Ni}^{2+}$-NTA agarose resin equilibrated in $100 \mathrm{mM}$ Tris- $\mathrm{HCl}$ (pH 8.0), $300 \mathrm{mM} \mathrm{KCl,} 2 \mathrm{mM} \beta \mathrm{ME}$, and $1 \mathrm{mM}$ PMSF (buffer A). The column was washed with 5 column volumes of buffer A followed by 5 column volumes of buffer A with $20 \mathrm{mM}$ imidazole and no PMSF. The recombinant protein was eluted with 7 column volumes of buffer B containing $200 \mathrm{mM}$ imidazole then concentrated to about 2 $\mathrm{mL}$ using the Amicon Ultra YM-10 and dialyzed overnight against $4 \mathrm{~L}$ of $50 \mathrm{mM}$ Tris$\mathrm{HCl}(\mathrm{pH} 8.0), 100 \mathrm{mM} \mathrm{KCl}$, and $1 \mathrm{mM}$ DTT at $4{ }^{\circ} \mathrm{C}$. The His ${ }_{6}-M J T G T$ was cleaved by Factor Xa and purified as previously described. The cleaved protein was stored in 50\% glycerol in $100 \mu \mathrm{L}$ aliquots at $-80{ }^{\circ} \mathrm{C}$.

\section{In Vitro transcription of $H$. volcanii tRNA ${ }^{\text {Ser }}$}

An RNA 76-mer corresponding to the sequence of the $H$. volcanii tRNA ${ }^{\text {Ser }}$ was transcribed in vitro from a template prepared from the pDF-II-42 plasmid after digestion with $M v a \mathrm{I}$. The $H$. volcanii $\mathrm{tRNA}^{\mathrm{Ser}}$ was synthesized in a reaction containing $80 \mathrm{mM}$ HEPES-KOH (pH 7.5), 12 mM MgCl 2,2 mM spermidine, $50 \mu \mathrm{g} / \mathrm{mL}$ BSA, $40 \mathrm{mM}$ DTT, $0.01 \%$ Triton-X-100, $3 \mathrm{mM}$ NTPs, $20 \mu \mathrm{g} / \mathrm{mL}$ template and $64 \mu \mathrm{g} / \mathrm{mL}$ recombinant $\mathrm{T} 7$ polymerase. The reaction was incubated at $37^{\circ} \mathrm{C}$ for 6 hours at which point the reaction was stopped by heating at $95{ }^{\circ} \mathrm{C}$ for 3 minutes, followed by centrifugation at 20,000 $\mathrm{x} g$ for 10 minutes followed by precipitation with an equal volume of isopropanol. 


\section{Purification of the tRNA ${ }^{\text {Ser }}$}

The crude RNA was treated with RNase free DNase (40 Units/ml of the in vitro transcription) in $40 \mathrm{mM}$ Tris- $\mathrm{HCl}(\mathrm{pH} 8.0), 10 \mathrm{mM} \mathrm{NaCl}, 6 \mathrm{mM} \mathrm{MgCl}_{2}$ and $10 \mathrm{mM}$ $\mathrm{CaCl}_{2}$, at $37{ }^{\circ} \mathrm{C}$ for 30 minutes. The RNA oligomer was purified by continuous elution PAGE using the BioRad 491 Prep Cell and a $7 \mathrm{M}$ urea, 10\% acrylamide gel in the following manner: approximately $10 \mathrm{mg}$ of RNA in $50 \%$ formamide (v/v), $10 \mathrm{mM}$ EDTA, 0.1\% (w/v) xylene cyanol FF, and $0.1 \%(\mathrm{w} / \mathrm{v})$ bromophenol blue were loaded onto the gel and the sample was electrophoresed at $300 \mathrm{~V}$ until the bromophenol blue was eluting at which point fraction collection began. Fractions $(5 \mathrm{~mL})$ were collected at a flow rate of $1 \mathrm{~mL} / \mathrm{min}$ and the elution of the RNA was monitored on Urea/PAGE gels. The fractions containing 76-mer were pooled and concentrated by lyophilizing to dryness. The tRNA was resuspended in $3 \mathrm{mM}$ sodium citrate ( $\mathrm{pH}$ 6.3) and washed with a 10-fold volume of $3 \mathrm{mM}$ sodium citrate ( $\mathrm{pH}$ 6.3) using the Amicon Ultra YM-10 in order to remove residual TBE.

\section{Preparation of preQ $_{0}$-tRNA ${ }^{\text {Ser }}$}

$\mathrm{PreQ}_{0}$ was inserted into the $\mathrm{RNA}^{\mathrm{Ser}}$ transcript by the native MJTGT. An aliquot of MJTGT $(10 \mu \mathrm{M})$ was added to a $1 \mathrm{~mL}$ solution containing $50 \mathrm{mM}$ succinate $(\mathrm{pH} 5.5), 20$ $\mathrm{mM} \mathrm{MgCl}_{2}, 100 \mathrm{mM} \mathrm{KCl}, 2 \mathrm{mM}$ DTT, $100 \mu \mathrm{M}$ tRNA ${ }^{\text {Ser }}$, and $1 \mathrm{mM}$ preQ ${ }_{0}$. After 45

minutes at $80^{\circ} \mathrm{C}$, the reaction was terminated by the addition of one-tenth volume of $2 \mathrm{M}$ $\mathrm{NaOAc}(\mathrm{pH} 4.0)$ followed by one volume of water-saturated phenol and one fifth volume 
chloroform:isoamyl alcohol (49:1). After vortexing for 20s, the solution was centrifuged in a swinging bucket rotor at $700 \times g$ for 20 minutes. The aqueous phase was recovered and applied directly to a Quick-Sep column containing $2 \mathrm{~mL}$ of Sephadex G-25. The sample was centrifuged at $700 \mathrm{x} g$ in a swinging bucket rotor for $1 \frac{1}{2}$ minutes to separate the unreacted $\mathrm{preQ}_{0}$ and exchanged guanine from the $\mathrm{preQ}_{0}-\mathrm{tRNA}{ }^{\mathrm{Ser}}$. The $\mathrm{preQ}_{0}-\mathrm{tRNA}{ }^{\text {Ser }}$ was precipitated from the eluate by the addition of 3 volumes of ethanol and cooling at $20{ }^{\circ} \mathrm{C}$ for 2 hours. The solution was centrifuged at $20,000 \times g$ for 20 minutes at $4{ }^{\circ} \mathrm{C}$, the supernatant removed, and the RNA pellet washed with $70 \%$ cold ethanol. After centrifugation again at $20,000 \mathrm{x}$ g the supernatant solution was removed and the $\mathrm{preQ}_{0^{-}}$ tRNA ${ }^{\text {Ser }}$ was resuspended in $3 \mathrm{mM}$ sodium citrate $\left(\mathrm{pH}\right.$ 6.3) and stored at $-20{ }^{\circ} \mathrm{C}$.

\section{pH and temperature dependence of $M j$ TgtA2 activity}

The $\mathrm{pH}$ dependence of $M j \mathrm{TgtA} 2$ was investigated using the tri-buffer system composed of $100 \mathrm{mM}$ Tris/Mes/Acetate ( $\mathrm{pH} 4.0$ - 9.0), $0.5 \mathrm{M} \mathrm{NaCl}, 20 \mathrm{mM} \mathrm{MgCl}, 1 \mathrm{mM}$ DTT, 10

$\mu \mathrm{M}\left[\mathrm{U}_{-}{ }^{14} \mathrm{C}\right]-\mathrm{L}-$ glutamine, $20 \mu \mathrm{M}$ preQ $\mathrm{Q}_{0} \mathrm{-tRNA}{ }^{\mathrm{Ser}}$, and $M j \mathrm{TgtA} 2(7.8 \mu \mathrm{g})$. The activity of MjTgtA2 was also determined in several discrete buffers, including HEPES, phosphate, citrate, and acetate. Assays were carried out at $40{ }^{\circ} \mathrm{C}$, initiated with the addition of MjTgtA2, and terminated after 10 minutes with the addition of 0.2 volume concentrated $\mathrm{NH}_{4} \mathrm{OH}$. 
Quantification of [U- $\left.{ }^{14} \mathrm{C}\right]-\mathrm{L}$-glutamate formation was carried out as described above. The temperature dependence of the reaction was determined in the presence of $100 \mathrm{mM}$ HEPES (pH 7.0), $0.5 \mathrm{M} \mathrm{NaCl}, 20 \mathrm{mM} \mathrm{MgCl} 2,1 \mathrm{mM}$ DTT, $10 \mu \mathrm{M}\left[\mathrm{U}-{ }^{14} \mathrm{C}\right]-\mathrm{L}-$ Glutamine, $20 \mu \mathrm{M}$ preQ $_{0}-\mathrm{tRNA}^{\mathrm{Ser}}$, and $M j \operatorname{TgtA} 2(7.8 \mu \mathrm{g})$. Assays were carried out as described above with temperatures from $30{ }^{\circ} \mathrm{C}$ to $80{ }^{\circ} \mathrm{C}$.

\section{Glutaminase assays}

Glutaminase activity was detected indirectly as a coupled assay to glutamate dehydrogenase under continuous conditions. For coupled assays varying concentrations of $M j$ TgtA2 were incubated in the presence or absence of $\operatorname{preQ}_{0}-\mathrm{tRNA}^{\mathrm{Ser}}(10 \mu \mathrm{M})$ in an assay solution containing $50 \mathrm{mM}$ phosphate (pH 7.5), $0.5 \mathrm{M} \mathrm{NaCl}, 15 \mathrm{mM} \mathrm{MgCl} 2,1 \mathrm{mM}$ DTT, $2.5 \mathrm{mM} \mathrm{Gln}, 1 \mathrm{mM} \mathrm{NADP}{ }^{+}$and $4 \mathrm{U}$ of glutamate dehydrogenase. Assays were run at $37{ }^{\circ} \mathrm{C}$ with $\mathrm{NADPH}$ production monitored at $340 \mathrm{~nm}$.

Direct assays of glutaminase activity were carried out for 10 minutes in $100 \mathrm{mM}$ HEPES (pH 7.0), $20 \mathrm{mM} \mathrm{MgCl}, 0.5 \mathrm{M} \mathrm{NaCl}, 2 \mathrm{mM}$ DTT, $12.4 \mu \mathrm{M}\left[\mathrm{U}^{14}{ }^{14} \mathrm{C}\right]-\mathrm{L}-\mathrm{Gln}, 50 \mu \mathrm{M}$ tRNA $^{\text {Ser }}$ with varying concentrations of MjTgtA2. The reactions were terminated by addition of 0.2 volume concentrated $\mathrm{NH}_{4} \mathrm{OH}$. A $6 \mu \mathrm{L}$ portion of the assay was spotted onto silica TLC plates and the plates developed in i-PrOH: $\mathrm{NH}_{4} \mathrm{OH}$ (conc) $(7: 3)$. The plates were then analyzed on the Typhoon 9200 . 


\section{Amidotransferase assays}

Assays of amidotransferase activity were carried out in $100 \mathrm{mM}$ HEPES (pH 7.0), $0.5 \mathrm{M}$ $\mathrm{NaCl}, 20 \mathrm{mM} \mathrm{MgCl} 2,1 \mathrm{mM}$ DTT, $10 \mu \mathrm{M} M j \mathrm{TgtA} 2,50 \mu \mathrm{M}$ preQ$_{0}-\mathrm{tRNA}^{\text {Ser }}$ in the presence of the 3 possible donors, $\mathrm{NH}_{4} \mathrm{Cl}(100 \mathrm{mM})$, Gln $(5 \mathrm{mM})$ or Asn $(5 \mathrm{mM})$. The reaction was carried out at $40{ }^{\circ} \mathrm{C}$ and stopped by the addition of 0.1 volume of $2 \mathrm{M}$ $\mathrm{NH}_{4} \mathrm{OAc}(\mathrm{pH} 4.0)$ followed by one volume of water-saturated phenol and 0.2 volume chloroform:isoamyl alcohol (49:1). After vortexing for 20s, the solution was centrifuged in a swinging bucket rotor at $700 \mathrm{x} g$ for 20 minutes. The aqueous phase was recovered and the product $\mathrm{G}^{+}-\mathrm{RNA}^{\mathrm{Ser}}$ was precipitated with 3 volumes of ethanol and placed at -20 ${ }^{\circ} \mathrm{C}$ for 2 hours. The solution was centrifuged at $20,000 \times g$ for 20 minutes at $4{ }^{\circ} \mathrm{C}$, the supernatant removed, and the RNA pellet washed with $70 \%$ cold ethanol. The solution was centrifuged again at $20,000 \times g$ for 20 minutes at $4{ }^{\circ} \mathrm{C}$, the supernatant removed, and the RNA was resuspended to $3 \mu \mathrm{g} / \mu \mathrm{L}$ in $\mathrm{H}_{2} \mathrm{O}$ and digested as previously described (63). Nucleosides were analyzed by HPLC using a Discovery HS C18 column (2.1 mm x 250 $\mathrm{mM}$, Supelco), with a mobile phase comprised of a linear gradient from $100 \% 5 \mathrm{mM}$ $\mathrm{NH}_{4} \mathrm{OAc}\left(\mathrm{pH} 5.3\right.$ ) to $85 \% 5 \mathrm{mM} \mathrm{NH}_{4} \mathrm{OAc} / 15 \%$ acetonitrile developed over 30 minutes at $0.3 \mathrm{~mL} / \mathrm{min}$.

LCMS analysis of nucleosides was performed on a MicroTOF-Q tandem mass spectrometry instrument (Bruker, Billerica, MA) utilizing electrospray ionization (ESI). The ESI interface was operated in the positive mode using the following settings: end plate offset $-500 \mathrm{~V}$, capillary voltage $-4500 \mathrm{~V}$, nebulizer gas $1.6 \mathrm{bar}$, dry gas $4 \mathrm{~L} / \mathrm{min}$, 
dry temperature $200^{\circ} \mathrm{C}$, funnel $1 \mathrm{RF} 350 \mathrm{Vpp}$, funnel $2 \mathrm{RF} 350 \mathrm{Vpp}$, hexapole $\mathrm{RF}$ $400 \mathrm{Vpp}$, collision energy $10 \mathrm{eV}$ and collision RF $300 \mathrm{Vpp}$. 


\subsection{NADPH 7-cyano-7-deazaguanine oxidoreductase}

\section{Expression and purification of wild type His Hen $_{6}$ QueF, His 6 -C55A and His $\mathrm{H}_{6}-\mathrm{E} 78 \mathrm{~A}$ mutants}

Recombinant QueF (ykvM) was expressed in E. coli BL 21(DE3) cells with the plasmid pET30-ykvM in LB/kan medium. The frozen cell stock was used to inoculate $3 \mathrm{~mL}$ of LB/kan medium. After 12 hours of incubation at $37^{\circ} \mathrm{C}$, a $1 \mathrm{~mL}$ aliquot was removed and used to inoculate $100 \mathrm{~mL}$ of $\mathrm{LB} / \mathrm{kan}$ medium in a $500 \mathrm{~mL}$ flask. The cultures were incubated at $37{ }^{\circ} \mathrm{C}$ and $250 \mathrm{rpm}$ for 12 hours and $5 \mathrm{~mL}$ aliquots were removed and used to inoculate $500 \mathrm{~mL}$ of $\mathrm{LB} / \mathrm{kan}$ medium in $2.5 \mathrm{~L}$ flasks. When an $\mathrm{OD}_{600}$ of 0.9 was reached, protein over-expression was induced by the addition of IPTG to a final concentration of $0.5 \mathrm{mM}$. The cell cultures were grown for an additional 4 hours at which time the cells were collected by centrifugation at 7,500 $\mathrm{x} g$ for 10 minutes at $4{ }^{\circ} \mathrm{C}$ and frozen with liquid nitrogen. Typically $20 \mathrm{~g}$ of cells were obtained from $4 \mathrm{~L}$ of media. The cells were stored at $-80{ }^{\circ} \mathrm{C}$ until further use. The expression of the mutants was carried out as described for the wild-type protein.

The cells were resuspended to a density of $250 \mathrm{mg} / \mathrm{mL}$ in $100 \mathrm{mM}$ Tris- $\mathrm{HCl}(\mathrm{pH} 8.0)$, $100 \mathrm{mM} \mathrm{KCl}, 1 \mathrm{mM} \beta \mathrm{ME}$, and $1 \mathrm{mM}$ PMSF. Lysozyme was added to a final concentration of $250 \mu \mathrm{g} / \mathrm{mL}$ and the cells incubated at $37{ }^{\circ} \mathrm{C}$ for 30 minutes, followed by 3 intervals of freeze thaw cycles. DNase was added to a final concentration of $10 \mu \mathrm{g} / \mathrm{mL}$ and the cells were left at $37^{\circ} \mathrm{C}$ for an additional 30 minutes. The cell lysate was 
centrifuged at 26,000 x $g$ for 30 minutes. The CFE was filtered using a low proteinbinding $0.45 \mu \mathrm{m}$ MCE syringe filter, then loaded onto $10 \mathrm{~mL}$ of $\mathrm{Ni}^{2+}$-NTA agarose resin equilibrated in $100 \mathrm{mM}$ Tris- $\mathrm{HCl}(\mathrm{pH} 8.0), 100 \mathrm{mM} \mathrm{KCl}, 1 \mathrm{mM} \beta \mathrm{ME}$, and $1 \mathrm{mM}$ PMSF (buffer A). For all the mutants only $2 \mathrm{~mL}$ of the $\mathrm{Ni}^{2+}$-NTA agarose was used. The columns were washed with: 5 column volumes buffer A followed by 5 column volumes buffer A with $20 \mathrm{mM}$ imidazole (buffer B) and finally with 5 column volumes of buffer A with no PMSF but with $50 \mathrm{mM}$ imidazole (buffer C). The recombinant fusion proteins were eluted with 5 column volumes of buffer C containing $200 \mathrm{mM}$ imidazole (Buffer D) to about $2 \mathrm{~mL}$ using the Amicon Ultra YM-10 and dialyzed overnight against $4 \mathrm{~L}$ of 100 $\mathrm{mM}$ Tris- $\mathrm{HCl}(\mathrm{pH} 8.0), 100 \mathrm{mM} \mathrm{KCl}$, and $1 \mathrm{mM}$ DTT at $4{ }^{\circ} \mathrm{C}$ (Buffer E). Following dialysis the recombinant fusion proteins were treated with Factor Xa.

\section{Purification of QueF proteins}

Factor Xa $(10 \mu \mathrm{g})$ was added to $20 \mathrm{mg}$ of purified QueF protein and the digestion was carried out in the presence of $100 \mathrm{mM}$ Tris- $\mathrm{HCl}(\mathrm{pH} 8.0), 100 \mathrm{mM} \mathrm{KCl}, 1 \mathrm{mM} \mathrm{CaCl}$, and $1 \mathrm{mM} \beta \mathrm{ME}$. The digestion was carried out for 20 hours at room temperature after which the digestion reaction was loaded onto a $\mathrm{Ni}^{2+}$-NTA agarose column that had been equilibrated in $100 \mathrm{mM}$ Tris- $\mathrm{HCl}(\mathrm{pH} \mathrm{8.0),} 100 \mathrm{mM} \mathrm{KCl}$, and $1 \mathrm{mM} \beta \mathrm{ME}$ (Buffer F). The cleaved wild type protein was eluted with 5 column volumes of buffer F. The protein was concentrated as previously described and stored in aliquots of $100 \mu \mathrm{L}$ at -80 ${ }^{\circ} \mathrm{C}$ in the presence of $50 \%$ glycerol. The same procedure was repeated for the mutants. 


\section{Preparation of glassware for metal analysis and apoprotein preparation}

Glassware and plasticware to be used in the analysis was soaked in $10 \%$ nitric acid for 48 hours. This was followed by repeated soaking in $5 \mathrm{mM}$ EDTA for 2 hours in the presence of chelex resin ( $3 x$ total). Chelex-treated water was used for the preparation of all the buffers and salts for the apoprotein preparation as well as the subsequent analysis. Native QueF was dialyzed against $4 \mathrm{~L}$ of $100 \mathrm{mM}$ Tris- $\mathrm{HCl}(\mathrm{pH} 8.0), 0.5 \mathrm{M} \mathrm{KCl}, 1 \mathrm{mM}$ $\beta M E, 10 \mathrm{mM}$ EDTA, and $2 \mathrm{~g}$ of chelex for 24 hours. This was followed by a second dialysis in the presence of $2 \mathrm{~L} 100 \mathrm{mM}$ Tris- $\mathrm{HCl}(\mathrm{pH} 8.0), 200 \mathrm{mM} \mathrm{KCl}, 1 \mathrm{mM} \beta \mathrm{ME}$, and $1 \mathrm{~g}$ chelex for 24 hours. The final dialysis was carried out in $2 \mathrm{~L}$ of $100 \mathrm{mM}$ Tris$\mathrm{HCl}(\mathrm{pH} 8.0), 100 \mathrm{mM} \mathrm{KCl}$, and $1 \mathrm{mM} \beta \mathrm{ME}$ for 2 hours.

\section{Determination of the effect of metals on QueF activity}

The activity of the native QueF was determined in the presence of $\mathrm{Mn}^{2+}, \mathrm{Cu}^{2+}, \mathrm{Ca}^{2+}, \mathrm{Zn}^{2+}$ and $\mathrm{Mg}^{2+}$, and in the presence of EDTA. The concentration of the metals was varied from 0 to $10 \mathrm{mM}$. The reaction conditions were $100 \mathrm{mM}$ Tris- $\mathrm{HCl}(\mathrm{pH} 7.5), 100 \mathrm{mM} \mathrm{KCl,} 1$ mM DTT, $80 \mu \mathrm{M}$ NADPH, $150 \mu \mathrm{M}$ preQ $_{0}, 1 \mu \mathrm{M}$ QueF, and the divalent metal (varied). The reactions were carried out at $30{ }^{\circ} \mathrm{C}$ and monitored by following the depletion of $\mathrm{NADPH}$ at $340 \mathrm{~nm}$.

The effect of $\mathrm{KCl}$ concentration on QueF activity was determined on both the native and "apparent apoprotein". Three concentrations of $\mathrm{KCl}$ were tested, $10 \mathrm{mM}, 50 \mathrm{mM}$ and 
$100 \mathrm{mM}$. The reaction conditions were $100 \mathrm{mM}$ Tris- $\mathrm{HCl} \mathrm{pH}(7.5), 1 \mathrm{mM}$ DTT, $80 \mu \mathrm{M}$ NADPH, $150 \mu \mathrm{M}_{\text {preQ }}, 250 \mu \mathrm{M} \mathrm{MnCl}_{2}, 1 \mu \mathrm{M}$ QueF, and $\mathrm{KCl}$ (varied).

\section{pH profile determination}

The effect of $\mathrm{pH}$ on the activity of QueF was examined using the following buffers; MES (pH 5.75 - 6.67), Tris- $\mathrm{HCl}(\mathrm{pH} 7.0-8.0)$, and potassium phosphate $(5.8-8.0)$. The following reaction conditions were used: $100 \mathrm{mM}$ Buffer, $50 \mathrm{mM} \mathrm{KCl,} 1 \mathrm{mM}$ DTT, 80 $\mu \mathrm{M} \beta$-NADPH, $100 \mu \mathrm{M}$ preQ $0,2 \mu \mathrm{M}$ QueF, and $250 \mu \mathrm{M} \mathrm{MnCl}_{2}$. The reactions were carried out at $30{ }^{\circ} \mathrm{C}$ and initiated by QueF addition in a final volume of $200 \mu \mathrm{L}$. The reaction was monitored by following the depletion of NADPH at $340 \mathrm{~nm}$.

\section{Size exclusion chromatography}

Size exclusion chromatography was used to determine the effect of ligands and salts on the quaternary structure of QueF using a BioSep-Sec-4000 column (Phenomenex) with a mobile phase of $25 \mathrm{mM}$ phosphate $(\mathrm{pH} 7.2), 25 \mathrm{mM} \mathrm{KCl}$, and a flow rate of $1 \mathrm{~mL} / \mathrm{min}$. The change in the retention time of QueF was analyzed in the presence of $\mathrm{MnCl}_{2}$ or $\mathrm{MgCl}_{2}$, varying concentrations at $\mathrm{KCl}$ and in the presence of preQ . The QueF was incubated with preQ $_{0}$ at least 10 minutes before analysis. However, for analyzing the effect of $\mathrm{KCl}$ on quaternary structure the protein was incubated for 3 hours in the presence of $0.5 \mathrm{M} \mathrm{KCl}$ and $10 \mathrm{mM}$ EDTA, and the $\mathrm{KCl}$ effect was determined using a mobile phase of $25 \mathrm{mM}$ phosphate ( $\mathrm{pH} 7.2), 0.5 \mathrm{M} \mathrm{KCl}$. 


\section{Development of fluorescence assays for use in stopped flow kinetics}

Fluorescence of the single tryptophan residue of QueF was determined by excitation at $295 \mathrm{~nm}$ and emission between $305-450 \mathrm{~nm}$. The fluorescence was determined in the presence of $50 \mathrm{mM}$ phosphate (pH 6.5), $50 \mathrm{mM} \mathrm{KCl,} 1 \mathrm{mM}$ DTT, $250 \mu \mathrm{M} \mathrm{MnCl}_{2}, 80 \mu \mathrm{M}$ QueF, and $100 \mu \mathrm{M}$ preQ $_{0}$ and without preQ $_{0}$. Fluorescence of NADPH was determined in the presence of QueF and preQ $_{0}$ by excitation at $340 \mathrm{~nm}$ and the emission from $360 \mathrm{~nm}$ to $700 \mathrm{~nm}$.

\section{Transient kinetics}

Rapid kinetic studies were performed using a double-mixing Hi-Tech Scientific (Salisbury, Wiltshire, UK) model SF-61 DX2 stopped-flow spectrophotometer/ fluorimeter controlled by KinetAsyst (version 3.16; Hi-Tech Scientific). Fluorescence and absorbance measurements were determined in single mixing mode (observation cell optical path-length of $1 \mathrm{~cm}$ ), equipped with a $75 \mathrm{~W}$ short arc mercury lamp. Some of the absorbance based kinetics experiments were also performed on a Hi-Tech Scientific SF61 AF single mixing stopped flow spectrophotometer. The reactions were carried out with a final volume of $120 \mu \mathrm{L}$ from solutions driven from high performance syringes through a high efficiency mixer. The resultant mixture passed through the measurement flow cell and into a stopping syringe. Steady flow of the mixture was achieved just before stopping. A schematic of a stopped flow instrument is shown in Figure 15. Temperature was controlled using a circulating waterbath. Apparent rate constants $\left(k_{\mathrm{obs}}\right)$ 
from kinetic traces were calculated using the KaleidaGraph software and rate constants were determined by use of Dynafit through global analysis of the data.

\section{Thioimide formation}

The kinetics of formation of the thioimide between QueF and $\mathrm{preQ}_{0}$ were measured using stopped-flow spectrophotometry. One syringe was filled with solution A (124 $\mu \mathrm{M}$ QueF, $50 \mathrm{mM}$ potassium phosphate ( $\mathrm{pH} 6.5), 50 \mathrm{mM} \mathrm{KCl}, 250 \mu \mathrm{M} \mathrm{MnCl}_{2}$, and $1 \mathrm{mM}$ DTT), whereas the second syringe was filled with solution B (i.e. solution A without QueF). Equal volumes $(60 \mu \mathrm{L}$ each) of solution A were mixed with solution B. Five or more shots were performed to flush the stopped-flow lines and to obtain a baseline. After the flushing was complete, the solution B in the second syringe was replaced with solution B containing preQ $_{0}$ (solution $\mathrm{C}$ ), and several shots were performed with varying concentrations of $\mathrm{preQ}_{0}$. The final concentrations of $\mathrm{preQ}_{0}$ in the reactions were 11.8, 17.0, 21.5, 26.3, 37.7, 51.0 $\mu \mathrm{M}$, and QueF final concentration was $62 \mu \mathrm{M}$. The reactions were carried out at $30{ }^{\circ} \mathrm{C}$ and monitored at $370 \mathrm{~nm}$ for 5 seconds. The data was fit to single and double exponential rise equations using KaleidaGraph;

$$
\begin{gathered}
\mathrm{y}=A\left(1-\exp \left(-k_{\text {obs }} t\right)\right)+a \\
y=A_{1}\left(1-\exp \left(-k_{\text {obs } 1} t\right)\right)+A_{2}\left(1-\exp \left(-k_{\text {obs } 2} t\right)\right)+a
\end{gathered}
$$


where $y$ is the absorbance signal, $A, A_{1}, A_{2}$, are the amplitudes, $a$ is the offset, and $k_{o b s}$, $k_{o b s l}$ and $k_{o b s 2}$ are apparent rate constants. Global data analysis was also carried out using DynaFit (Equations). The rates of the spectral changes at $370 \mathrm{~nm}$ were obtained from the best fits with the smallest residuals.

\section{Transient kinetics of substrate binding}

$\mathrm{PreQ}_{0}$ binding to wild-type and C55A QueF was measured using stopped-flow fluorescence spectroscopy by monitoring the intrinsic tryptophan fluorescence under pseudo first order conditions, where the QueF concentration was maintained high and preQ $_{0}$ concentration was varied. The excitation wavelength was $295 \mathrm{~nm}$, and emission was observed at $334 \mathrm{~nm}$ (a $334 \pm 5 \mathrm{~nm}$ band pass emission filter was used, Edmund Optics Inc, USA). For each experimental condition 12 shots were carried out and averaged. The fluorescence of the QueF solution without $\mathrm{preQ}_{0}$ was measured before the commencement of the experiment and was set as the $100 \%$ fluorescent signal. The reactions were carried out at $20{ }^{\circ} \mathrm{C}$ in the presence of $50 \mathrm{mM}$ potassium phosphate buffer (pH 6.5), $50 \mathrm{mM} \mathrm{KCl}, 250 \mu \mathrm{M} \mathrm{MnCl}_{2}$, and $1 \mathrm{mM}$ DTT. For the analysis of preQ binding to wild type QueF the final concentrations in reactions were $200 \mu \mathrm{M}$ QueF and

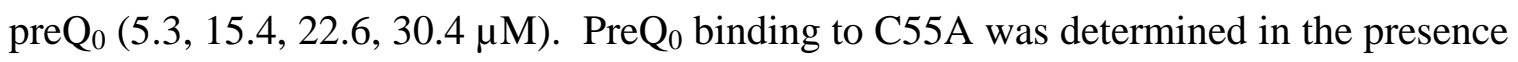
of $200 \mu \mathrm{M}$ QueF, and preQ $(6.8,11.8,18.2,23.3,29.2,38.8,50.0 \mu \mathrm{M})$. The QueF concentration was kept high and the $\mathrm{preQ}_{0}$ concentration was varied. At least 512 points 
were collected in each trace. The data was fit to single and double exponential decay equations using KaleidaGraph;

$$
\begin{gathered}
\mathrm{y}=A \exp \left(-k_{o b s} t\right)+a \\
y=A_{1} \exp \left(-k_{o b s} t\right)+A_{2} \exp \left(-k_{o b s 2} t\right)+a
\end{gathered}
$$

where $y$ is the absorbance signal, $A, A_{1}, A_{2}$, are the amplitudes, $a$ is the offset, and $k_{o b s}$, $k_{o b s 1}$ and $k_{o b s 2}$ are apparent rate constants. Global analysis was again carried out using Dynafit.

NADPH binding kinetics were also determined for the QueF mutant, E78A, which is capable of forming the thioimide bond but unable to facilitate its reduction. The binding was directly monitored by following the intrinsic NADPH fluorescence with excitation at $340 \mathrm{~nm}$ and emission was monitored by using a $455 \mathrm{~nm}$ long pass filter. The reaction was carried out at $20{ }^{\circ} \mathrm{C}, 50 \mathrm{mM}$ potassium phosphate buffer (pH 6.5), $50 \mathrm{mM} \mathrm{KCl}, 250$ $\mu \mathrm{M} \mathrm{MnCl}_{2}$, and $1 \mathrm{mM}$ DTT. The E78A QueF mutant $(200 \mu \mathrm{M})$ was preincubated with $700 \mu \mathrm{M}$ preQ $_{0}$ for at least 10 minutes before mixing with varying concentrations of NADPH. The final concentrations of NADPH in the assays were; 16.0, 23.5, 31.8, 39.4, 50.3, 57.4, 69.3 $\mu \mathrm{M}$, and the E78A QueF-*PreQ ${ }_{0}$ was $100 \mu \mathrm{M}$.

\section{Transient kinetics of thioimide reduction}

Reduction of the thioimide bond was monitored under single turnover conditions by using both the intrinsic NADPH fluorescence with excitation at $340 \mathrm{~nm}$ and the emission 
was monitored by using a $455 \mathrm{~nm}$ long pass filter as well as by monitoring the loss of the thioimide absorption at $390 \mathrm{~nm}$. The change in signal was monitored upon rapid mixing of equal volumes of premixed QueF-*PreQ $\mathrm{Q}_{0}$ solution from one syringe and varying concentrations of NADPH from the second syringe. For the fluorescence analysis the reaction was carried out at $20{ }^{\circ} \mathrm{C}$ in $50 \mathrm{mM}$ potassium phosphate buffer $(\mathrm{pH} 6.5), 50 \mathrm{mM}$ $\mathrm{KCl}, 250 \mu \mathrm{M} \mathrm{MnCl}_{2}$, and $1 \mathrm{mM}$ DTT. QueF was $(145 \mu \mathrm{M})$ was preincubated with 300 $\mu \mathrm{M}$ preQ $\mathrm{Q}_{0}$ for at least 10 minutes before mixing with varying concentrations of NADPH. The final concentrations of NADPH in the assay were 8; 16, 23.5 $\mu \mathrm{M}$, and the QueF* $\mathrm{PreQ}_{0}$ was $72.5 \mu \mathrm{M}$. For absorbance assays the reaction was carried out at $30{ }^{\circ} \mathrm{C}$ in 50 $\mathrm{mM}$ potassium phosphate buffer ( $\mathrm{pH}$ 6.5), $50 \mathrm{mM} \mathrm{KCl}, 250 \mu \mathrm{M} \mathrm{MnCl}_{2}$, and $1 \mathrm{mM}$ DTT, with final concentration of QueF-*PreQ ${ }_{0}$ at $180 \mu \mathrm{M}$ in the presence of 20 and $26.3 \mu \mathrm{M}$ NADPH.

\section{Thioimide decomposition}

Thioimide decomposition was monitored at $370 \mathrm{~nm}$ at $30{ }^{\circ} \mathrm{C}$ on the Cary 100 spectrophotometer. The reactions were carried out in the presence of $50 \mathrm{mM}$ potassium phosphate buffer (pH 6.5), $50 \mathrm{mM} \mathrm{KCl,} 250 \mu \mathrm{M} \mathrm{MnCl}_{2}, 1 \mathrm{mM}$ DTT, 154, 158 and 161 $\mu \mathrm{M}$ QueF-*PreQ . For the preparation of the thioimide $1 \mathrm{~mL}$ of $200 \mu \mathrm{M}$ QueF and 600 $\mu \mathrm{M}$ preQ $\mathrm{Q}_{0}$ were mixed and incubated for at least 10 minutes before the excess preQ $_{0}$ was removed by either dialysis against $4 \mathrm{~L}$ of $50 \mathrm{mM}$ phosphate $(\mathrm{pH} 6.5), 50 \mathrm{mM} \mathrm{KCl}, 250$ $\mu \mathrm{M} \mathrm{MnCl}_{2}$, and $1 \mathrm{mM}$ DTT or by 3 consecutive buffer exchanges with the dialysis buffer 
resulting in a 1000 times dilution. The resulting covalent $\mathrm{QueF}^{*} \mathrm{PreQ}_{0}$ complex was then monitored for at least 8 hours with either 5 or 10 minute intervals using multiple scanning kinetics. 


\subsection{S-Adenosylribosylmethionine:tRNA ribosyl transferase isomerase}

\section{Expression and purification of His 6 -QueA}

Recombinant QueA was expressed in pET30-QueA/BL21(DE3) E. coli cells at $37{ }^{\circ} \mathrm{C}$ in LB/kan medium. Cells from a glycerol stock were used to inoculate $3 \mathrm{~mL}$ of $\mathrm{LB} / \mathrm{kan}$ medium. After 12 hours a $1 \mathrm{~mL}$ aliquot was removed and used to inoculate $100 \mathrm{~mL}$ of $\mathrm{LB} / \mathrm{kan}$ medium in $500 \mathrm{~mL}$ flasks. The cultures were incubated at $37^{\circ} \mathrm{C}$ and $250 \mathrm{rpm}$ for 12 hours, after which $5 \mathrm{~mL}$ aliquots were taken and used to inoculate $500 \mathrm{~mL}$ of $\mathrm{LB} / \mathrm{kan}$ media in $2.5 \mathrm{~L}$ flasks. After $3 \frac{1}{2} 2$ hours of incubation at $37^{\circ} \mathrm{C}$ with shaking at $250 \mathrm{rpm}$ an $\mathrm{OD}_{600}$ of about 0.9 was reached, IPTG was added to a final concentration of $0.2 \mathrm{mM}$, and the cells were grown for an additional 4 hours. The cells were collected by centrifugation at 7,500 $\mathrm{x} g$ for 15 minutes at $4{ }^{\circ} \mathrm{C}$ and frozen with liquid nitrogen. The cells were stored at $-80^{\circ} \mathrm{C}$ until further use.

Cells were resuspended to a density of $250 \mathrm{mg} / \mathrm{mL}$ in $50 \mathrm{mM}$ Tris-acetate buffer $(\mathrm{pH}$ 8.0), $50 \mathrm{mM} \mathrm{KCl}, 2 \mathrm{mM} \beta \mathrm{ME}$, and $1 \mathrm{mM}$ PMSF. The cells were lysed by the addition of lysozyme to a final concentration of $250 \mu \mathrm{g} / \mathrm{mL}$ and lysis was carried out for 30 minutes at $37^{\circ} \mathrm{C}$. After which, one-fourth volume of chilled $400 \mathrm{mM}$ Tris-acetate (pH 8.0), $1.2 \mathrm{M}$ $\mathrm{KCl}, 8 \mathrm{mM} \beta \mathrm{ME}, 4 \mathrm{mM}$ PMSF, $4 \%$ Triton-X-100 and $40 \%$ glycerol was added to the mixture and placed on ice for 5 minutes. The cell lysate was centrifuged at 26,000 x $g$ for 30 minutes at $4{ }^{\circ} \mathrm{C}$, after which the $\mathrm{CFE}$ was filtered through a $0.45 \mu \mathrm{m}$ MCE syringe filter. 
The CFE was loaded onto a column containing $10 \mathrm{~mL}$ of $\mathrm{Ni}^{2+}-\mathrm{NTA}$ agarose resin equilibrated in $100 \mathrm{mM}$ Tris-acetate (pH 8.0), $300 \mathrm{mM} \mathrm{KCl,} 2 \mathrm{mM} \beta \mathrm{ME}, 1 \%$ Triton-X100 and $10 \%$ glycerol (buffer A). The column was washed with 5 column volumes buffer A followed by 5 column volumes of buffer A with $20 \mathrm{mM}$ imidazole (buffer B) and finally by 5 column volumes of buffer B without the triton X-100 or PMSF (buffer C). Protein elution was carried out with 7 column volumes of buffer C containing 200 $\mathrm{mM}$ imidazole (buffer D). The protein was concentrated to about $1 \mathrm{~mL}$ using an Amicon Ultra YM-10 and dialyzed overnight against $4 \mathrm{~L}$ of $50 \mathrm{mM}$ Tris acetate $(\mathrm{pH} 8.0), 50 \mathrm{mM}$ $\mathrm{KCl}$, and $1 \mathrm{mM} \mathrm{DTT}$ at $4{ }^{\circ} \mathrm{C}$. The protein determination was carried out using the Bradford method and protein purity was verified by use of SDS-PAGE. The protein was stored in aliquots of $100 \mu \mathrm{L}$ at $-80^{\circ} \mathrm{C}$ in the presence of $50 \%$ glycerol.

Assays for QueA activity were carried out in 100 mM Gly-gly (pH 8.7), 100 mM EDTA (pH 8.7), $100 \mathrm{mM} \mathrm{KCl}, 1 \mathrm{mM}$ DTT, and $20 \mu \mathrm{M}$ tRNA ${ }^{\mathrm{Tyr}}, 200 \mu \mathrm{M}$ [U-ribosyl- $\left.{ }^{14} \mathrm{C}\right]-$ AdoMet and $1 \mu \mathrm{M}$ QueA. The reactions were carried out in $50 \mu \mathrm{L}$ volumes and terminated by the addition of 4 volumes of $10 \%$ TCA and left to stand on ice for at least ten minutes before collecting the precipitated tRNA on Whatman GF-C fibers by vacuum filtration. The filters were washed with at least a liter of 5\% TCA followed by $95 \%$ ethanol, air dried and the radioactivity quantified by liquid scintillation counting 


\section{Expression and purification of $E$. coli tRNA-Guanine Transglycosylase (TGT)}

The recombinant $E$. coli TGT was expressed in $E$. coli BL21(DE3) with the plasmid pET30-Ectgt in LB/kan medium. Cells from a frozen glycerol stock were used to inoculate $3 \mathrm{~mL}$ of LB/kan medium. After 12 hours of incubation at $37^{\circ} \mathrm{C}, 1 \mathrm{~mL}$ aliquot was used to inoculate $100 \mathrm{~mL}$ of LB/kan medium. The cultures were incubated at $37^{\circ} \mathrm{C}$ and $250 \mathrm{rpm}$ for 12 hours and $5 \mathrm{~mL}$ aliquot was taken and used to inoculate $500 \mathrm{~mL}$ of LB/kan medium. After about 3 hours an $\mathrm{OD}_{600}$ of 0.9 was reached and protein overexpression was induced by the addition of IPTG to a final concentration of $0.2 \mathrm{mM}$. The cell cultures were grown for an additional 4-5 hours, after which the cells were collected by centrifugation at 5,000 x $g$ for 15 minutes and frozen with liquid nitrogen. The cells were stored at $-80^{\circ} \mathrm{C}$ until further use.

The cells were resuspended to a density of $250 \mathrm{mg} / \mathrm{mL}$ in $50 \mathrm{mM}$ Tris-acetate ( $\mathrm{pH} 7.5$ ), $50 \mathrm{mM} \mathrm{KCl}, 2 \mathrm{mM} \beta \mathrm{ME}$, and $1 \mathrm{mM}$ PMSF. Lysozyme was added to a final concentration of $250 \mu \mathrm{g} / \mathrm{mL}$ and the cells incubated at $37{ }^{\circ} \mathrm{C}$ for 30 minutes, followed by 3 intervals of freeze thaw cycles. DNase was added to a final concentration of $10 \mu \mathrm{g} / \mathrm{mL}$ and the cells were left at $37{ }^{\circ} \mathrm{C}$ for an additional 30 minutes. The cell lysate was centrifuged at 26,000 x $g$ for 30 minutes. The CFE was filtered using a low proteinbinding $0.45 \mu \mathrm{m}$ MCE syringe filter, then loaded onto $10 \mathrm{~mL}$ of $\mathrm{Ni}^{2+}$-NTA agarose resin equilibrated in $100 \mathrm{mM}$ Tris-acetate (pH 7.5), $300 \mathrm{mM} \mathrm{KCl,} 2 \mathrm{mM} \beta \mathrm{ME}, 4 \mathrm{mM}$ PMSF, $1 \%$ Triton X-100, and $10 \%$ glycerol ( buffer A). The column was washed with 5 column volumes buffer A with $20 \mathrm{mM}$ imidazole (buffer B) followed by 5 column volumes 
buffer B with no Triton X-100 or PMSF (buffer C). The fusion protein was eluted with 7 column volumes of buffer C containing $200 \mathrm{mM}$ imidazole (buffer D), then concentrated to about $2 \mathrm{~mL}$ using the Amicon Ultra YM-10 and dialyzed overnight against $4 \mathrm{~L}$ of 50 $\mathrm{mM}$ Tris-acetate (pH 7.5), $50 \mathrm{mM} \mathrm{KCl}$, and $2 \mathrm{mM}$ DTT at $4{ }^{\circ} \mathrm{C}$. The protein was stored in the presence of $50 \%$ glycerol in $100 \mu \mathrm{L}$ aliquots at $-80{ }^{\circ} \mathrm{C}$. Activity was measured as previously described (48).

\section{Adenine phosphoribosyltransferase (APRTase) expression and purification}

Recombinant APRTase was expressed from pQE-APT1 in E. coli B25 cells as a Histagged protein. Cell cultures were grown at $37{ }^{\circ} \mathrm{C}$ in $2 x Y T$ medium containing 100 $\mu \mathrm{g} / \mathrm{mL}$ ampicillin and $25 \mu \mathrm{g} / \mathrm{mL}$ kanamycin. The cells were grown in $3 \mathrm{~mL}$ cultures at $37^{\circ} \mathrm{C}$ for 12 hours and $250 \mathrm{rpm}$, after which $1 \mathrm{~mL}$ was taken and used to inoculate 100 $\mathrm{mL}$ of $2 \mathrm{xYT} / \mathrm{kan} / \mathrm{amp}$ medium and left to grow for another 12 hours. Erlenmeyer flasks

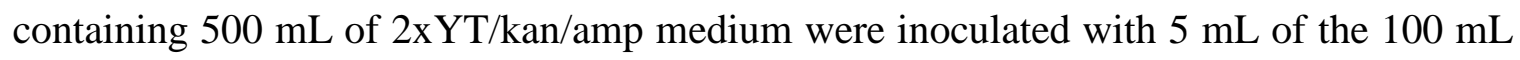
culture and left to grow until the $\mathrm{OD}_{600}$ had reached about 0.9 at which point the protein over-expression was induced by the addition of $0.25 \mathrm{mM}$ IPTG. The cell cultures were left to grow for an additional 4 hours after which they were harvested by centrifugation at $7,500 \times \mathrm{g}$ for 15 minutes and frozen immediately with liquid nitrogen. The cells were stored at $-80{ }^{\circ} \mathrm{C}$ until further use. Approximately $14 \mathrm{~g}$ of cells were obtained from $4 \mathrm{~L}$ of cell culture. 
The cells were resuspended to a final density of $250 \mathrm{mg} / \mathrm{mL}$ in lysis buffer of $50 \mathrm{mM}$ Tris- $\mathrm{HCl}(\mathrm{pH} 7.4), 5 \mathrm{mM} \mathrm{MgCl}{ }_{2}$ and $20 \mathrm{mM} \mathrm{KCl}$. Lysozyme was added to a final concentration of $250 \mu \mathrm{g} / \mathrm{mL}$ and the cells incubated at $37{ }^{\circ} \mathrm{C}$ for 30 minutes, followed by 3 intervals of freeze thaw cycles. DNase was added to a final concentration of $10 \mu \mathrm{g} / \mathrm{mL}$ and the cells were left at $37^{\circ} \mathrm{C}$ for an additional 30 minutes. The cell lysate was centrifuged at $26,000 \times g$ for 30 minutes. The CFE was filtered using a low proteinbinding $0.45 \mu \mathrm{m}$ MCE syringe filter, then loaded onto $10 \mathrm{ml} \mathrm{of} \mathrm{Ni}^{2+}$-NTA agarose resin, which had been previously equilibrated in lysis buffer. The column was washed with 10 column volumes of lysis buffer containing $50 \mathrm{mM}$ imidazole followed by elution with 4 column volumes using lysis buffer containing $150 \mathrm{mM}$ imidazole. The protein was concentrated using an Amicon Ultra YM-10 centrifugal device at $4{ }^{\circ} \mathrm{C}$. The sample was dialyzed overnight against $4 \mathrm{~L}$ of the same buffer without imidazole and stored as a $50 \%$ glycerol stock. Protein purity was confirmed by SDS-PAGE.

The activity of the purified protein was assayed in a solution containing, $50 \mathrm{mM}$ Tris- $\mathrm{HCl}$ (pH 7.0), 8 mM MgSO $4,1 \mathrm{mg} / \mathrm{mL}$ BSA, $200 \mu \mathrm{M}\left[8{ }^{-14} \mathrm{C}\right]$ Adenine, $5 \mu \mathrm{g} / \mathrm{mL}$ of PRPP, and $2 \mu \mathrm{g}$ APRTase. The assay was carried out at room temperature in $100 \mu \mathrm{L}$ reaction volume and the formation of AMP was monitored by the removal of $15 \mu$ l aliquots, quenching with the addition of EDTA to a final concentration of $100 \mathrm{mM}$ and applied onto DE-81 filters. The filters were washed with distilled water and placed in vials with scintillation fluid and counted. 


\section{5-phosphoribosyl-1-pyrophosphate (PRPP) synthetase expression and purification}

E. coli cells JM831 containing the pBSR11R plasmids were expressed in LB/amp medium at $37^{\circ} \mathrm{C}$. Cells from a glycerol stock were used to inoculate $3 \mathrm{~mL}$ of LB/amp medium and were grown for 12 hours at $37^{\circ} \mathrm{C}$ and $250 \mathrm{rpm}$, after which $1 \mathrm{~mL}$ was taken and used to inoculate $100 \mathrm{~mL} \mathrm{LB} / \mathrm{amp}$ medium and left to grow for 12 hours at $37^{\circ} \mathrm{C}$ at $250 \mathrm{rpm}$. Erlenmeyer flasks containing $500 \mathrm{~mL}$ of LB/amp medium were inoculated with $5 \mathrm{~mL}$ of the $100 \mathrm{~mL}$ culture and left to grow at $37^{\circ} \mathrm{C}$ and $250 \mathrm{rpm}$ until the $\mathrm{OD}_{600}$ had reached about 0.9 at which point the protein expression was induced by the addition of $0.25 \mathrm{mM}$ IPTG. The cell cultures were left to grow for an additional 4 hours after which they were harvested by centrifugation at 5,000 $\mathrm{g} g$ for 15 minutes and frozen immediately with liquid nitrogen. The cells were stored at $-80{ }^{\circ} \mathrm{C}$ until further use. Approximately 20 $\mathrm{g}$ of cells were obtained from $3.5 \mathrm{~L}$ of cell culture.

The cells were resuspended to a final concentration of $250 \mathrm{mg} / \mathrm{mL}$ in $50 \mathrm{mM}$ potassium phosphate (pH 7.5), $2 \mathrm{mM}$ DTT, and $1 \mathrm{mM}$ PMSF. Lysozyme was added to a final concentration of $250 \mu \mathrm{g} / \mathrm{mL}$ and the cells incubated at $37^{\circ} \mathrm{C}$ for 30 minutes, followed by 3 intervals of freeze thaw cycles. DNase was added to a final concentration of $10 \mu \mathrm{g} / \mathrm{mL}$ and the cells were left at $37{ }^{\circ} \mathrm{C}$ for an additional 30 minutes. The cell lysate was centrifuged at $26,000 \times \mathrm{g}$ for 30 minutes. The CFE was filtered using a low proteinbinding $0.45 \mu \mathrm{m}$ MCE filter. The PRPP synthetase was precipitated out by slow addition of small amounts of ammonium sulfate over an hour to a final concentration of $15 \%$ with constant swirling. The precipitated protein was left to stand on ice for an additional 30 
minutes after which it was pelleted by centrifugation at $26,000 \mathrm{x} g$ for 30 minutes at $4{ }^{\circ} \mathrm{C}$. The pellet was resuspended in an equal volume of the lysis buffer used to suspend the $E$. coli cells used to prepare the lysate, and the protein was concentrated using an Amicon Ultra YM-10 centrifugal device at $4{ }^{\circ} \mathrm{C}$. The sample was dialyzed overnight and against the same buffer and stored as a 50\% glycerol stock. Activity was assessed as previously described (64).

\section{S-adenosylmethionine synthetase (MetK) expression and purification}

Recombinant MetK was over-expressed from E. coli $\mathrm{DH} 5 \alpha / \mathrm{pK} 8$. Cell cultures were all grown at $37^{\circ} \mathrm{C}$ in LB/amp medium. Cells from a glycerol stock were used to inoculate 3 $\mathrm{mL}$ of LB/amp medium and were grown for 12 hours at $37^{\circ} \mathrm{C}$ and $250 \mathrm{rpm}$, after which 1 $\mathrm{mL}$ was taken and used to inoculate $100 \mathrm{~mL} \mathrm{LB} / \mathrm{amp}$ medium and left to grow for 12 hours at $37{ }^{\circ} \mathrm{C}$ at $250 \mathrm{rpm}$. Erlenmeyer flasks containing $500 \mathrm{~mL}$ of LB/amp medium were inoculated with $5 \mathrm{~mL}$ of the $100 \mathrm{~mL}$ culture and left to grow at $37^{\circ} \mathrm{C}$ and $250 \mathrm{rpm}$ until the $\mathrm{OD}_{600}$ had reached about 0.8 at which point the protein expression was induced by the addition of $1 \mathrm{mM}$ IPTG. The cells were harvested by centrifugation at 5,000 $\mathrm{x} g$ for 10 minutes, after which they were frozen with liquid nitrogen. About $12 \mathrm{~g}$ of cells were obtained from $3.5 \mathrm{~L}$ of media.

The cells were resuspended in $50 \mathrm{mM}$ Tris- $\mathrm{HCl}(\mathrm{pH} 8.0), 0.5 \mathrm{mM}$ EDTA and $1 \mathrm{mM}$ PMSF. Lysozyme was added to a final concentration of $250 \mu \mathrm{g} / \mathrm{mL}$ and the cells 
incubated at $37{ }^{\circ} \mathrm{C}$ for 30 minutes, followed by 3 intervals of freeze thaw cycles. DNase was added to a final concentration of $10 \mu \mathrm{g} / \mathrm{mL}$ and the cells were left at $37^{\circ} \mathrm{C}$ for an additional 30 minutes. The cell lysate was centrifuged at $26,000 \times \mathrm{g}$ for 30 minutes. The cell-free extract was filtered by a low protein binding $0.45 \mu \mathrm{m}$ MCE syringe filter. MetK was precipitated with ammonium sulfate at a final concentration of $65 \%$. The precipitated enzyme was collected by centrifugation and resuspended in $50 \mathrm{mM}$ Tris- $\mathrm{HCl}$ (pH 8.0), $0.5 \mathrm{mM}$ EDTA ( $\mathrm{pH} 8.0$ ), and $1 \mathrm{mM}$ PMSF and concentrated to about $2 \mathrm{~mL}$ using the Amicon YM-10. The protein was dialyzed overnight against $4 \mathrm{~L}$ of lysis buffer and stored in $50 \%$ of glycerol at $-80{ }^{\circ} \mathrm{C}$.

Protein activity was assayed by monitoring the conversion of $\left[1-{ }^{14} \mathrm{C}-\right]-\mathrm{L}-\mathrm{methionine}$ and ATP to $\left[1-{ }^{14} \mathrm{C}\right.$ - $]$-AdoMet. The reaction conditions were $100 \mathrm{mM}$ Tris- $\mathrm{HCl}$ (pH 8.0), 100 $\mathrm{mM} \mathrm{KCl}, 10 \mathrm{mM} \mathrm{MgCl}$ and $2 \mathrm{mM}\left[1-{ }^{14} \mathrm{C}-\right]-\mathrm{L}-$ methionine. The reactions were carried out at room temperature for 1 hour and stopped by addition of 100 mM EDTA. The reaction mixture was placed on Whatman p-81 filters and washed with at least $500 \mathrm{~mL}$ of distilled water before being placed in scintillation vials and counted.

\section{Preparation and purification of $\left[\mathrm{U}-\right.$-ribosyl- $\left.-{ }^{14} \mathrm{C}\right] \mathrm{ATP}$}

Synthesis of [U-ribosyl- $\left.{ }^{14} \mathrm{C}\right]$-ATP was carried by using 7 commercially available enzymes and 2 in-house purified enzymes and $\left[\mathrm{U}-{ }^{14} \mathrm{C}\right]$-glucose. The synthesis was carried out as previously described $(65,66)$ with a few modifications. A single reaction 
mixture of $1 \mathrm{~mL}$ contained $200 \mu \mathrm{M}\left[\mathrm{U}_{-}{ }^{14} \mathrm{C}\right]$-glucose, $50 \mathrm{mM}$ potassium phosphate $(\mathrm{pH}$ 7.5), $50 \mathrm{mM}$ gly-gly (pH 8.7), $10 \mathrm{mM} \mathrm{MgCl}_{2}, 3 \mathrm{mM}$ adenine, $20 \mathrm{mM}$ PEP, $1 \mathrm{mM}$ $\mathrm{NADP}^{+}, 1 \mathrm{mM}$ ATP , $10 \mathrm{mM} \alpha$-ketoglutarate, $0.8 \mathrm{U}$ of glusoe-6-phosphate dehydrogenase, $0.8 \mathrm{U}$ of phosphogluconate dehydrogenase, $8 \mathrm{U}$ of phosphoribisomerase, $100 \mu \mathrm{g}$ of 5-phosphoribosyl-1-pyrophosphate synthetase, $25 \mu \mathrm{g}$ of adenine phosphoribosyltransferase, $8 \mathrm{U}$ of myokinase, $16 \mathrm{U}$ of pyruvate kinase and $8 \mathrm{U}$ of hexokinase. All these enzymes were combined and washed with $10 \mathrm{ml}$ of $10 \mathrm{mM}$ phosphate buffer (pH 7.5) and concentrated in a Centricon YM-10 unit to remove salts. Glutamate dehydrogenase was added to provide a final concentration of $50 \mathrm{mM} \mathrm{NH}_{4}^{+}$required as a substrate by glutamate dehydrogenase. The reaction was carried out at $37{ }^{\circ} \mathrm{C}$ for about 4 hours, and was monitored by TLC analysis on PEI cellulose, which was cut into $1 \mathrm{~cm}$ strips as the reaction proceeded. The reaction was terminated by heating to $95{ }^{\circ} \mathrm{C}$ for 3 min followed by centrifugation at $20,000 \times \mathrm{x}$ for 20 minutes.

Purification of [U-ribosyl- $\left.{ }^{14} \mathrm{C}\right] \mathrm{ATP}$ was carried out on a C18 reverse-phase HPLC with a semi preparative Hypersil 5 C18 column (250 x $10 \mathrm{~mm}, 5 \mu \mathrm{m}$, phenomenex) (66). The ATP was eluted under isocratic conditions of $94 \% 83.3 \mathrm{mM}$ triethylammonium acetate $(\mathrm{pH} 6.0) / 6 \%$ methanol at a flow rate of $4 \mathrm{~mL} / \mathrm{min}$. The ATP fractions were pooled and lyophilized to dryness and dissolved in water. The concentration of ATP was determined by UV spectroscopy at $260 \mathrm{~nm}\left(\varepsilon_{260}=15.4 \times 10^{3} \mathrm{M}^{-1} \mathrm{~cm}^{-1}\right)$. 


\section{Synthesis and purification of unlabelled and $\left[\mathrm{U}-\right.$ ribosyl $\left.-{ }^{14} \mathrm{C}\right]$-AdoMet}

The purified [U-ribosyl- $\left.{ }^{14} \mathrm{C}\right]$-ATP was used in an enzymatic step to produce [U-ribosyl$\left.{ }^{14} \mathrm{C}\right]$-Adomet (67). The reaction was carried out in $100 \mathrm{mM}$ Tris- $\mathrm{HCl}(\mathrm{pH} 8.0), 50 \mathrm{mM}$ $\mathrm{KCl}, 26 \mathrm{mM} \mathrm{MgCl}$, $5 \mathrm{mM}$ DTT, $5 \mathrm{mM}$ methionine, $1 \mathrm{mM}$ [U-ribosyl- $\left.{ }^{14} \mathrm{C}\right]-\mathrm{ATP}, 20 \%$ acetonitrile, and $1.0 \mathrm{mg} / \mathrm{mL}$ of MetK. The reaction was monitored as previously described. The reaction was terminated by the addition of cold tricholoroacetic (TCA) acid to a final concentration of $8 \%(\mathrm{w} / \mathrm{v})$. After centrifugation at $20,000 \times \mathrm{x}$ for 30 minutes, the synthesized AdoMet was purified from ATP by reversed phase HPLC using a semi-preparative Hypersil 5 C18 column ( 250 x 10 mm, $5 \mu \mathrm{m}$, Phenomenex). The [Uribosyl- ${ }^{14} \mathrm{C}$-AdoMet was eluted under isocratic conditions of $98 \% 20 \mathrm{mM}$ ammonium acetate $\left(\mathrm{pH}\right.$ 6.0)/2\% Methanol. The $\left[\mathrm{U}-\right.$ ribosyl $\left.{ }^{14} \mathrm{C}\right]$-AdoMet fractions were immediately collected and acidified by addition of $\mathrm{H}_{2} \mathrm{SO}_{4}$ and lyophilized to dryness. The concentration was determined by UV-spectroscopy, the purity of the [U-ribosyl- $\left.{ }^{14} \mathrm{C}\right]-$ AdoMet was verified by TLC, UV/Vis spectroscopy and HPLC against the authentic material.

\section{In vivo expression and purification of tRNA ${ }^{\mathrm{Tyr}}$}

E. coli $\mathrm{K} 12 \mathrm{QueA} / \mathrm{pTRC} 99 \mathrm{~B}-\mathrm{Tyr}$ was grown in LB/amp medium at $37{ }^{\circ} \mathrm{C}$. A glycerol stock was used to inoculate $3 \mathrm{~mL}$ of $\mathrm{LB} / \mathrm{amp}$ medium and the culture was left to grow for 12 hours, after which $1 \mathrm{~mL}$ was taken and used to inoculate $100 \mathrm{~mL}$ of $\mathrm{LB} / \mathrm{amp}$ medium. The $100 \mathrm{~mL}$ cultures were grown for 12 hours at $37^{\circ} \mathrm{C}$ with shaking at $250 \mathrm{rpm}, 5 \mathrm{~mL}$ 
aliquots were taken from the $100 \mathrm{~mL}$ cultures and were used to inoculate $500 \mathrm{~mL}$ of LB/amp medium. The cells in the $500 \mathrm{~mL}$ culture were grown for about $3 \frac{1}{1} 2$ hours until an $\mathrm{OD}_{600}$ of about 0.9 was reached at which point the over-expression of tRNA ${ }^{\mathrm{Tyr}}$ was induced by the addition of IPTG to a final concentration of $0.5 \mathrm{mM}$. The cultures were allowed to grow for an additional 13 hours and were harvested by centrifugation at 5,000 $\mathrm{x} g$ for 15 minutes and frozen with liquid nitrogen. The cells were stored at $-80{ }^{\circ} \mathrm{C}$ until further use. Approximately $50 \mathrm{~g}$ of cells were obtained from $7 \mathrm{~L}$ of LB.

The acid guanidium thiocyanate-phenol-chloroform method was used to lyse the cells and extract the ribonucleic acids (68). Twenty grams of cells were suspended in $40 \mathrm{~mL}$ of $4 \mathrm{M}$ guanidium thiocyanate, $0.5 \%$ N-lauroylsarcosine, $100 \mathrm{mM} \beta \mathrm{ME}$ and $25 \mathrm{mM}$ sodium citrate ( $\mathrm{pH} 7.0)$. The cells were lysed by stirring at $4{ }^{\circ} \mathrm{C}$ for 1 hour followed by addition of $4 \mathrm{~mL}$ of $2 \mathrm{M}$ sodium acetate $(\mathrm{pH} 4.0)$. The mixture was stirred for an additional 5 minutes and $40 \mathrm{~mL}$ of water-saturated phenol was added. After shaking for 5 minutes, $8 \mathrm{~mL}$ of choloroform: isoamyl alcohol (49:1) were added and the solution shaken vigorously for 10s. The aqueous phase was recovered after centrifugation at 800 $\mathrm{x} g$ for 20 minutes and the RNA was precipitated with the addition of an equal volume of isopropanol followed by incubation at $-20{ }^{\circ} \mathrm{C}$ for 2 hours. The precipitate was collected by centrifugation at $20,000 \times g$ for 20 minutes and washed with $70 \%$ ethanol. The enriched RNA was subjected to a second round of the acid guanidium thiocyanatephenol-chloroform extraction using a quarter of the original volumes to ensure complete removal of the proteins. After washing the RNA pellet with $70 \%$ ethanol and 
centrifuging, the pellet was dissolved in DEPC-treated water and an equal volume of $8 \mathrm{M}$ $\mathrm{LiCl}$ was added. The solution was placed at $-20{ }^{\circ} \mathrm{C}$ for 2 hours, followed by centrifugation at 20,000 $\mathrm{x} g$ for 20 minutes to remove the large RNAs. The supernatant containing the $\mathrm{tRNA}^{\mathrm{Tyr}}$ was precipitated with isopropanol and washed with $70 \%$ ethanol as previously described. The pellet was suspended in $3 \mathrm{mM}$ sodium citrate $\mathrm{pH}$ 6.3. The concentration of tRNA ${ }^{\text {Tyr }}$ was estimated by UV-Vis spectroscopy $\varepsilon_{260}=861,000 \mathrm{~L} \mathrm{~mol}^{-}$ ${ }^{1} \mathrm{~cm}^{-1}$. Approximately $20 \%$ of the total RNA was determined to be $\mathrm{tRNA}^{\mathrm{Tyr}}$ by the tRNA synthetase activity assays and QueA assay.

\section{Purification of the tRNA ${ }^{\text {Tyr }}$}

Crude tRNA $(50 \mathrm{mg})$ was loaded on a $12 \mathrm{~mL}$ column $(1 \mathrm{~cm}$ ID) of BND cellulose in 20 mM NaOAc (pH 4.5), $10 \mathrm{mM} \mathrm{MgCl}_{2}$, and $0.5 \mathrm{M} \mathrm{NaCl}$ (69). A $100 \mathrm{~mL}$ linear salt gradient $0.5 \mathrm{M}$ to $1.0 \mathrm{M} \mathrm{NaCl}$ was applied followed by washing with $1 \mathrm{M} \mathrm{NaCl}$ until the absorbance reading was below 0.25 . A $40 \mathrm{~mL}$ ethanol gradient (0-20\%) was applied for the elution of $\mathrm{RNA}^{\mathrm{Tyr}}$. The volume of each fraction was $2 \mathrm{~mL}$ and the flow rate was 0.5 $\mathrm{mL} /$ minute. The presence of $\mathrm{RNA}^{\mathrm{Tyr}}$ was assayed by the tRNA-tyrosine synthetase assay and fractions which contained tRNA ${ }^{\text {Tyr }}$ were pooled and the tRNA was precipitated with isopropanol at $50 \%$ final concentration. The tRNA ${ }^{\mathrm{Tyr}}$ was further purified by continuous elution PAGE using BioRad 491 Prep Cell with 7 M Urea, 12\% acrylamide gel. The tRNA ${ }^{\text {Tyr }}$ was prepared in $50 \%$ formamide (v/v), $10 \mathrm{mM}$ EDTA, $0.1 \%(\mathrm{w} / \mathrm{v})$ xylene cyanol FF and $0.1 \%$ (w/v) bromophenol blue. The gel was run at $300 \mathrm{~V}$, and 3 
$\mathrm{mL}$ fractions were collected at a flow rate of $1 \mathrm{~mL} / \mathrm{min}$. The complete run took about 13 hours. To remove bound metal ions from the tRNA ${ }^{\text {Tyr }}$, it was washed with a 10 fold volume of $3 \mathrm{mM}$ sodium citrate followed by precipitation with isopropanol and cooling at $-20{ }^{\circ} \mathrm{C}$ for 2 hours followed by centrifugation. The pellet was resuspended in $3 \mathrm{mM}$ sodium citrate ( $\mathrm{pH}$ 6.3). The concentration of tRNA ${ }^{\mathrm{Tyr}}$ was determined by the tyrosinesynthetase assay and QueA assay and found to comprise greater than $70 \%$ of the isolated tRNA.

\section{In vitro transcription and purification of minihelix 17-mer}

An RNA 17-mer representing the E. coli tRNA $^{\text {Asn }}$ anticodon stem-loop (5'GCGGACUGUUAAUCCGC-3') was synthesized in a reaction containing $40 \mathrm{mM}$ Tris- $\mathrm{HCl}(\mathrm{pH} 8.0), 20 \mathrm{mM} \mathrm{MgCl} 2,1 \mathrm{mM}$ spermidine, $50 \mu \mathrm{g} / \mathrm{mL}$ BSA, $2.5 \mathrm{mM}$ DTT, $0.01 \%$ Triton $\mathrm{X}-100,80 \mathrm{mg} / \mathrm{mL}$ polyethylene glycol, $0.5 \mu \mathrm{M}$ of top and bottom DNA, 4 $\mathrm{mM}$ NTPs and $64 \mu \mathrm{g} / \mathrm{mL}$ T7-polymerase. The reaction was incubated at $37{ }^{\circ} \mathrm{C}$ for 6 hours at which point the reaction was stopped by heating at $95^{\circ} \mathrm{C}$ for 3 minutes, followed by centrifugation at $20,000 \times \mathrm{g}$ for 10 minutes. The $17-\mathrm{mer}$ was precipitated by an equal amount of isopropanol and cooling at $-80{ }^{\circ} \mathrm{C}$ for 2 hours. The cold solution was centrifuged at $20,000 \times \mathrm{g}$ at $4{ }^{\circ} \mathrm{C} 30$ minutes. The pellet was washed with cold $70 \%$ ethanol and placed at $-20{ }^{\circ} \mathrm{C}$ overnight. The solution was centrifuged at $20,000 \times \mathrm{g}$ for 30 minutes and the pellet was resuspended in $400 \mu \mathrm{L}$ of $3 \mathrm{mM}$ citrate $(\mathrm{pH} 6.3)$. 
The crude RNA was treated with RNase-free DNase (40 Units/mL of the in vitro transcription) in $40 \mathrm{mM}$ Tris- $\mathrm{HCl}(\mathrm{pH} 8.0), 10 \mathrm{mM} \mathrm{NaCl}, 6 \mathrm{mM} \mathrm{MgCl} 2$ and $10 \mathrm{mM}$ $\mathrm{CaCl}_{2}$ for 30 minutes. The RNA oligomer was purified by continuous elution PAGE using the BioRad 491 Prep Cell with a $7 \mathrm{M}$ urea, 20\% acrylamide gel in the following manner: $10 \mathrm{mg}$ of RNA in $80 \%$ formamide (v/v), $10 \mathrm{mM}$ EDTA, $0.1 \%(\mathrm{w} / \mathrm{v})$ xylene cyanol FF, and $0.1 \%(\mathrm{w} / \mathrm{v})$ bromophenol blue were loaded onto the gel and the sample was electrophoresed at $200 \mathrm{~V}$ until the bromophenol blue was eluted, at which point fraction collection began. Fractions $(5 \mathrm{~mL})$ were collected until xylene cyanol FF eluted. The elution of the 17-mer was monitored on Urea/PAGE gels. The fractions containing 17-mer were pooled and concentrated by lyophilizing. The concentration of the RNA was determined by UV/Vis spectroscopy with $\varepsilon_{260}=162,000 \mathrm{~L} \mathrm{~mol}^{-1} \mathrm{~cm}^{-1}$ and MW= 5442.4 Da.

\section{Insertion of pre $Q_{1}$ into the minihelix RNA}

The preQ $_{1}$ base was inserted into the 17-mer in an E. coli TGT-catalyzed reaction. A 75 $\mu \mathrm{g}$ aliquot of TGT was added to a $1 \mathrm{~mL}$ solution containing $20 \mathrm{mM}$ HEPES (pH 7.5), 10 $\mathrm{mM} \mathrm{MgCl} 2,50 \mathrm{mM} \mathrm{KCl,} 2 \mathrm{mM}$ DTT, $50 \mu \mathrm{M}$ 17-mer and $300 \mu \mathrm{M}$ preQ ${ }_{1}$. After 3 hours at $37{ }^{\circ} \mathrm{C}$, the reaction was terminated by the addition of 0.1 volumes of $2 \mathrm{M} \mathrm{NaOAc}(\mathrm{pH}$ 4.0) followed by one volume of water-saturated-phenol and 0.2 volumes of chloroform:isoamyl alcohol (49:1). After vortexing for 20s, the solution was centrifuged in a swinging bucket rotor at $700 \mathrm{x} g$ for 20 minutes. The aqueous phase was recovered 
and applied directly to a Quick-Sep column containing $2 \mathrm{~mL}$ of Sephadex G-25. The sample was centrifuged at $700 \times g$ in a swinging bucket rotor for $1 \frac{1 / 2}{2}$ min to separate the unreacted $\mathrm{preQ}_{1}$ from the 17 -mer. The 17 -mer in the eluate was precipitated by an equal amount of isopropanol and cooling at $-20{ }^{\circ} \mathrm{C}$ overnight. The solution was centrifuged at $20,000 \times g$ for 20 minutes and the RNA pellet was washed with $70 \%$ cold ethanol and centrifuged again at $20,000 \times g$ at $4^{\circ} \mathrm{C}$. The $17-$ mer was resuspended in $3 \mathrm{mM}$ citrate $(\mathrm{pH}$ 6.3) and stored at $-80{ }^{\circ} \mathrm{C}$.

\section{Determination of stereospecific abstraction of hydrogen by QueA}

The conversion of $\mathrm{preQ}_{1}$ from either the 17 -mer or $\mathrm{tRNA}^{\mathrm{Tyr}}$ was carried out under the conditions of: 100 mM Gly-gly (pH 8.7), 100 mM EDTA (pH 8.7), 100 mM KCl, $50 \mu \mathrm{M}$ tRNA, $25 \mu \mathrm{M}$ QueA and $1.0 \mathrm{mM}$ of either $\left(5^{\prime} S\right)-\left[5^{\prime}-{ }^{2} \mathrm{H}\right]-\operatorname{AdoMet}$ or $\left(5^{\prime} R\right)-\left[5^{\prime}-{ }^{2} \mathrm{H}\right]-$ AdoMet. The reaction was left to run for 1 hour and terminated by heating for 3 minutes at $95{ }^{\circ} \mathrm{C}$. The mixture was centrifuged at $20,000 \times g$ in order to remove precipitated protein, followed by separation of RNA from other reaction components by use of a spin column with $500 \mu \mathrm{l} \mathrm{G-25}$ sephadex. This process was performed twice and the collected RNA was precipitated out by adding 0.1 volumes of $2 \mathrm{M} \mathrm{NaOAc}(\mathrm{pH} 4.0)$ and one volume of isopropanol and cooling at $-20{ }^{\circ} \mathrm{C}$ for 2 hours. The RNA was resuspended in water to a final concentration of $1 \mu \mathrm{g} / \mathrm{mL}$. The RNA digestion was carried out as previously described (63). The RNA was denatured by heating at $100{ }^{\circ} \mathrm{C}$ and rapidly chilled in ice-water slush. One tenth volume of $\mathrm{NH}_{4} \mathrm{OAc} 0.1 \mathrm{M}(\mathrm{pH} 5.3), 5 \mu \mathrm{g}$ of 
Nuclease P1 was added for $1 \mathrm{mg}$ of RNA and the digestion was incubated at $42{ }^{\circ} \mathrm{C}$ for 4 hours. This was followed by adding 0.1 volumes of freshly made $1 \mathrm{M} \mathrm{NH}_{4} \mathrm{HCO}_{3}(\mathrm{pH}$ 7.8) and $0.05 \mathrm{U}$ of phosphodiesterase the digestion was carried out for another 4 hours at $37{ }^{\circ} \mathrm{C}$. Lastly 20 Units of alkaline phosphatase were added and the dephosphorylation was carried out for 2 hours at $37^{\circ} \mathrm{C}$.

The oQ was purified on the HPLC by use of an analytical Gemini column $(250 \times 4.6 \mathrm{~mm}$, 5 micron, Phenomenex), under gradient conditions of $100 \% 25 \mathrm{mM} \mathrm{NH}_{4} \mathrm{OAc}$ (pH 6.0) to $90 \% 25 \mathrm{mM} \mathrm{NH}_{4} \mathrm{OAc} / 10 \%$ Acetonitrile at a flow rate of $1 \mathrm{~mL} / \mathrm{min}$ over $30 \mathrm{~min}$. The oQ was collected, lyophilized and made up in $10 \mathrm{mM} \mathrm{NH}_{4} \mathrm{OAc}(\mathrm{pH}$ 6.0)/50\% methanol followed by direct infusion analysis using a Thermo LCQ ion trap mass spectrometer. The analysis was carried out in the positive mode. Proton NMR of the streospecifically labeled AdoMet used in this analysis was carried out under acidic conditions with a $\mathrm{pH}$ of approximately 3.0 in $\mathrm{D}_{2} \mathrm{SO}_{4}$. 


\section{RESULTS}

\subsection{MjTgtA2}

\section{Identification, cloning, and purification of $M j$ TgtA2}

Using the gene clustering tool of the SEED database, the gene families that physically clustered with $\operatorname{tg} t A$, which encodes the archael TGT and encoded proteins with RNAbinding domains were identified as possible candidates for the enzyme involved in the final transformation of $\mathrm{preQ}_{0}$-tRNA to $\mathrm{G}^{+}$-tRNA (Figure 16A). The tgtA2 family was identified as a possible candidate, as members of this family cluster with $\operatorname{tgtA}$ genes in phylogenetically distant archaea (Figure 16B). These genes had been previously annotated as encoding TGT enzymes in most archaeal genomes because the corresponding proteins present around 18\% sequence identity with the canonical TGT [the identity score was obtained from comparing the M. janaschii TGT (MJ0436) and TgtA2 (MJ1022)]. Detailed analysis of the sequence alignments of the TGT and TgtA2 families revealed that, while the $\mathrm{C} 2$ and PUA domains were well conserved between the two protein families, the $\mathrm{N}$-terminal and $\mathrm{C} 1$ domains were not (70). The major differences in those two domains are the following: (a) the N-terminal domain in the TgtA2 family is smaller than its counterpart in the TGT family by $70-130 \mathrm{~N}$-terminal residues, (b) active site and known catalytic residues in the N-terminal domain of TGT are not conserved in TgtA2, (c) the $\mathrm{C} 1$ domain in TgtA2 is much larger than its counterpart in TGT (200 residues in TgtA2, but only 40 in TGT) and (d) the C1 domain 
of TgtA2 contains a TgtA2-specific motif PC-X3-KPY-X2-S-X2-H (Figure 16C) not found in TGT (70). The combination of the clustering evidence and the presence of a PUA domain suggested that the $\operatorname{tgtA} 2$ gene family encoded an enzyme catalyzing one or more steps in the conversion of preQ $\mathrm{Q}_{0}$-tRNA to $\mathrm{G}^{+}$- tRNA and was not a canonical TGT.

The mj1022 gene corresponding to tgtA2 gene in $M$. jannaschii was initially cloned from genomic DNA via PCR and inserted into a pET32Xa/LIC vector to enable expression of the recombinant protein as an N-terminal $\mathrm{His}_{6}$-Trx-fusion protein. The over-expression of protein in E. coli BL21(DE3) was associated with low levels of recombinant protein and production of truncated proteins. Sequence analysis of the mj1022 gene revealed that it was highly A-T rich and contained numerous codons for lysine and arginine that are rarely used in E. coli. The expression profile was only marginally improved by expression in Rosetta2 TM cells, which are engineered to over-express a number of specific tRNAs to compensate for the presence of rarely used codons in E. coli. In order to improve protein expression, a codon-optimized synthetic gene was prepared for expression in E. coli, and cloned via PCR into pET32Xa/LIC and pET30Xa/LIC expression vectors harboring $\mathrm{N}$ - and $\mathrm{C}$-terminal $\mathrm{His}_{6}$ fusion tags.

Expression from pVCIII-28 and pVCIV-42, which encode the N- and C-terminal His 6 fusions, respectively, in E. coli BL21(DE3) was robust, and provided $\sim 25 \mathrm{mg}$ of recombinant protein per liter of culture. However, purified protein obtained after $\mathrm{Ni}^{2+}$ NTA agarose affinity chromatography was typically contaminated with one or more other 
polypeptides (Figure 17). In the case of the His $_{6}$-Trx-fusion protein, several large bands $\sim 15 \mathrm{KDa}$ less than the fusion were observed, as well as a small band that was $\sim 15 \mathrm{KDa}$, while in the samples of $\mathrm{C}$-terminal $\mathrm{His}_{6}$ fusion protein a single additional band $\sim 7 \mathrm{KDa}$ smaller than the fusion was observed. When these samples were kept at temperatures above freezing $\left(4{ }^{\circ} \mathrm{C}\right.$ to $\left.25{ }^{\circ} \mathrm{C}\right)$ over a period of days to weeks, all of the fusion protein converted to the smaller bands. Various protease inhibitors that were tested did not prevent or influence the cleavage reaction, suggesting that the protein was undergoing self-cleavage. The protein was prone to precipitation in different forms either as a fusion or the cleaved product and required at least $0.5 \mathrm{M} \mathrm{NaCl}$ to remain in solution.

\section{Determination of self-cleavage sites in $\mathrm{N}$ - and C-terminal fusions of MjTgtA2}

To allow the $\mathrm{N}$ - and C-terminal recombinant fusion proteins to self-cleave, the Trx-His ${ }_{6}^{-}$ $M j$ TgtA2 and $M j$ TgtA2-His 6 fusion constructs were incubated at $4{ }^{\circ} \mathrm{C}$ for up to 4 weeks and analyzed by Edman degradation. N-terminal sequencing revealed that while cleavage occurred in 2 specific regions, one within the fusion domain (Figure 18B) and a second $\sim 75$ residues into the N-terminal domain of the native protein (Figure 18C), Nterminal heterogeneity was observed due to multiple cleavage sites within each region (Table 1). 


\section{Size exclusion chromatography}

To evaluate the native molecular masses of $\mathrm{His}_{6}{ }_{-} \mathrm{Trx}-M j \operatorname{TgtA} 2$ and cleaved $M j \operatorname{TgtA} 2$, analytical size exclusion chromatography was carried out (Figure 19). A standard curve was generated using carbonic anhydrase (29KDa), BSA (66 KDa), alcohol dehydrogenase (150 KDa), $\beta$-amylase (200 KDa), apoferritin (443 KDa) and thyroglobulin (669 $\mathrm{KDa}$ ). The $\mathrm{His}_{6}$-Trx-MjTgtA2 eluted with a calculated $\mathrm{K}_{\mathrm{D}}$ of 0.592 . For cleaved MjTgtA2, the $\mathrm{K}_{\mathrm{D}}$ was 0.620 . These were consistent with molecular weights of $154 \mathrm{kDa}$ and $122 \mathrm{kDa}$, and both masses were consistent with the formation of a dimer.

\section{preQ $_{0}$-tRNA ${ }^{\text {Ser }}$ substrate preparation}

Continuous PAGE was used to purify the tRNA ${ }^{\text {Ser }}$ transcript (Figure 20) which was composed of mainly two bands. The purified larger band was used for the subsequent preQ $_{0}$ incorporation reaction catalyzed by $M j \mathrm{TGT}$. The lower band was assumed to be the $\mathrm{n}-1$ transcript product. The final product was pure as judged by PAGE (Figure 20). In order to determine the amount of tRNA ${ }^{\text {Ser }}$ that contained preQ $_{0}, M_{j}$ TGT was initially used to incorporate $\left[8-{ }^{14} \mathrm{C}\right]$ guanine into tRNA ${ }^{\text {Ser }}$. The $\left[8-{ }^{14} \mathrm{C}\right]$ guanine previously incorporated in $\mathrm{tRNA}^{\mathrm{Ser}}$ was then replaced by $\mathrm{preQ}_{0}$ in reaction catalyzed by $M_{j} \mathrm{TGT}$, and essentially no radioactivity was detected after the preQ $_{0}$ incorporation giving greater than $95 \%$ preQ $_{0}-\mathrm{tRNA}^{\mathrm{Ser}}$. 


\section{Glutaminase assays}

The transformation of preQ $_{0}$ to archaeosine suggested that the reaction could be catalyzed by an amidotransferase. Glutaminase activity was determined in the presence and absence of ATP and preQ $_{0}-\mathrm{tRNA}^{\mathrm{Ser}}$. To probe for potential glutaminase activity that is a characteristic trait of most amidotransferase enzymes, a coupled assay of MjTgtA2 with glutamate dehydrogenase was used, and the reaction was followed by monitoring NADPH production at $340 \mathrm{~nm}$ (Figure 21). [U- $\left.{ }^{14} \mathrm{C}\right]$-L-glutamate formation was also monitored directly by using $\left[\mathrm{U}_{-}{ }^{14} \mathrm{C}\right]-\mathrm{L}-$ glutamine. Glutamate formation in the MjTgtA2 assays, as deduced from glutamate dehydrogenase activity or from the direct production of $\left[\mathrm{U}-{ }^{14} \mathrm{C}\right]-\mathrm{L}-$ glutamate, was dependent on $\mathrm{Mj}$ TgtA2 (Figure 21 and 22) and did not require ATP. Glutaminase activity was also determined in the presence of buffers other than phosphate including, citrate, succinate, acetate, and HEPES. Glutaminase activity was observed over a broad $\mathrm{pH}$ range $(4.0-8.0)$ as shown in Figure 24, but was greatest in HEPES buffer at pH 7.0 (Figure 25). Optimal glutaminase activity occurred at $\sim 40{ }^{\circ} \mathrm{C}$ and dropped off significantly above $45{ }^{\circ} \mathrm{C}$ (Figure 23). Based on radiochemical assays for glutaminase activity, specific activities of $7.7,11.4$, and $16.3 \mu \mathrm{M} / \mathrm{min} / \mathrm{mg}$ were calculated for the self-cleaved protein, the full fusion protein, and the C-terminal tagged protein, respectively.

\section{In vitro amidotransferase activity of $M j \operatorname{TgtA2}$}

To determine if the glutaminase activity of MjTgtA2 was associated with an amidotransferase activity and the formation of archaeosine, the ability of $M j \operatorname{TgtA} 2$ to 
catalyze archaeosine formation under various conditions was investigated. LC analysis of the tRNA hydrolysates obtained from $M j \mathrm{TgtA} 2$ reactions carried out in the presence or absence of ATP revealed a new peak with a retention time 17.9 min and a chromophore (Figure 27A and 27C) that were distinct from that of preQ $_{0}(17.1 \mathrm{~min}$, Figure $27 \mathrm{~A}$ and B), but consistent with that of archaeosine (20). Subsequent LC-MS analysis of the MjTgtA2-catalyzed reaction tRNA hydrolysates provided a parent ion $\left(\mathrm{MH}^{+} 325.1 \mathrm{~m} / \mathrm{z}\right)$ shown in Figure 28A consistent with archaeosine, as well as a significant daughter ion $\left(\mathrm{BH}_{2}{ }^{+} 193 \mathrm{~m} / \mathrm{z}\right)$ consistent with the archaeosine nucleobase. Archaeosine formation was also observed when asparagine and $\mathrm{NH}_{4} \mathrm{Cl}$ were used in place of glutamine. Using $\left[{ }^{3} \mathrm{H}\right]$ asparagine, a specific activity of $3.23 \mu \mathrm{M} / \mathrm{min} / \mathrm{mg}$ was calculated for asparaginase activity with the fusion form of the enzyme in the absence of preQ ${ }_{0}$-tRNA (Figure 26). Formation of $\mathrm{G}^{+}$was also determined at various $\mathrm{pH}$ values; however unlike glutaminase activity that was found to occur at acidic $\mathrm{pH}$ values, $\mathrm{G}^{+}$formation was only observed at pH 7 and above (Table 2). 


\subsection{NADPH 7-cyano-7-deazaguanine oxidoreductase}

\section{Expression and purification of QueF proteins}

Wild type QueF, C55A and E78A mutants were all expressed as fusion proteins from pET30Xa-ykvm, pET30Xa-ykvm-E78A and pET30Xa-ykvm-C55A in E. coli BL21(DE3) and purified by $\mathrm{Ni}^{2+}$-NTA agarose chromatography. The SDS-PAGE gel showing QueF purification is shown in Figure 29. The proteins were all cleaved using Factor $\mathrm{Xa}$ and the native proteins were obtained. The cleaved fusion protein was removed by a second round of purification on $\mathrm{Ni}^{2+}$-NTA agarose, where the cleaved tag remained bound to the resin and the native protein was eluted in the absence of imidazole. The QueF proteins were obtained to over 95\% homogeneity as shown in Figure 30 .

\section{Metal analysis}

The effect of divalent metals on the activity of QueF was investigated. In order to circumvent any potential time dependence on metal binding, the protein was preincubated with the metal for at least 5 minutes before the reaction was initiated by the addition of preQ $_{0}$. The activity of the native proteins was determined in the presence of $\mathrm{Mn}^{2+}, \mathrm{Cu}^{2+}$, $\mathrm{Ca}^{2+}, \mathrm{Zn}^{2+}$ and $\mathrm{Mg}^{2+}$ against a control of native QueF with EDTA (Figure 31). The protein activity was observed to increase in the presence of divalent metals, however the presence of EDTA was observed to result in a decrease in activity (Figure 31). At 
concentrations $>1 \mathrm{mM}$ for the $\mathrm{Mn}^{2+}$ and $\mathrm{Ca}^{2+}$ an inhibitory effect was observed, however this was not observed in the presence of $\mathrm{Mg}^{2+}$. Increased protein activity was only observed at low concentrations for $\mathrm{Zn}^{2+}$ and $\mathrm{Cu}^{2+}(10 \mu \mathrm{M})$, however at concentrations $>10 \mu \mathrm{M}$ reduced activity was observed. Only $\mathrm{Ca}^{2+}, \mathrm{Mg}^{2+}$ and $\mathrm{Mn}^{2+}$ were used to further determine their effect of QueF activity (Figure 32), all three metals were found to increase the activity of the apparent apoprotein.

The effect of $\mathrm{KCl}$ on the activity of both the native and apparent apoprotein was investigated, in the absence and presence of $\mathrm{MnCl}_{2}$. The activities of both the native and apparent apoprotein were diminished in the presence of $100 \mathrm{mM} \mathrm{KCl}$. However in the presence of $\mathrm{MnCl}_{2}$, the activity of native QueF was found to be the same at both $50 \mathrm{mM}$ and $10 \mathrm{mM} \mathrm{KCl}$, while the activity of the apoprotein was found to be greatest in the presence of $\mathrm{MnCl}_{2}$ at $50 \mathrm{mM} \mathrm{KCl}$. The effect of $\mathrm{KCl}$ is shown in Figure 33.

\section{pH optima determination}

The effect of $\mathrm{pH}$ on the activity of QueF was determined in MES ( $\mathrm{pH} 5.5$ - 6.67), Tris$\mathrm{HCl}(\mathrm{pH} 6.8-7.9)$, and potassium phosphate buffer ( $\mathrm{pH}$ of $5.8-8.0)$. The optimal $\mathrm{pH}$ for QueF activity was determined to be 6.5. All subsequent analyses were determined in the presence of potassium phosphate $\mathrm{pH} 6.5$ at $30{ }^{\circ} \mathrm{C}$. The $\mathrm{pH}$ profiles are shown in Figure 34. 


\section{Size exclusion chromatography of QueF}

The role of $\mathrm{KCl}$, divalent metals, and the substrate $\mathrm{preQ}_{0}$ in the oligomeric structure of QueF was evaluated by analytical size exclusion chromatography using a BioSep-Sec4000 column (Phenomenex) with a mobile phase of $25 \mathrm{mM}$ phosphate (pH 7.2), $25 \mathrm{mM}$ $\mathrm{KCl}$, at $1 \mathrm{ml} / \mathrm{min}$. In experiments with $\operatorname{preQ}_{0}$ the enzyme and substrate were incubated together for at least 10 minutes before the sample was injected for analysis, with the $\mathrm{pre}_{0}$ concentration present at two times the concentration of QueF.

The elution behavior of QueF in the absence of preQ $_{0}$ and in the presence of a low salt concentration $(25 \mathrm{mM} \mathrm{KCl})$ exhibited a broad, asymmetric peak with a retention time of 8.57 minutes (Figure 35A), corresponding to a MW of $200.7 \mathrm{kDa}$. The retention time of QueF in the presence of $\mathrm{preQ}_{0}$ (i.e QueF-*PreQ ${ }_{0}$ ) shifted to 8.33 minutes (Figure 36A), and while still exhibiting asymmetry the peak was sharper and narrower than in the absence of $\mathrm{preQ}_{0}$. A smaller poorly defined peak was also observed to at an elution time of 10.4 minutes, corresponding to a MW of $15.8 \mathrm{kDa}$ close to the subunit MW of QueF (19.4 kDa). Analysis of the absorption spectra for both peaks revealed the presence of a distinct absorption at $376 \mathrm{~nm}$ (Figure $36 \mathrm{~B}$ and C) previously ascribed to the putative thioimide intermediate.

The effect of $\mathrm{KCl}$ on the quaternary structure of QueF was investigated by observing the elution behavior of the enzyme under different salt concentrations. The QueF protein sample was initially incubated for 3 hours in the presence of $0.5 \mathrm{M} \mathrm{KCl}$ and $10 \mathrm{mM}$ 
EDTA before analysis of the sample. At $0.5 \mathrm{M} \mathrm{KCl}$ the retention time of the apparent multimeric state of the protein eluted later ( 8.78 minutes, Figure 35B) compared to 8.57 minutes (Figure 35A) observed in the absence of salt. Additionally a peak consistent with a monomer was observed to elute with a retention time of 10.4 minutes (Figure 35B). The presence of an excess of either of the divalent metals $\mathrm{Mg}^{2+}$ or $\mathrm{Mn}^{2+}$ appeared to have no effect on quaternary structure as the retention times (data not shown) of QueF in the presence of the these ions were identical to that of QueF alone.

\section{QueF Crystal structure}

Crystal structures of QueF were determined in collaboration with Dr. Manal A. Swairjo (Western University of Medicine). Crystal structures of QueF at $2.5 \AA$ and $2.25 \AA$ resolution where solved for the covalent binary complex of QueF with preQ $\mathrm{Q}_{0}$ trapped in the thioimide intermediate state, and of a non-covalent ternary complex with $\mathrm{preQ}_{0}$ and a cofactor surrogate, respectively. The overall enzyme structure in both reveals an asymmetric tunnel-fold homodecamer of two head-to-head facing pentameric subunits possessing the characteristic architecture of unimodular pterin and purine binding enzymes (Figure 37). Each of the ten active sites in the QueF homodecamer lie at the interface between three subunits, two from one beta barrel and one from the opposite beta barrel. The active site is comprised of the substrate and cofactor binding pockets. The pre $_{0}$ binding pocket is defined by a cleft between the two subunits from the same beta barrel. PreQ $\mathrm{Q}_{0}$ forms hydrogen bonds via its $\mathrm{N} 1$ and N2 atoms with the invariant Glu97 
side chain, and via its N9 atom with the side chain of Glu79 (the first residue in the conserved QueF motif). The substrate binding pocket is also lined with hydrophobic residues that make Van der Waals interactions with pre $Q_{0}$. $\mathrm{PreQ}_{0}$ is bound in eight of ten active sites, and forms a thioimide covalent linkage with the conserved catalytic residue Cys55, consistent with previous biochemical evidence. The pentameric substructure of QueF is shown in Figure 38; the subunit without the thioimide is present in a different conformation when compared to the subunits with thioimide. Figure 39 shows the first structural evidence of the thioimide formed in the QueF active site. The crystal structure of the QueF-PreQ $Q_{0}$ thioimide intermediate complex clearly shows that the Cys55 sulfur atom forms a $1.87 \AA$ covalent bond with the preQ $_{0}$ nitrile carbon atom. The conformational changes seen in the active site upon thioimide formation are rotations in the side chains of Cys55 and Asp62.

Glucosamine originating from dextran sulfate, which was included as an additive in the crystallization buffer, is observed in the adjacent active site to the pre $\mathrm{Q}_{0}$ binding site (Figure 40). This ligand apparently acts a as surrogate of the enzyme cofactor NADPH and occupy the putative NADPH site predicted previously using modeling tools. The cofactor pocket is at the interface between three subunits and involves residues from all three. The QueF motifs from two subunits contribute side chains to the cofactor binding site. 


\section{QueF fluorescence assays}

The tryptophan residue has been used extensively in the determination of ligand and protein interactions. Since QueF has a single tryptophan residue at position 119, the fluorescence of QueF in the presence and absence of pre $_{0}$ was measured in order to study QueF and $\mathrm{preQ}_{0}$ interactions. When tryptophan was excited at $295 \mathrm{~nm}$, QueF was found to have an emission maximum at $334 \mathrm{~nm}$ while the emission maximum of quenched QueF-PreQ ${ }_{0}$ complex was observed to shift to $328 \mathrm{~nm}$ (Figure $41 \mathrm{~A}$ ). The optimal emission for NADPH was also determined under the reaction conditions to be at $465 \mathrm{~nm}$ (Figure 41B) when excited at $340 \mathrm{~nm}$.

\section{Transient state kinetics data analysis}

For data analysis with Dynafit, a model for the reaction taking place was put forth for different reactions in order for the program to calculate the rate constants for the various steps in the QueF-catalyzed reaction of reduction preQ $_{0}$ to $\mathrm{preQ}_{1}$.

The fitting function (model equation) for each individual data set is

$S(t)=S_{0}+\sum_{\mathrm{i}=1}^{\mathrm{n}} r_{\mathrm{i}} c_{\mathrm{i}}(t)$

where

$S(t) \quad$ the experimental signal observed at time $t$

$S_{0} \quad$ offset on the signal axis (a property of the instrument) 
$n \quad$ number of unique molecular species participating in the reaction mechanism

$c_{\mathrm{i}}(t) \quad$ the concentration of the $i$ th species at time $t$

$r_{\mathrm{i}} \quad$ the molar response coefficient of the $i$ th species

The molecular species participating in the mechanism are defined for each of the various reactions. The concentrations of these molecular species at time $t$ are computed from their initial concentrations (at time zero, $t=0$ ) by solving an initial-value problem defined by a system of simultaneous first-order Ordinary Differential Equations (ODEs) listed for each of the reactions below.

\section{Fluorescence measurements of preQ $Q_{0}$ binding to QueF C55A}

In order to investigate the binding of $\mathrm{preQ}_{0}$ to $\mathrm{QueF}$ in the absence of thioimide formation the kinetics of preQ $_{0}$ binding were first determined with the C55A mutant of QueF, which is incapable of reacting to form the thioimide. Binding was monitored by measuring the change in the intrinsic tryptophan fluorescence under pre-steady state conditions. The proposed model for binding of QueF (C55A) and preQ : $^{\text {: }}$

$$
\text { QueF }+ \text { PreQ }_{0} \underset{k d s}{\stackrel{k a s}{\rightleftharpoons} \text { QueF.PreQ }}
$$

\section{Ordinary Differential Equations}

Where $\mathrm{S}=\mathrm{PreQ}_{0}$ and $\mathrm{E}=\mathrm{QueF}$

$$
\mathrm{d}[\mathrm{E}] / \mathrm{d} t \quad=\quad-k_{\mathrm{as}}[\mathrm{E}][\mathrm{S}]+k_{\mathrm{ds}}[\mathrm{ES}]
$$




$$
\begin{array}{lll}
\mathrm{d}[\mathrm{S}] / \mathrm{d} t & = & -k_{\mathrm{as}}[\mathrm{E}][\mathrm{S}]+k_{\mathrm{ds}}[\mathrm{ES}] \\
\mathrm{d}[\mathrm{ES}] / \mathrm{d} t & = &
\end{array}
$$

When binding was initially investigated at $30{ }^{\circ} \mathrm{C}$, the normal assay temperature for QueF, the binding was too fast to be measured accurately in the millisecond time regime, so the temperature was lowered to $20{ }^{\circ} \mathrm{C}$. Under these conditions binding was clearly observable and the data were nicely fit with a single exponential, the association constant from global analysis of the data (Figure 42A); was calculated to be $1.06 \pm 0.31 \mu \mathrm{M}^{-1} \mathrm{~s}^{-1}$, with a dissociation constant of $1.35 \pm 0.26 \mathrm{~s}^{-1}$.

\section{Fluorescence measurements of pre $_{0}$ binding to wild type QueF}

In order to investigate $\mathrm{pre}_{0}$ binding and thioimide formation, fluorescence measurements were conducted on wild-type QueF. Previous experiments demonstrated that the thioimide intermediate was stable over several hours (71), and therefore the breakdown of the covalent adduct was assumed to be negligible in evaluating kinetic data under presteady state conditions. The proposed model for $\mathrm{preQ}_{0}$ binding and thioimide formation in wild type QueF thus was the following:

$$
\begin{gathered}
\text { QueF }+ \text { PreQ }_{0} \underset{k d s}{\frac{k a s}{2}} \text { QueF.PreQ }_{0} \\
\text { QueF.PreQ } \\
\stackrel{k r}{\longrightarrow} \text { QueF-*PreQ }{ }_{0}
\end{gathered}
$$




\section{Ordinary Differential Equations}

Where E = QueF, S = PreQ 0 , E-S = QueF-*PreQ $($ QueF with thioimide $)$

$\mathrm{d}[\mathrm{E}] / \mathrm{dt} \quad=-k_{a s}[\mathrm{E}][\mathrm{S}]+k_{d s}[\mathrm{E} . \mathrm{S}]$

$\mathrm{d}[\mathrm{S}] / \mathrm{dt} \quad=-k_{a s}[\mathrm{E}][\mathrm{S}]+k_{d s}[\mathrm{E} . \mathrm{S}]$

$\mathrm{d}[\mathrm{E} . \mathrm{S}] / \mathrm{dt} \quad=+k_{a s}[\mathrm{E}][\mathrm{S}]-k_{d s}[\mathrm{E} . \mathrm{S}]-k_{r}[\mathrm{E} . \mathrm{S}]$

$\mathrm{d}[\mathrm{E}-\mathrm{S}] / \mathrm{dt} \quad=+k_{r}[\mathrm{E} . \mathrm{S}]$

Experiments were again carried out at $20{ }^{\circ} \mathrm{C}$, but in this case the data was biphasic and was only adequately fit by a double exponential. The association constant from global analysis of the data was calculated to be $1.32 \pm 0.26 \mu \mathrm{M}^{-1} \mathrm{~s}^{-1}$, identical within experimental error to the value calculated with the C55A mutant, while the dissociation constant was found to be $7.95 \pm 1.52 \mathrm{~s}^{-1}$, roughly 8 -fold larger than in the mutant. The rate of thioimide formation was found to be $1.30 \pm 0.05 \mathrm{~s}^{-1}$.

\section{Absorbance measurements of thioimide formation in QueF under pre-steady state conditions}

The kinetics of thioimide formation were also investigated by directly observing the appearance of the thioimide absorbance band at $370 \mathrm{~nm}$. When the data were fit to a twostep mechanism comprising pre $_{0}$ binding followed by thioimide formation, identical to that utilized in the fluorescence experience, the residuals were clearly non-random (Figure 44C). In this case the data was better fit by a mechanism incorporating another step prior to the formation of the thioimide, such as an isomerization step or a shift in the 
equilibrium of a heterogeneous population of QueF to give the reactive form of the protein upon mixing with the $\mathrm{preQ}_{0}$. The proposed model for reaction of QueF with $\mathrm{preQ}_{0}$ is shown below:

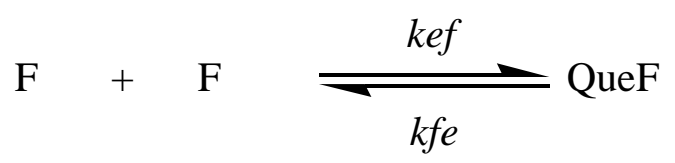

$$
\begin{aligned}
& \mathrm{QueF}+\mathrm{PreQ}_{0} \underset{k d s}{\stackrel{k a s}{\rightleftharpoons} \text { QueF.PreQ }}
\end{aligned}
$$

$$
\text { QueF.PreQ }{ }_{0} \stackrel{k r}{\longrightarrow} \text { QueF-*PreQ }
$$

\section{Ordinary Differential Equations}

Where $\mathrm{F}=$ pentamer, $\mathrm{E}=\mathrm{QueF}=$ decamer

$$
\begin{array}{ll}
\mathrm{d}[\mathrm{F}] / \mathrm{d} t & =-k_{\mathrm{ef}}[\mathrm{F}][\mathrm{F}]-k_{\mathrm{ef}}[\mathrm{F}][\mathrm{F}]+k_{\mathrm{fe}}[\mathrm{E}]+k_{\mathrm{fe}}[\mathrm{E}] \\
\mathrm{d}[\mathrm{E}] / \mathrm{d} t & =+k_{\mathrm{ef}}[\mathrm{F}][\mathrm{F}]-k_{\mathrm{fe}}[\mathrm{E}]-k_{\mathrm{as}}[\mathrm{E}][\mathrm{S}]+k_{\mathrm{ds}}[\mathrm{ES}] \\
\mathrm{d}[\mathrm{S}] / \mathrm{d} t & =-k_{\mathrm{as}}[\mathrm{E}][\mathrm{S}]+k_{\mathrm{ds}}[\mathrm{ES}] \\
\mathrm{d}[\mathrm{ES}] / \mathrm{d} t & =+k_{\mathrm{as}}[\mathrm{E}][\mathrm{S}]-k_{\mathrm{ds}}[\mathrm{ES}]-k_{\mathrm{r}}[\mathrm{ES}] \\
\mathrm{d}[\mathrm{E}-\mathrm{P}] / \mathrm{d} t & =+k_{\mathrm{r}}[\mathrm{ES}]
\end{array}
$$

Using this model global analysis of the data (Figure 44A and B) provided a rate for thioimide formation of $2.55 \pm 0.014 \mathrm{~s}^{-1}$ at $30^{\circ} \mathrm{C}$, in close agreement to the value calculated above from the fluorescence experiments carried out at $20^{\circ} \mathrm{C}$. 
Fluorescence measurements of NADPH binding to the E78A mutant QueF-*PreQ under transient state kinetics

Proposed model for NADPH binding to E78A QueF-*PreQ 0 :

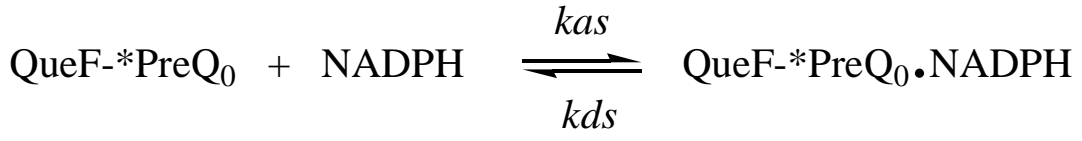

$$
\begin{aligned}
& \text { QueF-*PreQ } 0 \text { NADPH } \underset{k_{-1}}{\stackrel{k_{1}}{\rightleftharpoons}} \quad \mathrm{F}-* \operatorname{PreQ}_{0} \cdot \mathrm{NADPH}
\end{aligned}
$$

\section{Ordinary Differential Equations}

where E-S = QueF-*PreQ ${ }_{0}$, and F-*PreQ ${ }_{0}$ is a different state of the protein possibly after isomerization

$$
\begin{aligned}
\mathrm{d}[\mathrm{E}-\mathrm{S}] / \mathrm{d} t= & -k_{\mathrm{as}}[\mathrm{E}-\mathrm{S}][\mathrm{NADPH}]+k_{\mathrm{ds}}[\mathrm{E}-\mathrm{S} . \mathrm{NADPH}] \\
\mathrm{d}[\mathrm{NADPH}] / \mathrm{d} t= & -k_{\mathrm{as}}[\mathrm{E}-\mathrm{S}][\mathrm{NADPH}]+k_{\mathrm{ds}}[\mathrm{E}-\mathrm{S} . \mathrm{NADPH}] \\
\mathrm{d}[\mathrm{E}-\mathrm{S} . \mathrm{NADPH}] / \mathrm{d} t= & +k_{\mathrm{as}}[\mathrm{E}-\mathrm{S}][\mathrm{NADPH}]-k_{\mathrm{ds}}[\mathrm{E}-\mathrm{S} . \mathrm{NADPH}] \\
& -k_{1}[\mathrm{E}-\mathrm{S} . \mathrm{NADPH}]+k_{-1}[\mathrm{FS} . \mathrm{NADPH}] \\
\mathrm{d}[\mathrm{FS} . \mathrm{NADPH}] / \mathrm{d} t= & +k_{1}[\mathrm{E}-\mathrm{S} . \mathrm{NADPH}]-k_{-1}[\mathrm{FS} . \mathrm{NADPH}]
\end{aligned}
$$

The association constant from the Dynafit and KaleidaGraph analysis was found to be 0.2 $\pm 0.01 \mu \mathrm{M}^{-1} \mathrm{~s}^{-1}$ and the dissociation constant was found to be $0.24 \pm 0.06 \mathrm{~s}^{-1}$, the isomerization constants of the protein after binding of NADPH were calculated to be $k_{l}=$ $1.18 \pm 0.04 \mathrm{~s}^{-1}$ and $k_{-1}=0.12 \pm 0.02 \mathrm{~s}^{-1}$ at $20{ }^{\circ} \mathrm{C}$. The global analysis (Figure $45 \mathrm{C}$ ) and an example of residuals for the fit are shown in Figure 45 D, while the biphasic nature of the data is clearly shown by the Kaleidagraph fits for single and double exponential decay in Figure $45 \mathrm{~A}$ and $\mathrm{B}$. 
Fluorescence measurements of NADPH binding and thioimide reduction under single turnover conditions

The proposed model for NADPH binding and thioimide reduction in wild type QueF*Pre $\mathrm{Q}_{0}$ under single turnover conditions is shown below. NADPH fluorescence was monitored.

$$
\begin{aligned}
& \text { QueF-*PreQ }_{0}+\mathrm{NADPH} \underset{k d s}{\stackrel{k a s}{\rightleftharpoons}} \text { QueF-*PreQ }_{0} \cdot \mathrm{NADPH} \\
& \text { QueF-*PreQ } 0 \text {-NADPH } \stackrel{k r}{\longrightarrow} \text { QueF=*PreQ }{ }_{0} \cdot \mathrm{NADP}^{+}
\end{aligned}
$$

\section{Ordinary Differential Equations}

$\mathrm{d}[\mathrm{E}-\mathrm{S}] / \mathrm{d} t=-k_{\mathrm{as}}[\mathrm{E}-\mathrm{S}][\mathrm{NADPH}]+k_{\mathrm{ds}}[\mathrm{E}-\mathrm{S} . \mathrm{NADPH}]$

$\mathrm{d}[\mathrm{NADPH}] / \mathrm{d} t=-k_{\mathrm{as}}[\mathrm{E}-\mathrm{S}][\mathrm{NADPH}]+k_{\mathrm{ds}}[\mathrm{E}-\mathrm{S} . \mathrm{NADPH}]$

$\mathrm{d}[\mathrm{E}-\mathrm{S} . \mathrm{NADPH}] / \mathrm{d} t=+k_{\mathrm{as}}[\mathrm{E}-\mathrm{S}][\mathrm{NADPH}]-k_{\mathrm{ds}}[\mathrm{E}-\mathrm{S} . \mathrm{NADPH}]-k_{\mathrm{r}}[\mathrm{E}-\mathrm{S} . \mathrm{NADPH}]$

$\mathrm{d}\left[\mathrm{E}=\mathrm{S} . \mathrm{NADP}{ }^{+}\right] / \mathrm{d} t=+k_{\mathrm{r}}[\mathrm{E}-\mathrm{S} . \mathrm{NADPH}]$

The association constant $\left(\mathrm{k}_{\mathrm{as}}\right)$ from the Dynafit and KaleidaGraph analysis was found to be $0.06 \pm 0.0007 \mu \mathrm{M} \mathrm{s}^{-1}$ and the dissociation constant $\left(\mathrm{k}_{\mathrm{ds}}\right)$ was found to be $0.2 \pm 0.03 \mathrm{~s}^{-1}$ while the rate of reduction $\left(\mathrm{k}_{\mathrm{r}}\right)$ was calculated to be $0.12 \pm 0.01 \mathrm{~s}^{-1}$ at $20{ }^{\circ} \mathrm{C}$. The global analysis and an example of residuals for the fit are shown in Figure 46A and B. 


\section{Absorbance measurements of thioimide reduction monitored at $390 \mathbf{~ n m}$}

Thioimide reduction was also determined directly by monitoring the thioimide absorbance. In order to avoid the overlap in the NADPH and thioimide absorptions (Figure 47), the reaction was monitored at $390 \mathrm{~nm}$. The proposed model for NADPH binding and thioimide reduction in wild type QueF-*PreQ $Q_{0}$ under single turnover conditions is shown below.

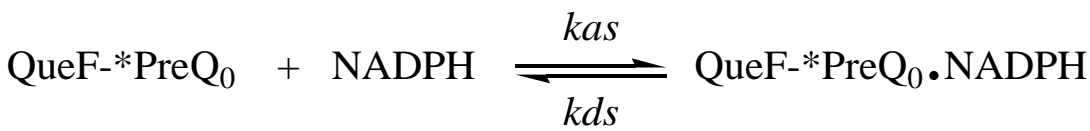

$$
\begin{aligned}
& \text { QueF-*PreQ } Q_{0} \text { NADPH } \stackrel{k r}{\longrightarrow} \text { QueF=*PreQ } \bullet \text { NADP }{ }^{+}
\end{aligned}
$$

\section{Ordinary Differential Equations}

$$
\begin{array}{ll}
\mathrm{d}[\mathrm{E}-\mathrm{S}] / \mathrm{d} t & =-k_{a s}[\mathrm{E}-\mathrm{S}][\mathrm{NADPH}]+k_{d s}[\mathrm{E}-\mathrm{S} . \mathrm{NADPH}] \\
\mathrm{d}[\mathrm{NADPH}] / \mathrm{d} t & =-k_{a s}[\mathrm{E}-\mathrm{S}][\mathrm{NADPH}]+k_{d s}[\mathrm{E}-\mathrm{S} . \mathrm{NADPH}] \\
\mathrm{d}[\mathrm{E}-\mathrm{S} . \mathrm{NADPH}] / \mathrm{d} t & =+k_{a s}[\mathrm{E}-\mathrm{S}][\mathrm{NADPH}]-k_{d s}[\mathrm{E}-\mathrm{S} . \mathrm{NADPH}]-k_{r}[\mathrm{E}-\mathrm{S} . \mathrm{NADPH}] \\
\mathrm{d}[\mathrm{E}-\mathrm{S} . * \mathrm{NADP}] / \mathrm{d} t & =+k_{r}[\mathrm{E}-\mathrm{S} . \mathrm{NADPH}]
\end{array}
$$

The kas $\left(0.06 \mu \mathrm{M} \mathrm{s}^{-1}\right)$ and $k d s\left(0.2 \mathrm{~s}^{-1}\right)$ used in this analysis were determined in the experiment monitoring NADPH fluorescence. The rate of reduction $\left(\mathrm{k}_{\mathrm{r}}\right)$ was calculated to be $0.24 \pm 0.0007 \mathrm{~s}^{-1}$ at $30{ }^{\circ} \mathrm{C}$ the global analysis and an example of residuals for the fit are shown in Figure 48. 


\section{Absorbance measurements of thioimide decomposition}

Thioimide decomposition was monitored at $370 \mathrm{~nm}$ and data was collected on the Carey 100 spectrophotometer. The proposed mechanism is shown below;

$$
\text { QueF-*PreQ }{ }_{0} \stackrel{k r}{\longrightarrow} \mathrm{QueF}+\mathrm{PreQ}_{0}
$$

\section{Ordinary Differential Equations}

Where $\mathrm{A}=\mathrm{QueF}^{*}$ PreQ $_{0}, \mathrm{E}=\mathrm{QueF}$ and $\mathrm{S}=\mathrm{PreQ}_{0}$

\begin{tabular}{|c|c|c|}
\hline $\mathrm{d}[\mathrm{A}] / \mathrm{d} t$ & $=$ & $-k_{\mathrm{r}}[\mathrm{A}]$ \\
\hline $\mathrm{d}[\mathrm{E}] / \mathrm{d} t$ & $=$ & $+k_{\mathrm{r}}[\mathrm{A}]$ \\
\hline $\mathrm{d}[\mathrm{S}] / \mathrm{d} t$ & $=$ & $+k_{\mathrm{r}}[\mathrm{A}]$ \\
\hline
\end{tabular}

The rate of thioimide decomposition $\left(\mathrm{k}_{\mathrm{r}}\right)$ was calculated to be $4.81 \pm 0.02 \mathrm{E}-6 \mathrm{~s}^{-1}$ at $30{ }^{\circ} \mathrm{C}$ the fitted data is shown in Figure 49. 


\subsection{S-Adenosylribosylmethionine:tRNA ribosyl transferase isomerase}

\section{Stereospecific abstraction of the C5' proton by QueA}

To investigate if the proton abstraction by QueA was stereospecific, stereospecifically labeled deuterium AdoMet was used. PreQ ${ }_{1}$-tRNA that had been converted to oQ-tRNA was digested as previously described (63). The proton NMR of the AdoMet used in the determination of stereospecific abstraction of the C5' proton by QueA is shown in Figure 53. The proR proton is at the chemical shift of $\delta 4.05$ in the unlabeled AdoMet while the proS proton is at the chemical shift of $\delta 3.919$.

Chromatograms showing the products of these digestions are shown in Figure 51, preQ ${ }_{1}$ had a retention time of 17 minutes while oQ had a retention time of 22.5 minutes. The oQ was collected from HPLC purification, oQ samples generated from 5'S-[5-D]AdoMet, 5' R-[5-D]-AdoMet, and unlabeled AdoMet were all lyophilized and analyzed by mass spectrometry. The results of these analyses are shown in Figure 52. The data obtained indicate that QueA removes the 5'S proton of AdoMet. 


\section{DISCUSSION}

\subsection{Archaeosine synthase}

Archaeosine is a modified nucleoside that has been found in most archaeal tRNAs analyzed to date. However, until recently its biosynthesis was poorly characterized. Early biosynthesis studies on queuosine and structurally related metabolites led to the proposal that GTP was a metabolic precursor to archaeosine (37). Even though TGT, the enzyme that catalyzes the insertion of pre $_{0}$ into tRNA was identified and characterized a decade ago $(55,72)$, candidate(s) for the transformation of $\mathrm{preQ}_{0}$-tRNA to archaeosinetRNA were yet to be identified and characterized. The goal of this work was to test the hypothesis that the TgtA2 enzyme catalyzes the formation of archaeosine from $\mathrm{preQ}_{0}$ in tRNA.

Comparative genomic analysis and in vivo studies were conducted to determine the participation of M. jannaschii TgtA2 (MjTgtA2) in archaeosine biosynthesis. H. volcanii was chosen to investigate the in vivo function of $\operatorname{tgtA2}$. A $\triangle \operatorname{tgtA2}$ mutant was constructed in $H$. volcanii and LC-MS analysis on the tRNA hydrolysates indicated that no archaeosine was present in the mutant strain, suggesting that the $\operatorname{tgt} A 2$ gene encoded a protein involved in the biosynthesis of archaeosine. To test this hypothesis, the tgtA2 gene from M. jannaschii was cloned and the encoded protein, $M j \operatorname{TgtA} 2$, was expressed and purified. 
The expression and purification of $M j \mathrm{TgtA} 2$ proved to be challenging as initial attempts to express from its native gene resulted in low levels of expression as well as truncated protein. A codon-optimized gene was constructed in order to improve expression; however truncated protein was still obtained. Slowing down transcription by lowering expression temperature as well as lowering the final IPTG concentration did not improve the protein expression. $M j$ TgtA2 was cloned in several vectors in order to improve both formation of full length protein as well as formation of soluble functional protein, but only the expression of soluble protein was improved. In order to determine if the protein was being truncated due to the activity of proteases from E. coli, a protease inhibitor cocktail as well as EDTA were added during protein purification, but truncated protein was still obtained. Expression of $M j \mathrm{TgtA} 2$ as a C-terminally tagged protein resulted in purification of full length protein. This suggested that the truncated protein obtained during the purification was not due to protease activity from endogenous $E$. coli proteins but most likely due to a characteristic of $M j \mathrm{TgtA} 2$. If the proteolysis observed was due to E. coli proteases the C-terminally tagged protein would have shown the same degree of cleavage observed in the N-terminally tagged protein. Due to observed loss in activity of $M j$ TgtA2 when stored at low temperatures $\left(\mathrm{e} . \mathrm{g}-20{ }^{\circ} \mathrm{C}\right.$ ), the protein was stored at $4{ }^{\circ} \mathrm{C}$. However, SDS-PAGE analysis of the C-terminal $\mathrm{His}_{6}-M j \mathrm{TgtA} 2$ indicated the presence of a lower protein band that was absent when the protein was initially purified (Figure 18). SDS-PAGE analysis of the Trx-His 6 - MjTgtA2 also revealed that after incubation of the protein for several weeks at $4{ }^{\circ} \mathrm{C}$ all the protein was truncated to fragments of lower molecular weight (Figure 18). 
Together, these results suggested that the protein was undergoing self cleavage. Edman degradation was used to determine the N-terminal sequences of the bands. The sequencing results indicated that proteolysis occurred in two regions in the protein, but did not appear to be highly specific. Close analysis of the data obtained after sequencing did not reveal any particular sequence characteristics that might be required for self cleavage to take place. It was interesting to note that the self cleavage in the protein appeared to occur quite readily during the purification in all the N-terminally tagged proteins, but when the recombinant protein was left to incubate at $4{ }^{\circ} \mathrm{C}$ the cleavage of the protein was very slow. In order to determine if the choice of purification resin $\left(\mathrm{Ni}^{2+}-\right.$ NTA agarose) was somehow catalyzing the cleavage reaction, the Trx-His ${ }_{6}-M j \operatorname{TgtA} 2$ was incubated with several divalent metals (data not shown) and the proteins were monitored for several weeks. However, no apparent increase in cleavage of the protein was noted when the samples incubated with divalent metals were compared to the sample with no additional divalent metal, suggesting that the $\mathrm{Ni}^{2+}$ or divalent metals did not influence the rate of cleavage. The significance of self cleavage that was observed in the heterologously expressed protein remains unclear. It was also not clear whether self cleavage would occur when the protein is expressed in its native environment.

Analytical gel filtration analysis of full length and purified self cleaved protein revealed that $M j$ TgtA2 formed dimers in solution. Interestingly TGT has also been observed to form dimers (73). 
Analysis of the possible chemistry in the transformation of a nitrile group to a formamidine group in tRNA resulted in a proposal of two possible routes (Figure 54). The first involved nitrile hydratase activity, to yield 7-amido-7-deazaguanosine, which could then be converted to archaeosine in a canonical amidotransferase catalyzed reaction. This route had precedence in a known nitrile hydratase from Streptomyces that hydrolyzes the nitrile of the structurally similar toyocamycin (7-cyano-7-deazaadenosine) to the amide sangivamycin $(74,75)$ and many well characterized amidotransferases. Alternatively, the formal addition of ammonia to the nitrile of $\mathrm{preQ}_{0}$ can generate archaeosine directly, representing a unique class of amidotransferase chemistry as well as the only example of the conversion of a nitrile to a formamidine known in biology.

Given the precedence of glutamine as the ammonia donor in amidotransferase reactions the activity was initially monitored in a coupled reaction to glutamine dehydrogenase in order to determine if any glutamate was being formed by observing the formation of NADPH. NADPH formation was observed, providing the first evidence that $M j$ TgtA2 was capable of glutaminase activity. Glutamate formation was also observed when [U$\left.{ }^{14} \mathrm{C}\right]$-L-glutamine was used and the assays were monitored by TLC. The temperature dependence of glutaminase activity was investigated, and activity was observed to drop significantly at temperatures above $40^{\circ} \mathrm{C}$, which was surprising given that this protein is from a thermophile whose optimal growth temperature is approximately $85{ }^{\circ} \mathrm{C}(76)$. Enzymes from thermophiles typically exhibit low activity at ambient temperatures where the mesophilic enzymes exhibiting similar function are optimally active (77). 
Additionally MjTGT, which catalyzes the preceding reaction, had already been shown to exhibit maximal activity at $80{ }^{\circ} \mathrm{C}(72)$. The thermal stability of the protein was investigated by heating the protein for 15 minutes at different temperatures from $50{ }^{\circ} \mathrm{C}$ to $80{ }^{\circ} \mathrm{C}$. Over $80 \%$ of the protein was found to stay in solution even when heated at $80{ }^{\circ} \mathrm{C}$ suggesting that the loss in activity at higher temperatures was not due to the protein precipitating out of solution at high temperatures. Given the comparable glutaminase activity observed in the presence and absence of tRNA, it is likely that the assay conditions are not optimal, and this might explain the temperature sensitivity of the enzyme activity.

Notably, MjTgtA2 was observed to utilize asparagine as well as glutamine as an ammonia donor, with glutaminase activity being $\sim 4$ fold higher than asparaginase activity.

The glutaminase activity was determined in different buffers and varying pHs and it was observed that optimal glutaminase activity was found to occur in HEPES buffer (pH 7.0), but archaeosine formation was only found to occur at pH's greater than 7. Archaeosine was also formed when either asparagine or $\mathrm{NH}_{3}$ was the substrate, however $\mathrm{NH}_{3}$ dependent activity was optimal at higher $\mathrm{pH}$, similar to what has been observed in other amidotransferases such as E. coli imidazole glycerol phosphate synthase (78). Under basic $\mathrm{pH}$ conditions there is a higher concentration of $\mathrm{NH}_{3}$ from $\mathrm{NH}_{4} \mathrm{Cl}$, which might explain why $\mathrm{G}^{+}$formation was only observed at basic $\mathrm{pH}$. Most glutamine 
amidotransferases have been found to be capable of substituting glutamine with $\mathrm{NH}_{3}(79$, 80). However the formation of $\mathrm{G}^{+}$in the presence of asparagine was surprising as only tRNA-dependent amidotransferases GatCAB and GatDE (81) have been shown to be able to use both glutamine and asparagine as nitrogen donors.

Sequence and structural comparisons of $M j \operatorname{TgtA} 2$ with other amidotransferases exhibited no sequence or structural homology to either the class I, class II or GatCAB/DE enzymes, suggesting that the amidotransferase activity of TgtA2 evolved separately from all other known amidotransferase enzymes. However a search for similar structures to the $\mathrm{C} 1$ domain of $M j$ TgtA2 resulted in multiple hits. An intriguing similarity was found to Pseudomonas glutaminase-asparaginase, which catalyzes the hydrolysis of glutamine/asparagine to glutamate/aspartate. The similarity of MjTgtA2 to the Pseudomonas glutaminase-asparaginase might explain MjTgtA2's ability to use both asparagine and glutamine as nitrogen donors.

The biochemical analysis carried out on MjTgtA2 activity provides the first clear demonstration that the enzyme catalyzing the ultimate step in archaeosine biosynthesis is an amidotransferase that utilizes novel chemistry to achieve the transformation of a cyano group to a formamidine. 


\subsection{QueF}

QueF catalyzes the NADPH-dependent reduction of 7-cyano-7-deazaguanine ( $\left.\mathrm{preQ}_{0}\right)$ to 7-aminomethyl-7-deazaguanine ( $\mathrm{preQ}_{1}$ ), a late step in the queuosine pathway (47). QueF exhibits sequence homology to the type I GTP cyclohydrolases (GTP-CH-I) exemplified by E. coli FolE. The homology between two protein families (Figure 55) resulted in an initial misannotation of QueF activity, however it was also used to predict that the two protein families belong to the same structural family, tunneling-fold structural family ( 47 , 56). The discovery of QueF activity added a novel type of chemistry in the biotransformation of a cyano group to an amine, a common reaction in organic chemistry but which had never been observed in nature. The activity of QueF places it in a class of enzymes traditionally known as $\mathrm{NAD}(\mathrm{P})^{+}$-dependent four-electron-transfer dehydrogenases (82). Interestingly, these enzymes lack sequence homology and also employ distinctly different chemical mechanisms (71), but ultimately result in the 4electron reduction or oxidation of their substrate.

The similarity between B. subtilis QueF and GTP-CH-I in sequence and multimeric quaternary structure resulted in a prediction that the active site of B. subtilis QueF would be in a similar location, i.e. at the intersubunit interface (56). Based on the crystal structure of E. coli GTP-CH-I, a three-dimensional homology model QueF was built with a preQ ${ }_{0}$ molecule was docked in the putative active site (Figure 56). In one monomer, the $\mathrm{preQ}_{0}$ interacts with the two invariant of Glu97 and Cys55, the two interactions are also 
found in the structure of the GTP-CH-I-GTP complex. Mechanistic studies previously carried out in our lab clearly demonstrated that (Cys55) (B. subtilis numbering) was involved in the formation of a covalent thioimide intermediate via reaction with preQ $_{0}$ (71), a mechanism for the reaction catalyzed by QueF was proposed based on the presence of a covalent intermediate (Figure 57). The role of Glu97 was also investigated, a conserved residue in the QueF family (Figure 55). Based on its position in the homology model Glu97 was implicated to play a role in anchoring bound preQ $_{0}$ in the active site, similar to other T-fold proteins. Steady state kinetic analysis of QueF Glu97 mutants showed that the relative specific activity to wild type activity was in the range of $1-6 \%$, suggesting that Glu97 might play the predicted role of positioning preQ $_{0}$ the active site of QueF as in other T-fold proteins (57). Isotope labeling studies with stereospecifically deuterium labeled NADPH were utilized to determine the stereospecificity of the hydride transfer reaction catalyzed by QueF, demonstrating that the hydride transfer was pro- $R$ specific. Steady state kinetic isotope measurements indicated a primary isotope effect $\left(k_{H} / k_{D}\right)$ of 2.59 , suggesting that the chemical step of bond breaking of $\mathrm{C}-\mathrm{H}$ in NADPH, transfer of the hydride and formation of the new $\mathrm{C}-\mathrm{H}$ bond is at least partially rate-determining on the overall $k_{c a t}$ of the reaction.

The goal of this work was the transient state kinetic analysis of substrate binding and catalysis by QueF as well as the investigation of ligand effects on the quaternary structure. Determination of the elementary rate constants allows the identification of the reaction(s) that limit the activity of QueF. Data from steady state kinetic analysis 
provides indirect information to define the pathway; however, because $k_{c a t}$ and $k_{m}$ are complex functions of individual rate constants, the individual reactions steps cannot be resolved under steady state conditions. Transient kinetic methods allow examination of the reaction pathway where the enzyme is examined as a stochioimetric reactant, allowing individual steps in the pathway to be determined by direct measurement. Single turnover experiments, which were utilized in elucidation of some of the rate constants, were performed under conditions in which the concentration of the enzyme is in excess of that of substrate. These conditions ensure that a single enzymatic turnover of the active site can be measured directly without the concern that the substrate binding or product release step is rate limiting.

Our proposed minimal kinetic mechanism for QueF is shown in Figure 9 a Bi-Uni-UniBi-Ter-Ter Ping Pong kinetic mechanism. PreQ $Q_{0}$ binding was determined in the wild type QueF as well as in the C55A mutant by monitoring the changes in the tryptophan fluorescence. Thioimide formation was monitored at $370 \mathrm{~nm}$ under single turnover conditions. For the data analysis we proposed a model based on previously established stability of the thioimide (71), which was found to be still present after several hours after dialysis. This knowledge simplified the kinetics for pre $_{0}$ binding and subsequent thioimide formation, as the thioimide decomposition step was taken to be essentially irreversible on the time scale for pre-steady state kinetics. The binding of $\mathrm{preQ}_{0}$ to $\mathrm{QueF}$ was initially determined and values found from this analysis were constrained in the calculation of thioimide formation rates. 
In order to isolate the step(s) for NADPH binding and catalysis from pre $\mathrm{Q}_{0}$ binding and thioimide formation, a preformed QueF-*PreQ $\mathrm{Q}_{0}$ complex for either the wild type or mutant E78A was used. The first eight proposed rates $\left(k_{1}, k_{-1}, k_{2}, k_{-2}, k_{3}, k_{4}, k_{-4}\right)$ were directly measured in either absorbance or fluorescence based stopped flow experiments. We also attempted to measure the kinetics of $\mathrm{NADP}^{+}$binding to QueF-*PreQ $\mathrm{Q}_{0}$ using fluorescence. Unfortunately the results were difficult to interpret because the quenching of the tryptophan fluorescence in the presence of the thioimide is so large that it obscured any possible changes due to $\mathrm{NADP}^{+}$binding, such that nothing conclusive was obtained from these experiments.

Multiple turnover kinetics were carried out in order to investigate the rate of catalysis for the second hydride transfer. From the multiple turnover analysis, only NADP ${ }^{+}$ dissociation and the second hydride transfer were calculated. The thioimide covalent intermediate was used in the analysis such that the $\mathrm{preQ}_{0}$ binding was excluded from the equations defining the reaction observed. NADPH binding previously determined was held constant and also assumed to be unchanged for two reduction cycles. An enzyme isomerization step was proposed to occur after the binding of the second equivalent of NADPH; values calculated from the E78A proposed isomerization were used in the fitting. In the end only the $\mathrm{NADP}^{+}$dissociation and second reduction were calculated; these steps were proposed to be irreversible under the conditions of the experiment as attempts to determine rates of the reverse reactions resulted in values with very high coefficients of variation making it highly unlikely that the reverse reactions for these two 
steps were significant under the experimental conditions. The results from the kinetic analysis indicate that the binding of $\mathrm{preQ}_{0}$ and NADPH to QueF, as well as thioimide formation, are very rapid; and that reduction of the thioimide is most likely the rate limiting step. Analysis of component rates suggests structural changes occur between these steps, further limiting the overall rate.

The structure of QueF was recently solved providing crystallographic evidence of the formation of the thioimide between Cys55 and preQ $Q_{0}$ Surprisingly, the crystal structure also revealed the presence of $\mathrm{Mg}^{2+}$ ions at the subunit interface between the two pentamers. Previously, activity analysis with divalent metals suggested that they did not have any effect on enzyme activity. However the presence of the $\mathrm{Mg}^{2+}$ in the crystal structure led to further investigation of a possible role of divalent metals in QueF assembly and activity. The activities of the native enzyme and its apparent apoprotein were determined in the presence of divalent metals as well as in the presence of EDTA. The presence of divalent metals was shown to increase QueF activity while addition of EDTA resulted in a decrease of QueF activity. The effect of $\mathrm{KCl}$ was also determined, and concentrations greater than $100 \mathrm{mM}$ were found to inhibit activity as previously shown (71). The effect of divalent metals on the activity of the protein suggested that, as observed in the crystal structure, the presence of a divalent metal is important to maintain the quaternary structure of QueF. Given the positions of the $\mathrm{Mg}^{2+}$ ions it seems unlikely that the divalent metal plays a direct role in catalysis. The QueF "apparent apoprotein" was found to have lower activity than native protein. The activity observed for the 
apparent apoprotein could be due to tightly bound metal that was not removed by the demetallating process; however this was not confirmed. It could also imply that the presence of the metal is not essential for quaternary structure, but that it helps to stabilize the quaternary structure allowing the reaction to take place more readily. The inhibitory effect observed by $\mathrm{KCl}$ at high concentrations might indicate some disruption of the quaternary structure. This is consistent with the observation that this effect is greatly attenuated when the reaction is carried out in the presence of divalent metals.

In order to further investigate the effects of the metals on the QueF structure, analytical size exclusion chromatography was carried out. One of the greatest limitations of size exclusion chromatography is that resolution of the emerging peaks is limited (83). Gel filtration is a relative technique, requiring calibration using molecular weight standards. However, when a heterogeneous system is analyzed it is not always possible to resolve intermediates that are present in the population being analyzed. Size exclusion analysis of a multimeric protein such as QueF is complicated by the increased probability that multimers of the subunits might be present in different multiplicities. Close analysis of Figure 35A reveals an asymmetrical peak, which is characteristic of a heterogeneous population where a sharp leading edge and an extended trailing edge is expected for rapidly equilibrating species (84). A system in rapid equilibrium between two or more states cannot be resolved into the different species present in the population if the rate of exchange of the conformers is much faster than the characteristic time of the chromatography. However, when the transition between the different conformations is 
sufficiently slower than the time of analysis, it is possible to show the presence of more than a single peak in a chromatographic run. The peak for QueF alone was observed to be broad, particularly when compared to the one obtained when QueF was preincubated with $\mathrm{preQ}_{0}$, i.e. QueF with thioimide present. The elution of QueF-*PreQ $\mathrm{Q}_{0}$ earlier than QueF alone suggests that there is either a change in the conformation of the protein when the thioimide is made or that there is a shift in the equilibrium of the QueF population. As gel filtration is a technique that is based on correlation of the measured retention time and Stokes radius of a protein (85), any change in conformation that changes the radius would also affect the retention time. Close analysis of the QueF-*PreQ ${ }_{0}$ (Figure 36A) peak $\left(8.33 \mathrm{~min}\right.$ ) reveals that while it is narrower than in the absence of preQ $_{0}$ it possesses a shoulder, suggesting that though the equilibrium is shifted towards the decamer, there is still a small fraction of the population that exists as a pentamer. Interestingly, a less pronounced peak was also observed eluting at about 10.4 minutes. The retention time and UV spectrum of this peak (Figure 36C) is consistent with the presence of a QueF monomer that has the thioimide present. Given that the monomer was clearly resolved from the multimeric peak it suggests that upon injection a fraction of the population was already present as monomer units. Attempts to collect the decamer QueF-*PreQ $Q_{0}$ peak and reinject it to determine if the monomer was originating from dissociation of the decamer were inconclusive as a broad peak was observed, suggesting a requilibration of the system between the decamer and pentamer states. The monomer subunit observed might also be due to possible equilibrium between monomers and the multimeric complexes, such that even if the monomer is unable to form the thioimide on its own, the 
existing equilibrium between the monomers and multimers result in part of the monomer population having a thioimide present. The two possible pathways for formation of the thioimide found in the monomer cannot be distinguished by gel filtration.

When a QueF sample was exposed to $0.5 \mathrm{M} \mathrm{KCl}$ in the absence either $\mathrm{Mg}^{2+}$ or $\mathrm{Mn}^{2+}$ ions, the protein was found to fall apart readily but a fraction of the population remained intact to give the decamer peak (data not shown). However, when QueF previously equilibrated with $\mathrm{Mg}^{2+}$ was incubated in the presence of $0.5 \mathrm{M} \mathrm{KCl}$ and $10 \mathrm{mM}$ EDTA, it resulted in two distinct peaks, a peak for the multimeric protein, which eluted later than when the analysis was carried out in the presence of low salt, and a peak corresponding to the monomer subunit. The elution of the peak corresponding to the multimeric protein at a later time is an indication that at high $\mathrm{KCl}$ concentrations, the equilibrium is shifted towards the pentameric state of the protein from the decamer. The mass of this peak was calculated to be approximately $150 \mathrm{kDa}$, which is an average of the masses of the pentamer and decamer oligomers. The presence of a clear peak for the monomer unit shows that a significant amount of protein is dissociated and suggests that the equilibrium between the monomer and multimeric forms of the protein is slow, as it is possible to separate the different populations on the time scale of the experiment, which would not be the case if there was a rapid exchange. These results suggest that the QueF population is not uniform and that there is a dynamic equilibrium between different forms of the protein. The binding of small inorganic ions has been shown to cause protein 
dissociation in other systems, such as the dissociation of tryptophanase in the presence of monovalent cations (86).

Two types of associations are found in macromolecules, static and dynamic. Static associations are slow, making it possible to distinguish the different states that constitute the population (87). Dynamic associations occur very rapidly (87) and it is not possible to separate the various components of the population, such that an average is observed, which appears to be what we see in gel filtration analysis of QueF. Analytical ultracentrifugation and the technique of sedimentation equilibrium can be used to determine the native molecular weight of oligomeric proteins as well as in the investigation of interacting systems, and is the method of choice in analyzing dynamic interactions as it provides information about signal-average buoyant molar mass (87). Sedimentation equilibrium is an absolute technique for molecular weight measurement; since the shape of the macromolecule does not affect the measurement. When sedimentation equilibrium (by collaborators Swairjo Group) analysis was carried out on QueF, it was observed to migrate with an apparent $\mathrm{Mr}$ of $182 \mathrm{kDa}$, lower than the theoretical Mr of the decamer (194 kDa), suggesting the presence of smaller multimeric species. When fitting the data assuming two multimeric species in equilibrium, pentamer and decamer, the apparent $\mathrm{K}_{\mathrm{d}}$ for the pentamer-decamer equilibrium was calculated to be 140-240 nM. There was no indication of a higher molecular weight aggregate for the native protein. The QueF-*PreQ ${ }_{0}$ complex ran with an apparent average $\mathrm{Mr} 189 \mathrm{kDa}$, indicating a shift in equilibrium toward the decamer. The apparent $\mathrm{K}_{\mathrm{d}}$ for decamer 
formation is 35-37 nM, lower than that of the QueF enzyme alone, indicating a substrateinduced tightening or stabilization of the decamer.

In transient kinetics when the kinetics of substrate binding is very fast, the observed kinetics are a reflection of the rate of catalysis at the active site (88). Stopped-flow methods are typically applied when there is an observable signal, the most commonly used being absorbance or fluorescence. These two signals are limited mainly by the fact that the concentration of the substrates is dictated by the extinction coefficients and quantum yields (89), but averaging of several reaction traces significantly increases the ratio of signal to noise $(S / N)$. Fluorescence has the disadvantage that it is difficult to obtain stoichiometric amplitude data.

Proteins exhibit intrinsic fluorescence due to the presence of phenylalanine, tyrosine and tryptophan. QueF sequence analysis revealed that it only contains one tryptophan residue and the crystal structure revealed that the tryptophan residue was $\sim 20 \AA$ from the active site cysteine residue. Therefore, any change in the tryptophan fluorescence would be a reflection of structural changes occurring in the protein and not due to tryptophan directly interacting with the preQ $Q_{0}$. Tryptophan is particularly useful as it is very sensitive to its immediate environment and can be used in monitoring conformational changes, subunit associations, and substrate binding, as these processes can be accompanied by changes in its emission spectra (90). Tryptophan fluorescence can be selectively excited at 295 $305 \mathrm{~nm}(90)$, in all the tryptophan fluorescence assays for substrate binding tryptophan 
was excited at $295 \mathrm{~nm}$. Analysis of the microenvironment (4 $\AA$ ) of the tryptophan residues in two subunits (in the presence and absence of $\mathrm{preQ}_{0}$ ) revealed two major differences (Figure 58); first an aspartic acid residue is present in very close proximity to the tryptophan residue in the subunit without $\mathrm{preQ}_{0}$ but not in the subunit with preQ $\mathrm{Q}_{0}$ Second, methionine and lysine residues are present close to the tryptophan in the subunit with $\mathrm{preQ}_{0}$ bound to it but not in the subunit without preQ $_{0}$. The emission spectra of QueF in the presence and absence of preQ $_{0}$ were obtained, and quenching of the tryptophan fluorescence was observed in the presence of preQ $_{0}$ as well as a shift in the

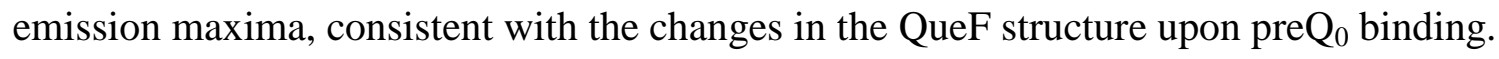

In the wild type QueF a covalent intermediate is formed. In order to investigate whether the quenching observed was due to thioimide formation or $\mathrm{preQ}_{0}$ binding, fluorescence measurements were made with the C55A mutant. The fluorescence of C55A, which lacks the cysteine residue required for the formation of the thioimide, was shown to be reduced in the presence of $\mathrm{preQ}_{0}$, supporting the hypothesis that the binding of preQ $\mathrm{Q}_{0}$ to QueF is accompanied by conformational changes in the protein. Stopped flow analysis of tryptophan fluorescence indicated that the fluorescence change in the wild type QueF was biphasic while the change in the C55A mutant was monophasic. The biphasic profile suggested that the observed fluorescence quenching was due to at least two events occurring upon the mixing of QueF with $\mathrm{preQ}_{0}$. Non-linear regression analysis of the fluorescence data from the experiments carried out with wild type and mutant showed that the fast phase in the binding of preQ $_{0}$ to the wild type gave a comparable rate to the 
calculated rate of preQ $_{0}$ binding observed in the C55A mutant $\left(1.32 \mu \mathrm{M}^{-1} \mathrm{~s}^{-1}\right.$ and $1.06 \mu \mathrm{M}^{-}$ ${ }^{1} \mathrm{~s}^{-1}$ respectively).

Stoppped flow kinetic analysis was also determined for thioimide formation. Interestingly, the rate of thioimide formation $\left(2.55 \mathrm{~s}^{-1}\right.$ at $\left.30{ }^{\circ} \mathrm{C}\right)$ was observed to be similar to the value determined for the slow phase in tryptophan quenching $\left(1.3 \mathrm{~s}^{-1}\right.$ at 20 ${ }^{\circ} \mathrm{C}$ ), indicating that the further quenching observed in the wild type protein and not in the C55A mutant was due to thioimide formation. The $\mathrm{preQ}_{0}$ binding experiments monitored by tryptophan fluorescence were determined at $20{ }^{\circ} \mathrm{C}$ instead of $30{ }^{\circ} \mathrm{C}$ because the fast phase of the preQ $_{0}$ binding was almost completely absent from the experiments determined at $30{ }^{\circ} \mathrm{C}$, such that the quenching observed was mainly due to thioimide formation. No significant differences in the crystal structures of the QueF with preQ $\mathrm{Q}_{0}$ bound and the one with the thioimide formed were observed, suggesting that no additional structural changes take place as a consequence of thioimide formation. Therefore, the slow second phase in the tryptophan fluorescence is formation of the thioimide, that locks the protein in the QueF-*PreQ ${ }_{0}$ conformation thereby the shifting the equilibrium towards the QueF.PreQ ${ }_{0}$ binary complex. The equilibrium between the free QueF and QueF.PreQ ${ }_{0}$ complex, which is apparent within a few milliseconds of mixing preQ $_{0}$ with the $\mathrm{C} 55 \mathrm{~A}$ mutant, is therefore not reached immediately due to the thioimide formation. 
Thioimide formation was directly followed by absorbance at $370 \mathrm{~nm}$. Fitting a simple two step mechanism to the thioimide formation resulted in residuals that were nonrandom from a global analysis of the data (Figure 44C), suggesting that the mechanism of thioimide formation was more complex. Given our knowledge of the presence of a preexisting equilibrium between the pentamer and decamer states of the protein, a step indicating such an equilibrium was added to the mechanism and this dramatically improved the residuals, suggesting that the pre-existing equilibrium between the different states of the protein might influence the kinetics observed. The need for a pre-existing equilibrium in fitting the thioimide data was unexpected as this was not necessary when preQ $_{0}$ binding data was analyzed. It is also possible that more than one form of QueF is able to form the thioimide, although we have is no direct evidence that addresses this issue.

Thioimide formation under single turnover conditions was shown to fit well to a single exponential equation in analyses using Kaleidagraph. However, when the $\mathrm{preQ}_{0}$ concentration was greater than the QueF concentration a second exponential rate was observed. Examples of this are shown in Figures 44D - F. The appearance of a second rate was not expected. The fast phase observed under single turnover conditions could be due to the reaction occurring between QueF in a more reactive conformation. In theory, preQ $_{0}$ could bind to either the pentamer or decamer states. Given the more open nature of the pentamer, the reaction might occur more readily in this state than in the decamer. It is clear though that the binding of preQ $_{0}$ shifts the equilibrium to the decamer state. 
The presence of a small population of monomer QueF-*PreQ ${ }_{0}$ observed in the gel filtration analysis might also be an explanation for the second rate observed in thioimide formation. There might be a fraction of the population that is still able to react with the preQ $_{0}$ but is slower than the predominant form. Though it seems unlikely, a monomer subunit of QueF might form the thioimide, when there is excess preQ $_{0}$ in solution such that the more reactive population has already reacted. This argument is consistent with the observation that the thioimide formation is strictly monophasic at low $\mathrm{preQ}_{0}$ concentrations. The presence of the second rate might also be due to re-estabilishing the equilibrium of the pentamer and decamer states of the protein accompanied by changes in extinction coefficient such that an increase in absorbance is observed. The thioimide formation was determined on two different instruments in order to check if the residual pattern was an artifact due to the instrument. However the same residual pattern was observed, suggesting that the observation of the non-random residuals was not due to the stopped flow instrument drifting but a characteristic of the reaction being observed.

The kinetics of NADPH binding were determined by following the fluorescence of NADPH, which is quenched upon binding to protein. Association and dissociation constants of NADPH to the E78A-*PreQ ${ }_{0}$ complex were determined under pseudo-first order conditions. The QueF mutant was used in order to look at the binding kinetics completely separate from NADPH oxidation. The kinetics observed were biphasic. Initial attempts to fit the data to a single exponential decay resulted in poor fitting, while fitting with a double exponential decay produced a better fit. We propose that the fast 
phase corresponds to the association and dissociation of the NADPH from the protein complex, while the slow phase is due to either isomerization of the binary complex $\left(\mathrm{QueF}-* \mathrm{PreQ}_{0} \cdot \mathrm{NADPH}\right)$ or it can also be an artifact of the E78A mutation since this residue interacts directly with preQ $_{0}$ and it is substituted with alanine which is unable to make the same interactions. The biphasic change noted in this protein, which is unable to reduce the thioimide in the active site, has been previously observed in other dehydrogenases such as aldolase reductase (91), acetohydroxy acid isomeroreductase (92), human aldolase reductase (93) where changes in conformation upon the binding of NADPH have been suggested to also occur.

The rate of reduction of the thioimide was analyzed using both fluorescence and UV absorption analysis. Direct monitoring of the loss of NADPH absorption at $340 \mathrm{~nm}$, as done previously in the steady state analysis of QueF (71), could not be used under single turnover conditions because of the overlap of the thioimide peak with that of NADPH (Figure 47). The kinetics of thioimide loss followed at $390 \mathrm{~nm}$ under single turnover conditions fit well to a single exponential decay. The change in absorbance at $390 \mathrm{~nm}$ was monophasic, an indication that the observed change was most likely due to a single event taking place, in this case the reduction of the thioimide. When fluorescence of $\mathrm{NADPH}$ was used as the reporter, the association and dissociation of NADPH was observed as the fast phase. The value of association of NADPH with QueF-*PreQ 0 complex was found to be $0.06 \mu \mathrm{M}^{-1} \mathrm{~s}^{-1}$, which is less than that measured for E78A $(0.2$ $\left.\mu \mathrm{M}^{-1} \mathrm{~s}^{-1}\right)$. This might be due to differences in the size and polarity of the R-groups of the 
two residues. Even though E78 appears not to directly interact with the NADPH in the crystal structure, having alanine in that position might make it more accessible for the NADPH binding because of its smaller R-group even though the mutation results in an inactive protein. The data for the single turnover of NADPH was fit to a double exponential decay, suggesting that under single turnover conditions there are at least two events taking place, the binding of NADPH and its subsequent oxidation in the reduction of the thioimide. This model was also supported by the data obtained from loss of the thioimide absorbance observed at $390 \mathrm{~nm}$ under single turnover conditions. The rate for the reduction of the thioimide was found to be comparable from both fluorescence and UV data suggesting that the proposed two step model is possible where an enzyme isomerization does not take place. The apparent absence of an isomerization step under single turnover conditions might be either because it induces such a subtle change in the protein complex that it makes it difficult to detect or that in the native protein the isomerization step occurs so fast that it does not change the overall kinetics being observed. The apparent isomerization in the E78A mutant might also be an artifact due to the mutation.

Multiple turnover kinetics of QueF was analyzed. Proposing a model for the calculation of rate constant was difficult. QueF-*PreQ $\mathrm{Q}_{0}$ was used in order to reduce the steps to be determined; other constraints on the model included the experimentally measured value for the first reduction of the thioimide, which was held constant, as well as the binding of the second NADPH, which was assumed to be identical to the first NADPH. The 
presence of a single NADPH site for two preQ $_{0}$ sites, and two reduction cycles for each pre $_{0}$ site, complicated the analysis. Some questions were difficult to answer, including the following: are the two sites equivalent? Upon binding of the second equivalent of $\mathrm{NADPH}$, does the intermediate from the first reduction preferentially get reduced over the thioimide or is this still random? Does the protein undergo structural changes in order to accommodate the reduction of the intermediate? The affinity for the enzyme for $\mathrm{NADP}^{+}$, which could affect its rate of diffusion, is also unknown at this point.

The data obtained for the multiple turnover experiment was complex (Figure 59) and it was not possible to fit simple decay equations to the data obtained. In the presence of low NADPH concentrations, the data could be fit to a double exponential decay. However, as the concentration was increased, the shape of the plot changed. The data was analyzed using Dynafit for a global fitting. The initial fast phase found in all the traces was attributed to the binding of NADPH and its subsequent quenching. However the almost constant fluorescence signal at higher NADPH concentrations might be due to several factors, which include, but are not limited to, the following: after the initial reduction of the thioimide, the $\mathrm{NADP}^{+}$does not readily diffuse away, it might require a conformational change to take place before it can diffuse or the binding of the second equivalent of NADPH is accompanied by conformational changes. Alternatively the apparent constant fluorescence at high NADPH concentrations might be due to the excess NADPH which has a higher quantum yield than protein bound NADPH which is associated with any of protein. Only the $k_{2}$ and $k_{5}$ were calculated from the multiple 
turnover data analysis and all other constants were determined by other experiments and were held constant for the analysis.

The transient kinetic analysis results indicate that the binding of $\mathrm{preQ}_{0}$ and NADPH to QueF, as well as thioimide formation are very rapid. Reduction of the thioimide and imine intermediate are most likely the rate-limiting steps, and analysis of component rates suggest that structural changes occur between these steps, further limiting the overall rate. Structural analysis of QueF indicates that this protein exists in equilibrium between the pentamer and decamer states. There is also evidence that there might be small fraction of the protein which exits as a monomer which is in equilibrium with the multimeric proteins. The addition of preQ $_{0}$ or divalent metals results in stabilization of the decamer structure. All the data combined is consistent with structural changes taking place after addition of a substrate. 


\subsection{QueA}

Previous work carried out has shown that the formation of the $\mathrm{C}-\mathrm{N}$ bond occurs at $\mathrm{C} 4$ ', which led to our proposed mechanism. Proton abstraction could occur by two possible routes which are shown in Figure 12. The first mechanism shows that deprotonation occurs prior to formation of the $\mathrm{C}-\mathrm{N}$ bond while the second mechanism shows that the $\mathrm{C}$ $\mathrm{N}$ bond is formed first before the $\mathrm{C} 5$ ' proton is removed, resulting in an $\mathrm{S}_{\mathrm{N}} 2$ mechanism. Even though the $\mathrm{S}_{\mathrm{N}} 2$ mechanism is simpler, such a reaction at a secondary carbon is highly unfavorable, and therefore the mechanism is more likely to occur by an elimination/addition mechanism that makes use of the favorable $\mathrm{pK}_{\mathrm{a}}$ in the first step. In the $\mathrm{S}_{\mathrm{N}} 2$ mechanism the known stereochemistry of the oQ limits this mechanism to only procede with loss of the pro- $R$ proton.

Elimination/addition mechanism is compatible with loss of either the proR or proS hydrogen since the stereochemistry at $\mathrm{C}^{\prime}$ is lost. However, elimination/addition mechanism requires syn or anti relationship between the proton removed and the C4'-O bond. The conformation about the C4'-C5' bond AdoMet indicates that the mechanism would most likely favor loss of proS hydrogen.

During the transfer of the ribosyl group from AdoMet to form oQ, one of the hydrogens at the C5' position is lost. Elucidating the stereochemistry of this reaction is fundamental to understanding the mechanism of QueA. To investigate the stereospecificity of QueA, 
stereospecifically labeled deuterated AdoMet was used to determine if the proton abstraction was stereospecific. PreQ ${ }_{1}$-tRNA, which had been converted to oQ-tRNA, was digested as previously described (63), and chromatograms showing the products of these digestions are shown in Figure 51. oQ samples generated from 5'R-[5'D]-AdoMet, 5'S[5’D]-AdoMet and unlabeled AdoMet were all lyophilized and analyzed by mass spectrometry. The results of these analyses are shown in Figure 52.

The results obtained from mass spectrometry analysis were consistent with an elimination/addition mechanism in which the proS hydrogen is lost. Loss of the deuterium was shown in the oQ prepared using proS AdoMet, which resulted in a mass of $426 \mathrm{~m} / \mathrm{z}$ the same as the one obtained when unlabeled AdoMet was used, while the oQ prepared using proR AdoMet was $427 \mathrm{~m} / \mathrm{z}$, consistent with loss of the proS proton as the deuterium label was retained in this sample (Figure 52). The results obtained support an elimination/addition mechanism. 


\section{Tables and Figures}

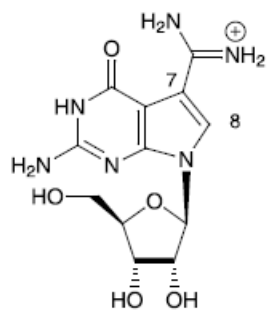

Archaeosine $\left(\mathrm{G}^{*}\right)$

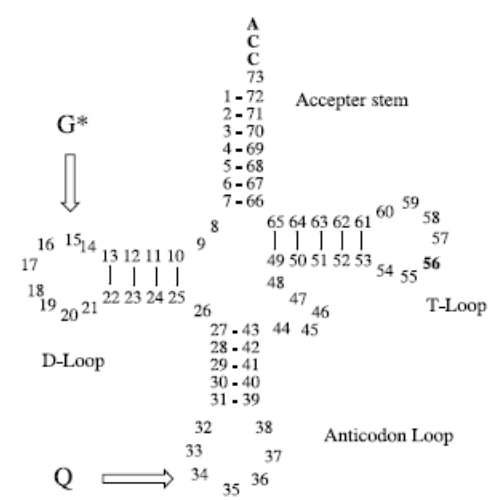

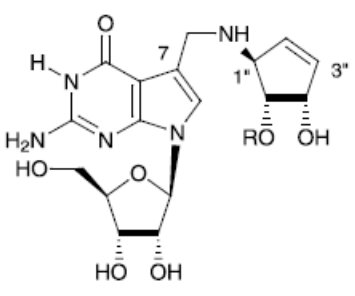

Queuosine (Q) $\mathrm{R}=\mathrm{H}$

Mann Q $R=\beta$-D-mannose

Gal Q $\quad R=\beta$-D-galactose

Figure 1: The structures of the 7-deazaguanosine hypermodified nucleosides of transfer RNA.

Figure taken from (37).

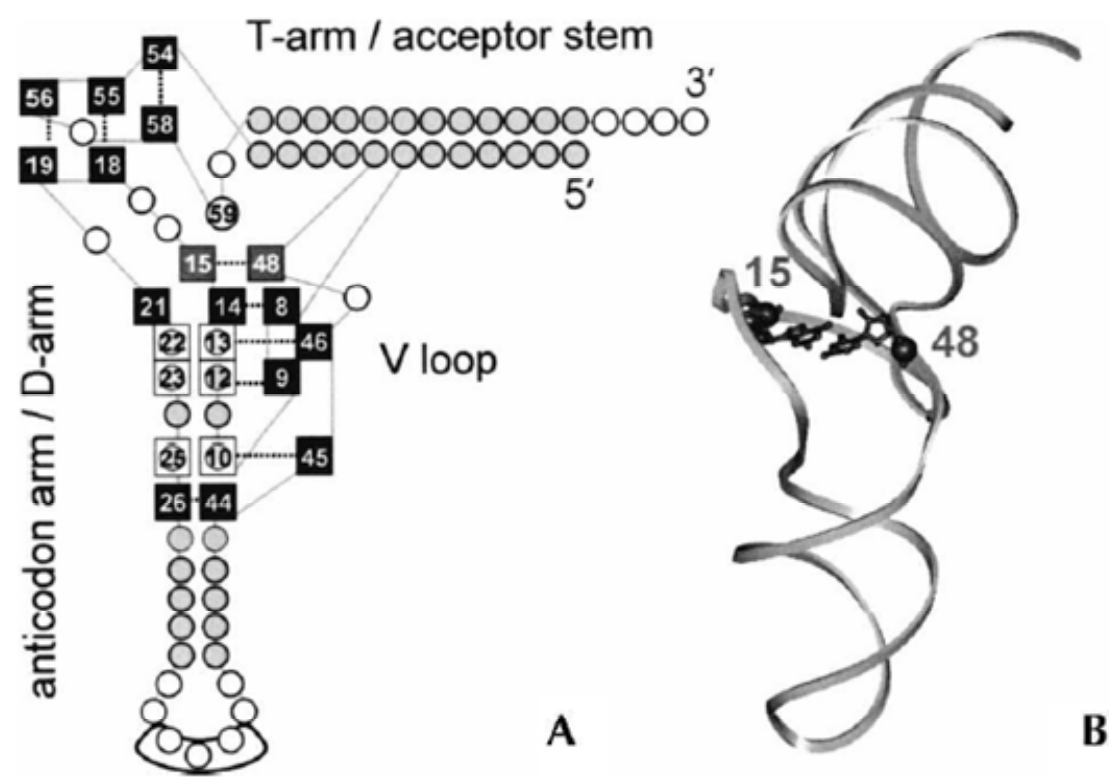

Figure 2: Class 1 tRNA canonical structure.

(A) Nucleotides 15 and 48, forming the Levitt base pair. (B) Ribbon representation of the yeast tRNA ${ }^{\text {Phe }}$ structure. Figure taken from (24). 


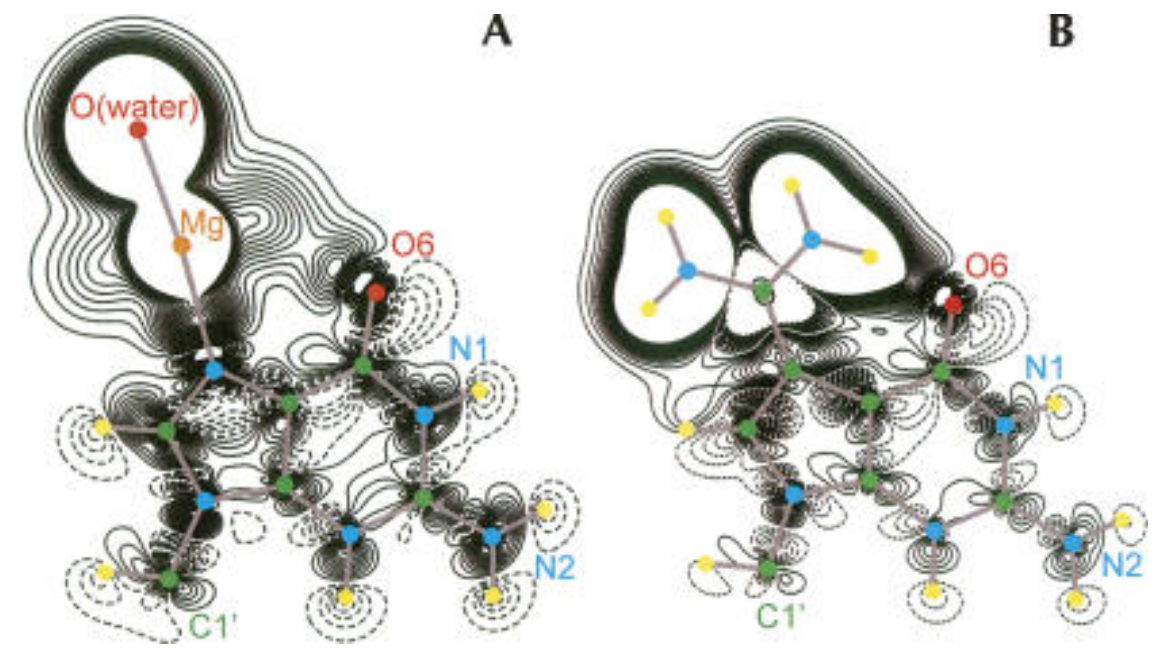

Figure 3: Electron density difference in the base plane between $\left[\mathrm{Mg}\left(\mathrm{H}_{2} \mathrm{O}\right)_{5} \mathrm{G}\right]^{2+}$ and the simple $\mathrm{G}$ base.

(A) archaeosine (fa7d7G) (B) G base. Figure taken from (24)<smiles>CC(C)C(C(=O)O)C(=O)OC1CNc2nc(N)[nH]c(=O)c2N1</smiles>

Figure 4: The biosynthetic pathway of the $\operatorname{pre}_{0}$.

Figure taken from (45). 


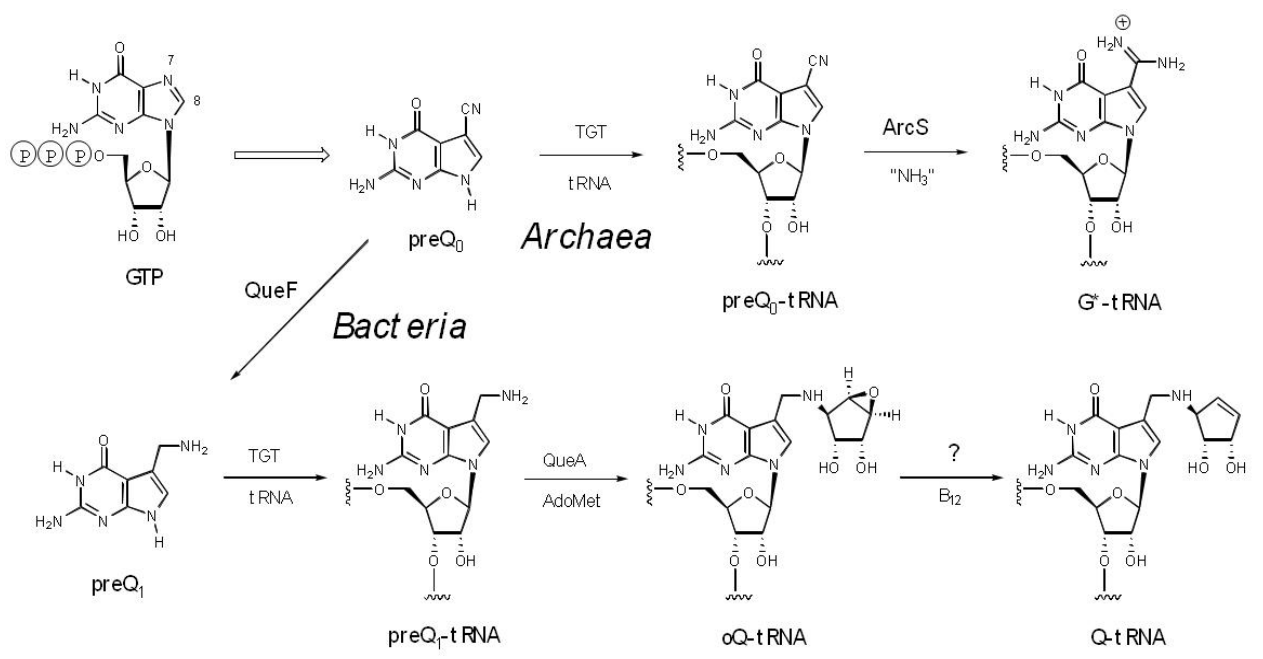

Figure 5: The biosynthetic pathways of archaeosine and queuosine in archaea and bacteria.

Figure taken from (41).

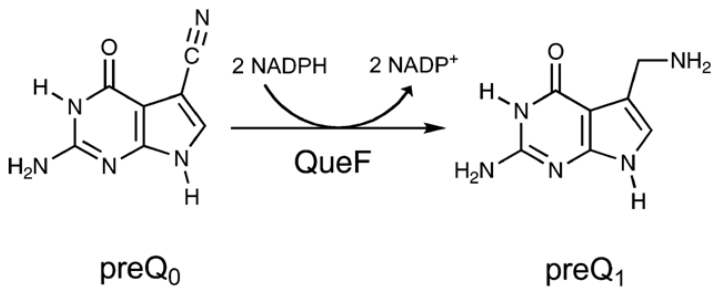

Figure 6: QueF catalyzed reaction. 


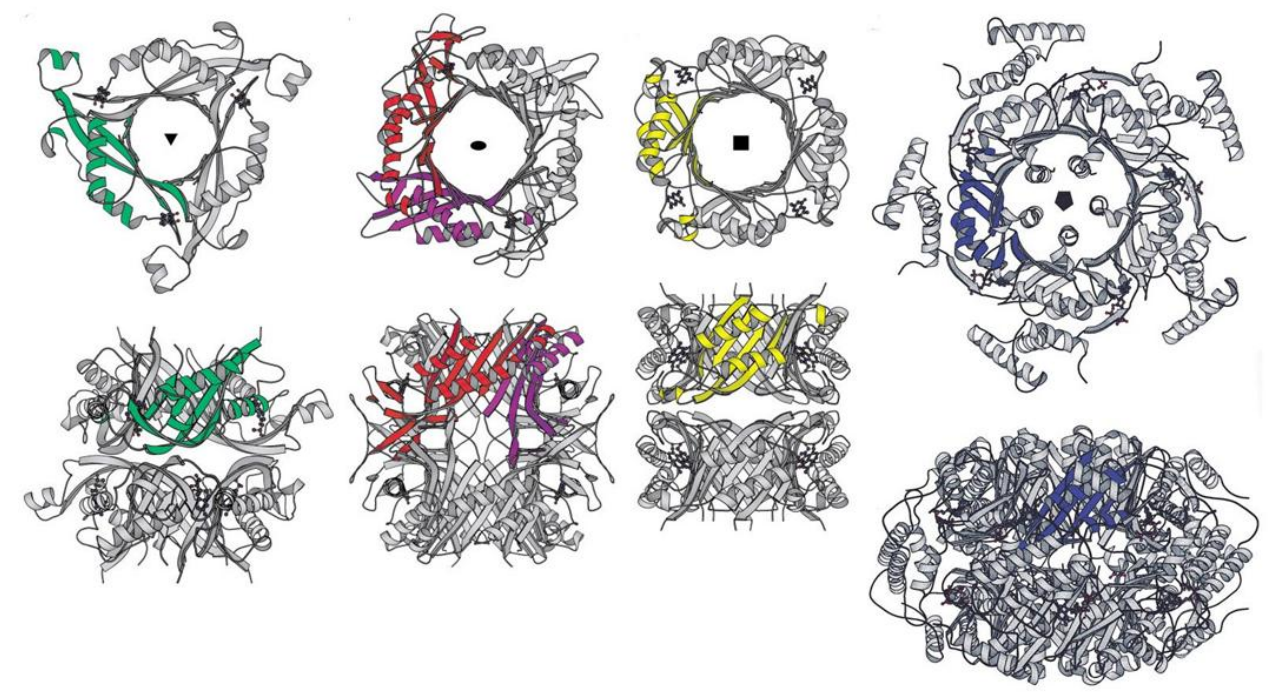

Figure 7: Multimeric barrels by the T-folds for functionally different enzyme.

The monomer units are shown in color. (A) 6-Pyruvyltetrahydropterin synthase (PTPS) (hexamer). (B) Urate oxidase (UOX) (tetramer). (C) Dihydroneopterin aldolase (DHNA) (octamer). (D) GTP cyclohydrolase I (GCYH I) (decamer). The enzymes are composed of barrels superposed face to face. Figure taken from (57).

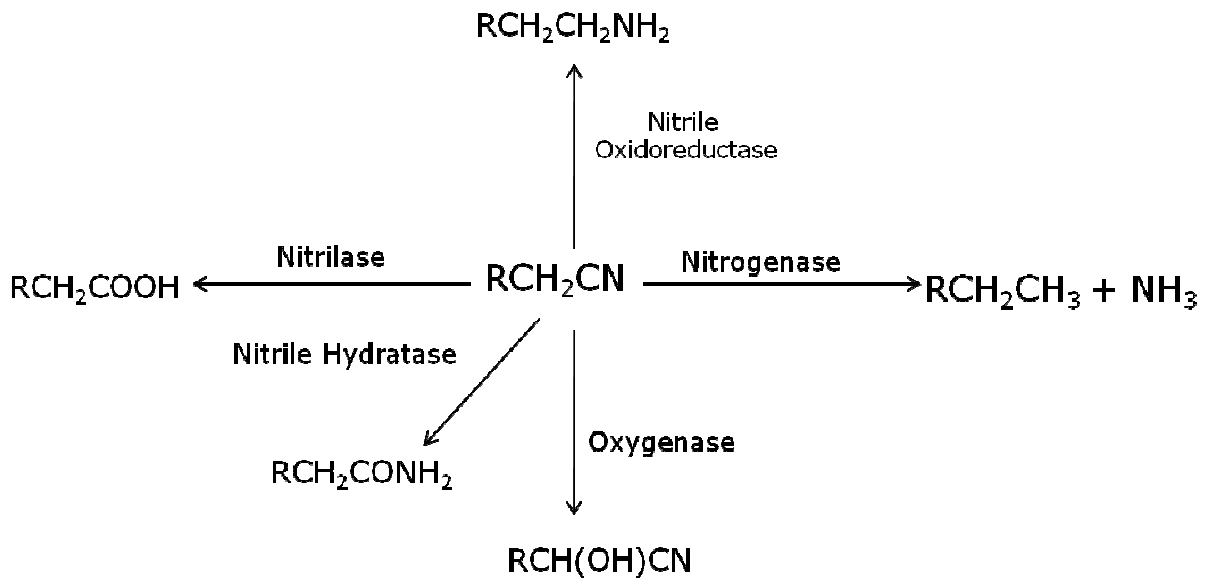

Figure 8: Different pathways of nitrile metabolism.

Figure adapted from (58) 

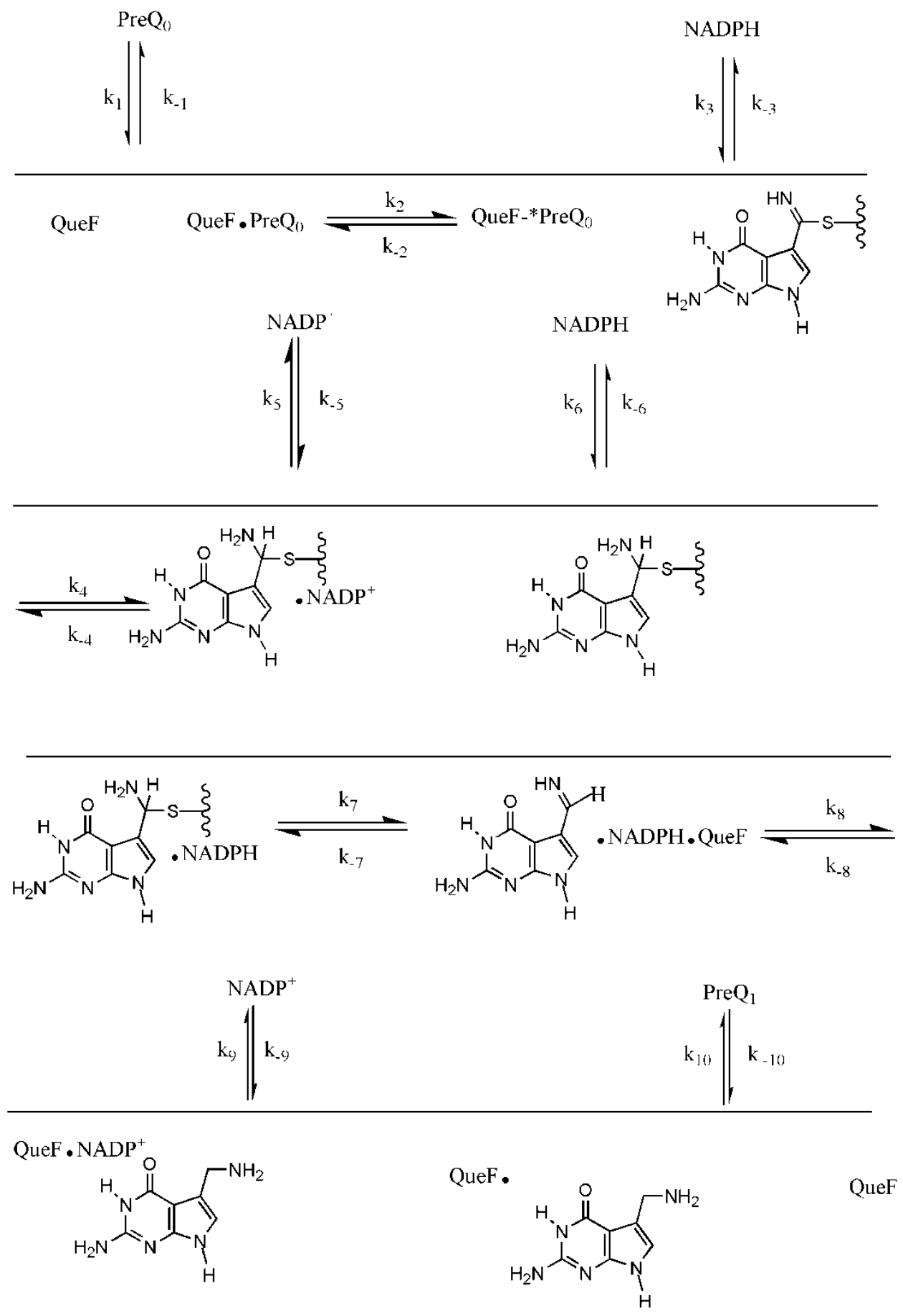

Figure 9: Proposed kinetic scheme of QueF based on the Bi-Uni-Uni Ter-Ter Ping Pong kinetic mechanism 


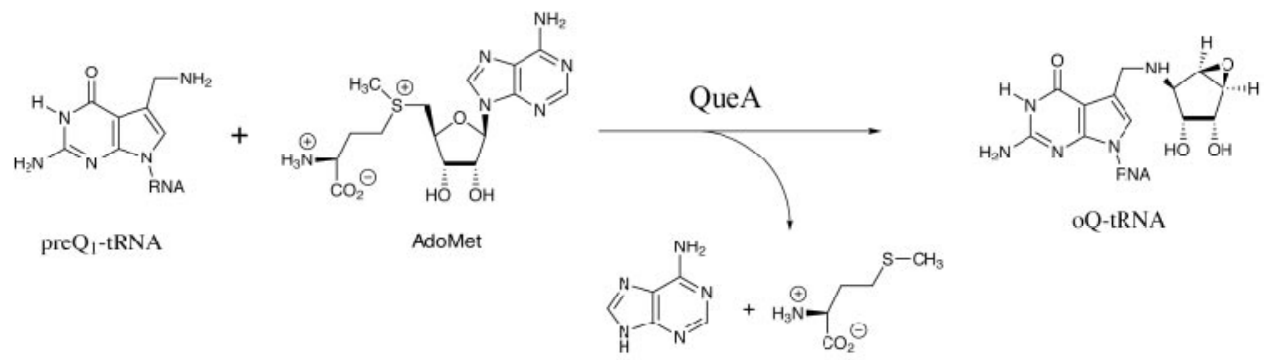

Figure 10: QueA catalyzed reaction.

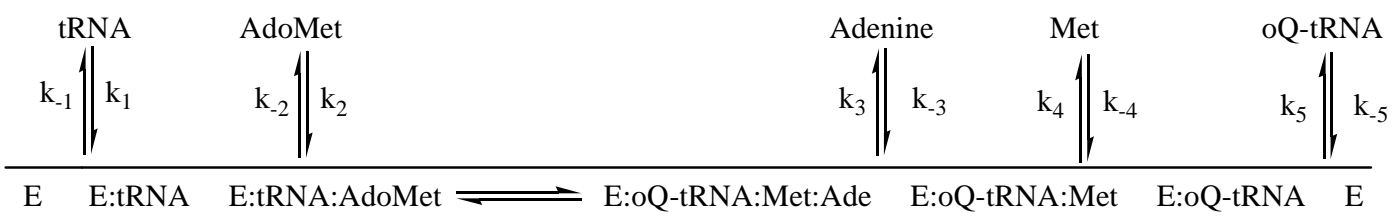

Figure 11: QueA follows an ordered Bi - Ter mechanism. 
(A)
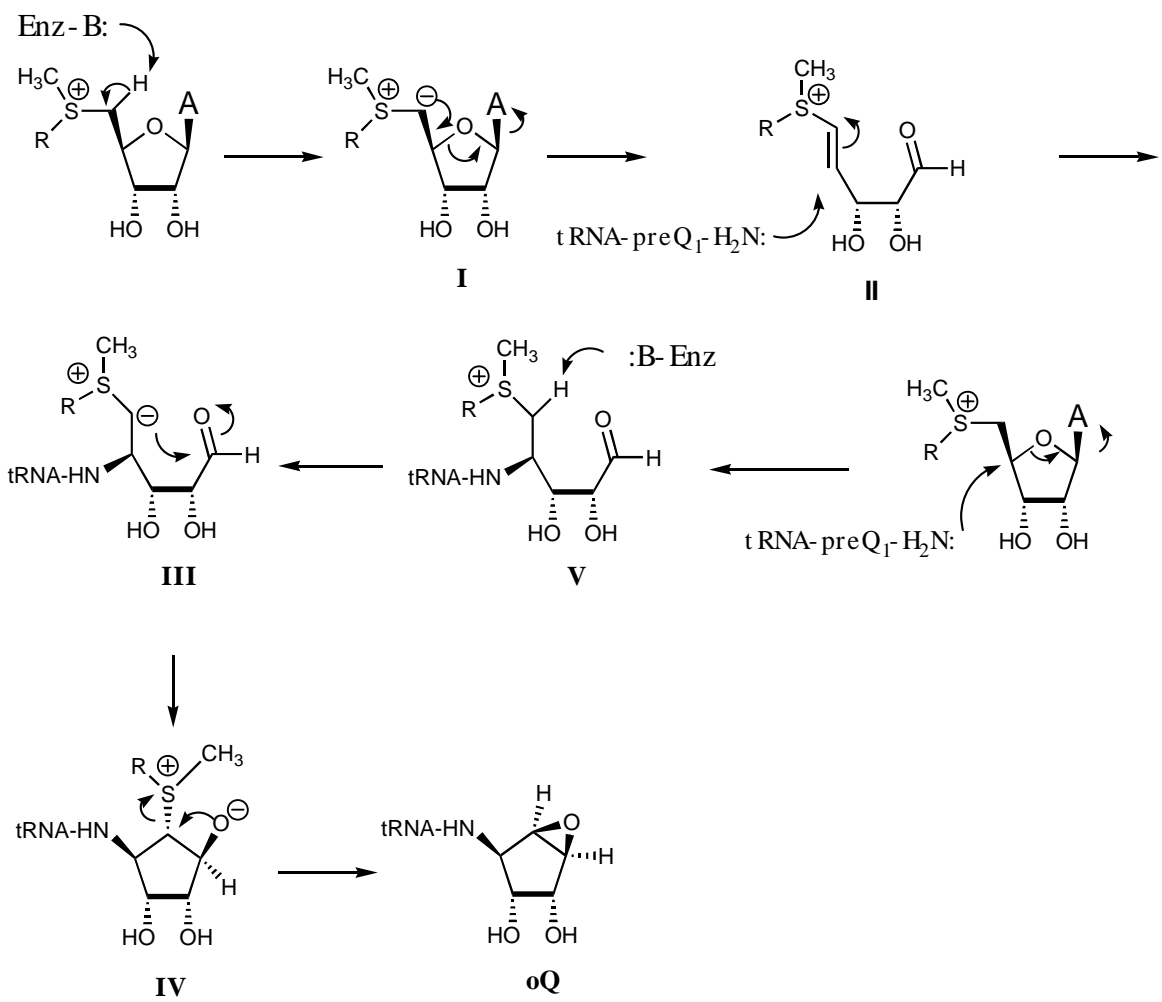

Figure 12: Possible Mechanisms of the QueA Reaction Consistent with C-N bond formation at C4'.

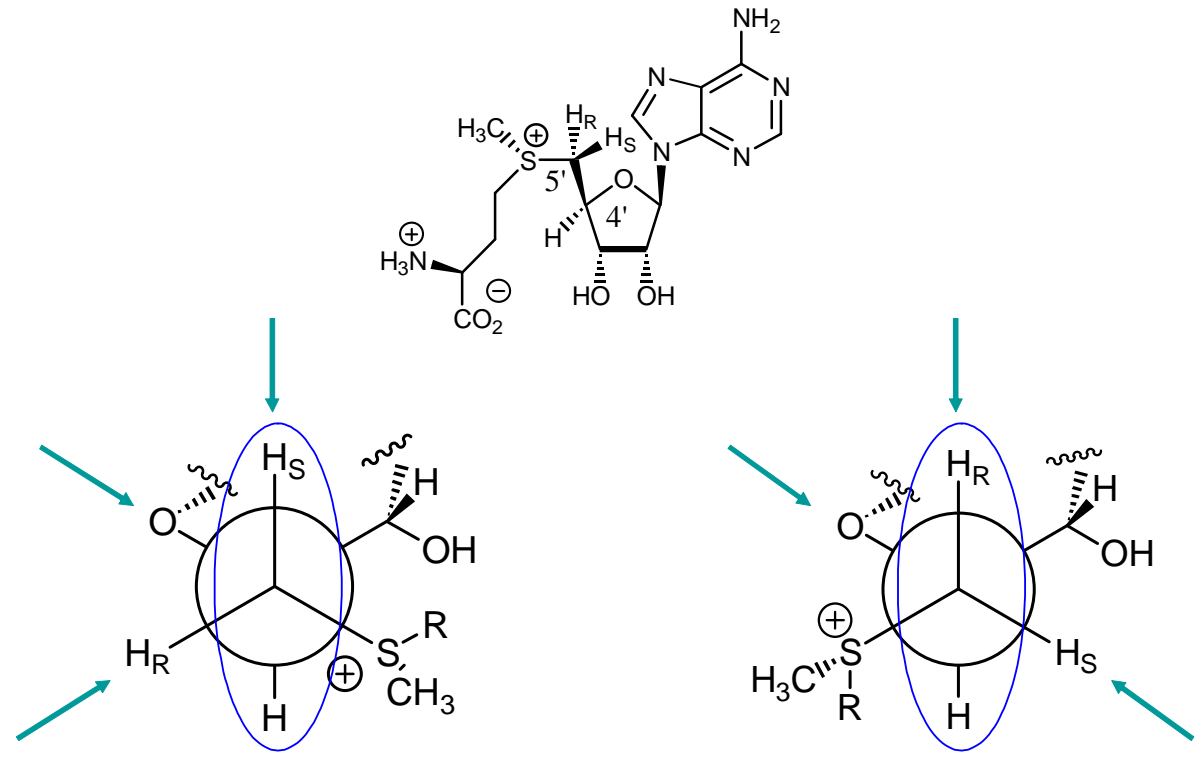

Figure 13: Conformations about the C4'-C5' bond of AdoMet. 


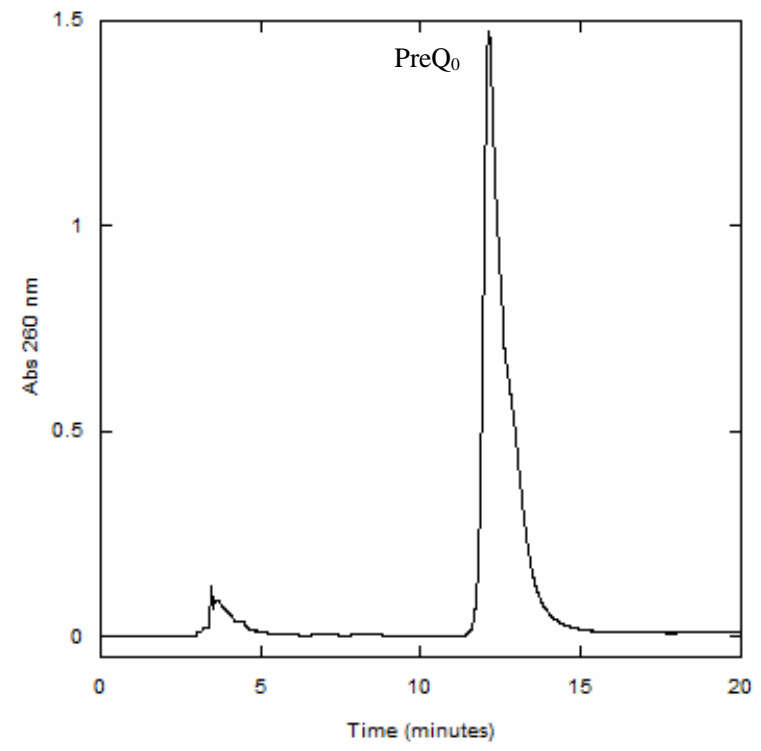

Figure 14: PreQ $_{0}$ semi-preparative HPLC purification.

$\mathrm{PreQ}_{0}$ was purified on a semi-preparative Luna C18 column $(250 \times 10 \mathrm{~mm}, 5 \mu \mathrm{m})$ from Phenomenex. The $\mathrm{preQ}_{0}$ eluted in a 20 minute run, eluting at 12.5 minutes under gradient conditions; $96 \% 25 \mathrm{mM} \mathrm{NH}_{4} \mathrm{OAc}$ (pH 6.0)/4\% methanol for 10 minutes followed by a gradient of $96 \% 25 \mathrm{mM} \mathrm{NH}_{4} \mathrm{OAc} / 4 \%$ methanol up to $85 \% 25 \mathrm{mM} \mathrm{NH}_{4} \mathrm{OAc} / 15 \%$ methanol over 10 minutes at a flow rate of $4 \mathrm{~mL} / \mathrm{min}$.

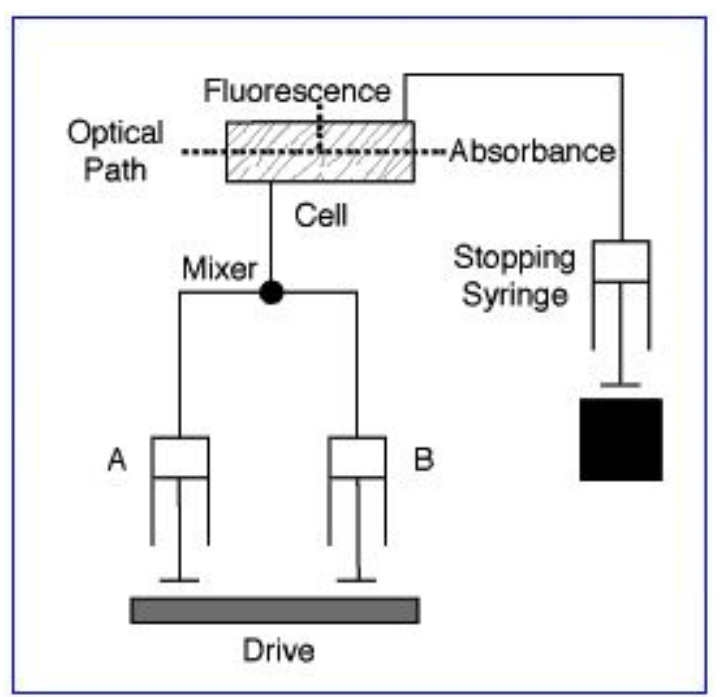

Figure 15: Schematic of a stopped flow instrument. 
A<smiles>N#Cc1c[nH]c2nc(N)[nH]c(=O)c12</smiles>

preQ $_{0}$

B

Sulfolobus todokaii Sulfolobus solfataricus

Archaeoglobus fulgidus

Haloarcula marismortui

Halobacterium NRC-1

Methanospirillum hungatei

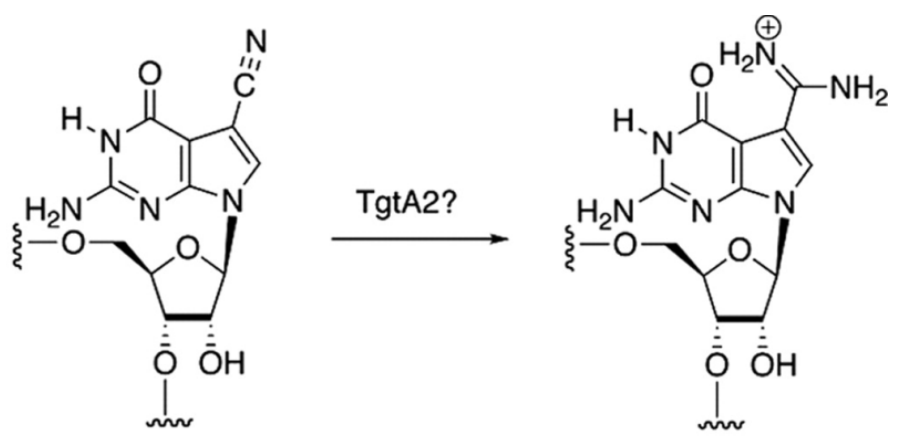

preQ-tRNA

$\mathrm{G}^{+}$-tRNA

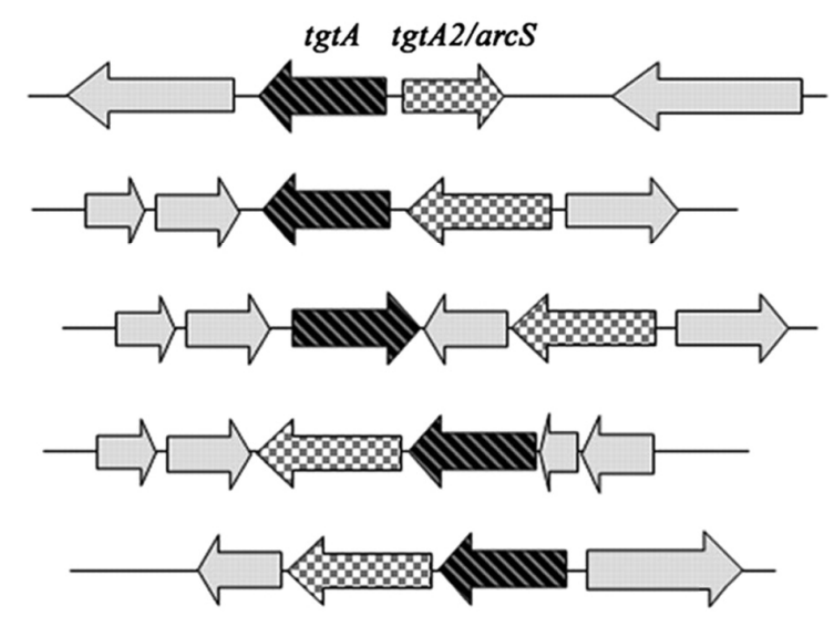

C

TgtA2

\begin{tabular}{|c|c|c|c|}
\hline & $210-260$ residues & 200 residues & 50 residues 80 residues \\
\hline 70-130 missing residues & $\underset{\text { Zinc binding site }}{\mathrm{N} \text {-term }}$ & C1_catalytic* & C3/PUA \\
\hline
\end{tabular}

TGT

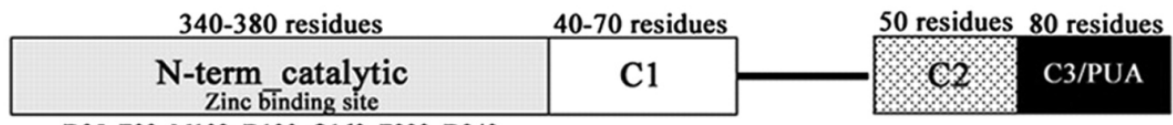

D95, F99, M102, D130, Q169, F229, D249

Figure 16: Analysis of the TgtA and TgtA2 families.

A) Predicted role of TgtA2 in archaeosine biosynthesis. B) Clustering of tgtA and tgtA2 genes in Archaea. C) Shared modular structure of TGT and TgtA2 proteins. Only the long (full-length) forms are shown. The active site and known catalytic residues of TGT ( $P$. horikoshii numbers) and the conserved TgtA2 motif (M. jannaschii numbers) in the presumably catalytic $\mathrm{C} 1$ domain (starred) of TgtA2 are shown. The zincbinding residues are found in all but six TGTs and in $\sim 60 \%$ of the TgtA 2 sequences analyzed. Figure taken from (70) 


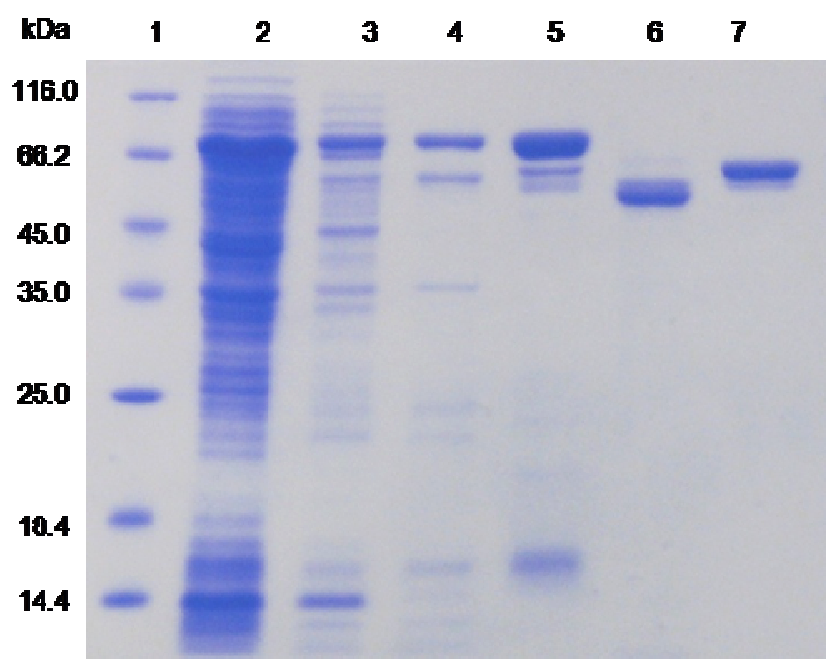

Figure 17: SDS-PAGE analyses of $M j$ TgtA2 purification.

lane 1, MW marker; lane 2, cell lysis free extract; lane 3, CFE after heating at $60{ }^{\circ} \mathrm{C}$; lane 4 , CFE after heating a $75^{\circ} \mathrm{C}$; lane 5, Trx-his ${ }_{6}-M j$ TgtA2; lane 6, Self cleaved MjTgtA2; lane 7 purified C-terminal his ${ }_{6}$ MjTgtA2 
A)

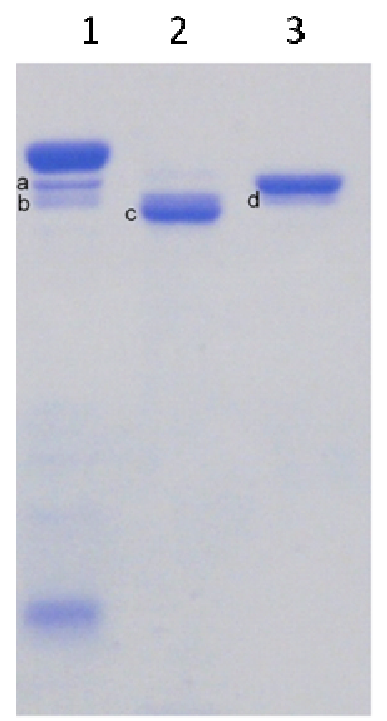

B)

MSDKIIHLTDDSFDTDVLKADGAILVDFWAEWCGPCKMIAPILDEIADEYQGKLTVAKLNIDQNPG TAPKYGIRGIPTLLLFKNGEVAATKVGALSKGQLKEFLDANLAGSGSGHMHHHHHHSSGLVPRGS GMKETAAAKFERQHMDSPDLGTGGGSGIEGR

C)

MLEPIAYDIGRLCKEEDKELTPKLIDIDVIGLSQEKIFYGIMTPFRCPNSKSIYELRKSYVKADGIKMP FDTFRELTSIFKKSFIGTVKYKGNVFKYQILNFGKHVDLIELEDADLYIIADGRRLIERKELQIIPKIR EKISPNSAIYSPAVFPWEIPLLAYIGVDYFDDSLAKLYASMGYKFTKNRAVKVDSFSFEELYNNNK KVYEEILEEVRIAIKNGFLRNVVEETAVSHPYLWANYRRYEPDLRNIPLSKENKIIVTTNINIPEVKK YLERLDNYEPYSNIIVLLPCSSKKPYSISQSHQKFIKAIKSAKVVVEEVILTSPYGLVPRALERLVNY DIPVTGEWSFEEIELINNCLKNFLKKVKEKFDDYIVIAHLPEHYLEILELDDIVITSKGNPTSEEALKN LTDTLKKYKELTKSKDINKKGQRIHNIQQLAEFQFGINFIPNEIFINHKGQIFTKINNKNQQIASINPK NGLLILTLSGGELLWNSGGKDINYIEVNYEIKKGSLFPPGFVDCNENISYNDEVVLIKDDTFLGIGR ALMSGFEMKKAKHGALVNIRNVKS

Figure 18: Edman degradation of $M j$ TgtA2 bands.

(A) SDS-PAGE indicating the bands sequenced by Edman degradation, lane 1, Trx-his ${ }_{6}-M j \operatorname{TgtA} 2$; lane 2,

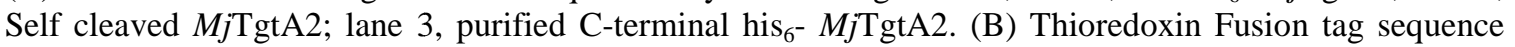
(from the pET32/Xa LIC vector) indicating the site of proteolysis in bold and underlined. (C) MjTgtA2 native sequence indicating the site of proteolysis in bold and underlined, the italics indicate the other site of proteolysis. 


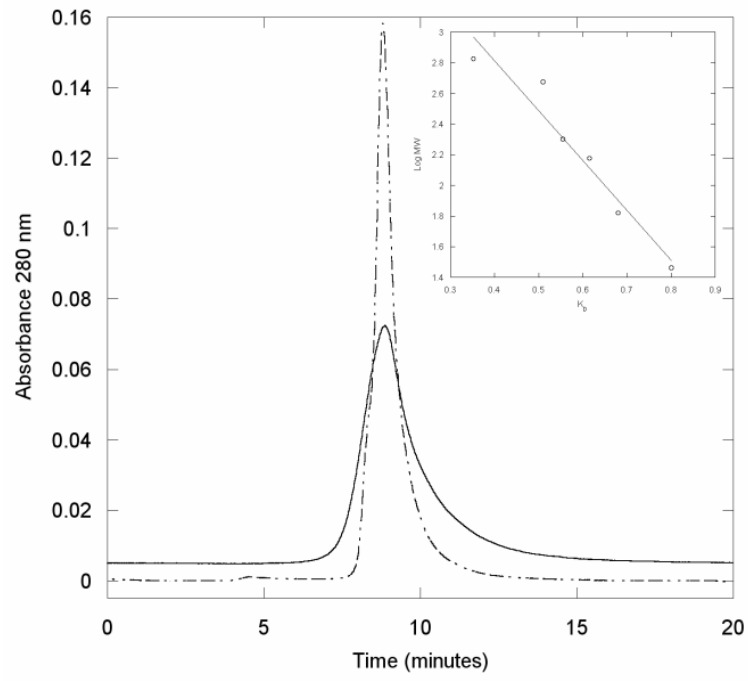

Figure 19: HPLC gel filtration analysis of Thioredoxin-His ${ }_{6} M j$ TgtA2 and cleaved $M j$ TgtA2.

MjTgtA2 (discontinuous line) elutes at 8.75 minutes and cleaved MjTgtA2 (continuous line) elutes at 8.88 minutes. Inset: standard curve presented as $\log \mathrm{MW}$ vs. KD. The standards used in the calibration included; Carbonic Anhydrase (29KDa), BSA (66 KDa), Alcohol Dehydrogenase (150 KDa), $\beta$-Amylase (200 KDa), Apoferritin $(443 \mathrm{KDa})$ and Thyroglobulin $(669 \mathrm{KDa})$. Each data point represents the average of 2 trials. The protein standard data fit the linear regression $\mathrm{y}=4.111-3.245 \mathrm{x}(\mathrm{R}=0.967)$. Determined Molecular mass of Thioredoxin- $\mathrm{His}_{6} \mathrm{MjTgtA}_{2}$ was $154 \mathrm{KDa}$ (Calculated for dimer $155 \mathrm{kDa}$ ). Determined molecular mass of cleaved MjTgtA2 $122 \mathrm{KDa}$ (Calculated for cleaved dimer $114 \mathrm{kDa}$ ).

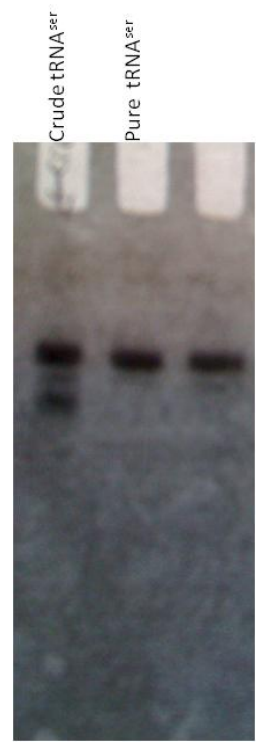

Figure 20: Purification of tRNA ${ }^{\text {Ser }}$ from prep cell. 


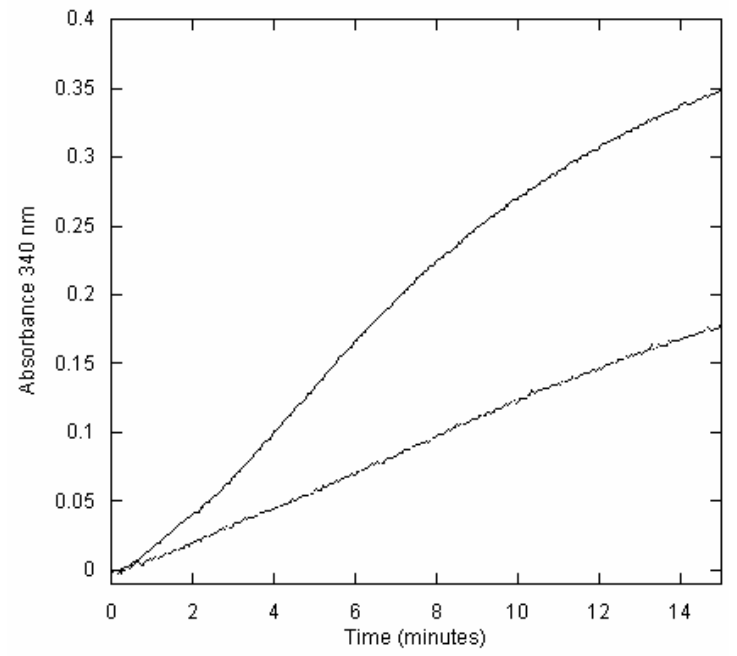

Figure 21: Glutaminase activity of $M j$ TgtA2 coupled with glutamate dehydrogenase activity.

NADPH formation was monitored at $340 \mathrm{~nm} .30$ and $60 \mu \mathrm{g}$ of protein were used, in a solution containing $50 \mathrm{mM}$ phosphate (pH 7.5), $0.5 \mathrm{M} \mathrm{NaCl}, 20 \mu \mathrm{M}_{\text {preQ }}$-tRNA ${ }^{\text {Ser }}, 15 \mathrm{mM} \mathrm{MgCl}_{2}, 1 \mathrm{mM}$ DTT, $2.5 \mathrm{mM}$ Gln, $1 \mathrm{mM} \mathrm{NADP}{ }^{+}$and $4 \mathrm{U}$ of glutamate dehydrogenase at $37^{\circ} \mathrm{C}$.

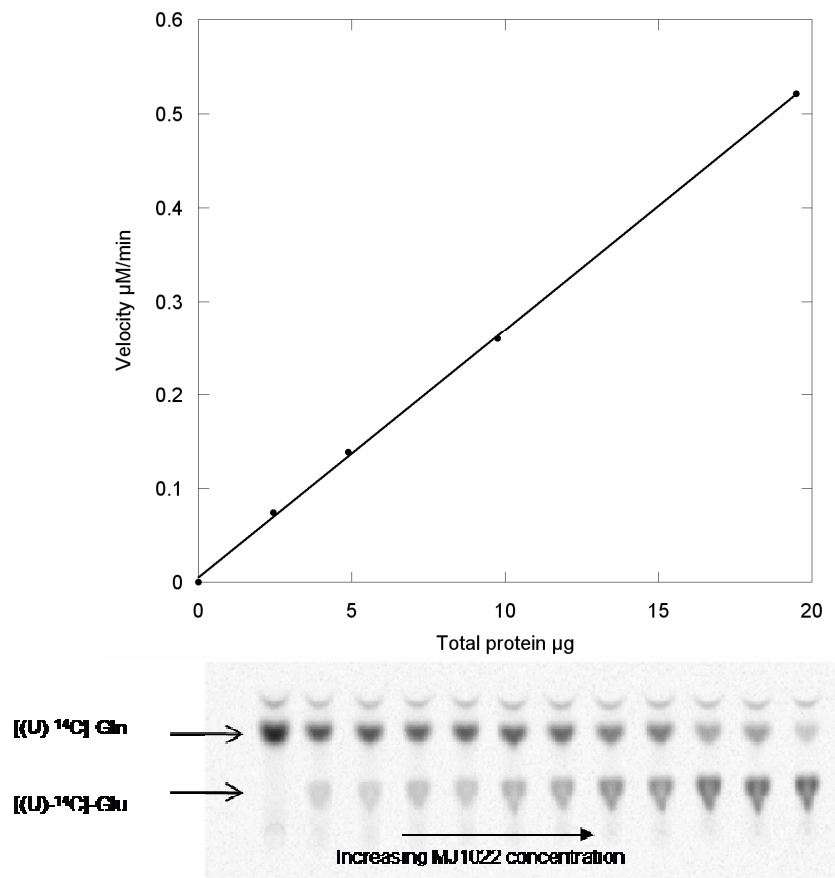

Figure 22: Glutaminase activity as a function of increasing concentration of MjTgtA2.

Reaction conditions; $100 \mathrm{mM}$ HEPES (pH 7.0), MjTgtA2 (MJ1022) $(2.0-20 \mu \mathrm{g}) .0 .5 \mathrm{M} \mathrm{NaCl}, 15 \mathrm{mM}$ $\mathrm{MgCl}_{2}, 2 \mathrm{mM}$ DTT, $12.4 \mu \mathrm{M}\left[(\mathrm{U})-{ }^{14} \mathrm{C}\right]-\mathrm{L}-\mathrm{Gln}, 20 \mu \mathrm{M}$ preQ $_{0}$-tRNA ${ }^{\text {Ser }}$ 


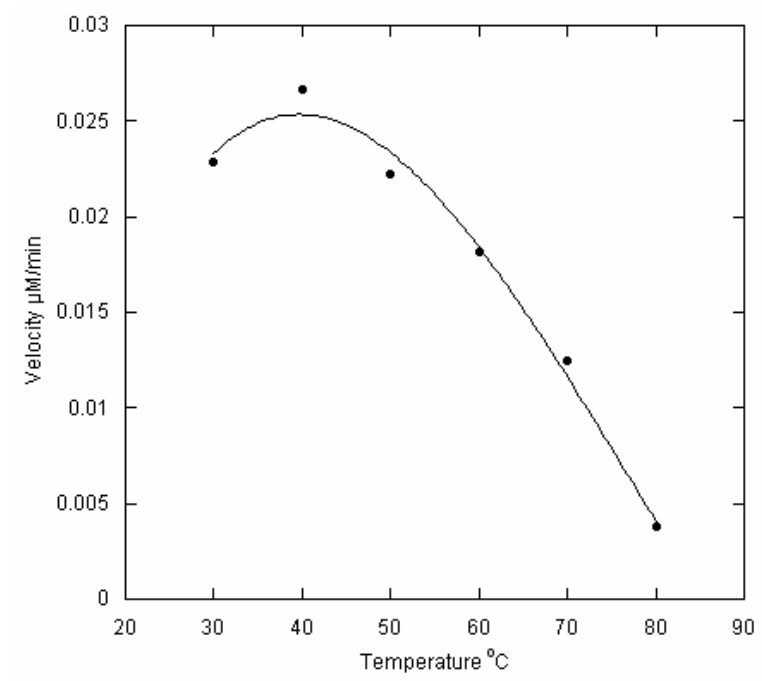

Figure 23: Temperature profile determination of $M j \operatorname{TgtA2}$.

Reaction conditions; $100 \mathrm{mM}$ HEPES (pH 7.0), $0.5 \mathrm{M} \mathrm{NaCl}, 20 \mathrm{mM} \mathrm{MgCl}, 1 \mathrm{mM}$ DTT, $10 \mu \mathrm{M}\left[(\mathrm{U})-{ }^{14} \mathrm{C}\right]-$ Gln and $20 \mu \mathrm{M}_{\text {preQ }}$-tRNA $^{\mathrm{Ser}}, 7.8 \mu \mathrm{g} M j \mathrm{TgtA} 2$

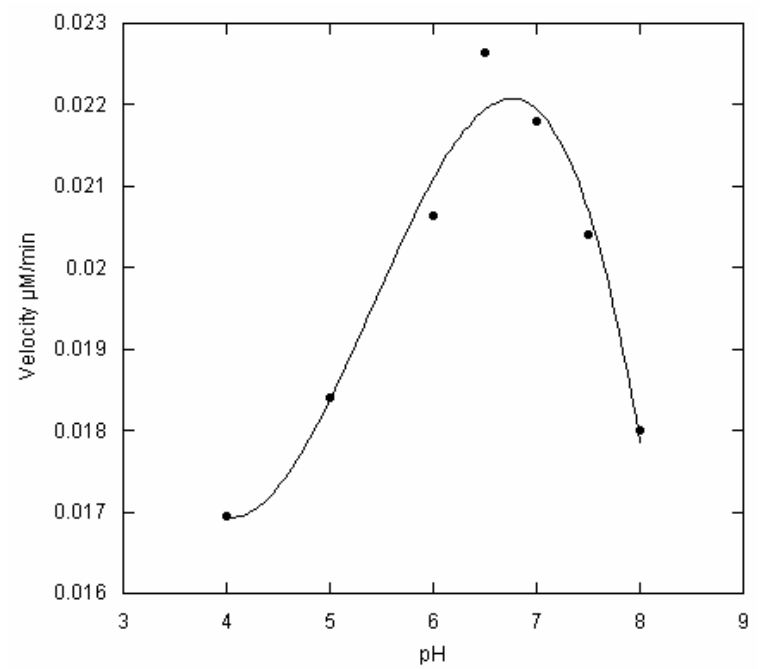

Figure 24: $\mathrm{pH}$ profile determination of $M j \mathrm{TgtA2}$.

Reaction conditions; $100 \mathrm{mM}$ Tris/Mes/Acetate, $0.5 \mathrm{M} \mathrm{NaCL}, 20 \mathrm{mM} \mathrm{MgCl} 2,1 \mathrm{mM}$ DTT, $10 \mu \mathrm{M}$ [(U)$\left.{ }^{14} \mathrm{C}\right]$-Gln and $20 \mu \mathrm{M}_{\text {preQ }}$-tRNA ${ }^{\mathrm{Ser}}, 7.8 \mu \mathrm{g} M j \mathrm{TgtA} 2$. 


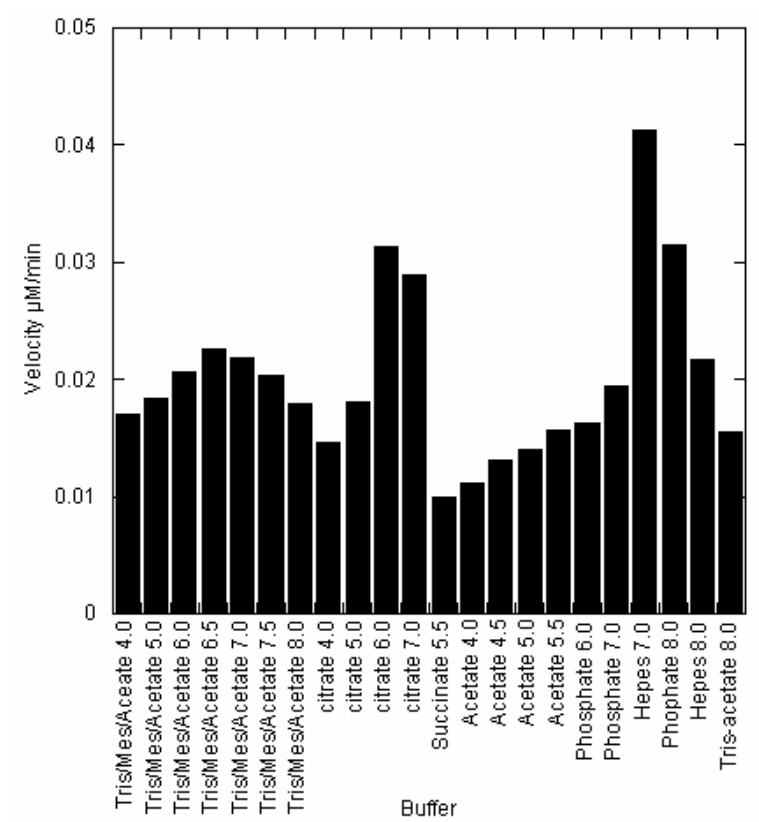

Figure 25: Activity of $M j$ TgtA2 in different buffers.

Reaction conditions; $100 \mathrm{mM}$ buffer, $0.5 \mathrm{M} \mathrm{NaCl}, 20 \mathrm{mM} \mathrm{MgCl} 2,1 \mathrm{mM}$ DTT, $10 \mu \mathrm{M}\left[(\mathrm{U}){ }_{-}^{14} \mathrm{C}\right]-\mathrm{Gln}$ and $20 \mu \mathrm{M} \mathrm{preQ}_{0}$-tRNA ${ }^{\mathrm{Ser}}, 7.8 \mu \mathrm{g} \mathrm{Mj}_{\mathrm{TgtA}} 2$

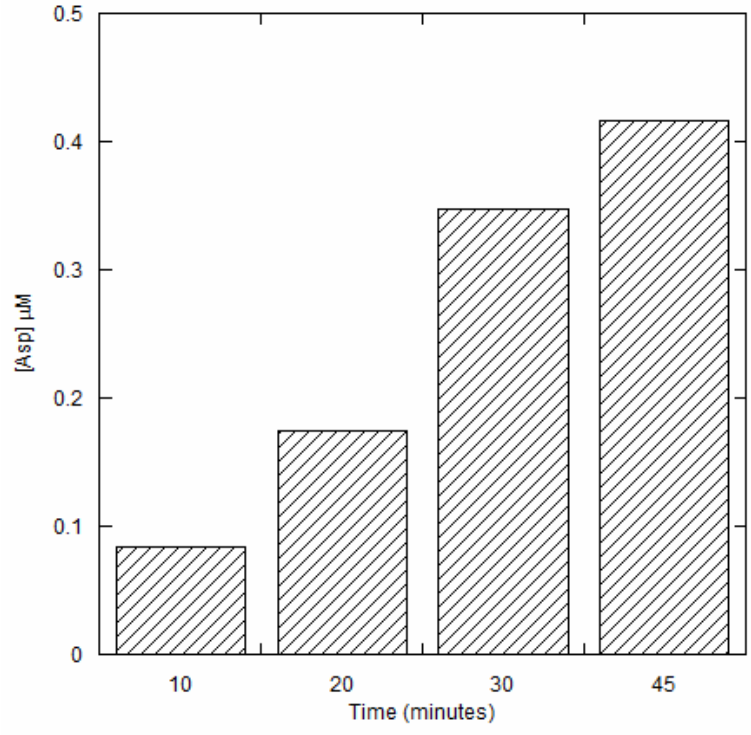

Figure 26: Asparaginase activity of MjTgtA2.

Reaction conditions; $100 \mathrm{mM}$ HEPES (pH 7.0), MjTgtA2, $0.5 \mathrm{M} \mathrm{NaCl}, 15 \mathrm{mM} \mathrm{MgCl} 2,2 \mathrm{mM}$ DTT, 12.4 $\mu \mathrm{M}\left[{ }^{3} \mathrm{H}\right]-\mathrm{L}-\mathrm{Asn}, 20 \mu \mathrm{M}_{\text {preQ }_{0}}$-tRNA ${ }^{\mathrm{Ser}}$ 
A.

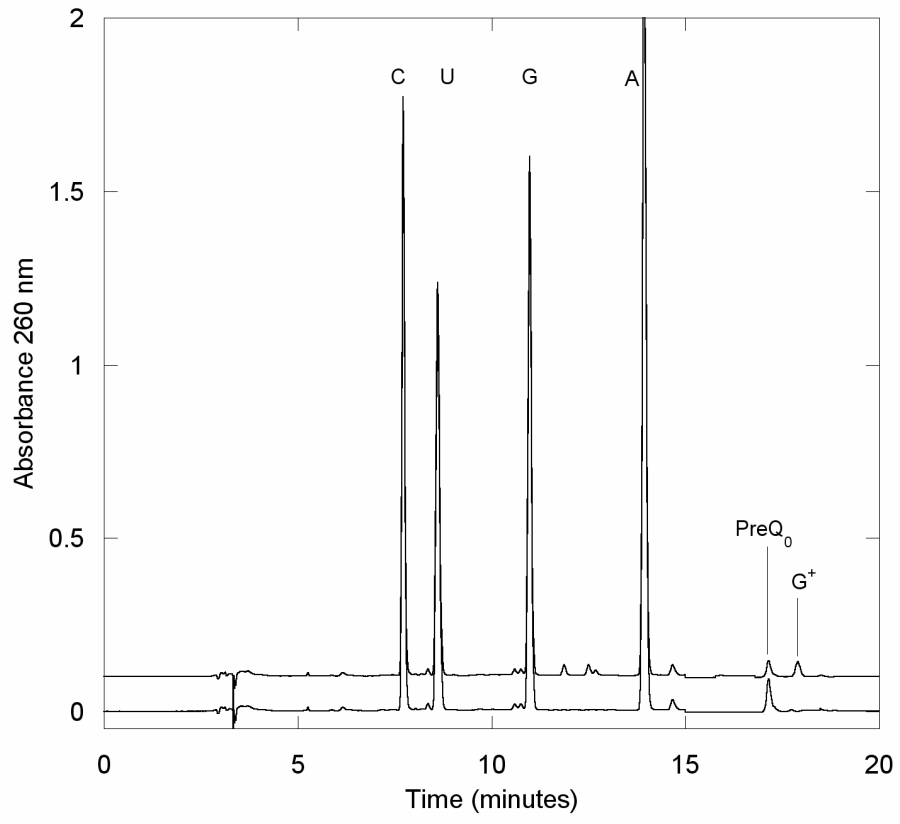

B.

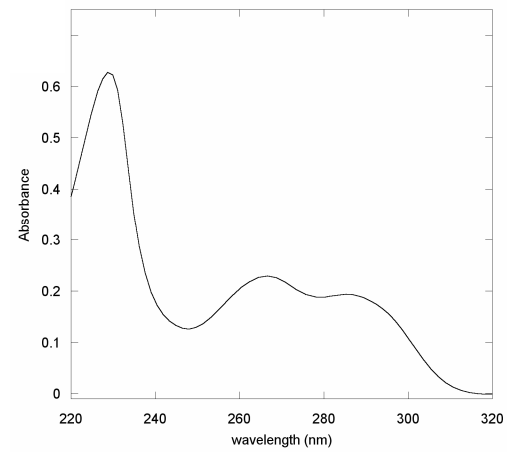

C.

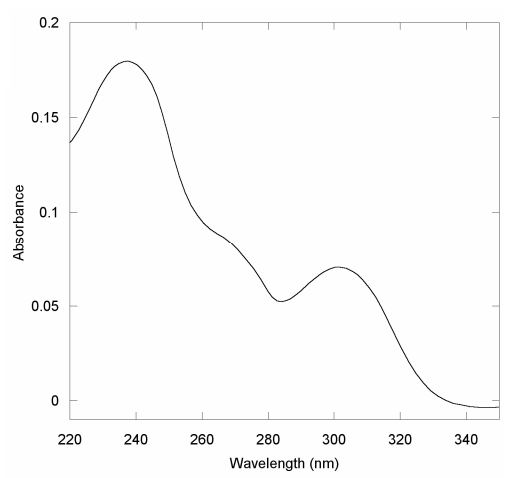

Figure 27: HPLC analysis of tRNA nucleosides from $M j$ TgtA2 activity.

Amidotransferase activity was determined in the presence of $\mathrm{NH}_{4} \mathrm{Cl}$, Gln or Asn at $40^{\circ} \mathrm{C}$. The tRNA was purified and digested as previously stated and analyzed on HPLC. (A) Reversed phase HPLC separation of nucleosides from $\mathrm{preQ}_{0}-\mathrm{tRNA}{ }^{\mathrm{Ser}}$ (red) and $\mathrm{G}^{+}-\mathrm{tRNA}{ }^{\mathrm{Ser}}$ (blue). (B) $\mathrm{PreQ}_{0}$ characteristic chromophore. (C) Archaeosine characteristic chromophore. 

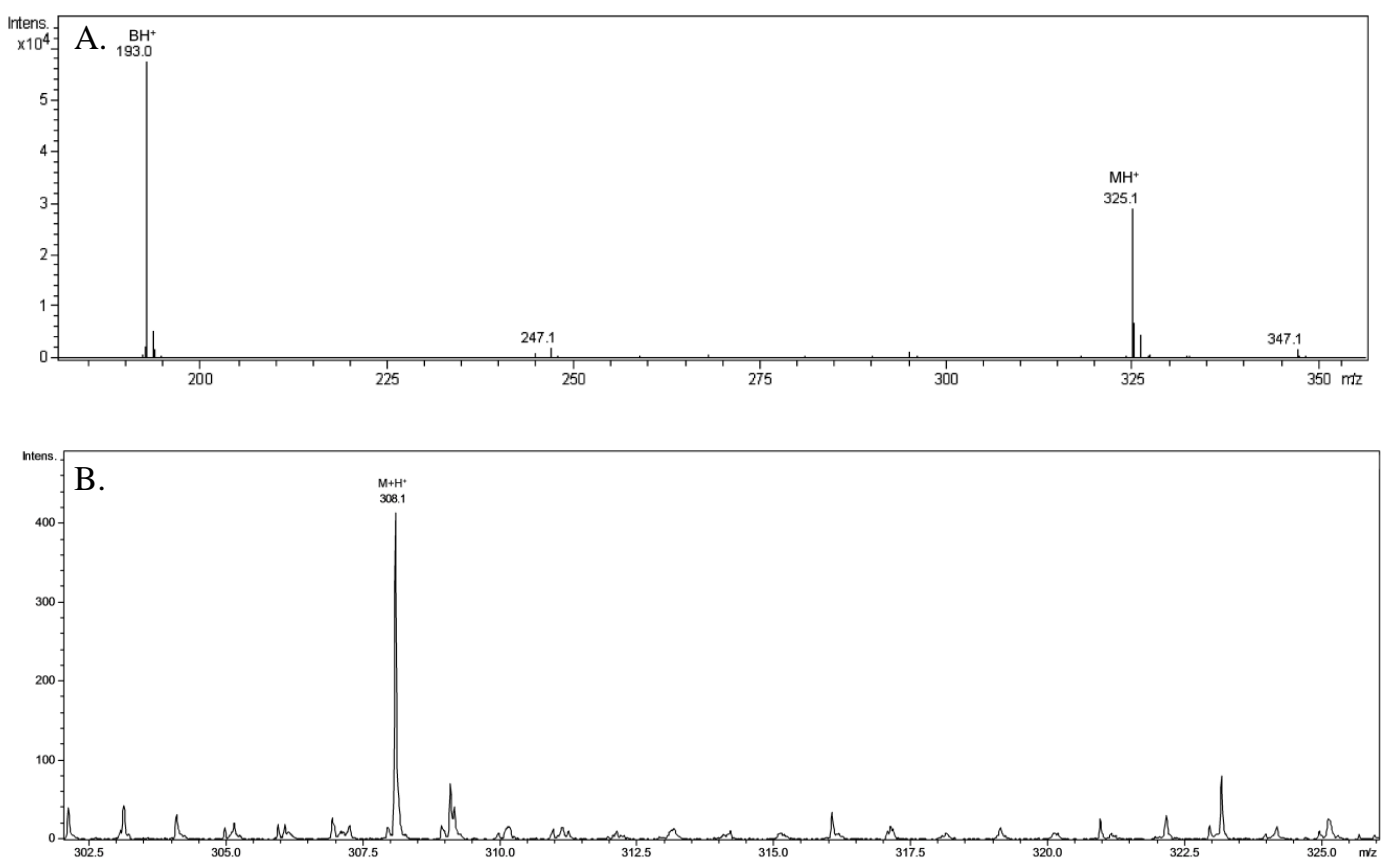

Figure 28: ESI mass spectrum of nucleosides archaeosine and pre $Q_{0}$ nucleoside

(A) $\mathrm{G}^{+} \mathrm{M}_{\mathrm{r}}$ calculated, 324, $\mathrm{MH}^{+}$ion $325, \mathrm{M}_{\mathrm{r}}$ of the neutral base of $\mathrm{G}^{+} 192, \mathrm{BH}_{2}{ }^{+}$ion 193. (B) $\mathrm{PreQ}_{0}$ calculated mass $307, \mathrm{MH}^{+}$ion 308 . 


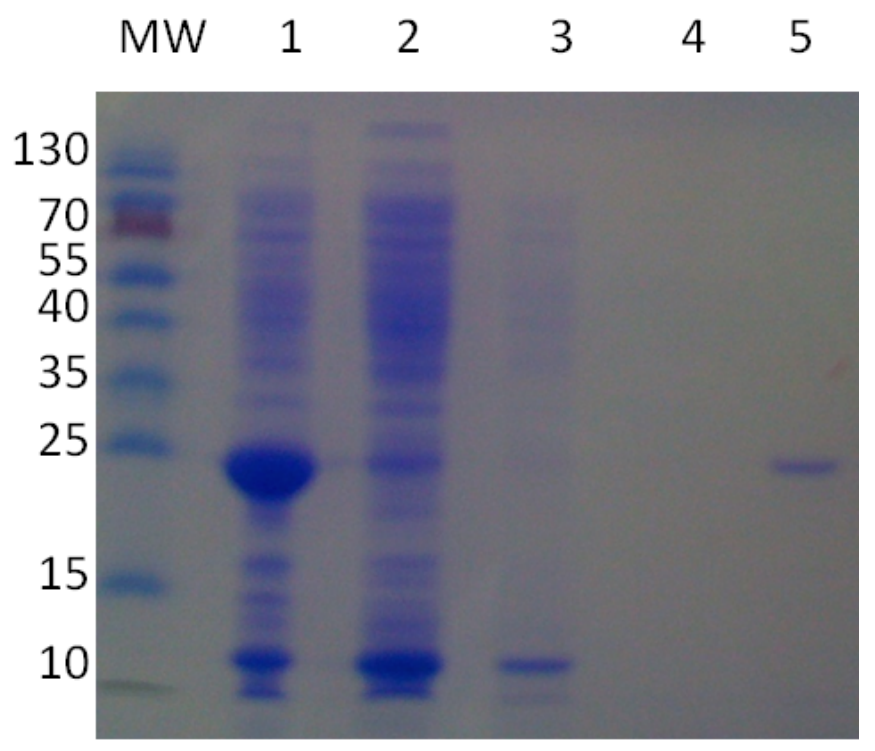

Figure 29: SDS/PAGE analyses of QueF purification by $\mathrm{Ni}^{2+}$-NTA agarose chromatography.

lane 1, MW marker ; lane 2, cell lysis free extract; lane 3, flow through; lane 4, wash ; lane 5, purified His $_{6}$-QueF.

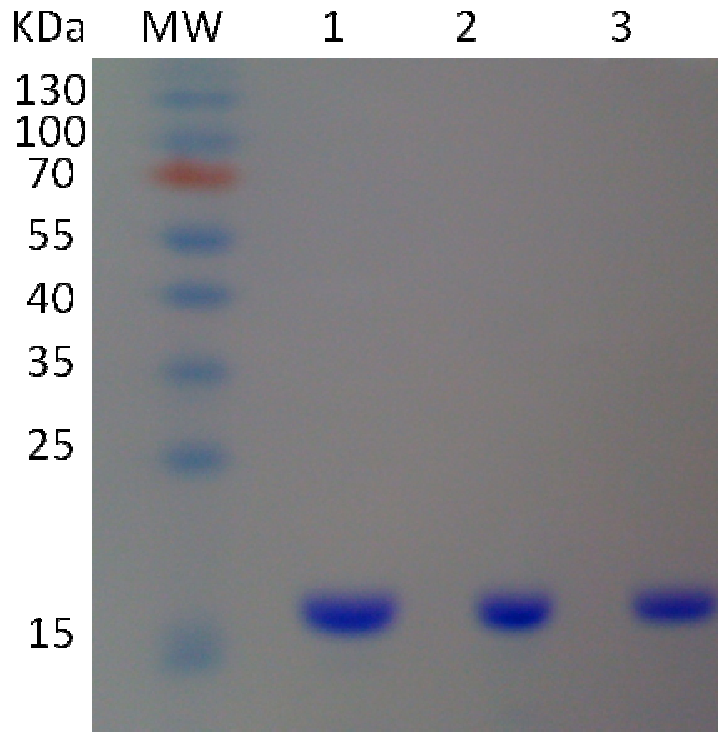

Figure 30: SDS/PAGE analyses of cleaved QueF proteins.

lane 1, MW marker ; lane 2, Wild type QueF; lane 3, C55A mutant; lane 4, E78A mutant 


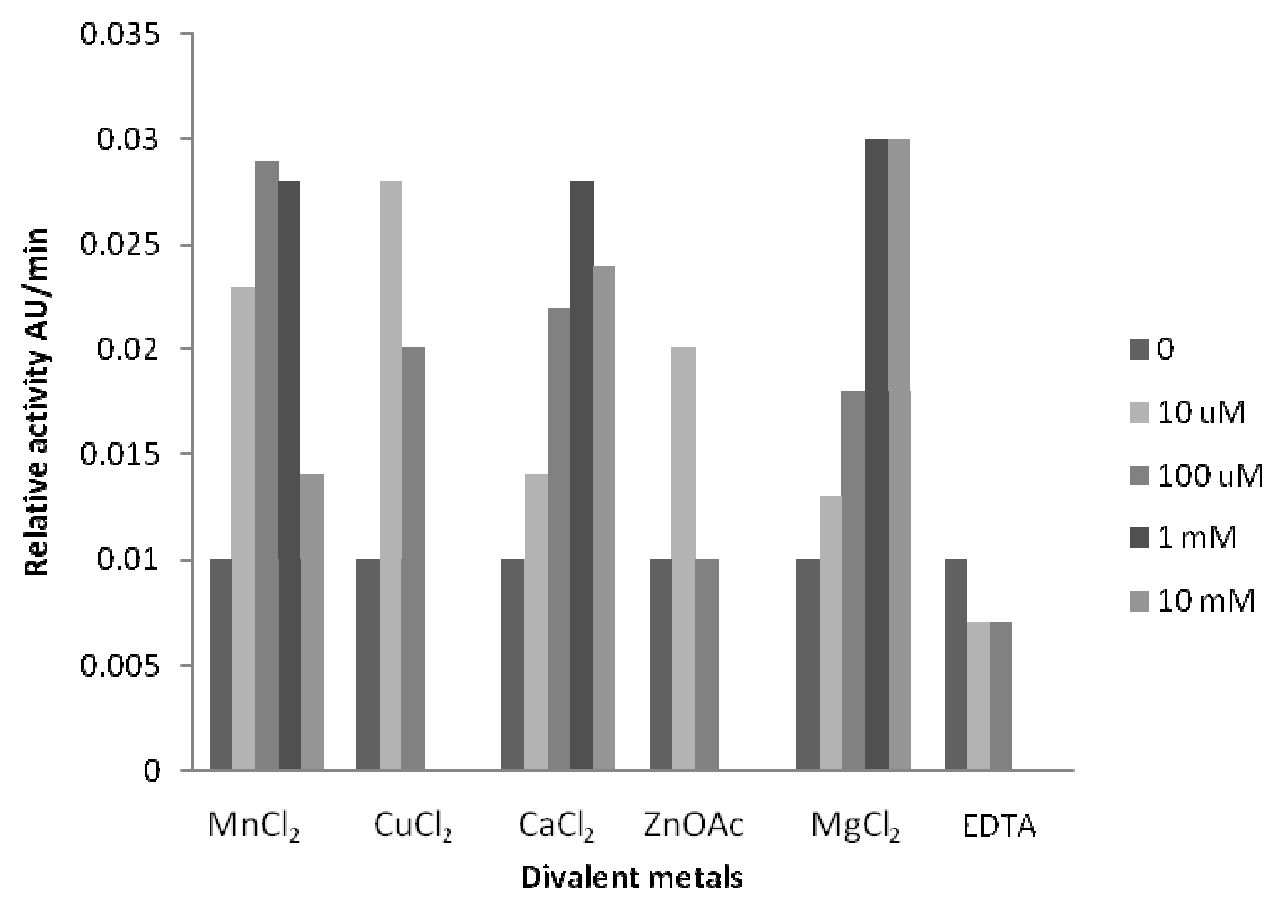

Figure 31: Effect of Divalent metals on native QueF activity.

Reaction conditions: $100 \mathrm{mM}$ Tris-HCl (pH 7.5), $100 \mathrm{mM} \mathrm{KCl,} 1 \mathrm{mM}$ DTT, $80 \mu \mathrm{M}$ NADPH, $150 \mu \mathrm{M}$ $\mathrm{preQ}_{0}, 1 \mu \mathrm{M}$ QueF, and the divalent metal $(0$ to $10 \mathrm{mM})$ at $30^{\circ} \mathrm{C}$. The change in absorbance of NADPH was monitored at $340 \mathrm{~nm}$. 

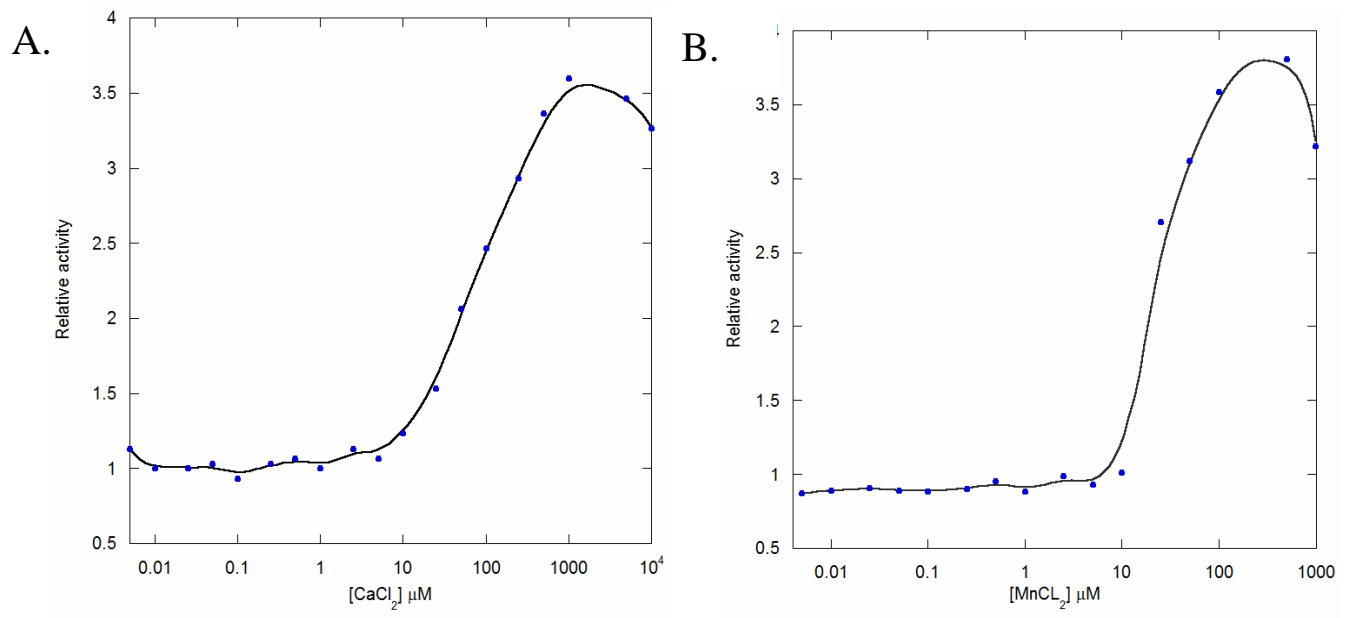

C.

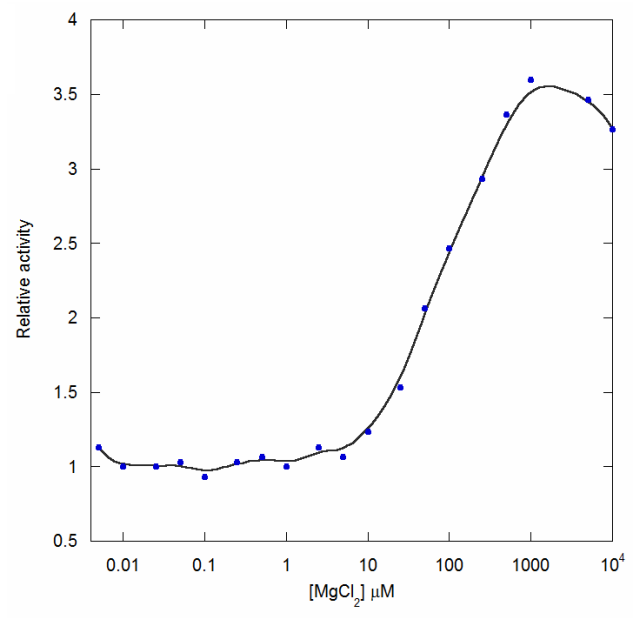

Figure 32: Effect of Divalent metals on demetallated QueF activity.

Reaction conditions: $100 \mathrm{mM}$ Tris- $\mathrm{HCl}$ (pH 7.5), $100 \mathrm{mM} \mathrm{KCl,} 1 \mathrm{mM}$ DTT, $80 \mu \mathrm{M}$ NADPH, $150 \mu \mathrm{M}$ preQ $_{0}, 1 \mu \mathrm{M}$ QueF, and the divalent metal $(0$ to $10 \mathrm{mM})$ at $30^{\circ} \mathrm{C}$. The change in absorbance of NADPH was monitored at $340 \mathrm{~nm}$. 
A.

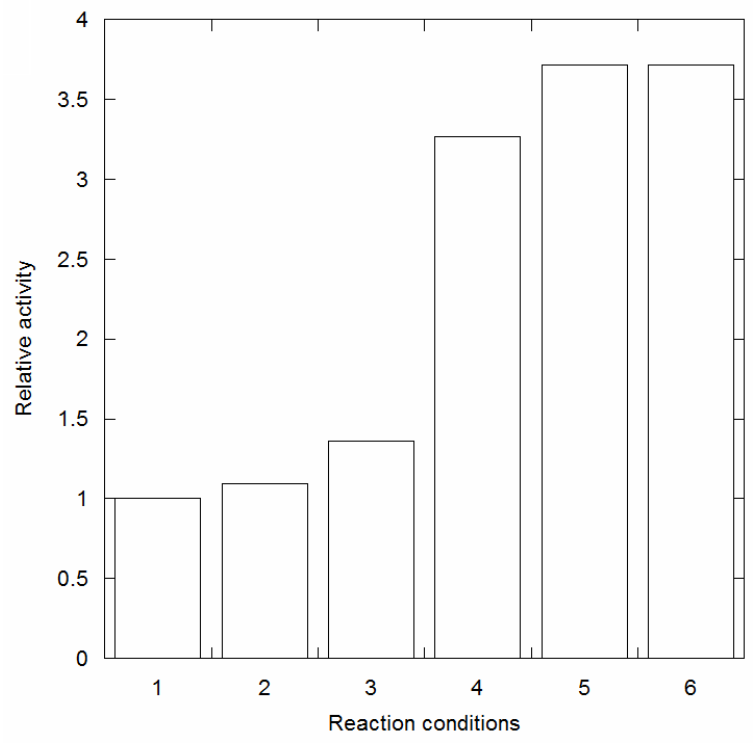

B.

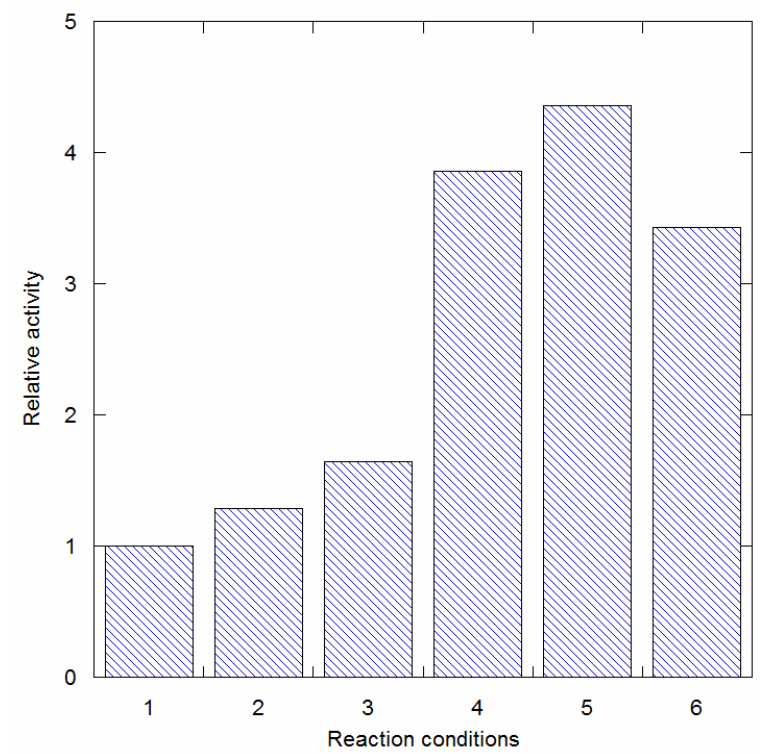

Figure 33: Effect of $\mathrm{KCl}$ concentration on QueF activity.

A) Native QueF B) Apoprotein 1) $100 \mathrm{mM} \mathrm{KCl} \mathrm{2)} 50 \mathrm{mM} \mathrm{KCl} \mathrm{3)} 10 \mathrm{mM} \mathrm{KCl} 4) 100 \mathrm{mM} \mathrm{KCl}$ and 0.25 $\mathrm{mM} \mathrm{MnCl}{ }_{2}$ 5) $50 \mathrm{mM} \mathrm{KCl}$ and $0.25 \mathrm{mM} \mathrm{MnCl}_{2}$ 6) $10 \mathrm{mM} \mathrm{KCl}$ and $0.25 \mathrm{mM} \mathrm{MnCl}_{2}$. Assay conditions; $100 \mathrm{mM}$ Tris-HCl, $1 \mathrm{mM}$ DTT, $80 \mu \mathrm{M} \beta-\mathrm{NADPH}, 150 \mu \mathrm{M}$ preQ $_{0}, 1 \mu \mathrm{M}$ QueF and $\mathrm{KCl}$ varied. 
A.

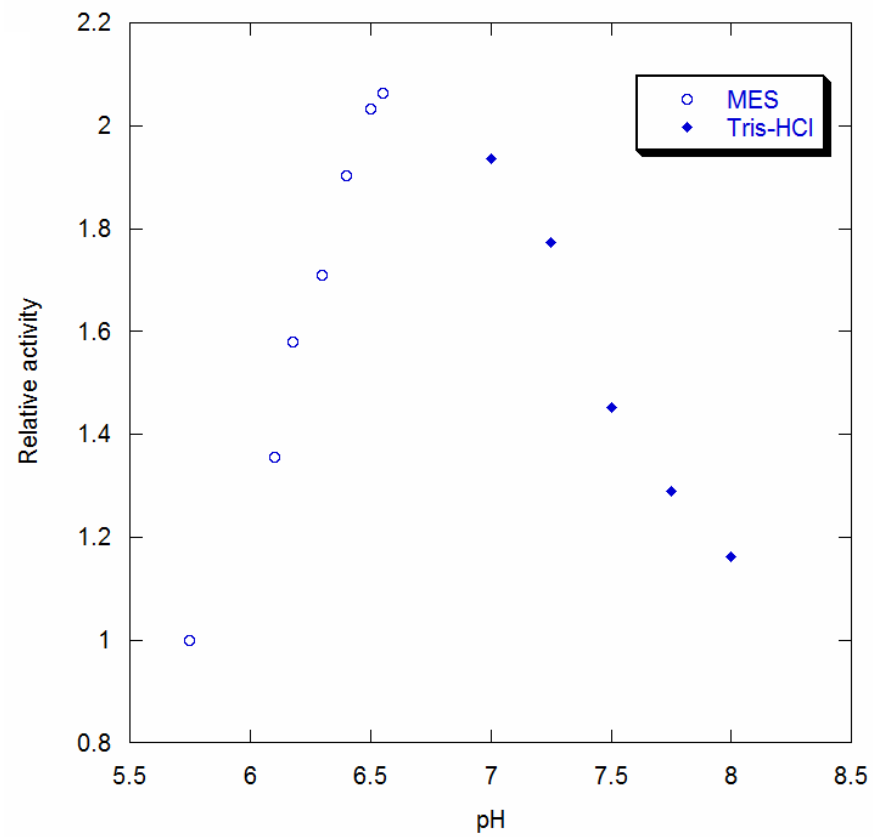

B.

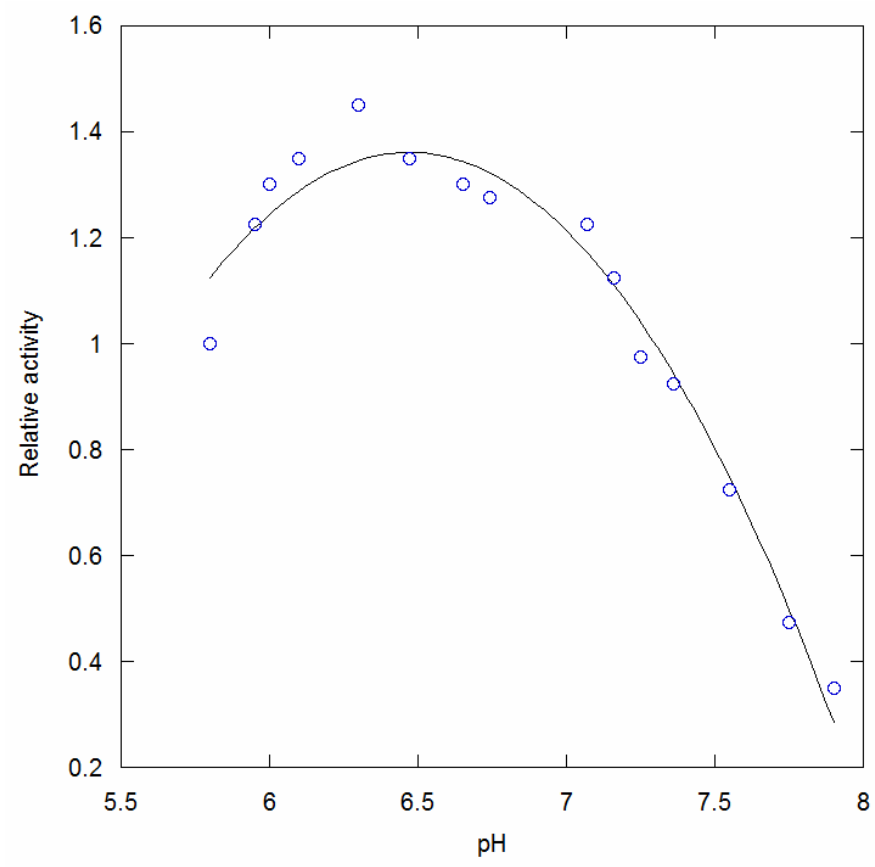

Figure 34: $\mathrm{pH}$ profile determination of QueF

Assay conditions: $100 \mathrm{mM}$ Buffer, $50 \mathrm{mM} \mathrm{KCl} 1 \mathrm{mM}$ DTT, $80 \mu \mathrm{M} \beta$-NADPH, $100 \mu \mathrm{M}$ preQ ${ }_{0}, 2 \mu \mathrm{M}$ QueF, and $250 \mu \mathrm{M} \mathrm{MnCl}_{2}$ reaction was carried out at $30^{\circ} \mathrm{C}$

(A) MES (pH 5.75 - 6.55) and Tris- $\mathrm{HCl}(\mathrm{pH} 7.0$ - 8.0) (B) potassium phosphate 
A.

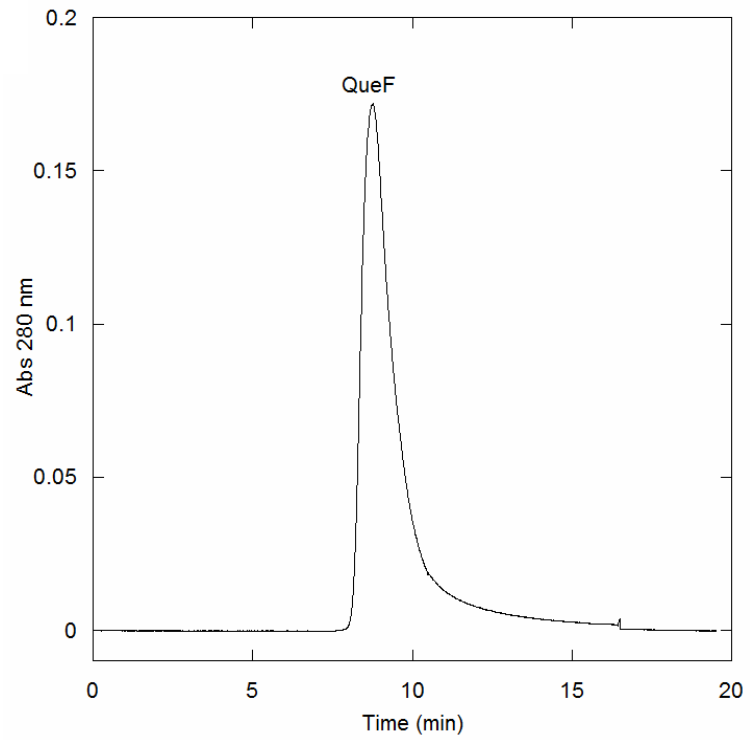

B.

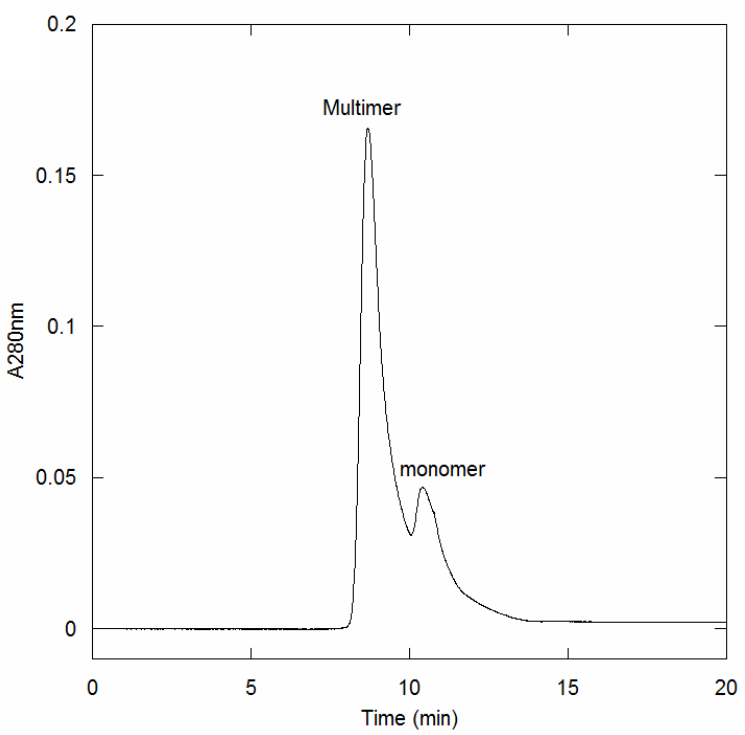

Figure 35: HPLC analytical gel filtration analysis of QueF.

(A) QueF alone elutes at $8.57 \mathrm{~min}$ (B) QueF alone in the presence of $0.5 \mathrm{M} \mathrm{KCl}$ and $10 \mathrm{mM}$ EDTA elutes at $8.78 \mathrm{~min}$ and at $10.4 \mathrm{~min}$. 


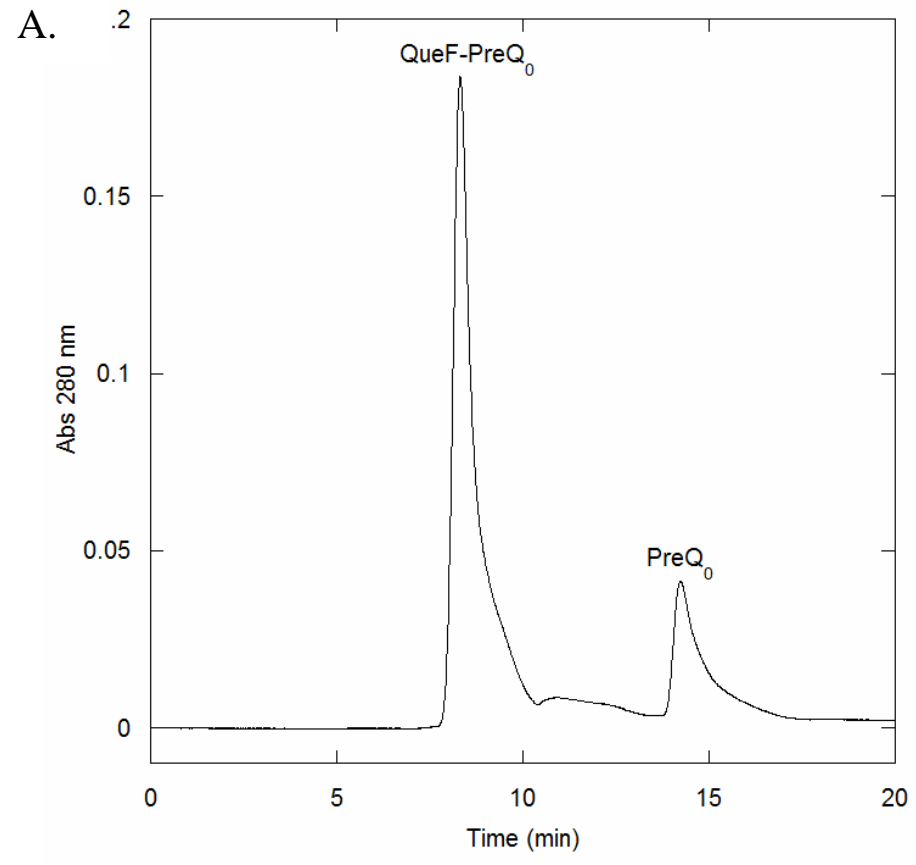

C.
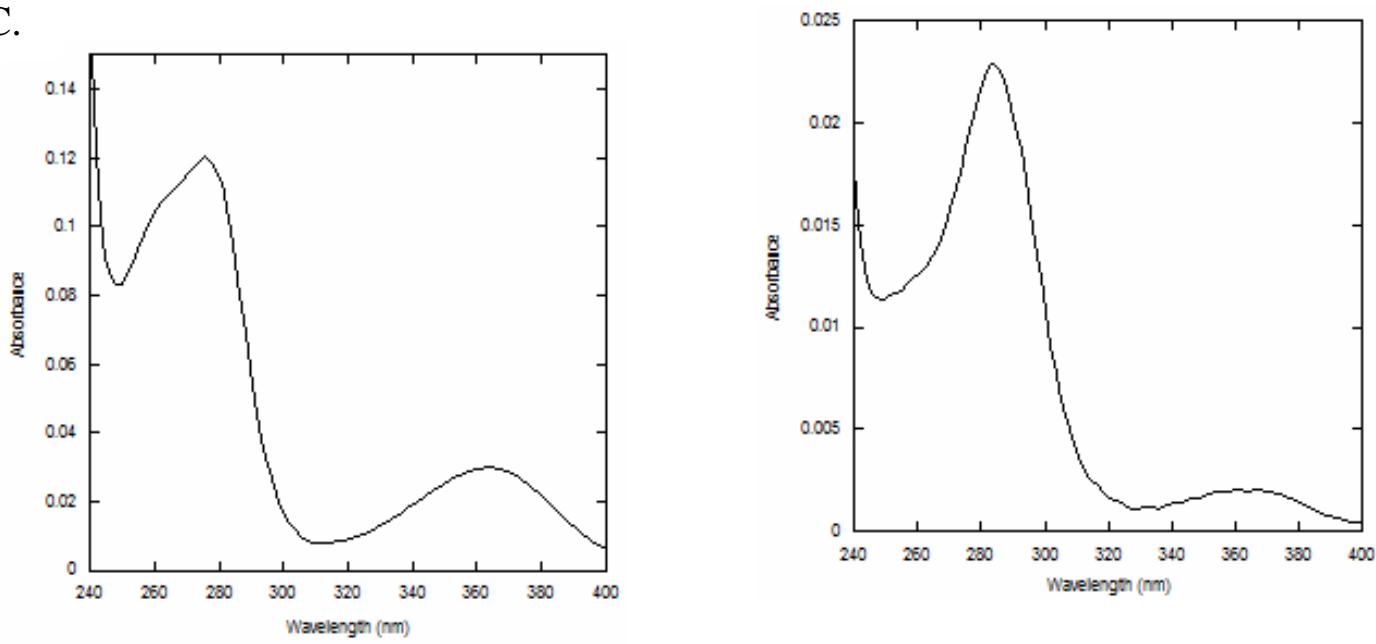

Figure 36: HPLC analytical gel filtration analysis of QueF-PreQ $_{0}$ complex.

(A) QueF-PreQ ${ }_{0}$ complex elutes at 8.33 min (B) Spectrum at 8.33 min i.e decamer (C) Spectrum at 10.4 min (monomer). 

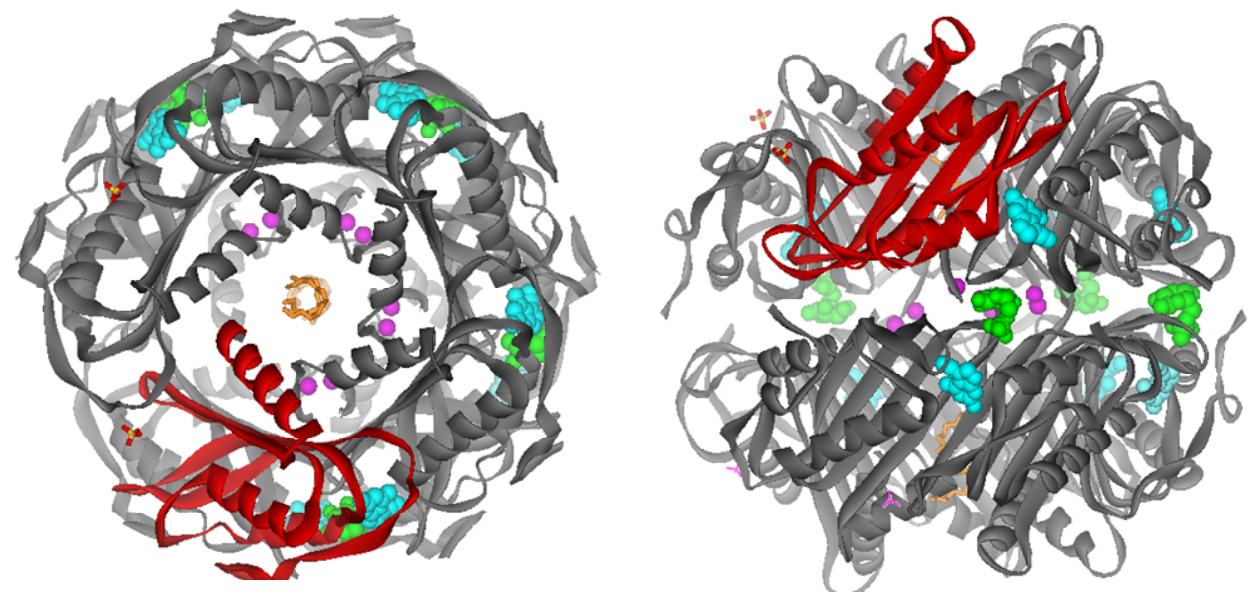

Figure 37: B. subtilis QueF Homodecamer.

One subunit is highlighted in red. $\mathrm{Mg}^{2+}$ ions are shown as magenta spheres. Bound preQ $_{0}$ molecules are shown in cyan. Bound glucose sulfate or glucosamine found in the non-covalent complex is shown in green in the NADPH binding pocket.

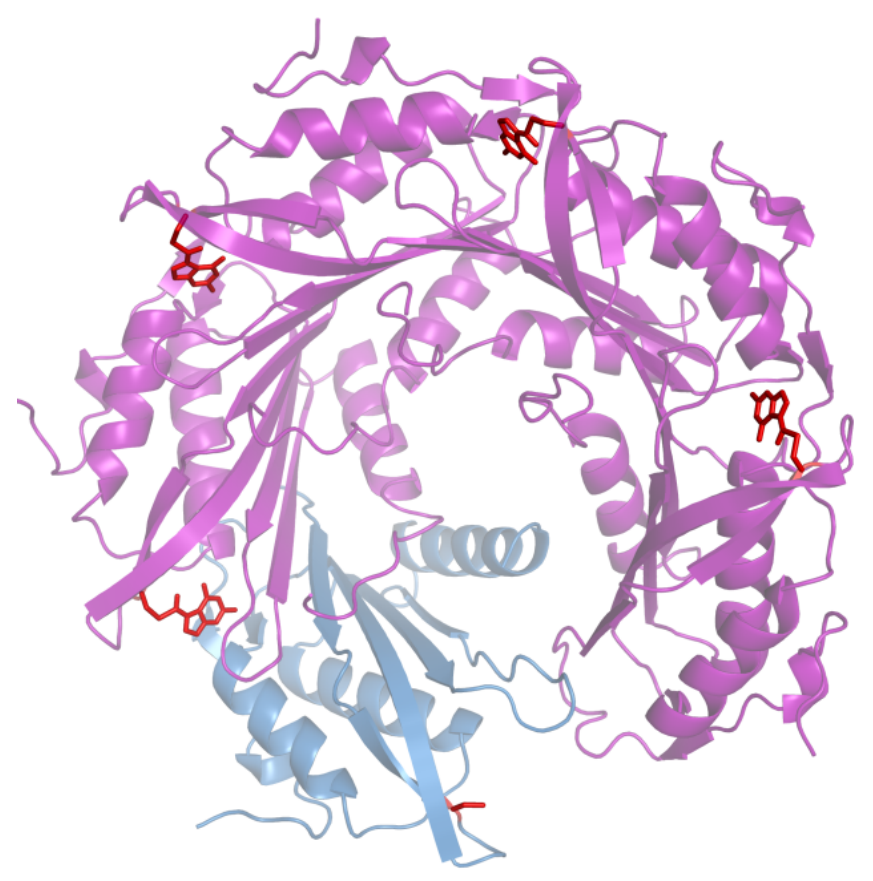

Figure 38: Crystal structure of QueF pentamer.

One subunit is highlighted in blue, the thioimide is shown in red. 


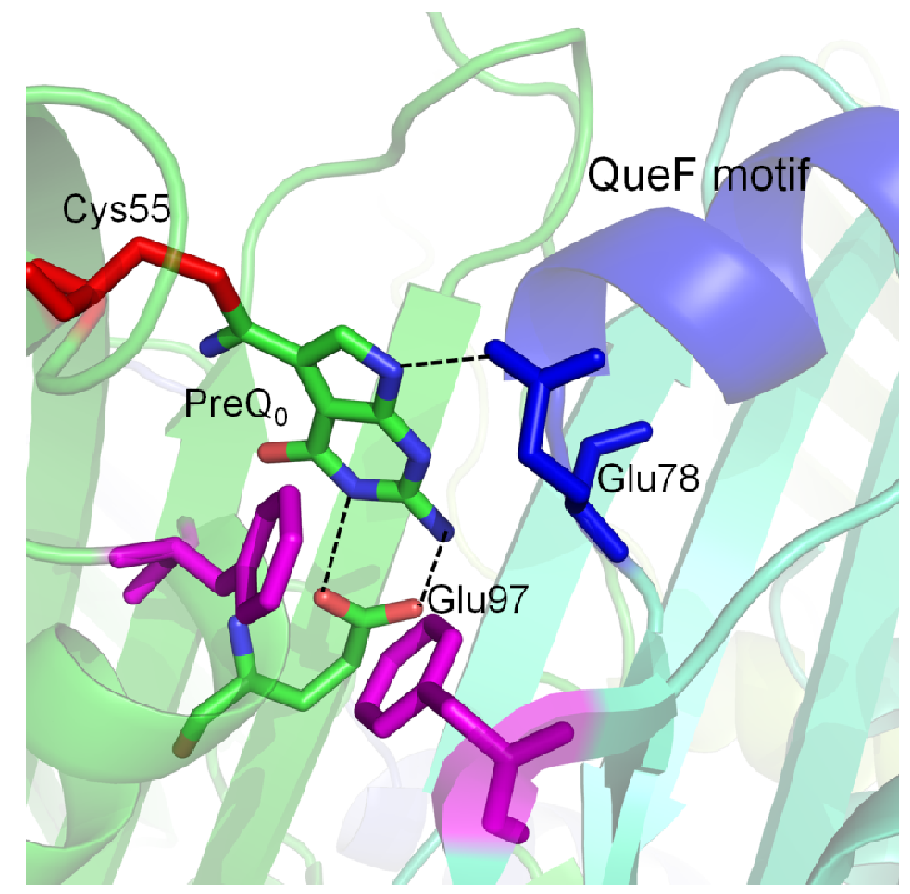

Figure 39: Thioimide formed in the active site of QueF.

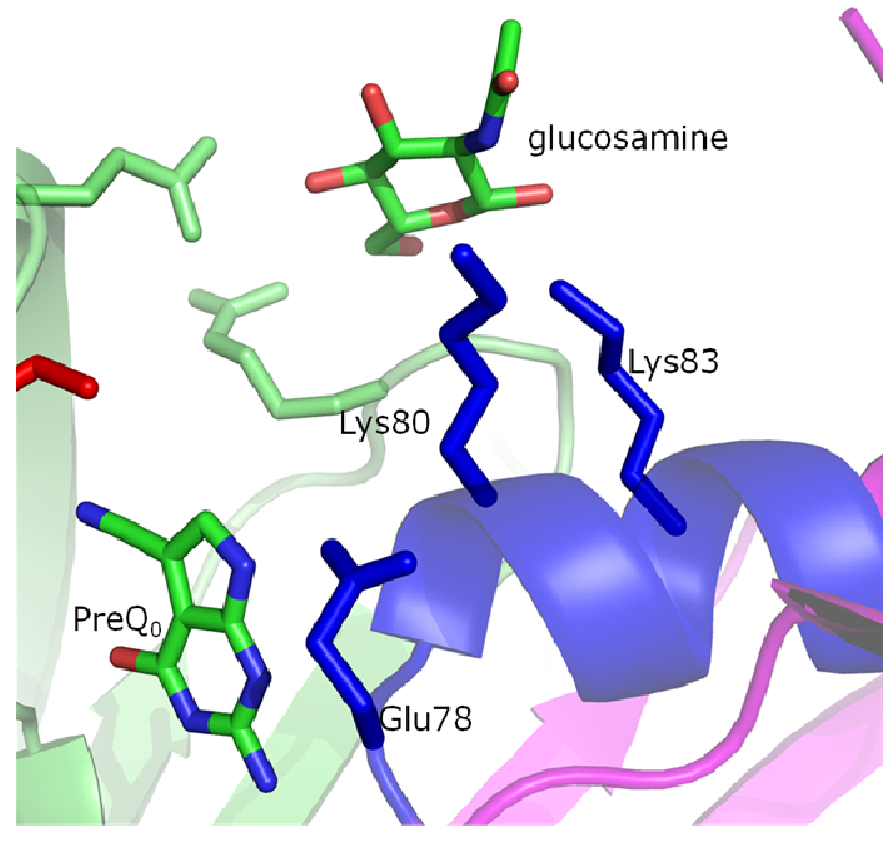

Figure 40: QueF Cofactor Binding site 

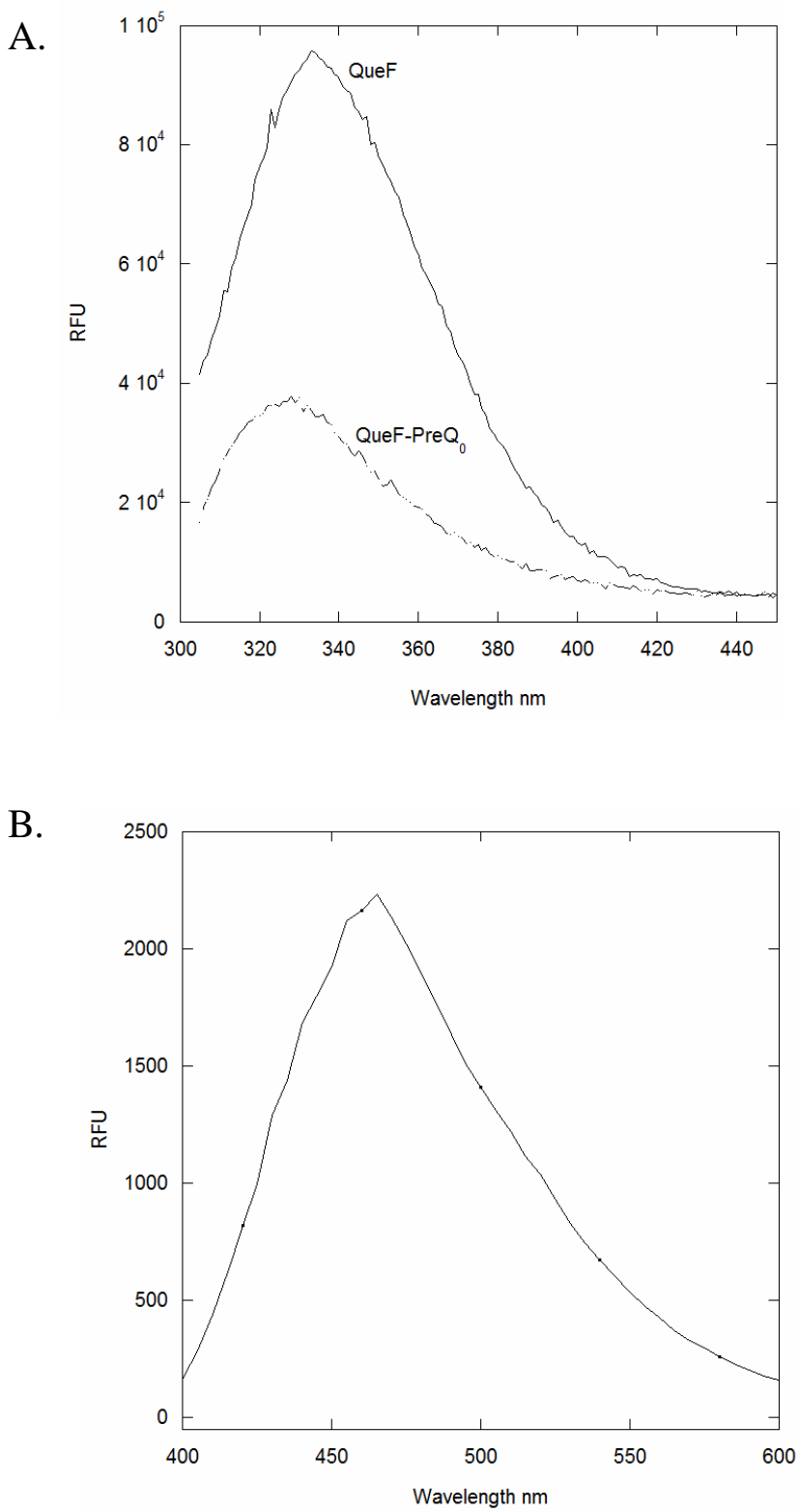

Figure 41: QueF and NADPH Fluorescence.

Excitation of QueF at $295 \mathrm{~nm}$ and of NADPH at $340 \mathrm{~nm}$ is shown. (A) $50 \mathrm{mM}$ phosphate (pH 6.5), $50 \mathrm{mM}$ $\mathrm{KCl}, 1 \mathrm{mM}$ DTT, $250 \mu \mathrm{M} \mathrm{MnCl}_{2}, 80 \mu \mathrm{M}$ QueF and $100 \mu \mathrm{M} \mathrm{preQ}_{0}$ (the solid line) and without preQ ${ }_{0}$ (broken line). (B) NADPH fluorescence. 


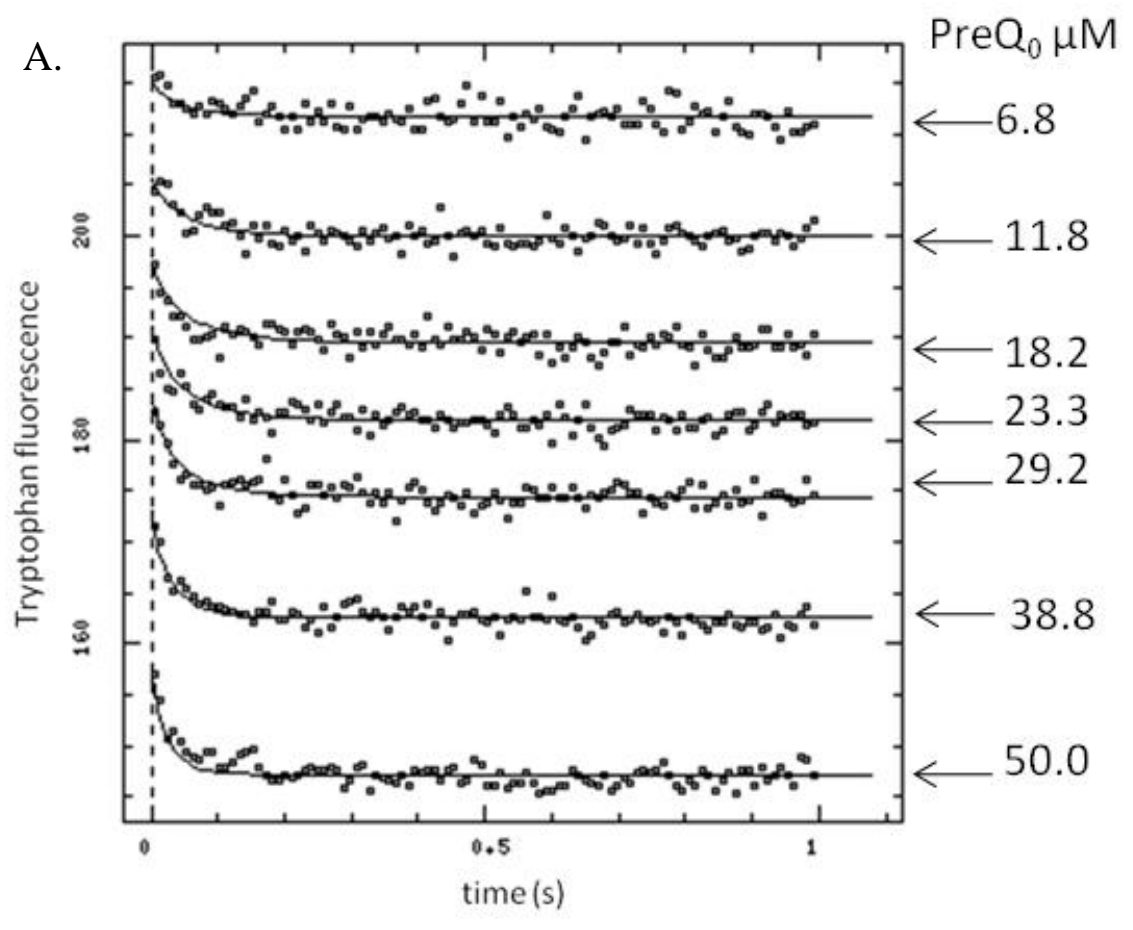

B.

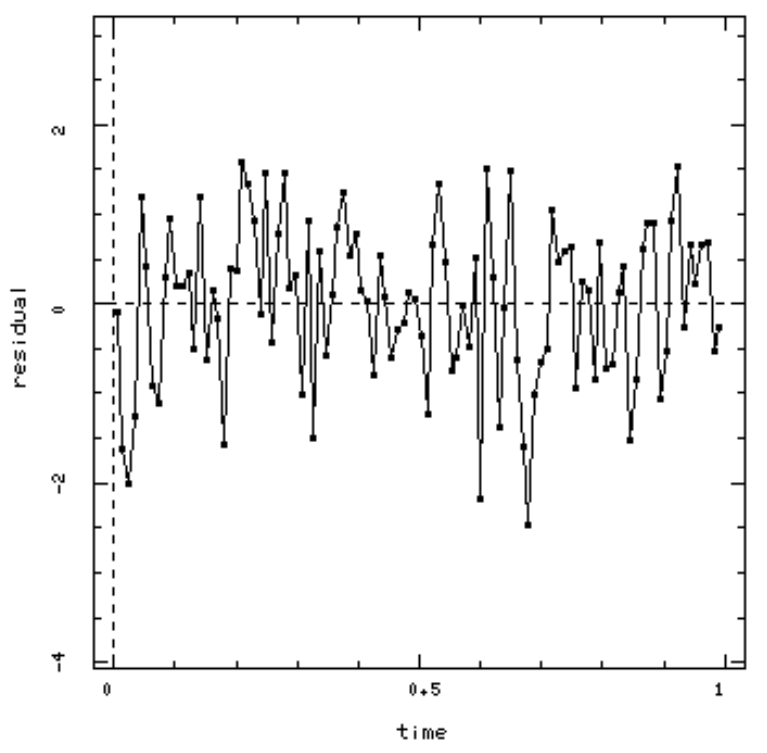

Figure 42: Transient state analysis of tryptophan quenching upon pre $Q_{0}$ binding to $\mathbf{C 5 5} \mathrm{A}$.

(A) Global analysis of pre $\mathrm{Q}_{0}$ binding (final concentrations in reaction: $200 \mu \mathrm{M}$ QueF, $50 \mathrm{mM}$ potassium phosphate (pH 6.5), $50 \mathrm{mM} \mathrm{KCl}, 250 \mu \mathrm{M} \mathrm{MnCl}_{2}, 1 \mathrm{mM}$ DTT and $\mathrm{preQ}_{0}(6.8,11.8,18.2,23.3,29.2,38.8$, $50.0 \mu \mathrm{M}$ ). The reaction was carried out at $20^{\circ} \mathrm{C}$. (B) residuals for the fit at $38.8 \mu \mathrm{M}$ preQ $\mathrm{Q}_{0}$. Time is in seconds. 
A.

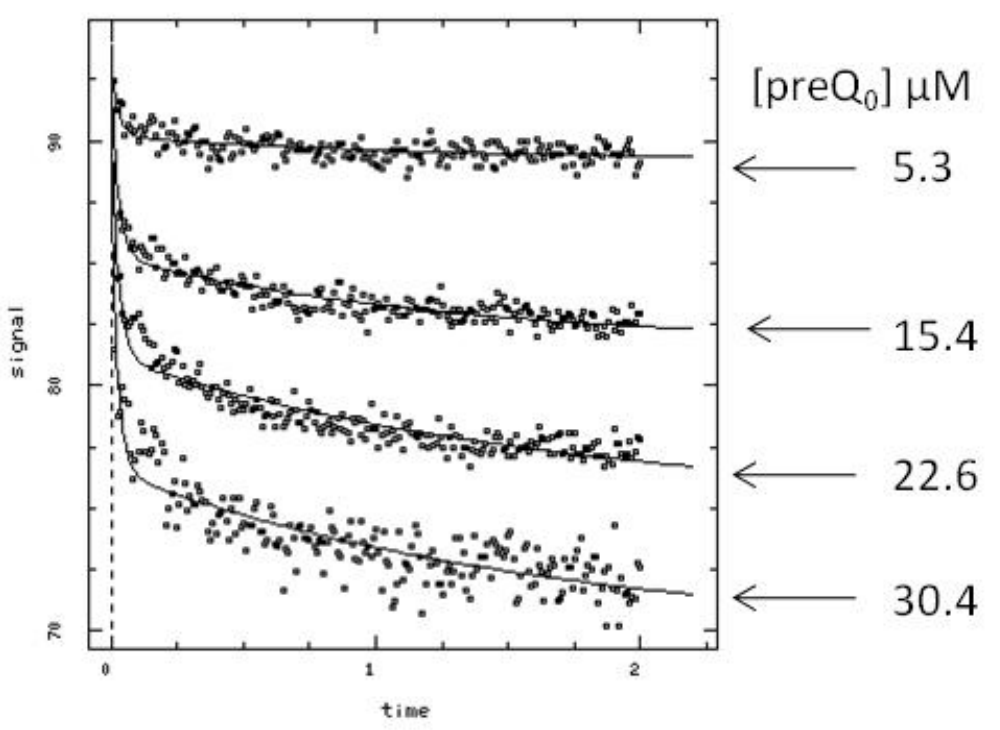

B.

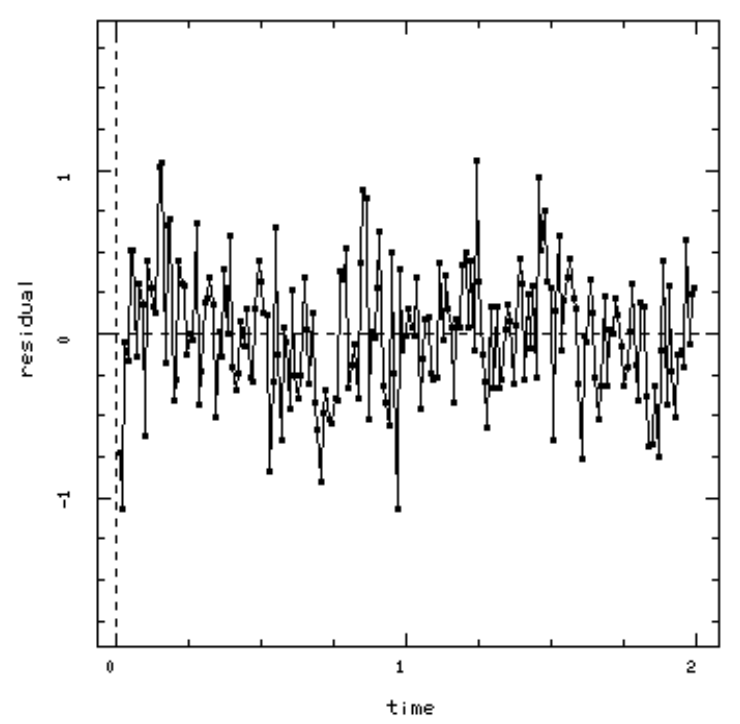

Figure 43: Transient state analysis of tryptophan quenching upon preQ $_{0}$ binding to wild type QueF.

(A) Global analysis of pre $\mathrm{Q}_{0}$ binding (final concentrations in reaction: $200 \mu \mathrm{M}$ QueF, $50 \mathrm{mM}$ potassium phosphate (pH 6.5), $50 \mathrm{mM} \mathrm{KCl}, 250 \mu \mathrm{M} \mathrm{MnCl}_{2}, 1 \mathrm{mM}$ DTT and $\mathrm{preQ}_{0}(5.3,15.4,22.6,30.4 \mu \mathrm{M})$. The reaction was carried out at $20^{\circ} \mathrm{C}$. (B) residuals for the fit at $15.4 \mu \mathrm{M}$ preQ $\mathrm{Q}_{0}$. Time is in seconds. 
A.

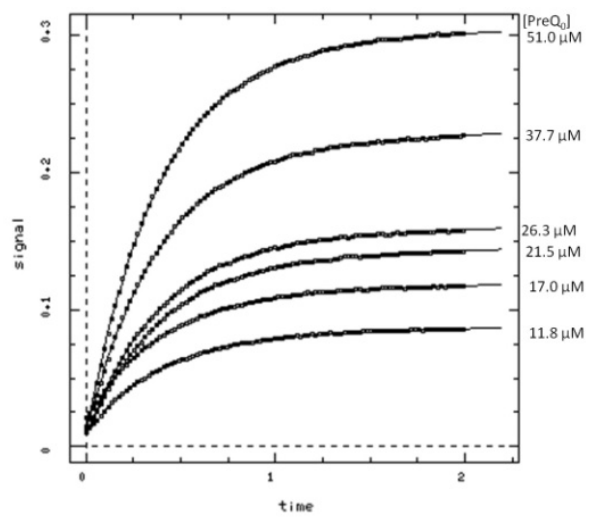

C.

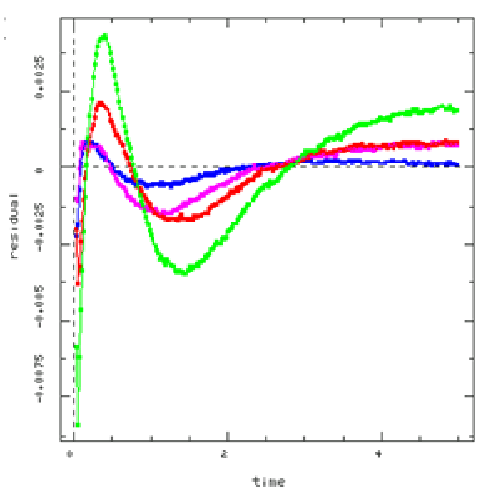

E.

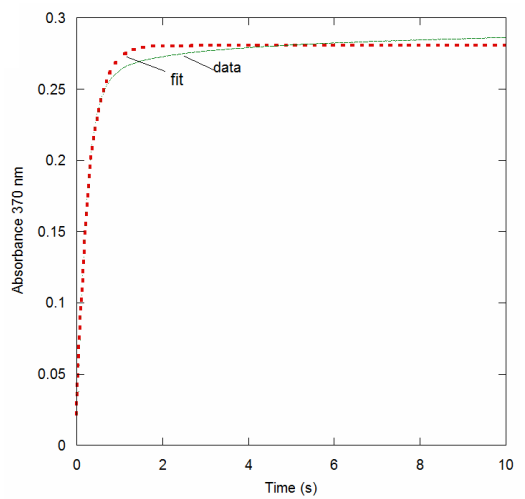

B.

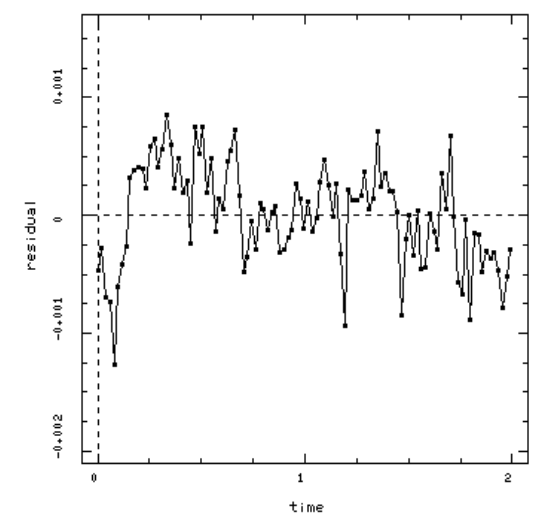

D.

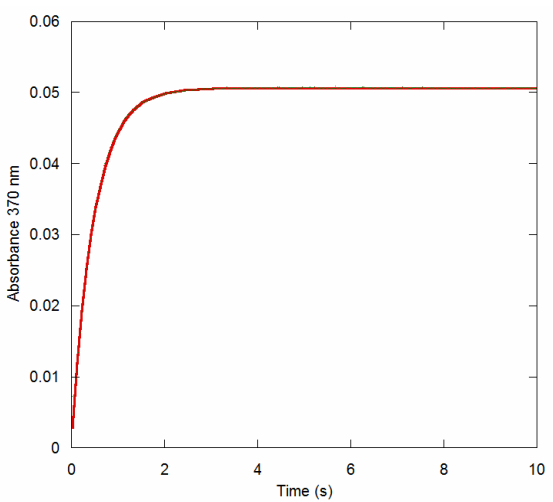

F.

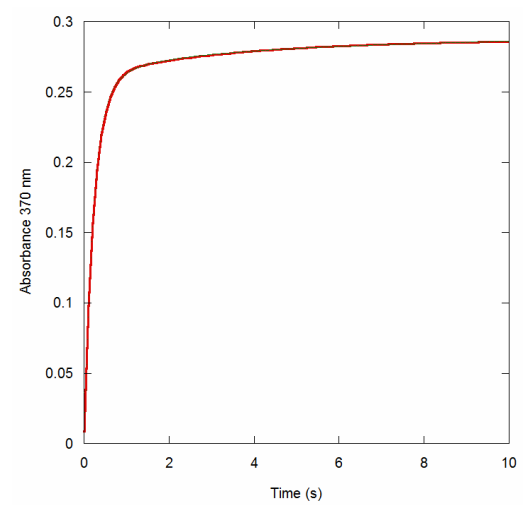

Figure 44: Absorbance measurements of thioimide formation in QueF under transient state conditions.

(A) Global analysis of thioimide formation (final concentrations in reaction: $62 \mu \mathrm{M}$ QueF, $50 \mathrm{mM}$ potassium phosphate ( $\mathrm{pH} 6.5$ ), $50 \mathrm{mM} \mathrm{KCl}, 250 \mu \mathrm{M} \mathrm{MnCl}_{2}, 1 \mathrm{mM}$ DTT and $\mathrm{preQ}_{0}$ concentration was varied (shown in figure). (B) Residuals for the fit in the presence of an isomerization step. (C) Residuals obtained in the absence of isomerization. (D) Thioimide formation at low preQ $_{0}$ concentrations $(40 \mu \mathrm{M}$ QueF and $7.8 \mu \mathrm{M}$ preQ $\mathrm{Q}_{0}$ ). (F) Single exponential fit for thioimide formation at high $\mathrm{pre}_{0}$ concentrations $\left(40 \mu \mathrm{M}\right.$ QueF and $400 \mu \mathrm{M}$ preQ ${ }_{0}$ ). (F) Double exponential fit for thioimide formation at high pre $\mathrm{Q}_{0}$ concentrations ( $40 \mu \mathrm{M}$ QueF and $400 \mu \mathrm{M}$ preQ $\left.{ }_{0}\right)$. 
A.

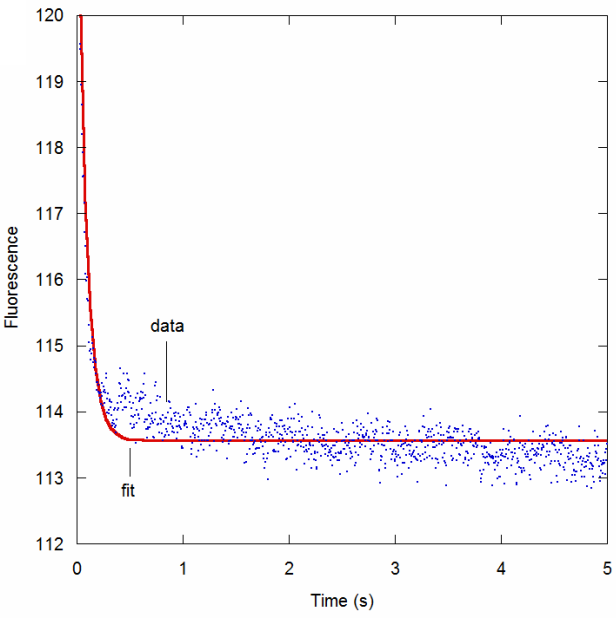

C.

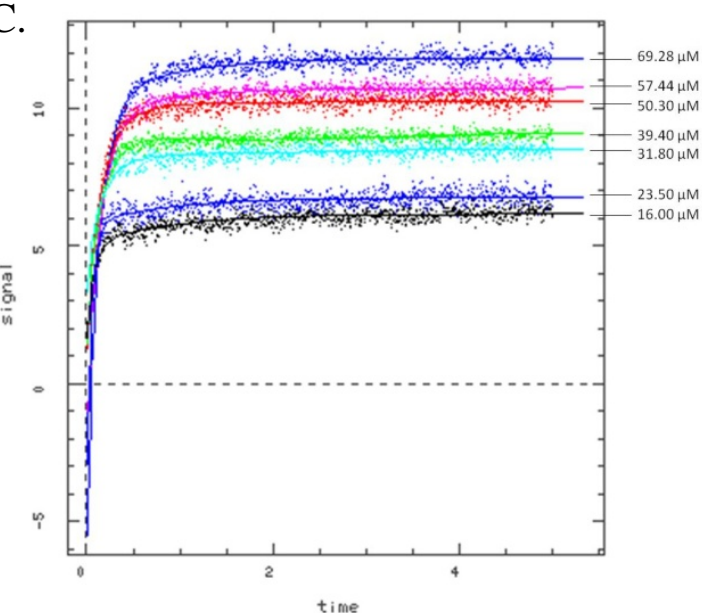

B.

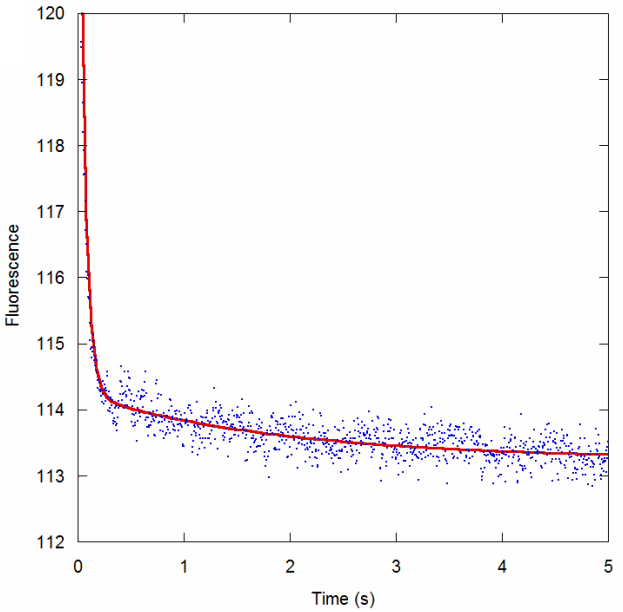

D.

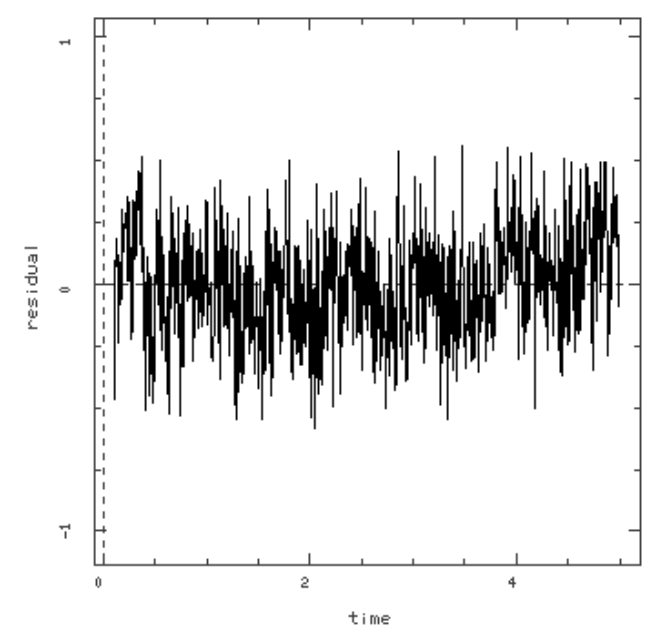

Figure 45: Transient state analysis of NADPH binding to E78A

(A) Single exponential decay fit for NADPH binding (100 $\mu \mathrm{M}$ E78A-*PreQ ${ }_{0}$ and $69.28 \mu \mathrm{M}$ NADPH). (B) Double exponential decay fit for NADPH binding $\left(100 \mu \mathrm{M}\right.$ E78A-*PreQ $Q_{0}$ and $69.28 \mu \mathrm{M}$ NADPH). (C) Global analysis of NADPH binding to $\mathrm{E}^{2} \mathrm{AA}-\mathrm{PreQ}_{0}$. (C) Residuals for the global fit analysis. The reaction was carried out at $20{ }^{\circ} \mathrm{C}$ in $50 \mathrm{mM}$ potassium phosphate buffer (pH 6.5), $50 \mathrm{mM} \mathrm{KCl}, 250 \mu \mathrm{M}$ $\mathrm{MnCl}_{2}$, and $1 \mathrm{mM}$ DTT. The E78A QueF mutant $(200 \mu \mathrm{M})$ was incubated with $700 \mu \mathrm{M}$ preQ $\mathrm{Q}_{0}$ for 10 minutes before mixing with varying concentrations of NADPH. The final concentrations of NADPH in the assay were; $16,23.5,31.8,39.4,50.3,57.44$, and $69.28 \mu \mathrm{M}$. The final concentration of $\mathrm{E}^{2} 8 \mathrm{~A}-* \mathrm{PreQ}_{0}$ in the reaction mixture was $100 \mu \mathrm{M}$. 

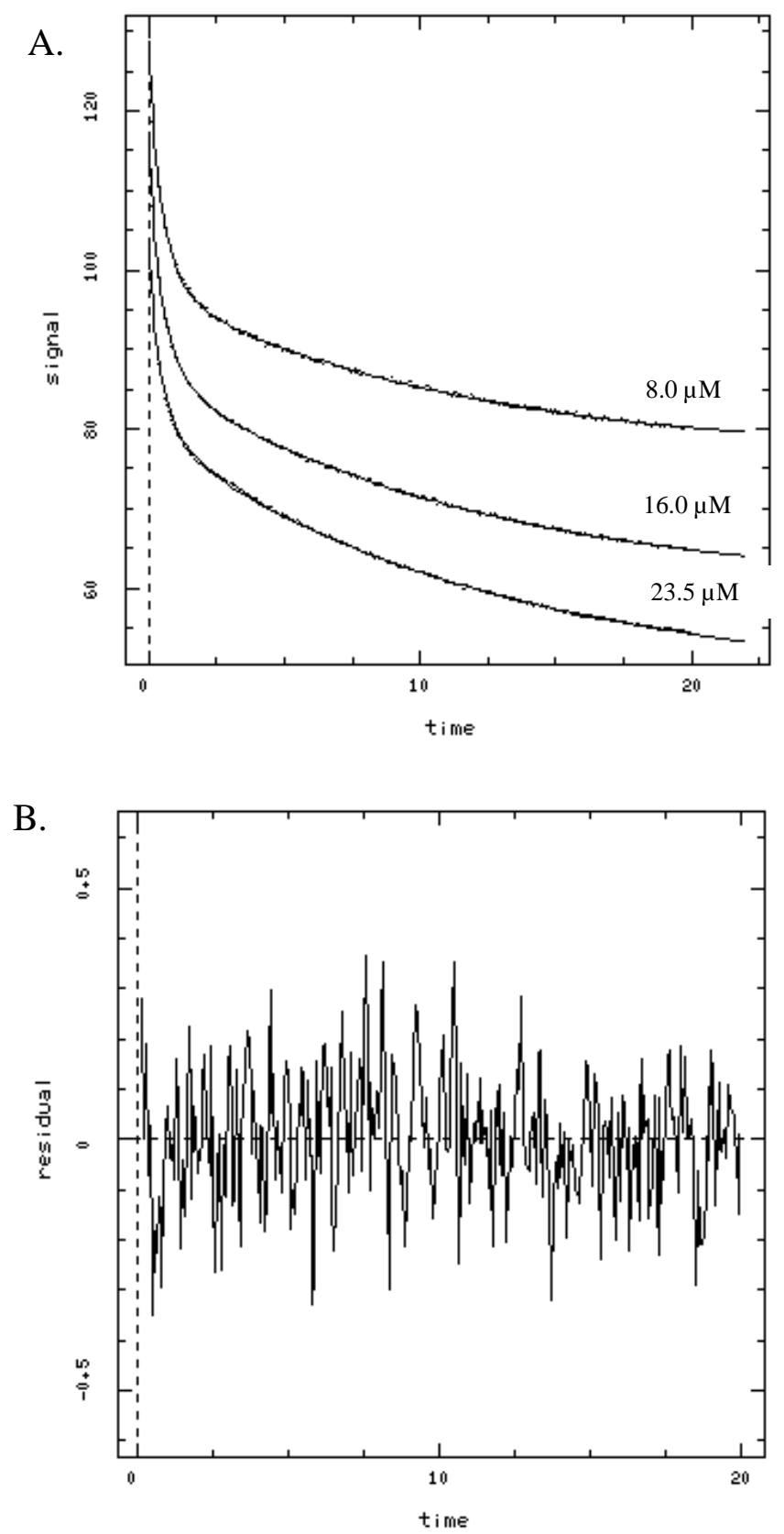

Figure 46: Transient state analysis of NADPH fluorescence

(A) Global analysis of NADPH binding to QueF-*PreQ $Q_{0}$. (B) Residuals for the global fit analysis. The reaction was carried out at $20{ }^{\circ} \mathrm{C}, 50 \mathrm{mM}$ potassium phosphate buffer $(\mathrm{pH} 6.5), 50 \mathrm{mM} \mathrm{KCl}, 250 \mu \mathrm{M}$ $\mathrm{MnCl}_{2}$, and $1 \mathrm{mM}$ DTT. The final concentrations of NADPH in the assay were 8; 16, $23.5 \mu \mathrm{M}$ and QueF*PreQ $\mathrm{Q}_{0}$ was $72.5 \mu \mathrm{M}$. 


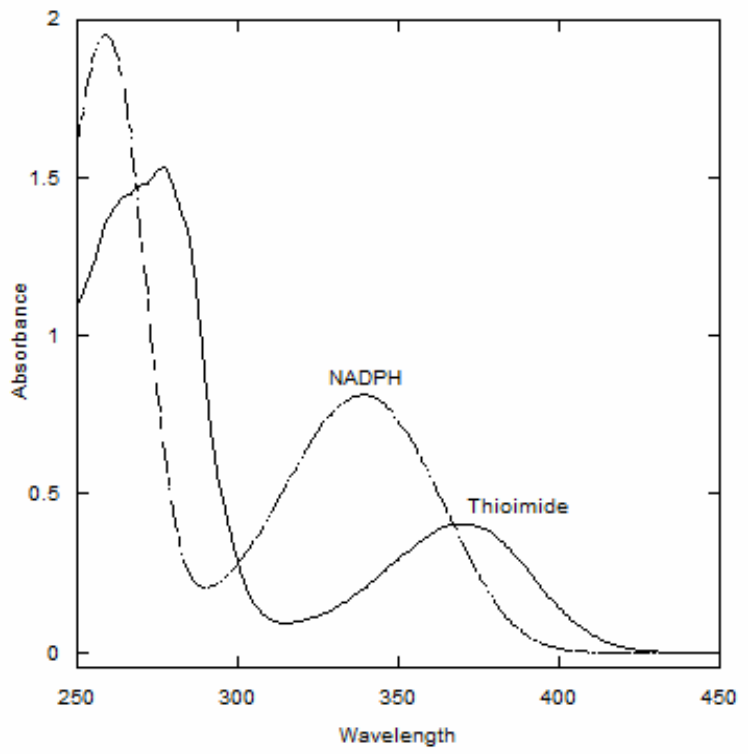

Figure 47: Thioimide and NADPH spectra

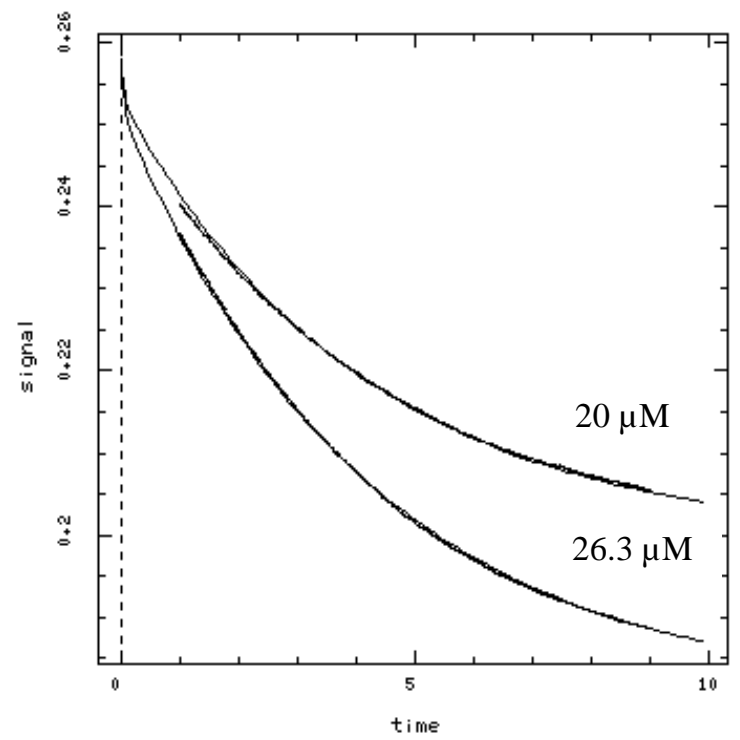

Figure 48: Transient state analysis of thioimide loss $390 \mathrm{~nm}$.

The reaction was carried out at $30^{\circ} \mathrm{C}$ in $50 \mathrm{mM}$ potassium phosphate buffer (pH 6.5), $50 \mathrm{mM} \mathrm{KCl}, 250 \mu \mathrm{M}$ $\mathrm{MnCl}_{2}$, and $1 \mathrm{mM}$ DTT, with final concentrations of QueF-*PreQ ${ }_{0}$ at $180 \mu \mathrm{M}$ in the presence of 20 and $26.3 \mu \mathrm{M}$ NADPH. 


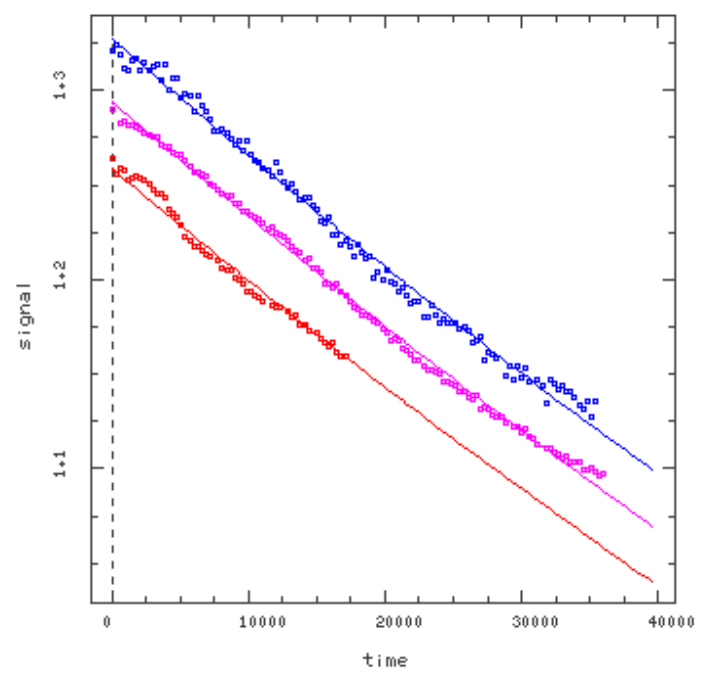

Figure 49: Thioimide decomposition.

Thioimide decomposition was monitored at $370 \mathrm{~nm}$ at $30{ }^{\circ} \mathrm{C}$, in the presence of $50 \mathrm{mM}$ potassium phosphate buffer (pH 6.5), $50 \mathrm{mM} \mathrm{KCl}, 250 \mu \mathrm{M} \mathrm{MnCl}_{2}, 1 \mathrm{mM}$ DTT, 154, 158 and $161 \mu \mathrm{M}$ QueF${ }^{*}$ PreQ ${ }_{0}$.

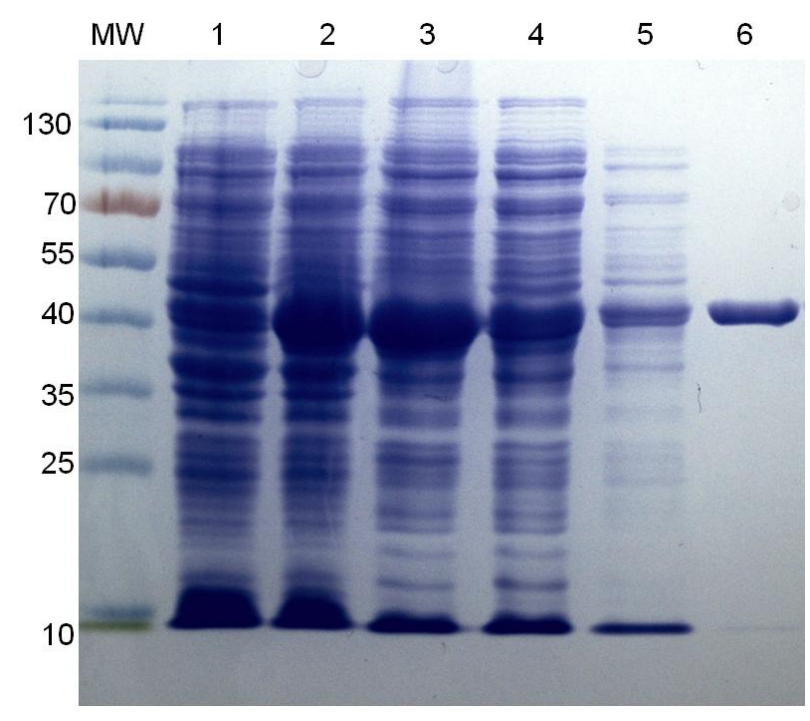

Figure 50: SDS/PAGE analyses of QueA purification.

MW marker; lane 1, Cell free extract; land 2 , flow through; lane 3, wash 1; lane 4 wash 2; lane 5, wash 3 , lane 6, purified $\mathrm{His}_{6}$-QueA. 


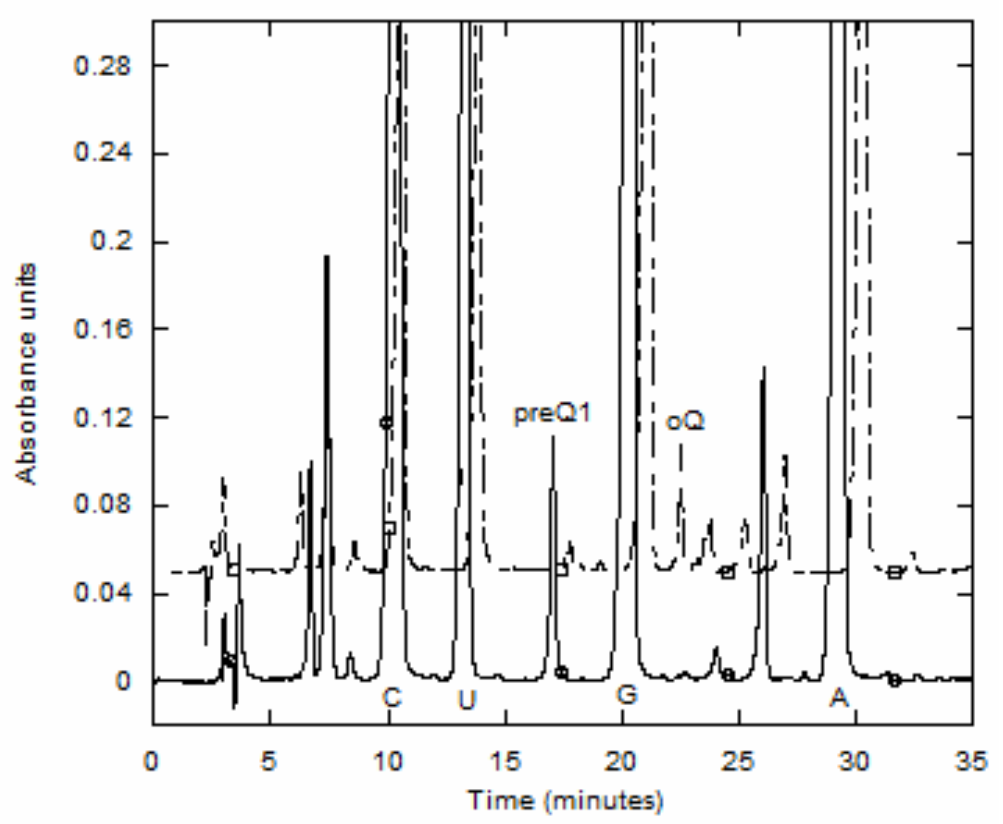

Figure 51: LC analysis of tRNA ${ }^{\text {tyr }}$ hydrolysates before and after QueA catalysis
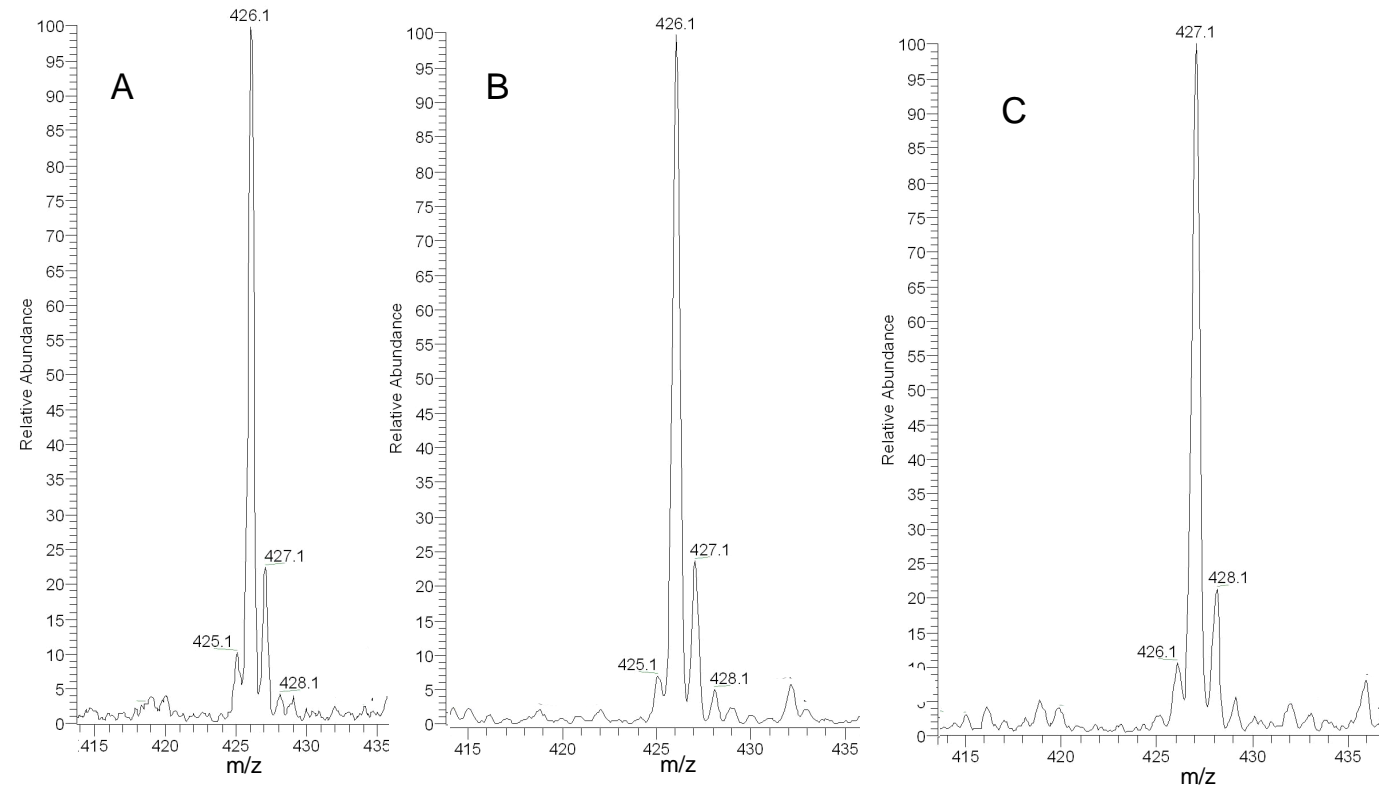

Figure 52: Mass spectrometry analysis of the $0 Q$ generated from QueA reactions (A) Unlabelled AdoMet (B) 5'S-[5-D]-AdoMet (C) 5' R-[5-D]-AdoMet 
A.

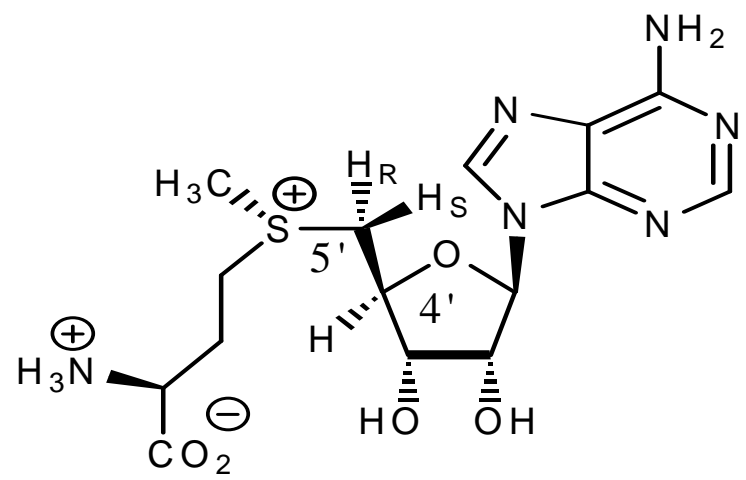

B.
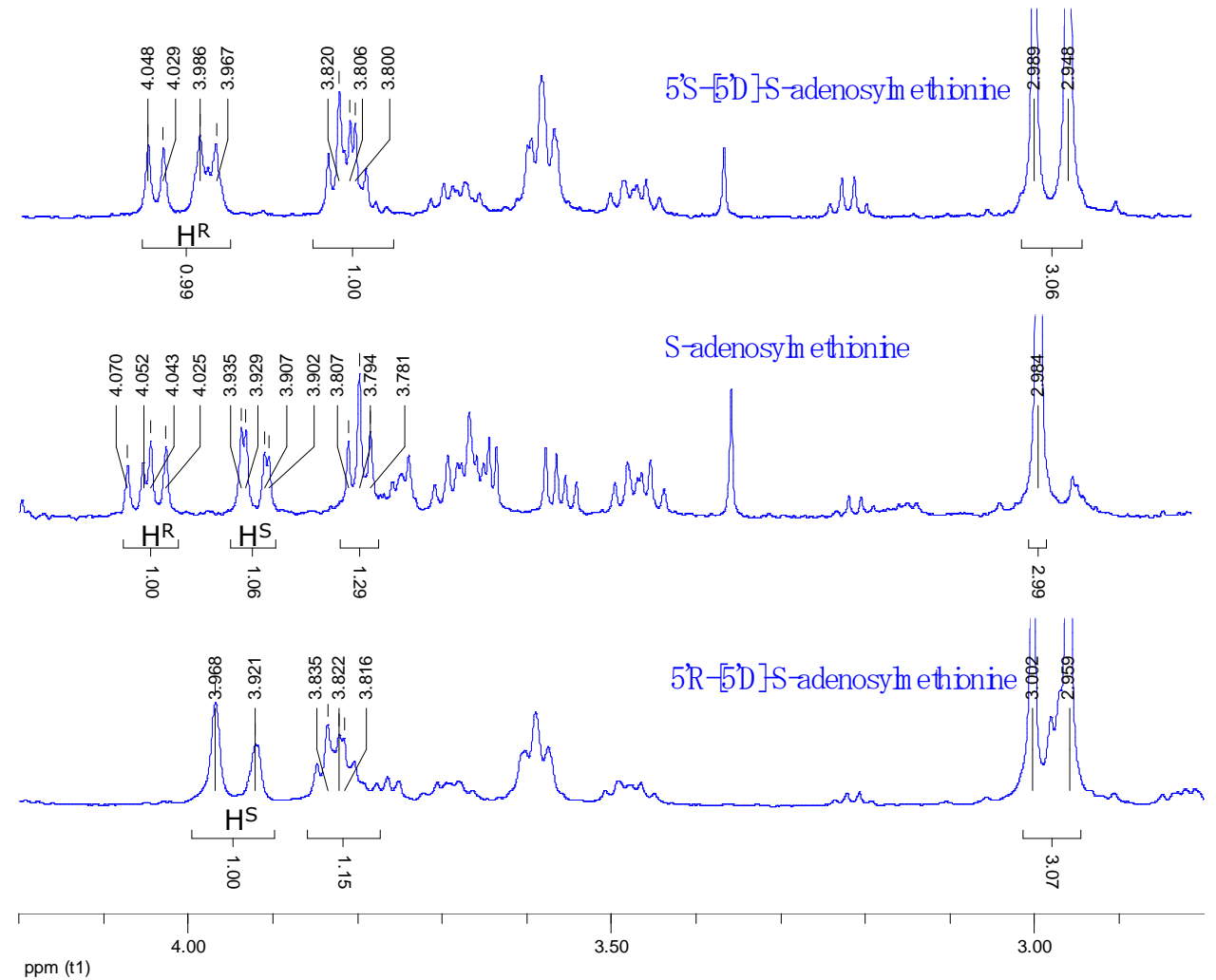

Figure 53: AdoMet NMR analysis.

(A) AdoMet showing the stereospecificity of the C5' hydrogens (B) Proton NMR of the AdoMet used in the determination of stereospecific abstraction by QueA. The proR proton is at the chemical shift of $\delta 4.05$ in the unlabeled AdoMet while the proS proton is at the chemical shift of $\delta 3.919$. 


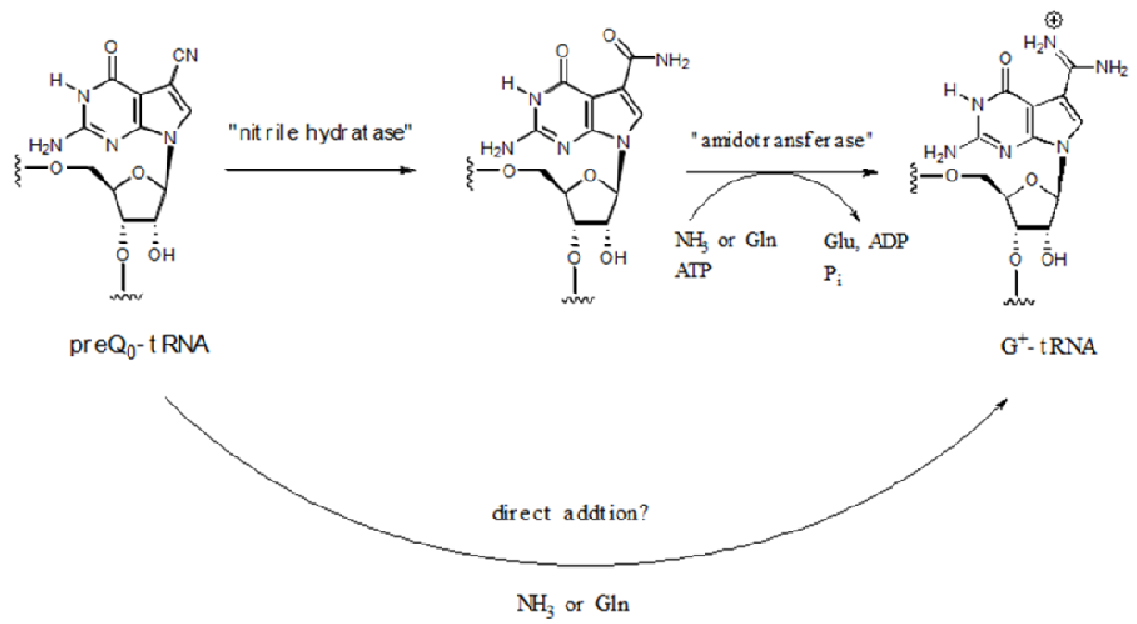

Figure 54: Possible routes for the formation of $\mathbf{G}^{+}$.
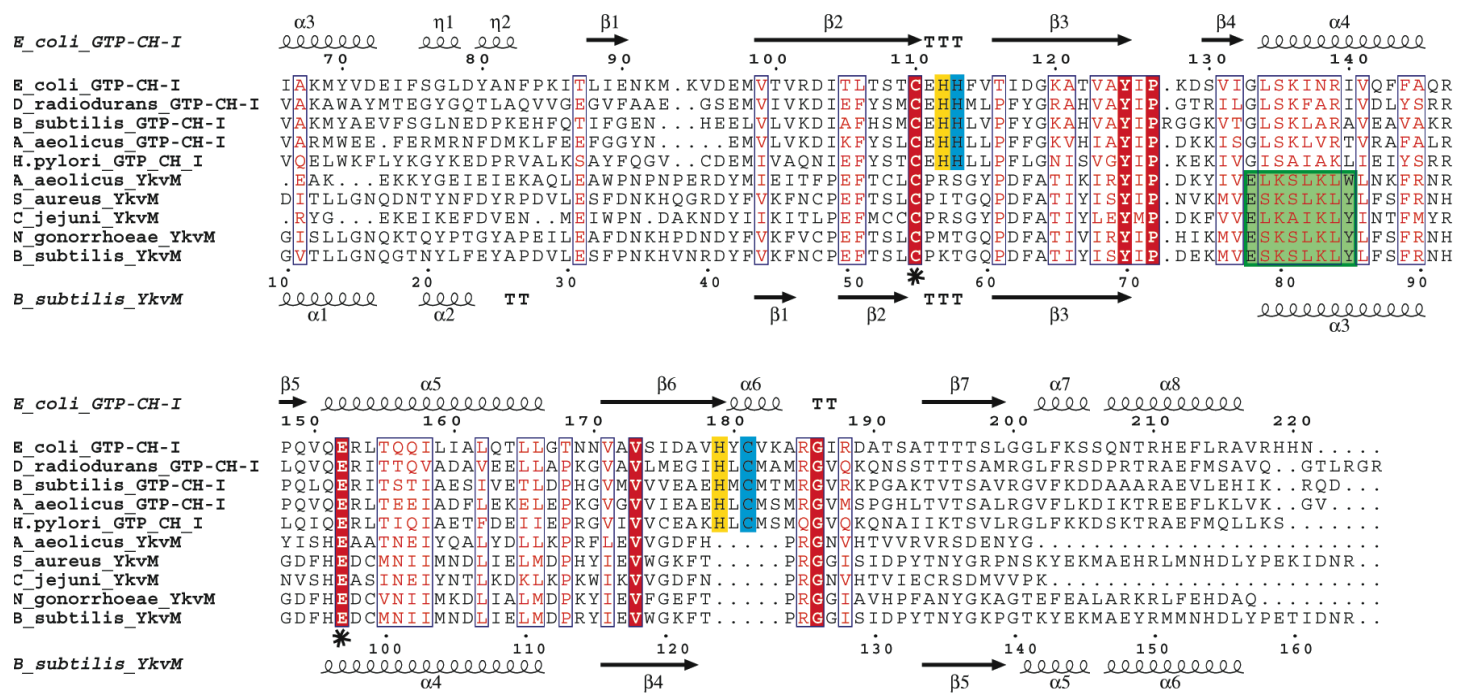

Figure 55: Alignment of unimodular FolE (GTP cyclohydrolase I) and YkvM (QueF) sequences.

The conserved Cys and Glu found in the substrate binding pocket of both protein families are indicated by asterisks. The QueF motif, specific for the QueF family, is highlighted in green. The zinc binding His and Cys residues found in FolE and not in QueF are highlighted in blue. Other catalytic residues in FolE not found in QueF are highlighted in yellow. The absence of the zinc-binding and catalytic residues of FolE is the best identifier of QueF sequences in genome databases. Taken from reference (47) 


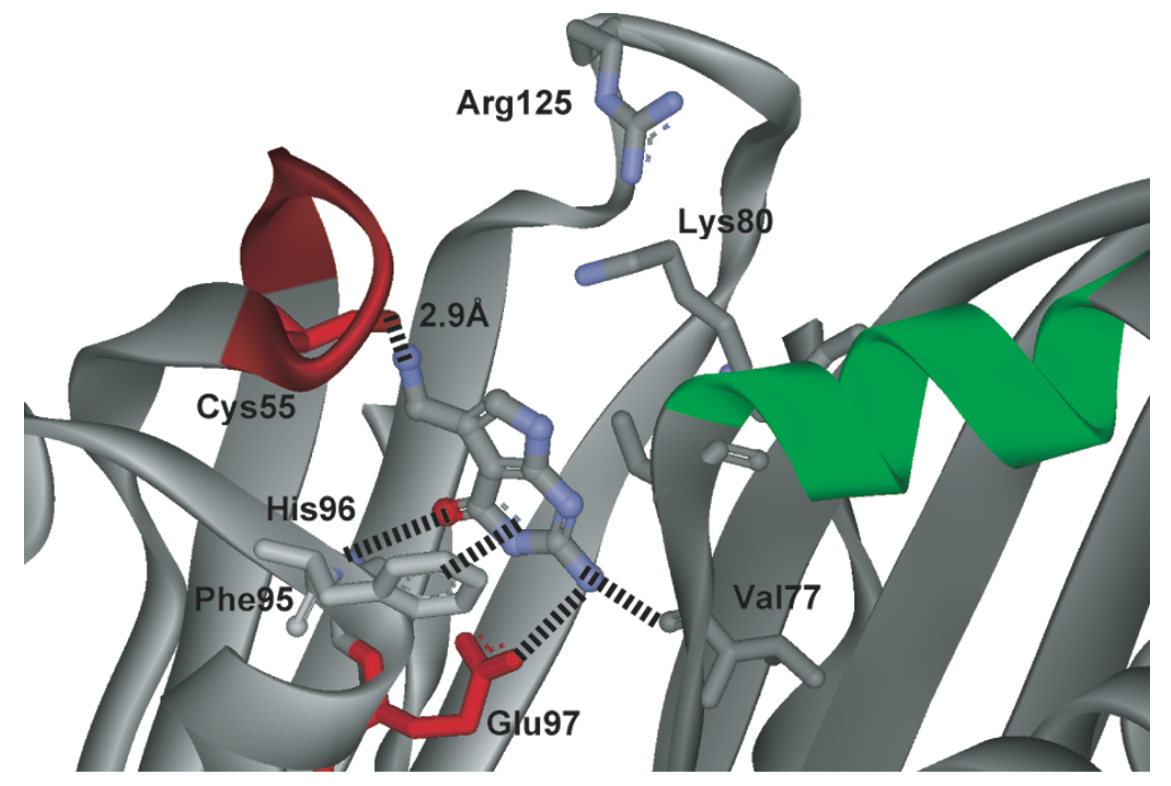

Figure 56: Three-dimensional model B. subtilis QueF.

Putative active site of B. subtilis QueF based on the homology model built from the crystal structure of $E$. coli GTP-CH-I. The active site is located at the interface between two monomers shown in light and dark grey. Potential active-site interactions are indicated. The conserved QueF motif region is highlighted in green. The conserved Glu characteristic of T-fold enzymes and the invariant Cys shared between QueF and GTP-CH-I are shown in black.
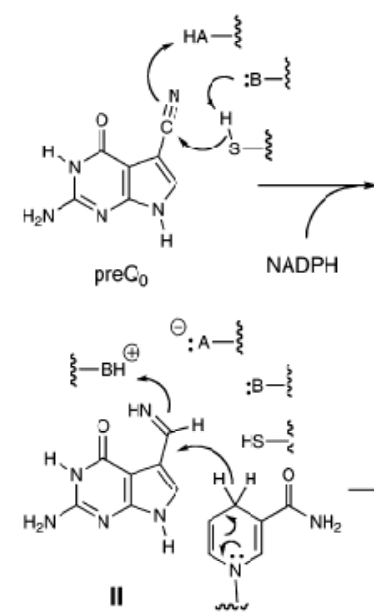<smiles></smiles>

$\ominus_{: A-\xi}$<smiles>[13CH3][18OH]</smiles>

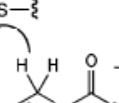<smiles>CC(N)c1cccnc1</smiles>

i<smiles>C1CC[C+]2CCC[C+]2C1</smiles>
$\Theta_{: A-\xi_{2}}$

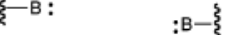<smiles>NCC1=CNC2N=C(N)NC(=O)C12</smiles>

Figure 57: Proposed chemical mechanism for the QueF catalyzed reaction. 


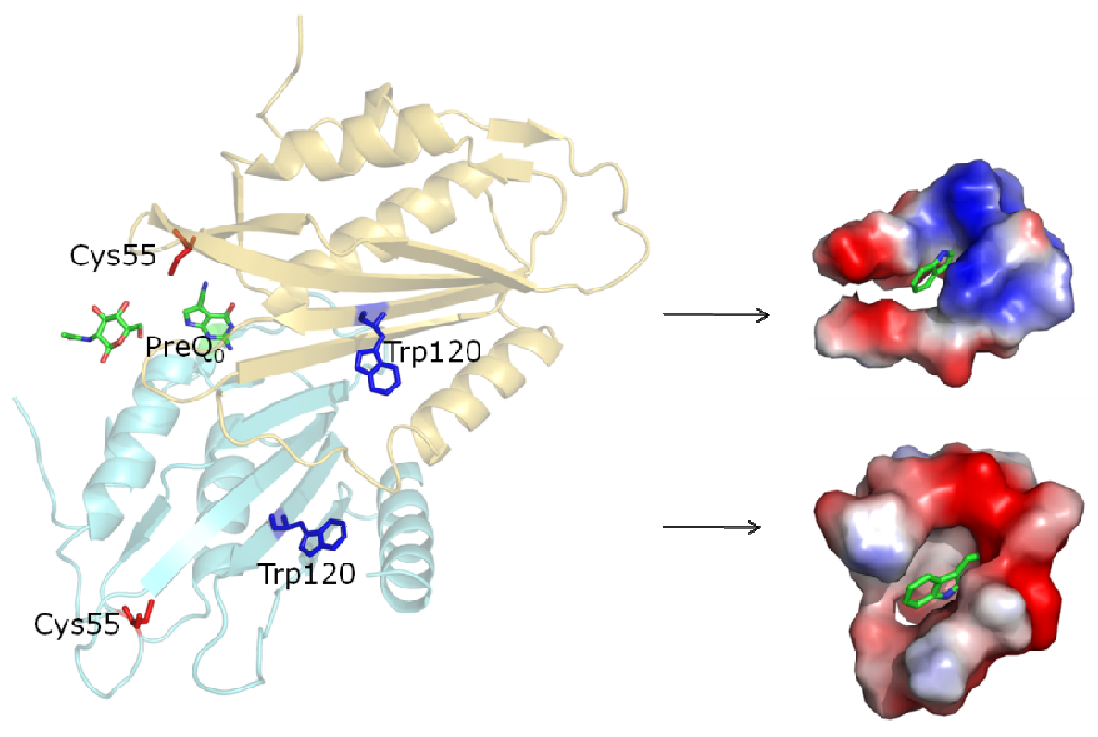

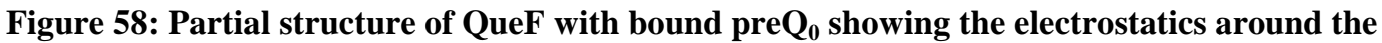
tryptophan residue in the presence and absence of pre $_{0}$ 


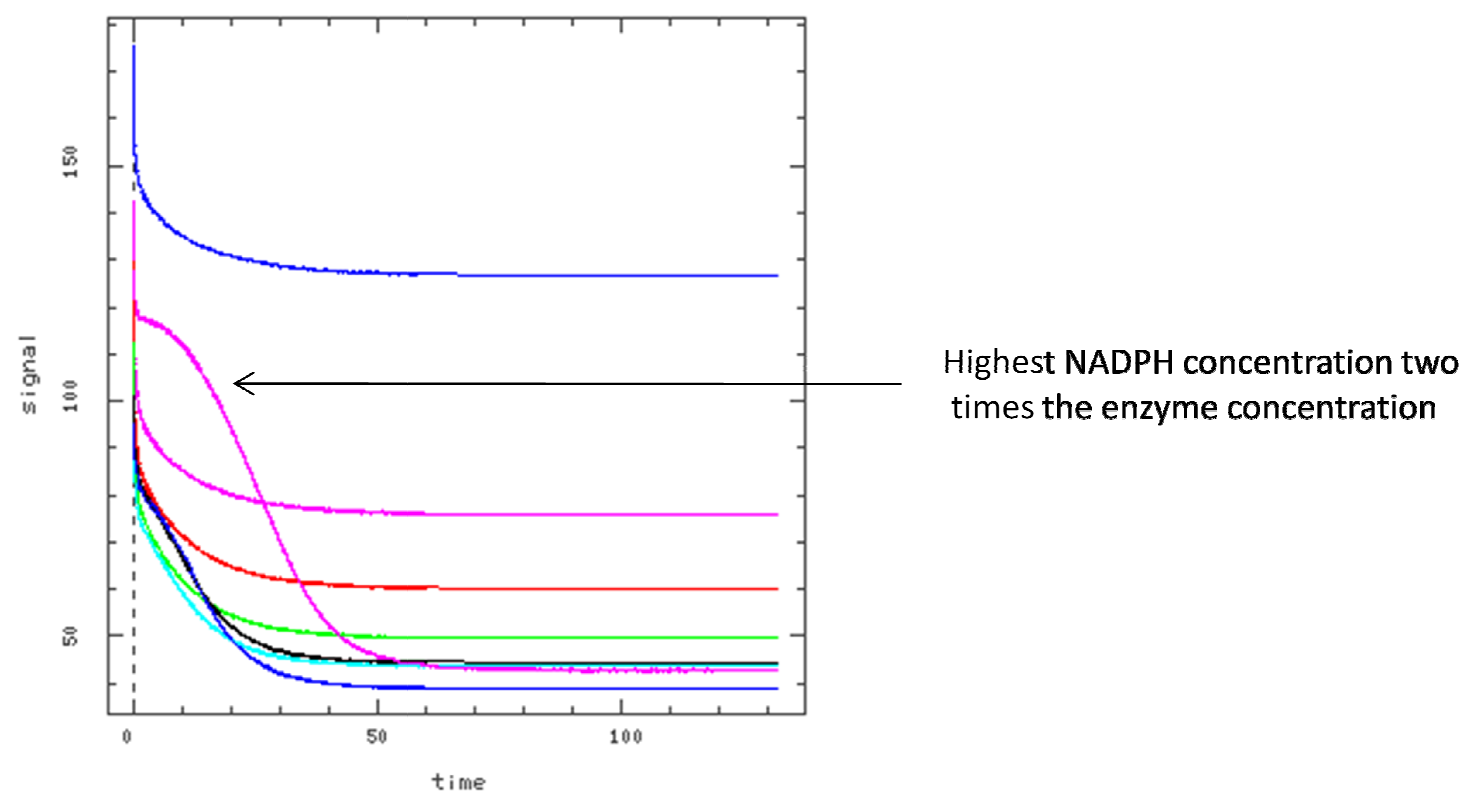

Figure 59: NADPH quenching in a reaction with $\mathrm{QueF}^{*} \mathrm{Pre}_{0}$ under mutiple turnover conditions.

Proposed mechanism for the observed reaction shown below (summary of the determined rates is shown in table 4).
$\mathrm{E}-\mathrm{S}+\mathrm{NADPH} \rightleftharpoons \mathrm{E}-\mathrm{S} \cdot \mathrm{NADPH} \quad: \mathrm{k}_{\mathrm{as}} \mathrm{k}_{\mathrm{ds}}$
E-S.NADPH $\longrightarrow$ ES.NADP ${ }^{+}: \mathrm{k}_{1}$
ES.NADP ${ }^{+} \longrightarrow \mathrm{ES}+\mathrm{NADP}^{+} \quad: \mathrm{k}_{2}$
$\mathrm{ES}+\mathrm{NADPH} \rightleftharpoons \mathrm{ES} \cdot \mathrm{NADPH} \quad \mathrm{k}_{3} \mathrm{k}_{-3}$
ES.NADPH $\rightleftharpoons$ FS.NADPH $: \mathrm{k}_{4} \quad \mathrm{k}_{-4}$
FS.NADPH $\longrightarrow$ F.P.NADP ${ }^{+}: \mathrm{k}_{5}$ 
Table 1 : Edman Degradation results.

Bands correspond to the bands in Figure 18A.

\begin{tabular}{|c|l|}
\hline Band Name & N-terminal sequences \\
\hline A & HMDSPD; DSPDLG \\
\hline B & ELTSI \\
\hline C & IFKKSF, KKSFIG ( minor SIFKKS) \\
\hline D & SIFKK \\
\hline
\end{tabular}

Table $2: \mathrm{G}^{+}$formation as function of $\mathrm{pH}$

\begin{tabular}{|c|c|}
\hline $\mathrm{pH}$ & $\mathrm{G}^{+}$ \\
\hline 5 & Absent \\
\hline 6 & Absent \\
\hline 7 & Present \\
\hline 8 & Present \\
\hline 8.5 & Present \\
\hline
\end{tabular}

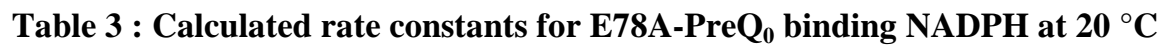

\begin{tabular}{ll}
\hline Constant & Value \\
\hline $\mathrm{k}_{\mathrm{as}}$ & $0.20 \mu \mathrm{M}^{-1} \mathrm{~s}^{-1}$ \\
$\mathrm{k}_{\mathrm{ds}}$ & $0.24 \mathrm{~s}^{-1}$ \\
$\mathrm{k}_{1}$ & $1.18 \mathrm{~s}^{-1}$ \\
$\mathrm{k}_{-1}$ & $0.12 \mathrm{~s}^{-1}$ \\
\hline
\end{tabular}

Table 4: Calculated rate constants for wild type QueF for NADPH binding and catalysis at $20{ }^{\circ} \mathrm{C}$ (NADPH fluorescence)

\begin{tabular}{ll}
\hline Constant & Value \\
\hline $\mathrm{k}_{\mathrm{as}}$ & $0.06 \mu \mathrm{M}^{-1} \mathrm{~s}^{-1}$ \\
$\mathrm{k}_{\mathrm{ds}}$ & $0.20 \mathrm{~s}^{-1}$ \\
$\mathrm{k}_{1}$ & $0.12 \mathrm{~s}^{-1}$ \\
$\mathrm{k}_{2}$ & $0.067 \mathrm{~s}^{-1}$ \\
$\mathrm{k}_{3}$ & $0.060 \mu \mathrm{M}^{-1} \mathrm{~s}^{-1}$ \\
$\mathrm{k}_{-3}$ & $0.20 \mathrm{~s}^{-1}$ \\
$\mathrm{k}_{4}$ & $1.2 \mathrm{~s}^{-1}$ \\
$\mathrm{k}_{-4}$ & $0.053 \mathrm{~s}^{-1}$ \\
$\mathrm{k}_{5}$ & $0.12 \mathrm{~s}^{-1}$ \\
\hline
\end{tabular}


Table 5: Calculated rate constants for wild type $Q u e F$ for $\operatorname{pre}_{0}$ binding and catalysis $20{ }^{\circ} \mathrm{C}$ (tryptophan fluorescence)

\begin{tabular}{ll}
\hline Constant & Value \\
\hline $\mathrm{k}_{\mathrm{as}}$ & $1.32 \mu \mathrm{M}^{-1} \mathrm{~s}^{-1}$ \\
$\mathrm{k}_{\mathrm{ds}}$ & $7.95 \mathrm{~s}^{-1}$ \\
$\mathrm{k}_{\mathrm{r}}$ (thiomide formation) & $1.30 \mathrm{~s}^{-1}$ \\
\hline
\end{tabular}

Table 6: Calculated rate constants for C55A QueF for preQ $_{0}$ binding $20{ }^{\circ} \mathrm{C}$ (tryptophan fluorescence)

\begin{tabular}{ll}
\hline Constant & Value \\
\hline $\mathrm{k}_{\mathrm{as}}$ & $1.06 \mu \mathrm{M}^{-1} \mathrm{~s}^{-1}$ \\
$\mathrm{k}_{\mathrm{ds}}$ & $1.35 \mathrm{~s}^{-1}$ \\
\hline
\end{tabular}

Table 7: Other rates determined by $\mathrm{UV}$ absorbance determined at $30{ }^{\circ} \mathrm{C}$

\begin{tabular}{ll}
\hline Constant & Value \\
\hline Thoimide formation $(370 \mathrm{~nm})$ & $2.55 \mathrm{~s}^{-1}$ \\
Thioimide reduction $(390 \mathrm{~nm})$ & $0.24 \mathrm{~s}^{-1}$ \\
Thiomide decomposition $(370 \mathrm{~nm})$ & $4.81 \times 10^{-6} \mathrm{~s}^{-1}$ \\
\hline
\end{tabular}




\section{Reference List}

1. Bjork, G. R. (1995) tRNA: Structure, Biosynthesis, and Function (ASM Press, Washington, DC.).

2. Brian Clark (1978) in Transfer RNA, ed. Sidney Altman (The MIT press, Cambridge, Massachusetts and London, England), pp. 14-47.

3. Limbach, P. A., Crain, P. F., \& McCloskey, J. A. (1994) Nucl. Acids Res. 22, 2183-2196.

4. Rozenski, J., Crain, P. F., \& McCloskey, J. A. (1999) Nucl. Acids Res. 27, 196197.

5. Henri Grosjean (2009) in DNA and RNA Modification Enzymes: Structure, Mechanism, Function and Evolution, ed. Henri Grosjean (Landes Bioscience, Austin).

6. Anantharaman, V., Koonin, E. V., Aravind, L., \& Journals, O. (2002) Nucl. Acids Res. 30, 1427-1464.

7. Agris, P. F., Vendeix, F. A., \& Graham, W. D. (2007) J Mol Biol 366, 1-13.

8. Helm, M. (2006) Nucl. Acids Res. 34, 721-733.

9. Agris, P. F. (2004) Nucl. Acids Res. 32, 223-238.

10. Ikeuchi, Y., Soma, A., Ote, T., Kato, J., Sekine, Y., \& Suzuki, T. (2005) Mol. Cell 19, 235-246.

11. Gefter, M. L. \& Russell, R. L. (1969) J. Mol Biol. 39, 145-157.

12. Bjork, G. R., Wikstrom, P. M., \& Bystrom, A. S. (1989) Science 244, 986-989.

13. Hauenstein, S. I. \& Perona, J. J. (2008) J. Biol. Chem. 283, 22007-22017.

14. Zhang, C. M., Liu, C., Slater, S., \& Hou, Y. M. (2008) Nat Struct Mol Biol 15, 507-514.

15. Auxilien, S., Keith, G., Le Grice, S. F. J., \& Darlix, J. L. (1999) J. Biol. Chem. 274, 4412-4420.

16. Turchi, L., Loubat, A., Rochet, N., Rossi, B., \& Ponzio, G. (2000) Experimental Cell Research 261, 220-228. 
17. Arps, P. J. \& Winkler, M. E. (1987) Journal of Bacteriology 169, 1071-1079.

18. Kasai, H., Oashi, Z., Harada, F., Nishimura, S., Oppenheimer, N. J., Crain, P. F., Liehr, J. G., von Minden, D. L., \& McCloskey, J. A. (1975) Biochemistry 14, 4198-4208.

19. Okada, N., Noguchi, S., Nishimura, S., Ohgi, T., Goto, T., Crain, P. F., \& McCloskey, J. A. (1978) Nucl. Acids Res. 5, 2289-2296.

20. Gregson, J. M., Crain, P. F., Edmonds, C. G., Gupta, R., Hashizume, T., Phillipson, D. W., \& McCloskey, J. A. (1993) J. Biol. Chem. 268, 10076-10086.

21. Kilpatrick, M. W. \& Walker, R. T. (1982) Zentralblatt fur Bakteriologie Mikrobiologie und Hygiene I Abteilung Originale C-Allgemeine Angewandte und Okologische Mikrobiologie 3, 79-89.

22. Leontis, N. B., Stombaugh, J., \& Westhof, E. (2002) Nucl. Acids Res. 30, 34973531.

23. Nobles, K. N., Yarian, C. S., Liu, G., Guenther, R. H., \& Agris, P. F. (2002) Nucl. Acids Res. 30, 4751-4760.

24. Oliva, R., Tramontano, A., \& Cavallo, L. (2007) RNA 13, 1427-1436.

25. Kersten, H. (1988) Biofactors 1, 27-29.

26. Reader, J. S., Metzgar, D., Schimmel, P., \& de Crecy-Lagard, V. (2004) J. Biol. Chem. 279, 6280-6285.

27. Kasai, H., Kuchino, Y., Nihei, K., \& Nishimura, S. (1975) Nucl. Acids Res. 2, 1931-1939.

28. Katze, J. R., Basile, B., \& McCloskey, J. A. (1982) Science 216, 55-56.

29. Harada, F. \& Nishimura, S. (1972) Biochemistry 11, 301-308.

30. Salazar, J. C., Ambrogelly, A., Crain, P. F., McCloskey, J. A., \& Soll, D. (2004) Proceedings of the National Academy of Sciences of the United States of America 101, 7536-7541.

31. Van Lanen, S. G., Reader, J. S., Swairjo, M. A., Crecy-Lagard, V., Lee, B., \& Iwata-Reuyl, D. (2005) Proceedings of the National Academy of Sciences of the United States of America 102, 4264-4269.

32. Huang, B. S., Wu, R. T., \& Chien, K. Y. (1992) Cancer Res 52, 4696-4700. 
33. Carlson, B. A., Kwon, S. Y., Chamorro, M., Oroszlan, S., Hatfield, D. L., \& Lee, B. J. (1999) Virology 255, 2-8.

34. Carlson, B. A., Mushinski, J. F., Henderson, D. W., Kwon, S. Y., Crain, P. F., Lee, B. J., \& Hatfield, D. L. (2001) Virology 279, 130-135.

35. Durand, J. M., Okada, N., Tobe, T., Watarai, M., Fukuda, I., Suzuki, T., Nakata, N., Komatsu, K., Yoshikawa, M., \& Sasakawa, C. (1994) J. Bacteriol. 176, $4627-$ 4634.

36. Morris, R. C., Brown, K. G., \& Elliott, M. S. (1999) J Biomol Struct Dyn 16, 757774.

37. Iwata-Reuyl, D. (2003) Bioorganic Chemistry 31, 24-43.

38. Dineshkumar, T. K., Thanedar, S., Subbulakshmi, C., \& Varshney, U. (2002) Microbiology 148, 3779-3787.

39. Kuchino, Y., Kasai, H., Nihei, K., \& and Nishimura S. (1976) Nucl. Acids Res. 3, 393-398.

40. Suhadolnik, R. J. \& Uematsu, T. (1970) J. Biol. Chem. 245, 4365-4371.

41. Phillips, G., El Yacoubi, B., Lyons, B., Alvarez, S., Iwata-Reuyl, D., \& de CrecyLagard, V. (2008) J. Bacteriol. 190, 7876-7884.

42. Grochowski, L. L., Xu, H. M., Leung, K. P., \& White, R. H. (2007) Biochemistry 46, 6658-6667.

43. Reader, J. S., Metzgar, D., Schimmel, P., \& Crecy-Lagard, V. (2004) J. Biol. Chem. 279, 6280-6285.

44. McCarty, R. M., Somogyi, A., \& Bandarian, V. (2009) Biochemistry 48, 23012303.

45. McCarty, R. M., Somogyi, A., Lin, G., Jacobsen, N. E., \& Bandarian, V. (2009) Biochemistry 48, 3847-3852.

46. Sofia, H. J., Chen, G., Hetzler, B. G., Reyes-Spindola, J. F., \& Miller, N. E. (2001) Nucleic Acids Res 29, 1097-1106.

47. Van Lanen, S. G., Reader, J. S., Swairjo, M. A., Crecy-Lagard, V., Lee, B., \& Iwata-Reuyl, D. (2005) Proceedings of the National Academy of Sciences of the United States of America 102, 4264-4269. 
48. Okada, N. \& Nishimura, S. (1979) J. Biol. Chem. 254, 3061-3066.

49. Garcia, G. A. \& Kittendorf, J. D. (2005) Bioorganic Chemistry 33, 229-251.

50. Slany, R. K., Boesl, M., Crain, P. F., \& Kersten, H. (1993) Biochemistry 32, 7811-7817.

51. Burg, A. W. \& Brown, G. M. (1968) J. Biol. Chem. 243, 2349-2358.

52. Gunduz, U. \& Katze, J. R. (1984) J. Biol. Chem. 259, 1110-1113.

53. Katze, J. R., Gunduz, U., Smith, D. L., Cheng, C. S., \& McCloskey, J. A. (1984) Biochemistry 23, 1171-1176.

54. Shindo-Okada, N., Okada, N., Ohgi, T., Goto, T., \& Nishimura, S. (1980) Biochemistry 19, 395-400.

55. Watanabe, M., Matsuo, M., Tanaka, S., Akimoto, H., Asahi, S., Nishimura, S., Katze, J. R., Hashizume, T., Crain, P. F., McCloskey, J. A. et al. (1997) J. Biol. Chem. 272, 20146-20151.

56. Swairjo, M. A., Reddy, R. R., Lee, B., Van Lanen, S. G., Brown, S., CrecyLagard, V., Iwata-Reuyl, D., \& Schimmel, P. (2005) Acta Crystallographica Section F-Structural Biology and Crystallization Communications 61, 945-948.

57. Colloc'h, N., Poupon, A., \& Mornon, J. P. (2000) Proteins 39, 142-154.

58. Banerjee, A., Sharma, R., \& Banerjee, U. C. (2002) Appl. Microbiol. Biotechnol. 60, 33-44.

59. Slany, R. K., Boesl, M., \& Kersten, H. (1994) Biochimie 76, 389-393.

60. Van Lanen, S. G. \& Iwata-Reuyl, D. (2003) Biochemistry 42, 5312-5320.

61. Kinzie, S. D., Thern, B., \& Iwata-Reuyl, D. (2000) Organic Letters 2, 1307-1310.

62. Migawa, M. T., Hinkley, J. M., Hoops, G. C., \& Townsend, L. B. (1996) Synthetic Communications: An International Journal for Rapid Communication of Synthetic Organic Chemistry 26, 3317-3322.

63. Pamela F.Crain (90 A.D.) Mehods in Enzymology 193, 782-790.

64. Braven J, Hardwell TR, Seddon R, \& Whittaker M (1984) Annals of clinical biochemistry. 21. 
65. LoBrutto, R., Bandarian, V., Magnusson, O. T., Chen, X., Schramm, V. L., \& Reed, G. H. (2001) Biochemistry 40, 9-14.

66. Lim, C. K. \& Peters, T. J. (1989) J. Chromatogr. 461, 259-266.

67. Park, J., Tai, J., Roessner, C. A., \& Scott, A. I. (1996) Bioorg. Med. Chem. 4, 2179-2185.

68. Chomczynski, P. \& Sacchi, N. (1987) Anal. Biochem. 162, 156-159.

69. Gillam, I., Millward, S., Blew, D., von Tigerstrom, M., Wimmer, E., \& Tener, G. M. (1967) Biochemistry 6, 3043-3056.

70. Phillips, G., Chikwana, V. M., Maxwell, A., El-Yacoubi, B., Swairjo, M. A., Iwata-Reuyl, D., \& de Cr+רcy-Lagard, V. r. (2010) J. Biol. Chem. 285, 1270612713.

71. Lee, B. W. K., Van Lanen, S. G., \& Iwata-Reuyl, D. (2007) Biochemistry 46, 12844-12854.

72. Bai, Y., Fox, D. T., Lacy, J. A., Van Lanen, S. G., \& Iwata-Reuyl, D. (2000) J. Biol. Chem. 275, 28731-28738.

73. Stengl, B., Meyer, E. A., Heine, A., Brenk, R., Diederich, F., \& Klebe, G. (2007) Journal of Molecular Biology 370, 492-511.

74. Uematsu, T. \& Suhadoln, R. J. (1974) Archives of Biochemistry and Biophysics 162, 614-619.

75. Uematsu, T. \& Suhadolnik, R. J. (1975) in Methods in Enzymology

Antibiotics, ed. John, H. H. (Academic Press, pp. 759-762.

76. (1995) Archaea: A Laboratory Manual (Cold Spring Harbor Laboratory, Cold Spring Harbor, NY).

77. Mehrotra, S. \& Balaram, H. (2008) Biochimica et Biophysica Acta-Proteins and Proteomics 1784, 2019-2028.

78. Klem, T. J. \& Davisson, V. J. (1993) Biochemistry 32, 5177-5186.

79. Zalkin, H. (1993) Advances in Enzymology and Related Areas of Molecular Biology 66, 203-309.

80. Massie`re \& Badet-Denisot, M. A. (1998) Cellular and Molecular Life Sciences 54, 205-222. 
81. Tumbula, D. L., Becker, H. D., Chang, W. z., \& Soll, D. (2000) Nature 407, 106110.

82. Feingold, D. S. \& Franzen, J. S. (1981) Trends Biochem. Sci. 6, 105.

83. Bollag, D. M. (1995) in Peptide analysis protocols (Humana Press, New Jersey), pp. 1-9.

84. Stevens, F. J. (1989) Biophysical Journal 55, 1155-1167.

85. Uversky, V. N. (1993) Biochemistry 32, 13288-13298.

86. Morino, Y. \& Snell, E. E. (1967) J. Biol. Chem. 242, 5602-5610.

87. Howlett, G. J., Minton, A. P., \& Rivas, G. (2006) Current Opinion in Chemical Biology 10, 430-436.

88. Johnson, K. A. (1995) Enzyme Kinetics and Mechanism, Pt D 249, 38-61.

89. Fierke, C. A. \& Hammes, G. G. (1995) Enzyme Kinetics and Mechanism, Pt D 249, 3-37.

90. Joseph R.Lakowicz (2006) in Principles of Fluorescence Spectroscopy (Springer, New York), pp. 530-577.

91. Kubiseski, T. J., Hyndman, D. J., Morjana, N. A., \& Flynn, T. G. (1992) J. Biol. Chem. 267, 6510-6517.

92. Halgand, F., Dumas, R., Biou, V., Andrieu, J. P., Thomazeau, K., Gagnon, J., Douce, R., \& Forest, E. (1999) Biochemistry 38, 6025-6034.

93. Grimshaw, C. E., Bohren, K. M., Lai, C. J., \& Gabbay, K. H. (1995) Biochemistry 34, 14356-14365. 